The Economics of Railroad Safety 
This manuscript was published by Kluwer Academic Publishers in 1998. It was originally prepared using WordPerfect and Lotus 1-2-3 software. In 2014, the manuscript files were converted into the latest version of Microsoft Word. The font was enlarged (to Times New Roman 12 point from CG Times 10 point) and the margins were made narrower, but otherwise the text is unaltered. 


\title{
The Economics of Railroad Safety
}

by

\author{
lan Savage \\ Department of Economics and \\ the Transportation Center \\ Northwestern University
}

Kluwer Academic Publishers

Boston/Dordrecht/London 

In Memory of my Grandmother

\section{Madge Lucy Grinyer}

1911-1996 



\section{CONTENTS}

$\begin{array}{ll}\text { Abbreviations } & \text { ix }\end{array}$

Preface $\quad$ xi

$\begin{array}{lc}\text { Acknowledgements } & \text { xiii }\end{array}$

1 Setting the Scene 1

$2 \quad$ Historical Trends $\quad 11$

$3 \quad$ Public Policy 19

$4 \quad$ How Safe are American Railroads?

$5 \quad$ Risk Evaluation $\quad 31$

$6 \quad$ The Story So Far 41

7 Economic Theory of Bilateral Accidents 45

$8 \quad$ Highway Grade Crossings $\quad 57$

$\begin{array}{lll}9 & \text { Trespassers } & 71\end{array}$

$\begin{array}{lll}10 & \text { Occupational Injuries } & 77\end{array}$

11 Benchmark Levels of Operational Safety 91

12 Market Power $\quad 97$

$\begin{array}{lll}13 & \text { Imperfect Information } & 103\end{array}$

14 Customer Rationality 111 
$15 \quad$ Railroad Myopia 113

$16 \quad$ Externalities $\quad 121$

17 Non-Regulatory Responses $\quad 129$

$\begin{array}{lll}18 & \text { Federal Safety Regulations } & 137\end{array}$

$\begin{array}{lll}19 & \text { Evaluation of Regulations } & 147\end{array}$

20 A New Era for Safety Regulation $\quad 163$

21 The Way Forward 193

$\begin{array}{lll}\text { Appendix A } & \text { Federal Regulations } & 207\end{array}$

$\begin{array}{llr}\text { Appendix B Historical Data } & 215\end{array}$

$\begin{array}{ll}\text { References } & 217\end{array}$

$\begin{array}{lr}\text { Subject Index } & 229\end{array}$ 


\section{ABBREVIATIONS}

$\begin{array}{ll}\text { AAR } & \text { Association of American Railroads } \\ \text { ASLRRA } & \text { American Short Line and Regional Railroad Association } \\ \text { CFR } & \text { Code of Federal Regulations } \\ \text { DOT } & \text { United States Department of Transportation } \\ \text { EPA } & \text { United States Environmental Protection Agency } \\ \text { FHWA } & \text { United States Federal Highway Administration } \\ \text { FRA } & \text { United States Federal Railroad Administration } \\ \text { GAO } & \text { United States General Accounting Office } \\ \text { ICC } & \text { United States Interstate Commerce Commission } \\ \text { NHTSA } & \text { United States National Highway Traffic Safety Administration } \\ \text { NTSB } & \text { United States National Transportation Safety Board } \\ \text { OSHA } & \text { United States Occupational Safety and Health Administration } \\ \text { OTA } & \text { United States Office of Technology Assessment } \\ \text { TRB } & \text { Transportation Research Board }\end{array}$





\section{PREFACE}

The American public has a fascination with railroad wrecks that goes back a long way. One hundred years ago, staged railroad accidents were popular events. At the Iowa State fair in 1896, 89,000 people paid \$20 each, at current prices, to see two trains, throttles wide open, collide with each other. "Head-on Joe" Connolly made a business out of "cornfield meets" holding seventy-three events in thirty-six years. Picture books of train wrecks do good business presumably because a train wreck can guarantee a spectacular destruction of property without the messy loss of life associated with aircraft accidents.

A "train wreck" has also entered the popular vocabulary in a most unusual way. When political maneuvering leads to failure to pass the federal budget, and a shutdown is likely of government services, this is widely called a "train wreck." In business and team sports, bumbling and lack of coordination leading to a spectacular and public failure to perform is also called "causing a train wreck." A person or organization who is disorganized may be labelled a "train wreck."

It is therefore not surprising that the public perception of the safety of railroads centers on images of twisted metal and burning tank cars, and a general feeling that these events occur quite often. After a series of railroad accidents, such as occurred in the winter of 1996 or the summer of 1997, there are inevitable calls that government "should do something."

However, the reality of railroad safety is much different from the perception. The major safety issues are not collisions or derailments, but rather occupational injuries to employees, collisions with negligent road users at highway grade crossings, and the general proclivity of people to trespass on the railroad. Contrary to popular perception, accident rates have fallen throughout the twentieth century. Employee injury rates are a third of those of a generation ago, and grade crossing fatalities per automobile owned have fallen by half over the same period. It is ten times safer to travel by train than to drive.

Yet the railroads are subject to considerable safety regulation. It may come as somewhat of a shock to many readers to realize that much of this regulation is quite recent. Back in those halcyon days when passenger trains were the primary means of long-distance travel, the industry had little formal governmental regulation but substantial self-regulation. Then in 1970 the Federal Railroad Safety Act gave government rulemaking authority over "all areas of railroad safety." Nowadays the 
Code of Federal Regulations reads like an engineering textbook on how to build, maintain and operate a railroad.

A generation ago, transportation economists were at the forefront of questioning whether economic regulation of prices and quantity of service by government was in the public interest. This book explores whether similar questions can be raised about regulation of the quality of service: What is the justification for the current safety regulations of the railroads? Why did it happen? Are the current regulations in the public interest? Are there better alternatives? 


\section{ACKNOWLEDGMENTS}

I would like to thank the following people for their help and assistance in preparation of this book. First and foremost is Scott Dennis, Senior Economist of the Association of American Railroads who provided the initial impetus for the book (I was originally going to write about safety in the trucking industry), continual feedback, encouragement and industry insights. My colleague, Professor John Panzar at Northwestern University provided wisdom during the early days of my research on the economic theories on safety.

The following people at the Association of American Railroads provided me with helpful insights into the industry: Peter French, William Browder, Patrick Ameen, Gary Held, and Louis Cerny. Alice Saylor and William Loftus of the American Short Line and Regional Railroad Association discussed with me their part of the industry.

Corporate lawyers Thomas J. Wamser of the Consolidated Rail Corporation, Wiley F. Mitchell, Jr. of Norfolk Southern Corporation, and Paul Hoferer of Burlington Northern Santa Fe Corporation provided me with an education on tort law. I hope I fully understood their teachings.

As always the exceptional staff of Northwestern University's Transportation Library provided outstanding service and proved why they are the world's premier transportation library.

This work was funded in part by the United States Department of Transportation through a University Transportation Centers grant administered by the Great Lakes Center for Truck and Transit Research at the University of Michigan, Ann Arbor. Of course, neither they nor any of the other people who have helped me should be held responsible for my calculations, interpretations and conclusions. 



\section{SETTING THE SCENE}

\section{THE BIG PICTURE}

To the lay person the image of railroad safety is of spectacular train wrecks and burning tank cars. However, the reality is much different. Just over 1,000 people were killed on the railroad in 1996 (table 1.1). Deaths due to grade-crossing accidents and trespassing account for ninety-two percent of all fatalities. In 1996 these two causes of death were of roughly equal magnitude. Preliminary figures for 1997 suggest that trespassing fatalities will exceed those at grade crossings for the first time in over half a century. Compared with these risks, highly-visible collisions and derailments accounted for the deaths of nine passengers and eleven employees.

Table 1.1: Fatalities and Injuries by Type of Person 1996

\begin{tabular}{|l|c|c|}
\hline & Fatalities & Injuries \\
\hline Employees and contractors & $42(4.0 \%)$ & $9635(76.7 \%)$ \\
\hline Highway users at grade crossings & $487(46.9 \%)$ & $1505(12.0 \%)$ \\
\hline Trespassers not at grade crossings & $471(45.3 \%)$ & $474(3.8 \%)$ \\
\hline $\begin{array}{l}\text { Non-trespassers (public lawfully on the } \\
\text { railroad / adjacent to the railroad) }\end{array}$ & $27(2.6 \%)$ & $431(3.4 \%)$ \\
\hline Passengers on trains & $12(1.2 \%)$ & $513(4.1 \%)$ \\
\hline TOTAL & 1039 & 12558 \\
\hline
\end{tabular}

Source for all tables in chapter 1: FRA (1997a,b)

\section{EMPLOYEE FATALITIES \& INJURIES}

Railroad work is hardly a risk-free occupation. Much of the work has to be undertaken outdoors in the elements, sometimes in hostile terrain far from medical care, and using heavy moving machinery. Fatality and injury rates vary by the type of work undertaken (table 1.2). Locomotive and train crews, and way and structure maintenance personnel face the highest annual risk of fatal injuries of 1 in 4,200 and 1 in 5,000 respectively. Workshop employees, managerial and clerical staff, and 
those operations personnel not involved in actually staffing the trains rarely suffer fatal injuries. The injury rates of all non-managerial and clerical staff are remarkably uniform at an annual risk of injury of between 1 in 25 and 1 in 30.

Table 1.2: Casualties per 100,000 Employees for Class I Railroads 1996

\begin{tabular}{|l|c|c|}
\hline & Fatalities & Injuries \\
\hline Train and Locomotive Crew & 23.6 & 3,914 \\
\hline Maintenance of Way and Structure & 20.2 & 3,320 \\
\hline Maintenance of Equipment and Stores & 2.8 & 3,348 \\
\hline $\begin{array}{l}\text { Executives, Officials, Staff Assistants, } \\
\text { Professional and Administrative Staff }\end{array}$ & 3.0 & 813 \\
\hline Operations Employees (not train \& loco) & 0.0 & 3,967 \\
\hline
\end{tabular}

The data represent the large ("Class I") freight railroads which account for $80 \%$ of industry employment (AAR, 1997). Data are not available on the numbers of employees by job type for smaller railroads.

Table 1.3: Leading Employee Fatality and Injury Risks 1996

\begin{tabular}{|l|l|c|}
\hline \multicolumn{1}{|c|}{ Employee Type } & \multicolumn{1}{|c|}{ Hazard Type } & $\begin{array}{c}\text { Risk per } \\
100,000 \\
\text { Employees }\end{array}$ \\
\hline FATALITY RISKS & Collisions \& Derailments & 14.0 \\
\hline Train Crew & Maintenance work (train moving) & 10.3 \\
\hline Way \& Structure & Maintenance work (no train moving) & 6.1 \\
\hline Way \& Structure & Coupling \& Uncoupling & 2.5 \\
\hline Train Crew & Falls & 2.5 \\
\hline Train Crew & Maintenance (no train moving) & 3,800 \\
\hline INJURY RISKS & Maintenance (no train moving) & 3,500 \\
\hline Way \& Structure & General operations (no train moving) & 1,650 \\
\hline Equipment \& Stores & Falls (no train moving) & 1,100 \\
\hline Train Crew &
\end{tabular}

Casualty figures by job category and circumstance of injury are given for the entire industry. To obtain a denominator of risk, employment in the large freight railroads in each job category is inflated by 1.23 which is the ratio of total railroad employee-hours to employee-hours in Class I freight railroads (FRA, 1997a). As a result of this approximation, this table may not be directly comparable with table 1.2.

The leading causes of employee fatalities and injuries are shown in table 1.3. The table shows the type of employee exposed to the risk and the annual risk per 100,000 employees of that type. The most severe fatality risks are those posed by collisions and derailments to train and locomotive crew, and in maintenance work for track workers. Deaths by these causes represent two-thirds of all employee 
fatalities. Train crews are also exposed to fatality risks during coupling and uncoupling operations, and from falling while getting on or off rolling stock or while walking beside the track.

In stark contrast to the fatality risks, eighty-five percent of employee injuries do not involve a moving train. The leading risks are to workers who are maintaining equipment or way and structure. The next highest risks are faced by train and locomotive crews coupling and uncoupling stationary locomotives or cars, operating switches, falling from stationary rolling stock, or slipping while walking.

\section{HIGHWAY GRADE CROSSINGS}

There are 265,000 rail-highway grade crossings in the United States. This large number is partly a consequence of geography, and partly a legacy of history. In the plains of the Midwest and South most highway crossings are at-grade rather than on bridges or in underpasses. In the early days of railroading a crossing was provided at every point where a road intersected the right of way to accommodate horse and buggy traffic. There has been a reluctance to close crossings, despite the fact that many see little road traffic and have alternative crossings close by. Sixty percent of crossings are by public highways. The other forty percent are private crossings which are used solely by agricultural (24 percent), industrial ( 9 percent) or residential (5 percent) users whose property is adjacent to the railroad (table 1.4). About two-fifths of the public crossings are equipped with active warning devices such as flashing lights, bells, gates, highway stop lights or manual flagging of trains that indicate to road users that a train is approaching. Most of the remaining public crossings have passive warning devices, such as "crossbucks" or stop signs, which warn the road user of the existence of the crossing but do not show any indication of whether a train is approaching.

Table 1.4: Numbers of Crossings by Type 1996

\begin{tabular}{|l|c|c|c|c|}
\hline \multirow{2}{*}{} & \multicolumn{4}{|c|}{ Type of Crossing Warning } \\
\cline { 2 - 5 } & Active & Passive & None & Total \\
\hline Public Crossings & 65,667 & 90,709 & 6,050 & 162,426 \\
\hline Private Crossings & 1,069 & 24,959 & 77,267 & 103,295 \\
\hline & & & & 265,721 \\
\hline
\end{tabular}

Of course, active warning devices are primarily installed at the busiest crossings. Eighty-four percent of crossings with an average daily road traffic of greater than 5,000 vehicles have active warning devices. Currently about 500 crossings are upgraded from passive to active warning devices each year. Very few private crossings have active warning devices. Indeed three-quarters of them do not even have warning signs. 
During 1996, 415 motor-vehicle users, 71 pedestrians and one railroad employee were killed at grade crossings. Only 39 fatalities, or nine percent of the total, occurred at private crossings despite the fact that these crossings represent forty percent of all crossings. Because data on road traffic usage of private crossings are not collected, one cannot be certain whether there is a higher or lower risk at private crossings compared with public crossings.

Information is available on motor-vehicle, but not pedestrian, fatalities at public crossings by the type of warning devices installed (table 1.5), and on the distribution of road traffic at public crossings with different types of warning devices. Therefore one can estimate fatality rates per billion road-vehicle crossings. As shown in table 1.6, crossings that are only provided with passive devices have a fatality risk four times that of crossings with active warning devices. There were no fatalities at public crossings without warning devices in 1996. The good record of the latter type of crossing is probably because sixty-eight percent of these crossings witness two trains a day or less.

Table 1.5: Motor Vehicle Fatalities by Crossing Type 1996

\begin{tabular}{|l|c|c|c|c|}
\hline & \multicolumn{4}{|c|}{ Type of Crossing Warning } \\
\cline { 2 - 5 } & Active & Passive & None & Total \\
\hline Public Crossings & 168 & 209 & 0 & 377 \\
\hline Private Crossings & 0 & 31 & 7 & 38 \\
\hline & & & & 415 \\
\hline
\end{tabular}

Table 1.6: Author's Estimate of Motor Vehicle Fatality Risk per Billion Vehicle Crossings at Public Crossings 1996

\begin{tabular}{|l|c|}
\hline At crossings with active warning devices & 1.74 \\
\hline At crossings with passive warning devices & 7.45 \\
\hline At crossings with no warning devices & 0.00 \\
\hline
\end{tabular}

Sixty percent of collisions occur in rural areas (National Highway Traffic Safety Administration (NHTSA), 1994). While road traffic may be heavier on urban crossings, these crossings are likely to be provided with active warning devices. The location of collisions is quite dispersed and not concentrated on a few black-spot crossings. Over the seven-year period from 1988 to 1994, collisions occurred at fourteen percent of crossings. Most crossings only experienced one collision, but three-and-one-half percent experienced two or more.

Grade-crossing collisions have characteristics that are both similar and different from highway crashes in general. A disproportionate number of highway crashes occur in the late evening. In contrast, grade-crossing collisions occur at all times of day. Indeed sixty percent of collisions occur in daylight hours. There is a higher 
involvement of older drivers in grade-crossing collisions than in highway crashes in general, and a lower involvement by younger drivers. That said, drivers under the age of thirty-five still account for fifty-six percent of grade-crossing fatalities. As with highway crashes in general, four-fifths of grade-crossing fatalities are male. A third had been drinking, and a quarter had a blood-alcohol content greater than the legal limit.

The proportion of crossing collisions that are due to road user negligence or inattention is unclear. Road user negligence may play a small role in the quarter of total collisions where a stationary motor vehicle is struck by a train. These collisions fortunately result in only nine percent of total crossing fatalities presumably because people have time to exit the motor vehicle. More questionable levels of road-user negligence are involved in the half of all collisions where a vehicle moving across the crossing is struck by a train. Considerable road user negligence is likely in the quarter of all collisions where the road user enters the crossing so late as to drive into the side of the train. Indeed in ten percent of collisions the road user strikes the train behind the leading rail locomotive or car! At gated crossings, eighty-six percent of the fatalities occur when the road vehicle drives around or through the closed gates. At crossings with flashing lights, ninety-two percent of the fatalities occur when the road user ignores the light signals.

\section{TRESPASSERS}

Throughout this book "trespassers" will be defined as those people trespassing at locations other than grade crossings. Almost 500 trespassers are killed each year. This total does not include fatalities that are judged suicides by a coroner. Undoubtedly some of the recorded trespasser fatalities are by suicidal people who do not leave notes or other evidence of their intentions. As shown in table 1.7, a third of the trespassers were killed while sitting or lying in the right of way which may suggest deliberate endangerment by the victim. A study in Britain, where reporting requirements are similar to the United States, looked at circumstantial evidence and found that up to half of all reported trespasser fatalities were probably by people with suicidal intent (Railtrack, 1994).

Two studies give some insights into whom trespassers are, and the circumstances and locations in which they are struck by trains. One is a National Transportation Safety Board (NTSB, 1978a) study of 280 fatalities that occurred between March 1976 and October 1977. The other examined coroners' reports for all of the 138 trespasser deaths in North Carolina for the years 1990-94 (Pelletier, 1997). The results of the two studies are almost identical.

More than ninety percent of victims are adult males, with the vast majority between the ages of 20 and 49. Eighty percent of the adult victims are unmarried. Pelletier's study found that for those adults whose education was known, only forty-five percent had graduated from high school. Only about ten percent were transients. Eighty percent of deaths occurred within the victim's county of residence 
which suggests that trespassers are killed close to home. Pelletier found that blacks were overrepresented as thirty-eight percent of the victims whereas they formed only twenty-two percent of the population of North Carolina.

Table 1.7: Trespasser and Non-Trespasser Fatalities by Cause

\begin{tabular}{|l|c|c|}
\hline \multirow{2}{*}{ Struck by train while .. } & 1996 & $1992-5$ \\
\cline { 2 - 3 } & Trespassers & Non-trespassers \\
\hline walking on the track & & \\
\hline sitting or lying on the track & $216(46 \%)$ & $29(27 \%)$ \\
\hline crossing the track & $167(35 \%)$ & $25(24 \%)$ \\
\hline crossing a bridge or trestle & $28(6 \%)$ & $7(7 \%)$ \\
\hline passing under or over a car & $14(3 \%)$ & $2(2 \%)$ \\
\hline Collisions and derailments & $5(1 \%)$ & $1(1 \%)$ \\
\hline Falling, hit by flying objects, burns & $12(3 \%)$ & $4(4 \%)$ \\
\hline Getting on / off rolling stock & $9(2 \%)$ & $4(4 \%)$ \\
\hline Other & $8(2 \%)$ & \\
\hline & $12(3 \%)$ & $34(32 \%)$ \\
\hline
\end{tabular}

The data on non-trespassers were obtained from the original FRA database so as to exclude fatalities by contractor's employees.

In contrast to the grade-crossing problem, the trespasser problem appears to be an urban one with less than a quarter of fatalities occurring outside of city or town limits. The NTSB reports that nearly all of the fatalities occurred on multiple-track mainlines. In eighty percent of the cases there was no fence erected to protect the right of way.

A disproportionate number of fatalities occur at night on the weekends. Sixty percent of the victims in the NTSB study and eighty percent in Pelletier's study had been drinking heavily. The average blood-alcohol content was 0.23 which is two to three times the legal limit for driving, and according to the National Safety Council puts a person in a state of "confusion." Twenty-eight percent of victims in Pelletier's study had previously received medical treatment for alcoholism.

\section{NON-TRESPASSERS}

This rather clumsy term covers a multitude of different people. The official definition is "a person who is lawfully on any part of railroad property which is used in railroad operations or a person who is adjacent to railroad premises when injured as a result of railroad operations." Examples of non-trespassers include: utility crews working on or near the railroad; shippers' representatives at sidings; truck drivers delivering freight to yards; official guests of the railroad; passengers when 
they are not on a train or boarding and alighting from one; and third parties adjacent to the railroad who are injured by a railroad accident. In some tables in the official statistics, fatalities to employees of contractors are included in this definition, but I have included these people with employees.

There were 106 non-trespasser fatalities over the four-year period 1992-95. A special analysis was conducted using the federal accident database to determine the circumstances of these fatalities (table 1.7). Three people were bystanders who were killed by train accidents: one person was struck by a runaway freight car; another was a highway user who was hit by a derailed freight car falling off a bridge; and the third occurred when shrapnel from a railroad accident landed on a highway. Only one person is recorded as having been "working on or along the track." Fourteen people could well have been passengers at stations who were killed by an assault, flying objects, falling, or crossing the tracks.

However, the circumstances of eighty percent of non-trespasser deaths do not seem to be consistent with the official definition: 25 victims were sitting or lying in the right of way, 29 were walking along the tracks, and 31 deaths were undefined as to cause. Moreover, a third of all non-trespasser fatalities are people under the age of fifteen. It is possible that very young victims may be misclassified by those completing the accident-report forms as non-trespassers due to confusion as to the legal definition of whether persons under the age of twelve can be held legally responsible for knowing that they are trespassing. I have a strong suspicion that many of the recorded non-trespasser victims are in fact trespassers whose purpose on the railroad was mistakenly reported on accident-report forms.

\section{PASSENGERS ON TRAINS}

Table 1.8: Passenger Casualties by Cause 1996

\begin{tabular}{|l|c|c|}
\hline & Fatalities & Injuries \\
\hline Boarding and alighting & $2(17 \%)$ & $156(30 \%)$ \\
\hline Fallings, flying objects, burns & $1(8 \%)$ & $132(26 \%)$ \\
\hline Collisions and derailments & $9(75 \%)$ & $111(22 \%)$ \\
\hline Operation of doors and windows & & $41(8 \%)$ \\
\hline Result of grade-crossing accident & & $24(5 \%)$ \\
\hline Other causes & & $49(10 \%)$ \\
\hline & 12 & 513 \\
\hline
\end{tabular}

Twelve passengers were killed in 1996 and about 500 injured (table 1.8). Total fatalities were somewhat above the typical annual average due to the collision and train fire at Silver Spring, Maryland. Absent a major disaster, there are usually three to five passenger deaths a year, most due to boarding and alighting accidents. 
Boarding and alighting also causes about a third of total passenger injuries, with another quarter due to passengers falling while moving about within the train.

\section{COLLISIONS AND DERAILMENTS}

In 1996 there were 205 collisions and 1816 derailments which were serious enough to cause either a fatality, an injury, or more than $\$ 6,300$ of damage to railroad property. These accidents resulted in the deaths of nine passengers, eleven employees and twelve trespassers. In addition, 111 passengers and 127 employees sustained injuries. While the number of fatalities and injuries is quite small, collisions and derailments result in substantial amounts of damage to railroad property, shippers' goods, and the property of people adjacent to the railroad. In recent years there has been increasing concern about accidents that result in a release of hazardous materials. During 1996, thirty-four separate accidents caused the release of hazardous materials from sixty-nine cars, and resulted in the evacuation of 8,547 people from their homes or workplaces.

Table 1.9: Collision \& Derailment Accidents by Location 1996

\begin{tabular}{|l|c|c|}
\hline & Collisions & Derailments \\
\hline Main line & $53(26 \%)$ & $752(41 \%)$ \\
\hline Yard Track & $135(66 \%)$ & $858(47 \%)$ \\
\hline Siding & $17(8 \%)$ & $206(11 \%)$ \\
\hline & 205 & 1816 \\
\hline
\end{tabular}

As can be seen in tables 1.9 and 1.10, the majority of both collisions and derailments occur in yards or sidings during switching operations, with collisions due to poor operating procedures, and derailments due to poor track. On the main line the major causes of collisions are inappropriate brake use and failures in dispatching and signaling. For derailments the most prevalent cause is track condition, primarily geometry defects and broken rails, with a substantial number caused by defects with car trucks, axles or journal bearings.

About a third of collisions and derailments are due to incorrect operating practices. The NTSB (1972) investigated these instances of employee negligence using data from the 1960s. Using an index that combined frequency of occurrence and severity of outcomes, the NTSB concluded that ten leading operating-practice failures were (in descending order): disregard of a stop signal, excessive speed on the main line, improper switch setting, disregarding a restricting signal, failure to secure handbrakes, absence of a lookout on the leading car of a propelled train, excessive speed in yards, failure to provide flag protection, moving locomotives without orders, and failure to clear a train beyond the fouling point at switches. 
Table 1.10: Causes of Collision \& Derailment Accidents 1996

\begin{tabular}{|l|c|c|c|c|}
\hline & \multicolumn{2}{|c|}{ Collisions } & \multicolumn{2}{c|}{ Derailments } \\
\hline Track, roadbed and structures & & $4 \%$ & & $48 \%$ \\
\hline Locomotive failure & & $0 \%$ & & $1 \%$ \\
\hline Car failure & & $6 \%$ & & $13 \%$ \\
\hline Operating practices & & & & \\
\hline Incorrect braking & $10 \%$ & & $2 \%$ & \\
\hline Drugs, alcohol, fatigue & $1 \%$ & & $0 \%$ & \\
\hline Signaling & $17 \%$ & & $1 \%$ & \\
\hline Switching & $38 \%$ & & $11 \%$ & \\
\hline Train handling & $4 \%$ & & $7 \%$ & \\
\hline Speed & $4 \%$ & & $1 \%$ & \\
\hline Other & $4 \%$ & $78 \%$ & $1 \%$ & $23 \%$ \\
\hline Other (mainly environmental) & & $12 \%$ & & $15 \%$ \\
\hline
\end{tabular}




\section{HISTORICAL TRENDS}

The previous chapter described contemporary safety. The next two chapters set the current performance in its historical context. This chapter describes trends in safety since statistics were first collected in 1890. The next chapter describes how public policy toward safety has responded to, and influenced, these trends.

\section{SOURCES OF DATA}

The Interstate Commerce Commission (ICC) started to collect information on collisions and derailments in 1901. In 1910, the Accident Reports Act required that railroads report all accidents to the ICC. Summary data are made available to the public in an annual publication entitled the Accident / Incident Bulletin. Data analysis and publication of this report subsequently passed to the Federal Railroad Administration (FRA), a division of the federal Department of Transportation (DOT). In the early years the ICC retroactively collected data from as far back as 1890. This chapter looks at safety trends since 1890. It primarily focuses on fatalities and injuries rather than the number of accidents. This is because the definition of an "accident" has changed over time. The most serious problem is with the threshold dollar figure, currently \$6,300, used to determine whether a property-damage-only accident is reportable. This threshold has not changed consistently with inflation over the years. Most notably, the dollar threshold remained constant during the late 1960s and early 1970s, a period of both rampant inflation and public debate about supposedly worsening safety.

\section{AGGREGATE CASUALTIES}

Figures 2.1 and 2.2 present aggregate numbers of fatalities and injuries at the turn of each decade since 1890, and the average for 1994-96. The base data are given in appendix tables B1 and B2. Figure 2.2 does not include injury data for employees because of a definitional change in 1975. Prior to 1975, "injuries" were only counted if they required the employee to miss more than two workdays. This changed to a much more encompassing definition which led to a threefold increase in reported injuries. 
Figure 2.1: Annual Railroad Fatalities

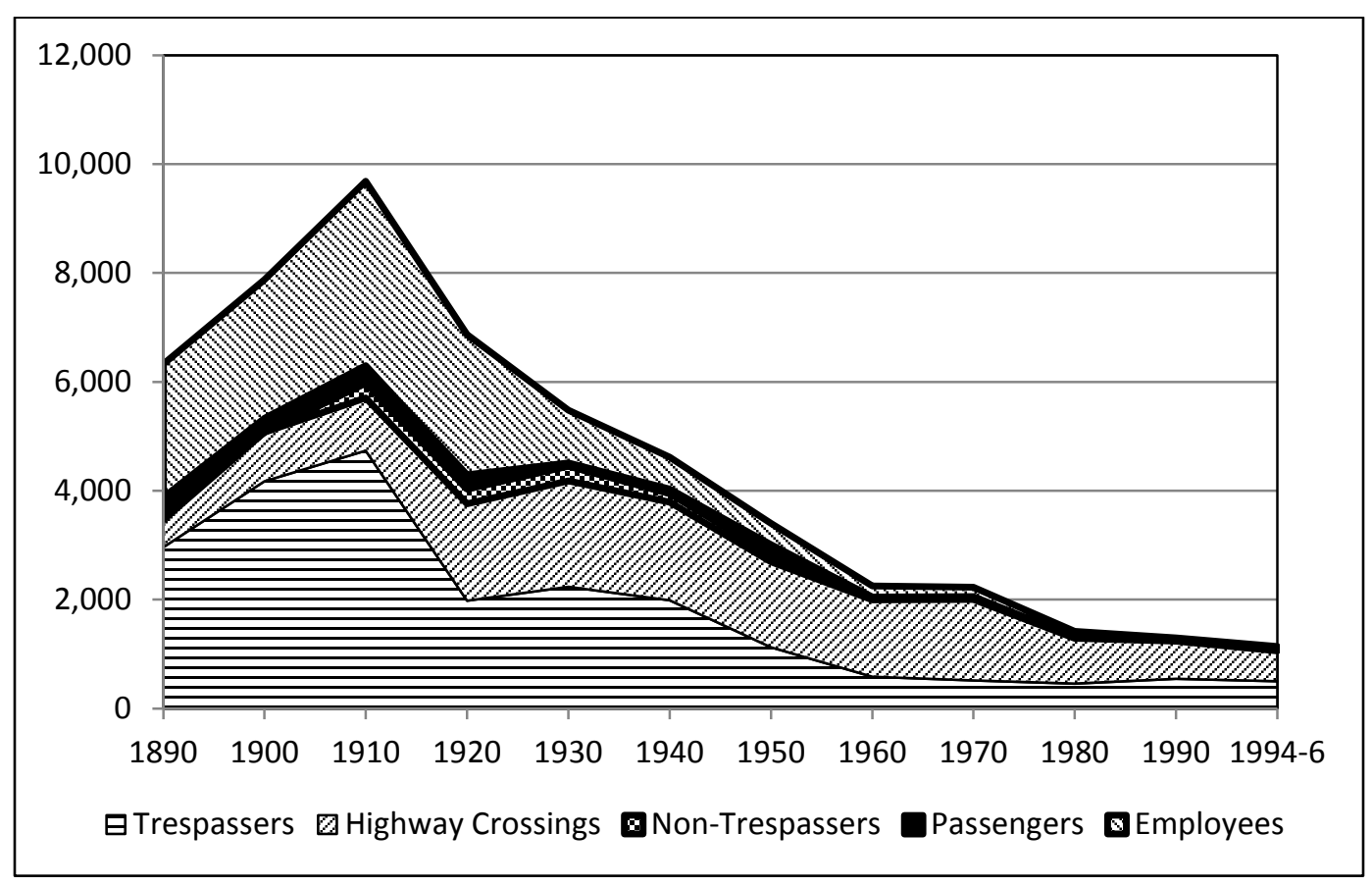

Figure 2.2: Annual Railroad Injuries (Excluding Employees)

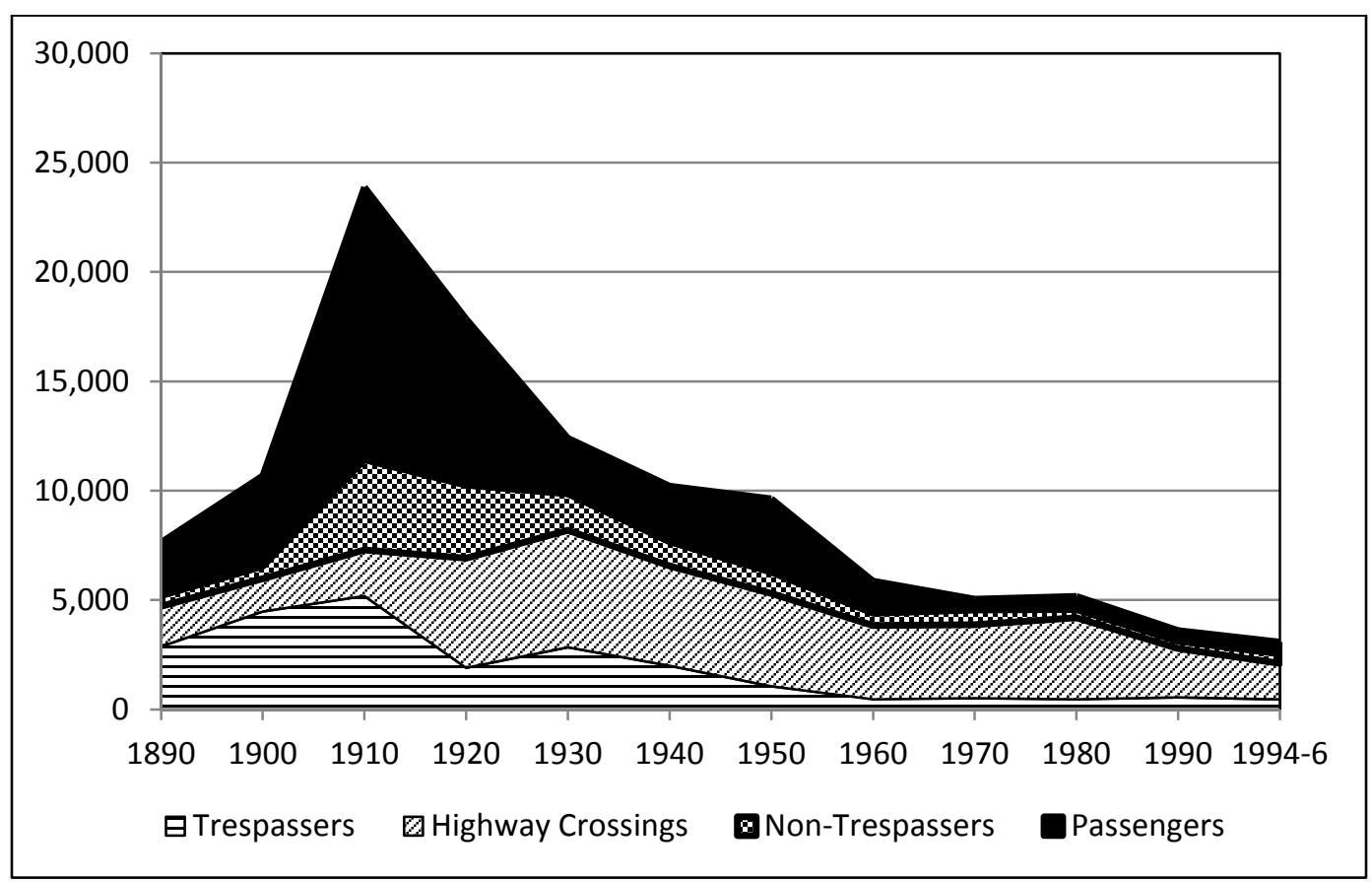


The number of fatalities and non-employee injuries increased to reach a peak in 1910. The next two decades saw a sharp drop, and the improvement continued until 1960. There was then a leveling off of performance until fatalities started to decline again in the 1970s, and injuries started to decline in the 1980s. Today the annual number of railroad fatalities is only half of what it was in 1960, and an eighth of the number in the peak year of 1910 .

Of course, the absolute numbers are only part of the picture. Exposure to accidents has also changed. Passenger miles have declined, employee numbers have fallen drastically, and highway traffic has increased. Data for some important exposure measures are given in table B3 in appendix B. The next sections of this chapter combine exposure measures with the fatality and injury data to produce casualty rates for employees, highway-crossing users, trespassers, and passengers.

\section{EMPLOYEE CASUALTY RATES}

Casualty rates per billion employee hours are shown in table 2.1. Immediately noticeable is the leap in injuries after 1975 caused by the definitional change that was referred to above. There are three major periods of interest. The first is during the 1920s when there was a forty percent reduction in fatality rates and a two-thirds reduction in injury rates. The second is the 1960s when the steady improvement in casualty rates was reversed. The third period is since 1980 when injury rates have fallen by two-thirds, and fatality rates by one-third.

\section{Table 2.1: Employee Casualty Rates per Billion Employee Hours}

\begin{tabular}{|c|c|c|}
\hline Year & Fatalities & Injuries \\
\hline 1920 & 395 & 26790 \\
\hline 1930 & 249 & 9397 \\
\hline 1940 & 210 & 7054 \\
\hline 1950 & 132 & 7995 \\
\hline 1960 & 112 & 7560 \\
\hline 1970 & 130 & 13174 \\
\hline 1980 & 96 & $55718^{*}$ \\
\hline 1990 & 72 & $37879^{*}$ \\
\hline 1994 & 60 & $25220^{*}$ \\
\hline 1995 & 67 & $21131^{*}$ \\
\hline 1996 & 65 & $18230^{*}$ \\
\hline
\end{tabular}

* definitional change in 1975

Excluding casualties to employees not-on-duty and contractors. Data on employee hours were first collected in 1916. 


\section{HIGHWAY-CROSSING USER CASUALTY RATES}

Highway grade-crossing user casualty rates since the mass introduction of the motor vehicle in 1920 are shown in table 2.2. Relative to the number of train miles, casualty rates peaked in 1970, and have subsequently fallen substantially and are now under half of what they were in 1970. Given the massive expansion in automobile ownership, perhaps a more relevant measure of the changes in risk over time is the rate of casualties per million highway vehicles. The improvement in safety is much more pronounced using this measure, and has improved continually since the introduction of the automobile. Casualty rates per road vehicle are about a sixth of those in 1970 and a thirteenth of what they were in 1950.

Table 2.2: Highway-Crossing User Casualty Rates

\begin{tabular}{|c|c|c|c|c|}
\hline \multirow{2}{*}{ Year } & \multicolumn{2}{|c|}{ Per Billion Train Miles } & \multicolumn{2}{c|}{ Per Million Vehicles } \\
\cline { 2 - 5 } & Fatalities & Injuries & Fatalities & Injuries \\
\hline 1920 & 968 & 2327 & 193.1 & 543.2 \\
\hline 1930 & 1221 & 3365 & 72.6 & 200.1 \\
\hline 1940 & 1374 & 3477 & 56.2 & 142.2 \\
\hline 1950 & 1128 & 3056 & 31.8 & 86.1 \\
\hline 1960 & 1417 & 3360 & 19.1 & 45.3 \\
\hline 1970 & 1769 & 4010 & 13.7 & 31.0 \\
\hline 1980 & 1159 & 5182 & 5.3 & 23.9 \\
\hline 1990 & 1138 & 3651 & 3.7 & 11.8 \\
\hline 1994 & 937 & 2671 & 3.1 & 8.8 \\
\hline 1995 & 860 & 2518 & 2.9 & 8.4 \\
\hline 1996 & 726 & 2243 & 2.4 & 7.5 \\
\hline \multicolumn{5}{|l}{} \\
\hline
\end{tabular}

\section{TRESPASSER CASUALTY RATES}

Trespasser fatality and injury rates are shown in table 2.3. Relative to the number of train miles the trend is somewhat mixed. There was a large decline between 1900 and 1920, and then a more gradual downward trend until 1960. Since then there has been a worrying upward trend. Fatality and injury rates per train mile are now twenty percent higher than in 1960. However, the population of the United States has grown threefold since 1910 and by almost half since 1960 . Relative to the population of the country, casualty rates have fallen continuous since the start of the century, although there does appear to be some leveling off since 1980 . 
Table 2.3: Trespasser Casualty Rates

\begin{tabular}{||c|c|c|c|c|}
\hline & \multicolumn{2}{|c|}{ Per Billion Train Miles } & \multicolumn{2}{c|}{ Per Million U.S. Residents } \\
\hline Year & Fatalities & Injuries & Fatalities & Injuries \\
\hline 1890 & 4111 & 4010 & 47.09 & 45.93 \\
\hline 1900 & 4708 & 5047 & 54.94 & 58.90 \\
\hline 1910 & 3875 & 4251 & 51.48 & 56.49 \\
\hline 1920 & 1073 & 1036 & 18.71 & 18.06 \\
\hline 1930 & 1407 & 1790 & 18.23 & 23.20 \\
\hline 1940 & 1519 & 1533 & 15.10 & 15.24 \\
\hline 1950 & 809 & 759 & 7.38 & 6.93 \\
\hline 1960 & 589 & 505 & 3.24 & 2.78 \\
\hline 1970 & 616 & 607 & 2.52 & 2.48 \\
\hline 1980 & 637 & 637 & 2.01 & 2.08 \\
\hline 1990 & 892 & 920 & 2.17 & 2.24 \\
\hline 1994 & 808 & 690 & 2.03 & 1.73 \\
\hline 1995 & 737 & 696 & 1.88 & 1.77 \\
\hline 1996 & 702 & 707 & 1.77 & 1.79 \\
\hline
\end{tabular}

The leveling off of casualty rates since 1980 coupled with a fifteen percent increase in the population accounts for the increasing number of trespasser fatalities in recent years. Unless casualty rates fall, the absolute number of trespassers killed and injured each year will continue to climb as the population expands. Preliminary data for 1997 suggest that the number of annual trespasser fatalities will exceed the number of fatalities at grade crossings for the first time since 1941. Yet as recently as 1970 the number of grade-crossing fatalities exceeded those of trespassers by a ratio of 2.8:1.

It is quite astonishing to realize that trespasser fatalities per head of population were ten times higher than current levels in the 1920s and 1930s. In part this is explained by the large number of hoboes who rode the trains during the depression years. It is also true that more people were exposed to trespassing risks earlier this century because the railroads served a mass market, and provided extensive freight and passenger service to small communities. Expressed as a rate per train mile, trespasser fatality rates were twice current levels in the 1920s and 1930s. It is also quite clear that in the early days of railroading the public was quite complacent about trespassing risks. The casualty rate per head of population was thirty times higher in 1900 than it is today, and the rate per train mile was six times higher. 


\section{SUMMARY OF RECENT TRENDS}

To summarize recent trends, figure 2.3 shows fatality rates for employees, trespassers and grade crossing users each year since 1960. Employee fatalities are expressed relative to employee hours, trespassers relative to the United States population, and crossing fatalities relative to the number of motor vehicles registered. All of the fatality rates are shown as an index with 1960 set equal to 100 . Fatality rates at crossings have recorded the most impressive improvement falling rapidly since 1967 . The trespasser fatality rates also started to decline rapidly after 1967 but leveled out after 1975 at about forty percent below the fatality rate in 1960 . If anything, there may be a slight upward trend in recent years. Employee fatality rates show a different pattern with an upward trend in the 1960s and early 1970s, and a subsequent improvement. In the peak years of the early 1970s, fatality rates were thirty percent above those in 1960, and twice what they are now.

Figure 2.3: Railroad Fatality Rates since 1960

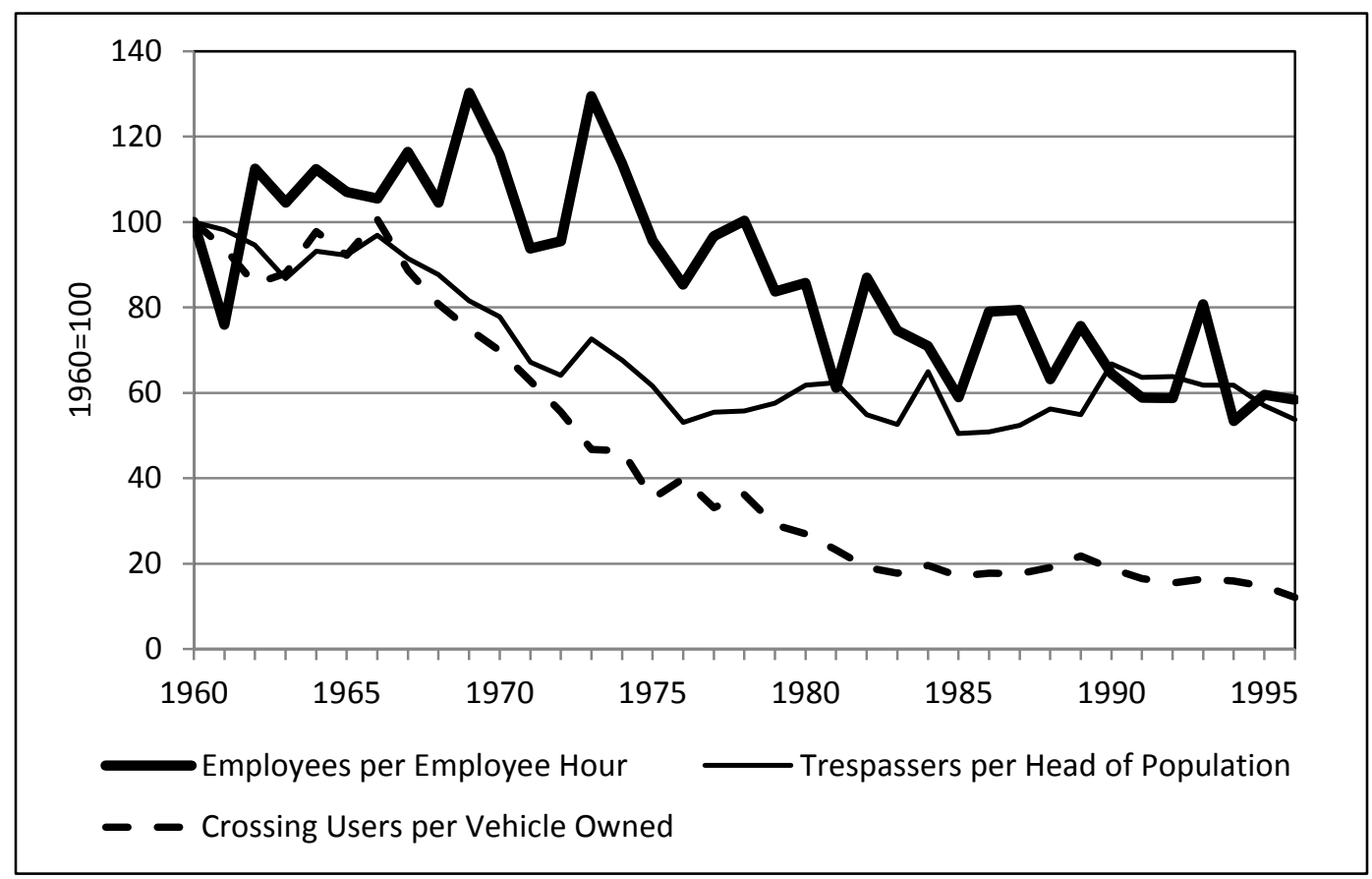

\section{PASSENGER CASUALTY RATES}

Passenger fatality and injury rates per billion passenger miles are shown in table 2.4. For the period when passenger traffic was extensive, and accidents frequent, the data are shown at the turn of each decade between 1890 and 1940. For the postwar years, when the decline in passenger traffic has meant that major disasters with much loss of life occur rarely and randomly, average casualty rates are calculated for three 
periods: 1946-1959, 1960-1979, and 1980-1996. In recent years, passenger fatality rates are only half of what they were in the immediate postwar years, and a thirteenth of those when railroads were the primary means of travel at the beginning of the twentieth century.

Table 2.4: Passenger Casualty Rates per Billion Passenger Miles

\begin{tabular}{||c|c|c|}
\hline Year & Fatalities & Injuries \\
\hline 1890 & 24.14 & 205 \\
\hline 1900 & 15.52 & 257 \\
\hline 1910 & 10.02 & 385 \\
\hline 1920 & 5.57 & 160 \\
\hline 1930 & 2.01 & 95 \\
\hline 1940 & 3.65 & 105 \\
\hline $1946-59$ & 1.64 & 78 \\
\hline $1960-79$ & 1.07 & 82 \\
\hline $1980-96$ & 0.73 & 42 \\
\hline
\end{tabular}

\section{COLLISIONS AND DERAILMENTS}

Data on collisions and derailments can only be meaningfully analyzed since 1975 when the dollar threshold for reporting property-damage-only accidents started to be adjusted for price inflation. The rate of collisions and derailments per train mile is shown in figure 2.4 as the line with the squares. It is shown as an index with the value in 1975 set equal to 100 . The rate increased until 1979 and subsequently declined. It is now only a quarter of what it was in the late 1970s. One explanation for this reduction is a change in the way that railroads do business. Railroad mergers and the move toward unit trains and away from single-car service have reduced the amount of switching. In the mid-1970s switching represented about thirty percent of all train miles while that ratio is now thirteen percent. The line with the diamonds represents this ratio with the value in 1975 set equal to 100 . As seventy percent of collisions and sixty percent of derailments occur in yards and sidings, it is not surprising that the rate of collisions and derailments has fallen. Albeit that the decline in the rate of collisions and derailments since 1979 has been much swifter than the decline in switching operations which suggests that there must be other factors at work. 
Figure 2.4: Collision and Derailment Rate since 1975

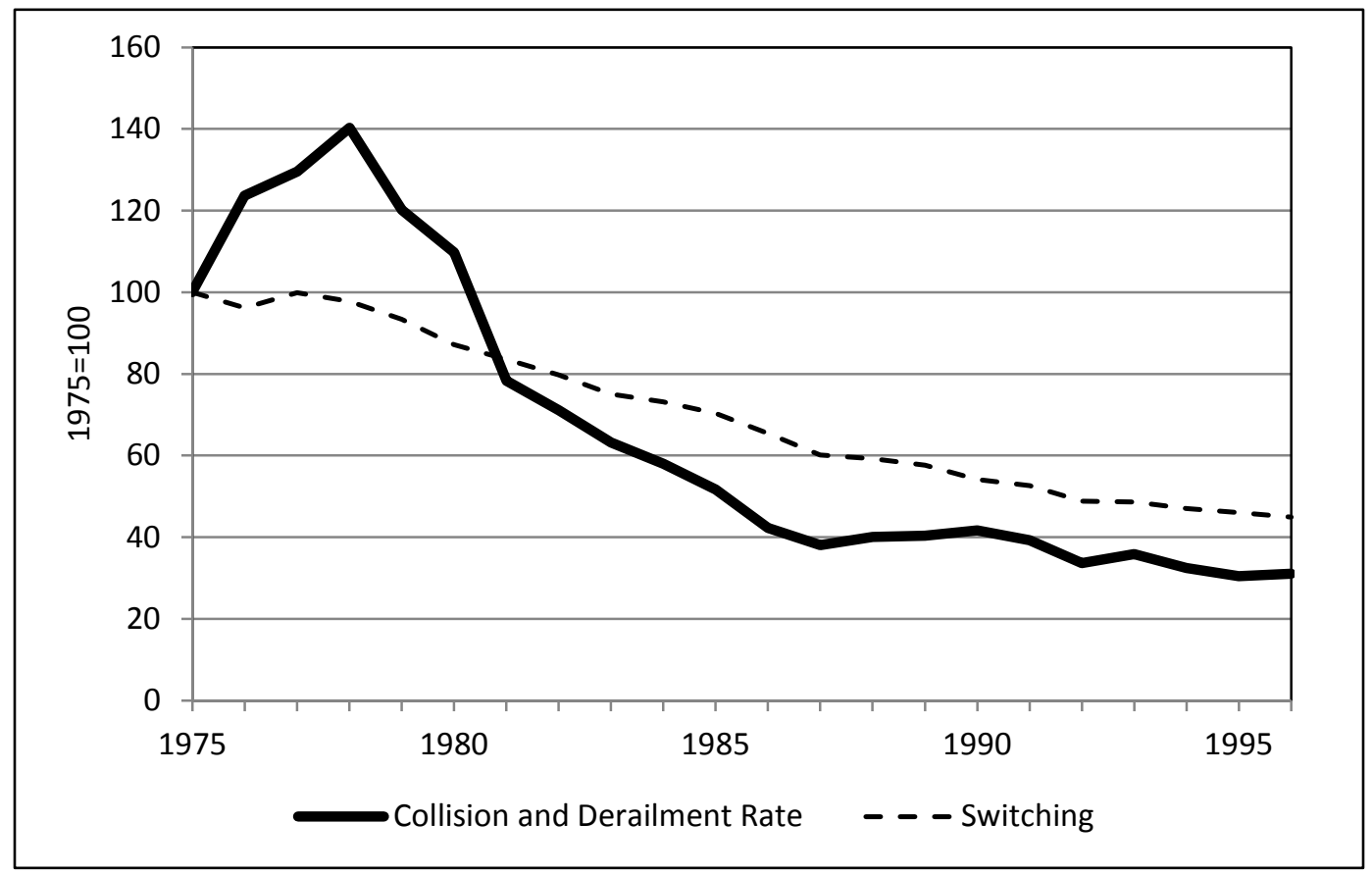




\section{PUBLIC POLICY}

This chapter provides a sketch of the development of public policy towards railroad safety. There are four key dates in this history: 1853, 1893, 1900-1910 and 1970. Readers seeking more details are directed to Robert Shaw's 1978 book A History of Railroad Accidents, Safety Precautions and Operating Practices which provides an encyclopedic review of the period prior to 1950. Another source is Robert Reed's 1968 book Train Wrecks: A Pictorial History of Accidents on the Main Line. While primarily a picture book, it does provide a quick, readable and informative introduction to the subject.

\section{3: THE YEAR OF DISASTER}

In the 1830s and 1840s there was little public concern about safety. The network was small, speeds were low, traffic was light and there was little nighttime operation. No wreck claimed more than six lives. That changed in 1853. A series of wrecks claiming 234 lives, injured the president-elect, and led to considerable public outrage. An editorial in the Railroad Record opined:

"Public feeling has been grossly outraged by these reckless sacrifices of life on railroads. Indignation meetings have been called, and several Legislatures have taken action upon the matter. We sincerely trust they will continue to agitate the matter until some remedy shall be applied to this great evil. Corporations have no souls, but they have pockets, and if they cannot be reached in any other way, heavy damages should be required of them in every instance where loss of life was the result of carelessness."

and a New York paper editorialized:

"That a vast majority of railroad disasters are directly owing to stupidity and neglect of the employees, and the apathy and avarice of the railroad officers."

The carnage continued into 1854, 1855 and 1856 and remained a serious problem through the Civil War. The situation was inflamed by sensationalist press reporting which would make today's coverage of aviation accidents look gentile. Screaming headlines and very graphic lithographs and text made such accidents as Camp Hill, Pennsylvania (1856), the "Angola (New York) Horror" (1867), Ashtabula, Ohio (1876) and Chatsworth, Illinois (1887) part of popular folklore. Despite the publicity, Shaw (1978) notes that the railroads were much safer than the 
stagecoaches they replaced, and considerably safer than contemporary steamboats which routinely exploded and sank.

The root cause of the safety problem was the hasty construction of new lines by undercapitalized firms who wished to take advantage of land grants. This resulted in sharp curves, poorly-constructed wooden bridges, steep grades, light rolling stock, and inadequate road bed which could not cope with frosty and muddy conditions. Often minor derailments and collisions were made worse by the telescoping of flimsily constructed wooden carriages and the threat of fire from coal-heating stoves and kerosene lighting. Rear-end and head-on collisions were a persistent problem. Prior to the invention of the telegraph in 1855, trains were dispatched from stations based on the published timetable. This method of protection was useless when trains were delayed or stalled between stations. Even when it came available, not all companies invested in telegraph, so head-on collisions persisted into the 1880s.

\section{3: THE FIRST REGULATION}

Despite the outrage in the 1850s, it was to be thirty years before there was any major political intervention. In the 1880s the state legislatures in Ohio, Illinois, New York and Massachusetts started to conducted investigations of major accidents. A proposal was introduced into the New York legislature to set up a State Railroad Commission to deal with safety issues. This was blocked by State Senator Webster Wagner, a car builder and railroad ally. Ironically he perished in the rear-end collision at Spuyten Duyvil in 1882 and the Commission was subsequently formed.

Later that decade the initiative passed to the federal government. As railroads commonly cross state boundaries, Article I, Section 8 of the United States Constitution gives the federal government powers to regulate commerce between states. An important implication is that federal laws take preeminence over state laws for interstate movements. The railroads became the first industry to be economically regulated by the federal government with the passage of the Interstate Commerce Act of 1887 . The first federal safety regulations followed six years later. After a series of legal challenges, the United States Supreme Court ruled in 1915 that the constitutional powers of the federal government applied to safety as well as economic regulations (Southern Railroad v. Railroad Commission of Indiana (236 U.S. 439 (1915)).

The federal Safety Appliance Act of 1893 required the use of the Westinghouse air brake on locomotives and Janney-type semiautomatic couplers. Both devices had been in existence since the late 1860s but had not been uniformly adopted. There had been pressure to improve braking for some time. Some states, such as Iowa, had taken the lead by requiring the Westinghouse brake in the 1880s. There was also concern that the lack of uniformity between cars had led to the continued use of simple pin-and-link couplers which caused a high levels of casualties to employees who had to go between cars to engage them. Subsequent to the 
widespread use of the Janney coupler, the number of employees injured in switching operations fell by three-quarters between 1891 and 1915 (Clark, 1974).

About the same time the industry introduced some self-regulation for purely commercial reasons. Even in the mid-1880s there were more than twenty different track gauges and each railroad had uniquely designed rolling stock. Goods that needed to travel over multiple railroads had to be transshipped between cars at places where railroads met. Consequently, there was a commercial motivation for railroads to agree on a level of standardization. In 1886 a uniform national standard rail gauge was adopted which required the shifting of rails on 15,000 miles in the

south. The increased ability to interchange cars between railroads required standardization of couplers, and a commonality of components so that cars could, if necessary, be repaired far from home. The Master Car Builders Association, which had been founded in 1867, drew up a model interchange agreement and developed rules on the design and condition of cars that were binding on all subscribing railroads. Signatories to interchange agreements were obliged to use the Janney coupler in 1887 and the Westinghouse automatic brake in 1888. These industry requirements predated the Safety Appliance Act by some five or six years.

The need for standardization resulted in similar cooperation between railroads to set standards for: motive power design (through the American Railway Master Mechanics Association founded in 1868); painting and marking of cars (Master Car and Locomotive Painters Association from 1870); time zones (General Time Convention of 1883); recommended operating rules (the Standard Code of Railroad Operating Rules of 1887); and telegraph train orders (1887). It is interesting to note that it was not until 1918 that Congress followed the lead of the railroads in establishing national time zones.

\section{0-1910: MORE REGULATIONS AND SAFETY FIRST}

By the end of the nineteenth century technological advances had improved safety immensely as compared with the time of the civil war. These advances included the introduction of steel rail (1865), continuous air brakes (1869), interlocking of signals and switches (1870), track circuits (1872), steam train heating (1881), and electric train lighting (1882). In the first decade of the new century steel cars came into widespread use which reduced the chances of telescoping and fires following a derailment or collision.

Despite these improvements there was a great public outcry at the start of the century (Clark, 1974). The main reason was the expansion of the railroads which resulted in increased frequency and visibility of accidents. Between 1890 and 1910, train miles increased by seventy percent and passenger miles by 175 percent. While fatality rates did not increase over the period, the absolute number of casualties did. Total annual fatalities increased by half from 1890 to 1910 (figure 2.1). Over the same period the number of non-employee injuries increased threefold (figure 2.2), 
and the number of employee injuries increased fourfold. Clark notes that casualties were much higher in the United States than on comparable railroads in Europe.

Consequently, a series of Acts was introduced to deal with the perceived safety problems. These Acts essentially governed safety for the following sixty years. The Acts dealt with five main areas: accident reporting, specification of safety equipment, transportation of explosives, hours of work, and financial responsibility to injured employees and shippers whose freight was damaged.

The Accident Reports Act of 1910 required railroads to report all fatality, injury and property damage accidents to the ICC. The ICC was also given powers to investigate serious railroad accidents.

A group of Acts specified items of safety hardware and equipment. The existing Safety Appliances Act was extended and amended a number of times to require air brakes on cars as well as locomotives, standardization of the location of handholds and steps on rolling stock, and to introduce new rules on brake inspection, testing and maintenance. The Block Signal Systems Act of 1906, Safety Devices Testing Authorization Act of 1908, and Signal Inspection Act of 1920 allowed for research and then implementation of automatic signaling and interlocking. The Ashpan Act of 1908 required steam locomotive ashpans that could be emptied without needing an employee to go under the locomotive. The Locomotive Inspection Act of 1911 required boiler inspections. While boiler explosions rarely killed the traveling public, they were a leading cause of employee casualties. In the eighteen years after the Act the number of deaths and injuries due to boiler failures fell by ninety percent (Clark, 1974).

The federal government had been concerned about the dangers of the storage and transportation of explosives since the civil war. These laws were updated and expanded as new industrial processes led to the manufacture or extraction of new hazardous chemicals and gases. The railroads were affected by a series of Acts: the Transportation of Explosives Act of 1908, Transportation of Explosives and Other Hazardous Materials Act of 1909, and Explosives and Other Dangerous Articles Act of 1960. These laws are quite general, and prior to 1967 the authority for devising specific rules and the implementation of these rules were delegated to the industry through the Association of American Railroads' (AAR) Bureau of Explosives.

The government was also concerned that employees were working excessive hours, and that fatigue was a major source of operational errors. The Hours of Service Act of 1907 established a limit of sixteen consecutive working hours in twenty-four for those operating trains, and nine to thirteen hours on duty in twenty-four for dispatchers. Following the Act the average work week for employees fell from sixty-one hours in 1916 to forty-nine hours in 1923 (Clark, 1974).

Railroads were also given financial incentives to improve safety. The 1906 Carmack Amendment to the Interstate Commerce Act required railroads to compensate freight shippers for "full loss and damage" if their goods were lost or damaged in transit. Injured railroad employees were also given the legal right to obtain compensation from their employer by filing a tort claim under the Federal 
Employers' Liability Act of 1908. Previously, injury costs had been borne by the employee either personally or through employee-supported mutual aid societies. The requirement that occupational injury claims should be settled by torts was in contrast to the "no-fault" system of workers' compensation that subsequently emerged in other industries. This unusual feature of railroading persists to the present day.

Not surprisingly, railroads became much more concerned with encouraging safe practices on the job and ensuring that employees were properly trained (Aldrich, 1992). The Chicago and North Western Railway started the first accident prevention, or Safety First, program in 1910, following from the principles pioneered by U.S. Steel in 1906. In 1918 all of the large Class I railroads were required by the government to adopt such programs, and encouraged to join the Steam Railroad Section of the National Safety Council. As a result, employee injuries rates fell by three-quarters between 1920 and 1940. Only the iron and steel industry could claim a larger improvement in employee safety.

\section{0: COMPREHENSIVE SAFETY REGULATION}

Between 1920 and 1960 accident rates improved considerably, and the industry was largely left to self-regulate. Technical committees of the AAR and the National Safety Council managed the initiatives arising from Safety First programs. There were technological advances including the Sperry broken rail detector car (1927), ultrasonic track inspection (1959), centralized train control (1927), and the automatic inductive train stop (1933). By 1960 passenger services were in serious decline and it seemed that the future of the railroads was as a freight carrier, which one might imagine would reduce the pressure for government oversight.

However, then came the disastrous decade of the 1960s. The improvement in safety witnessed in previous decades was reversed. Employee fatality and injury rates increased by sixteen percent and seventy-five percent respectively between 1960 and 1970. The major cause was the decline in railroad finances, especially in the East and Midwest with the bankruptcies of the Penn Central, Rock Island and Milwaukee Road, which lead to considerable deferred track maintenance. The rate of accidents per ton-mile caused by track defects doubled between 1966 and 1974 (Office of Technology Assessment, 1978). Simultaneously with the decline in track maintenance was the introduction of larger freight cars. This led to a sharp rise in derailments due to broken rails (NTSB, 1974).

These derailments become more of a public concern because of the expanded carriage of hazardous materials. While the railroads had always carried explosives and munitions, they now carried flammable liquids, pressurized liquefied gases, and corrosive liquids. In 1969 there was a series of accidents where tank cars ruptured with disastrous consequences for people who lived next to the railroad.

There was consequently agitation for some government intervention, not least from the labor unions whose members' jobs were under threat as railroads attempted 
to improve their financial situation. The unions argued, for example, that the increase in collisions and derailments was linked to the removal of firemen from diesel locomotives in the mid-1960s. (See the academic paper by Fisher and Kraft (1971) whose econometric argument appears, in the fullness of time, to be misleading.)

This was an era when government was probably receptive to expanded safety powers. The FRA was created in 1967, and assumed the powers of the ICC's Bureau of Railroad Safety. Cynical readers might suspect that the FRA was looking for new powers to consolidate its position and justify expansions in staffing. It is also notable that the late 1960s was the highpoint of "big government" with the formation of powerful federal commissions with safety missions: the National Highway Traffic Safety Administration, the Occupational Safety and Health Administration (OSHA), the Environmental Protection Agency (EPA), the Consumer Product Safety Commission, and the Nuclear Regulatory Commission.

An alternative viewpoint that has been suggested to me by then-senior officials of the FRA was that a major motivation was a desire to make a preemptive strike to prevent OSHA from taking a lead role in regulating railroad safety. OSHA is forbidden from intervening if other government agencies have already established safety regulations. The understandable reaction of the FRA was that it was better for safety regulation to be decided on by people familiar with the industry rather than by outsiders.

The Congress was also interested in railroad safety. Public pressure prompted investigations by Congressional committees. These committees concluded that the vast majority of accidents, especially those involving track defects, were caused by factors that were not covered under existing statutes. There was also concern that the industry was largely self-regulated. The Congressional Research Service (1979) quotes a congressional committee's displeasure that "the ICC [had] practically turned the hazardous materials transportation safety program over to AAR's Bureau of Explosives."

The result of FRA and congressional initiatives was the Federal Railroad Safety Act of 1970 which gave the FRA rulemaking authority to:

"promote safety in all areas of railroad operations and to reduce railroad related accidents, and to reduce deaths and injuries to persons and damage to property caused by accidents involving any carrier of hazardous materials."

The FRA's first order of business was to set up a committee to decide on recommended track standards. Six categories of track were established each with a maximum allowable speed. Detailed engineering specifications were written to define each category of track. The FRA was given powers to hire track inspectors to enforce these standards, and assess penalties for noncompliance.

The FRA then dealt with defective rolling stock by taking the existing AAR rules on interchange of freight cars and writing those parts dealing with safety-related equipment into federal law. The regulations deal with defining defects in wheels, axles, bearings, trucks, bodywork, couplers and cushioning. Again, the FRA hired inspectors to randomly inspect cars, write citations and assess penalties. 
Subsequently, rules were also introduced on various aspects of diesel locomotive design, and the frequency with which certain components should be inspected.

The concern about accidents caused by human factors was addressed in the Federal Railroad Safety Authorization Act of 1976 which promulgated rules to protect workers going between cars. The Rail Safety Improvement Act of 1988 introduced qualification requirements for railroad engineers. Previously qualifications had been decided by collective bargaining between railroads and unions.

The safety of railroad engineering workers was further affected by the Occupational Safety and Health Act of 1970. The objectives were "to assure so far as possible every working man and woman in the Nation safe and healthful working conditions." Employers are given a duty to furnish "employment and a place of employment which are free from recognized hazards that are causing or are likely to cause death or serious physical injury to his employees." As already discussed OSHA regulations only apply when regulations set by other government agency are absent. Under an agreement between the FRA and OSHA in 1978, it was agreed that OSHA regulations are only applicable to the maintenance shop operations (except when trains are moving) and offices.

The problem of fatalities at highway grade crossing, which in 1970 were almost three times as numerous as they are now, was addressed by the Highway Safety Acts of 1973 and 1976, and the Surface Transportation Acts of 1978 and 1982 . These Acts authorized ninety-percent federal funding to states for public grade-crossing improvements such as the installation of flashing lights and gates. This is commonly referred to as the Section 130 program. While the federal government has a substantial funding role, decisions on which crossings to improve and what types of warning device to install are left with individual state highway authorities. The government and the railroads instituted a public information effort under the Operation Lifesaver banner to educate the public on the dangers of highway-rail crossings. These programs have been very successful in reducing the risks at grade crossings.

An area of considerable rulemaking and congressional action has been the transportation of hazardous materials. In 1967 the DOT set up a Hazardous Materials Regulations Board (now part of the Research and Special Projects Administration) to deal with intermodal shipments of hazardous materials, and make rules on packaging and placarding. The major piece of legislation to support these activities was the Hazardous Materials Transportation Act of 1975 which brought together the fragmented provisions already in effect, and provided for federal preemption of state laws. Later Acts such as the Hazardous Materials Transportation Uniform Safety Act of 1990, and Sanitary Food Transportation Act of 1990 imposed greater requirements on both the shipper and the railroad to adequately placard cars, and provide detailed information for firefighters on the consists of trains containing hazardous materials, and the recommended way to respond to specific hazards. 
Concurrently with the increased safety regulation, there was a reduction in economic regulation. The Railroad Revitalization and Regulatory Reform Act of 1976 allowed the ICC to exempt some commodities from price regulation. In response to industry complaints that the forced retention of lines which had long since lost all passenger and most freight service was a financial drain, the procedures for abandonment of uneconomic branch lines were made easier.

The Staggers Act of 1980 exempted even more commodities from regulation and made price regulation much looser. The ICC retained powers to review rates for shipments, such as coal, where rail is the dominant form of transportation. Private contracts between railroads and shippers were allowed for the first time since 1887. The Act also encouraged the shedding of branch lines by large railroads by transferring them to small companies. With the removal of most of its regulatory powers, the ICC was disbanded by the ICC Termination Act of 1995 . The remaining railroad powers concerning approval of abandonments and mergers, and the review of bulk shipment rates were transferred to a new Surface Transportation Board within the DOT.

Subsequent to deregulation the railroad industry has flourished. In the 1970s the average rate of return on equity was less than two percent. It grew to six percent in the mid-1980s and to twelve percent in the mid-1990s (AAR, 1997). Traffic has expanded with the number of revenue ton-miles increasing by forty-seven percent between 1980 and 1996, albeit that traffic had reversed a longstanding decline starting in the 1960s. What is more important, the railroads have stabilized, and even somewhat increased, their market share of domestic freight movements at about forty percent despite strong competition from trucks, barges and pipelines. 


\section{4 hOW SAFE ARE AMERICAN RAILROADS?}

How safe are American Railroads? That question can only be answered by making comparisons with other types of risks. This chapter compares employee risks in railroads with those in other industries, passenger risks across modes of transportation, railroads versus other hazards of modern life, and United States to railroads to those in Canada and Great Britain.

\section{OCCUPATIONAL RISKS}

Table 4.1: Fatal and Lost-Workday Injuries per 100,000 Employees 1995

\begin{tabular}{|l|c|c|}
\hline & Fatalities & Injuries \\
\hline Agriculture, Forestry, Fishing & 48.2 & 4200 \\
\hline Taxis, School Buses & 29.2 & 8000 \\
\hline Water Transportation & 29.2 & 4800 \\
\hline Mining & 26.8 & 3800 \\
\hline Trucking \& Warehousing & 24.6 & 6900 \\
\hline Construction & 20.6 & 4800 \\
\hline Railroads & 12.8 & 3200 \\
\hline Utilities & 10.1 & 3500 \\
\hline Aviation & 9.7 & 7900 \\
\hline Manufacturing & 3.8 & 4600 \\
\hline Wholesale and Retail & 3.4 & 3100 \\
\hline Services & 2.4 & 2700 \\
\hline Finance, Insurance, Real Estate & 1.9 & 900 \\
\hline Communications & 1.8 & 1500 \\
\hline Source: Bureau of Labor Statistics (1996a,b) & & \\
\hline
\end{tabular}

Table 4.1 presents 1995 data on occupational risks for a number of industries. Fatalities and injuries that require at least one lost workday are shown as a rate per 100,000 employees. The industries are shown in descending order of fatality risk. Compared with other occupations that require work out of doors and involve heavy 
moving machinery, the occupational risks of railroading are at the lower end of the scale and are comparable with working for a utility company. Workers in the trucking, maritime and taxi industries have fatality rates twice that of railroad workers.

While the overall average occupational risks in railroads are relatively low, the risks vary by type of employee. In the first chapter it was calculated that train crews face the most risk with a fatality rate of 23.6 per 100,000 employees. This would place the occupational risk to train crews as equivalent to the average risk to workers in mining or trucking. However, given that the mining industry also has a mix of different classes of employees who face different risk levels, train crews face less risk than people working at the mine face.

\section{PASSENGER RISKS}

Major transportation disasters with large loss of life occur randomly and rarely, so an appropriate view of the risks of different modes can only be calculated as an average over a lengthy time period. Table 4.2 shows the passenger fatality risk per billion passenger miles for different modes of transportation calculated for the period 1986 to 1995 . The railroad fatality rate of 0.81 per billion passenger miles is three to four times worse than buses and commercial aviation, but ten times safer than driving.

Table 4.2: Passenger Fatalities per Billion Passenger Miles 1986-1995

\begin{tabular}{|l|c|}
\hline Automobile (1990-95) & 8.29 \\
\hline Railroad & 0.81 \\
\hline Bus (school, transit and intercity) & 0.23 \\
\hline Commercial Aviation & 0.21 \\
\hline Source: National Safety Council (1997) & \\
\hline
\end{tabular}

\section{GENERAL PUBLIC HAZARDS}

Table 4.3 compares the fatality risks of railroads versus other common hazards found in society. This table only considers hazards that the public faces at home and in public places and excludes occupational fatalities. The 600 fatality figure for railroads represents deaths to trespassers, passengers on trains, passengers at stations, pedestrians at grade crossings, and those adjacent to the railroad. Highway-user fatalities at grade crossings are included in the 20,000 people killed in private automobile driving.

Even when one includes fatalities at grade crossings, the approximately 1,000 people killed in accidents involving railroads each year represent a risk that is only slightly more than the risk of drowning in a home swimming pool or bath. 


Table 4.3: Non-Occupational Fatalities 1996
\begin{tabular}{|l|c|}
\hline Homicide & 25,000 \\
\hline Private auto driving & 20,000 \\
\hline Falls & 13,500 \\
\hline Suffocation \& poisoning & 10,300 \\
\hline Drowning & 3,400 \\
\hline Fires & 3,100 \\
\hline Firearms accidents & 1,300 \\
\hline Aviation & 800 \\
\hline Railroads & 600 \\
\hline Boating & 500 \\
\hline Floods & 110 \\
\hline Lightning & 90 \\
\hline Hurricanes \& tornadoes & 70 \\
\hline Source: National Safety Council (1997) & \\
\hline
\end{tabular}

\section{INTERNATIONAL RAILROAD COMPARISONS}

There is no publication that permits easy and extensive comparison of international railroad safety data. However, table 4.4 contains a comparison between the United States in 1994, Canada in 1994 and Great Britain in 1993/94. The fatality and injury rates are expressed as an index with the United States equal to 100 . Canada provides the best peer comparison with the United States because of similar terrain and the predominance of freight traffic. The British railway system is primarily a passenger system and the data, unlike the United States and Canada, includes mass transit.

Employee casualty rates in the United States are slightly higher than in Canada and twice those in Great Britain. One explanation for the lower British casualty rates is that as a passenger railroad, there are more people in customer service functions that are removed from the danger of moving trains.

Comparisons of passenger casualties are difficult because due to the random nature of passenger train accidents that result in large loss of life. In 1994 the British passenger fatality rate is comparable with the seventeen-year average for the United States. The Canadians in the early 1990s had a passenger-fatality rate twice that of the United States. Britain does have a high rate of passenger injuries. A major contributing factor in Britain is the widespread use of hinged passenger car doors that open outward.

There is a quite remarkable similarity among the three countries in the propensity of the population to trespass on the railroad, and get struck by a train. This similarity is despite the fact that Britain's railways are largely fenced. 
Table 4.4: International Comparisons (United States = 100) for USA (1994), Canada (1991-94 average) and Great Britain (1993/94)

\begin{tabular}{|l|l|c|c|c|c|c|c|}
\hline Casualty & \multirow{2}{*}{$\begin{array}{l}\text { Exposure } \\
\text { Type }\end{array}$} & \multicolumn{3}{|c|}{ Fatalities } & \multicolumn{3}{c|}{ Injuries } \\
\cline { 3 - 9 } & Measure & USA & CAN & GB & USA & CAN & GB \\
\hline Employees & $\begin{array}{l}\text { employee } \\
\text { hours }\end{array}$ & 100 & 83 & 45 & 100 & 89 & 52 \\
\hline Passengers & $\begin{array}{l}\text { passenger } \\
\text { miles }\end{array}$ & $100^{*}$ & 198 & 102 & $100^{*}$ & 159 & 713 \\
\hline Trespassers & $\begin{array}{l}\text { population } \\
\text { motor } \\
\text { Grade } \\
\text { Crossings }\end{array}$ & 100 & 98 & 1111 & 100 & 84 & 89 \\
\hline
\end{tabular}

* Average for 1980-1996

Sources: United States: FRA (1995a,b), FHWA (1995), Department of Commerce (1995).

Canada: Transportation Safety Board of Canada (1995), Statistics Canada (1995), American

Automobile Manufacturers Association (1996), Human Resource Development Canada (1998).

Great Britain: Health and Safety Executive (1995).

The most striking difference between the countries is the risk of grade crossing fatalities. The fatality risk per vehicle registered in America and Canada is five times higher than in Britain. Unlike North America, the British system was built with extensive grade separation, which reduces the exposure to highway-rail collisions. 


\section{RISK EVALUATION}

The previous chapter presented actuarial evidence on the risks of railroading and compared them with other hazards in society. However, no judgment was drawn as to whether these risks were "acceptable" or "too high." The purpose of this chapter is to provide a bridge between the actuarial risks and understanding the public policy response to risk. While public policy is influenced by actuarial risk calculations, it is largely swayed by public opinion. There is now a large body of literature by psychologists concerning the way in which people form opinions about the magnitudes of risk, and whether they find the risks acceptable. There is also a literature by economists and political scientists on the appropriate public policy response to different levels of risks.

Throughout this chapter, reference will be made to annual fatality risks expressed as a probability. To provide a frame of reference here are some railroad fatality probabilities:

Working as a train crew member for one year

(based on average fatality rate for 1990-6)

1 in $\quad 3,500$

Working on the railroad for a year (all employment categories)

(based on average fatality rate for 1990-6)

1 in $\quad 6,000$

Crossing a highway crossing with passive warning devices twice a day for a year:

1 in 185,000

Commuting by train twenty miles a weekday for a year (based on average fatality rate for 1990-6)

1 in 215,000

Annual risk per head of population from trespassing or as a bystander

1 in 530,000

Crossing a highway crossing with active warning devices twice a day for a year:

1 in 790,000

And as a way of comparison, other fatality probabilities are:

Working in agriculture, forestry or fishing for a year

1 in $\quad 2,000$

Driving 20 miles (round trip) to work for a year

1 in 22,000

Working in a wholesale or retail trade for a year

1 in 30,000

Annual non-occupational risk of fire

1 in 85,000

Annual risk of floods, storms and lightning

1 in $1,000,000$ 


\section{PUBLIC PERCEPTION OF RISK PROBABILITIES}

Empirical experiments by psychologists have found that lay people are unable to accurately judge the frequency of hazards that they face. Moreover, there are some systemic biases in the way that people misperceive risk frequencies. The seminal work is Lichtenstein et al. (1978). Lay people were told the actual annual number of fatalities in America for either electrocution (about 1,000 per year) or motor vehicle accidents (50,000 per year). The respondents then had to give their estimates for the annual number of deaths for forty other lethal events. The plot of results is shown in figure 5.1.

Figure 5.1: Judged Versus True Frequency of Death

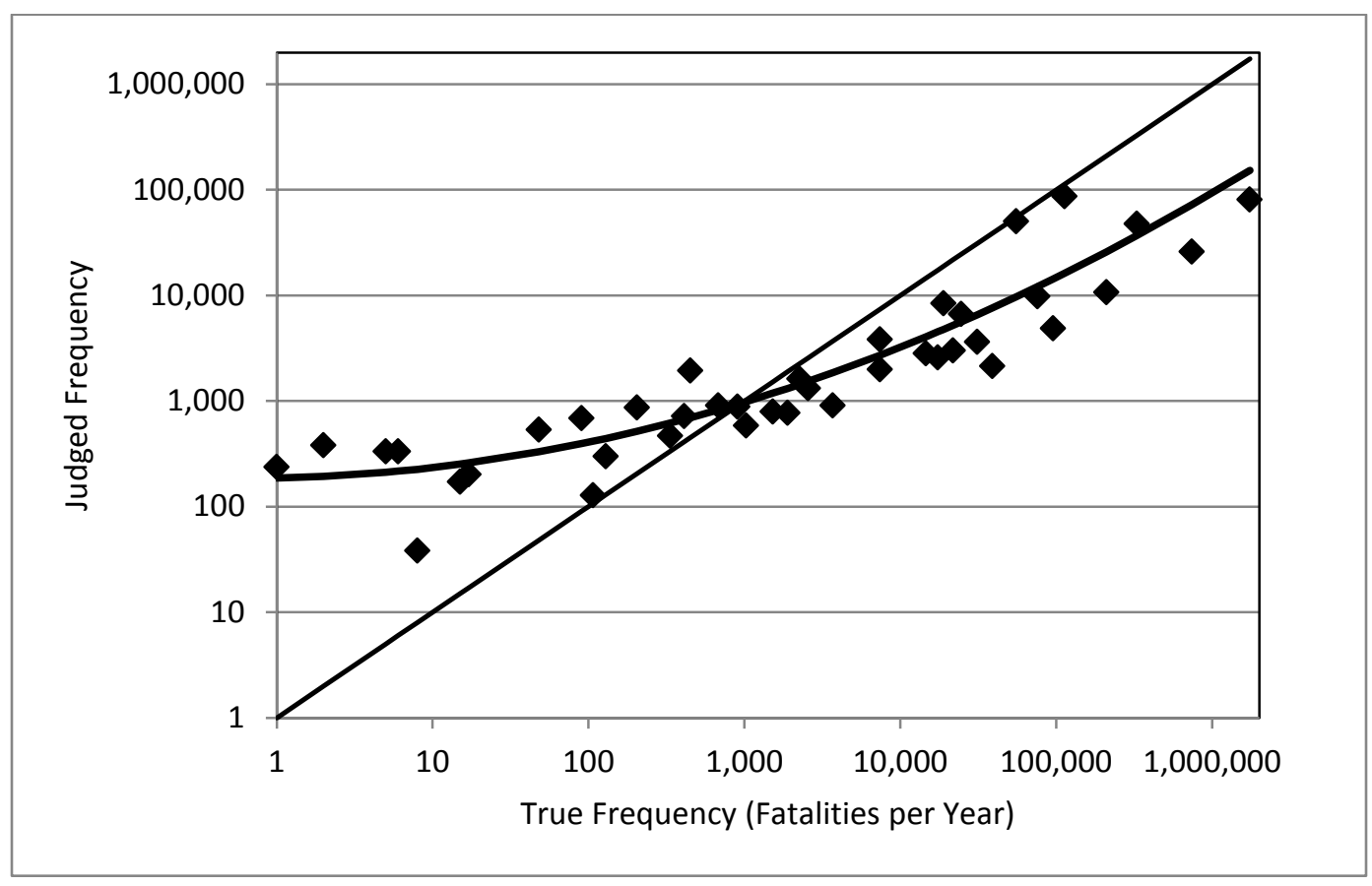

On the horizontal axis is shown the actual annual number of fatalities, and the vertical axis the geometric mean of the respondents' judged frequency. Hazards that fall below the $45^{\circ}$ line are those which respondents judged were less risky than in reality, whereas those hazards that lie above the $45^{\circ}$ line are whose for which respondents overestimate the real risk.

The most striking result, which is termed primary bias by the psychologists, is the tendency to overestimate infrequent causes of death (for example, botulism, floods and tornadoes) while underestimating more frequent causes (for example, heart disease and cancer). This is represented by the curved line of best fit shown in figure 5.1. The 'crossover' point where perception and reality were closest was for hazards with a probability of about 1 in 225,000 such as appendicitis. The researchers concluded that the observed bias was due to the nature of the hazards 
studied and not associated with potential psychometric problems such as a reticence to use large or small numbers.

Of course, most of the hazards do not lie exactly on the line of best fit. For example both botulism and risks from smallpox vaccinations are both low probability events, the frequencies of which are generally overestimated by lay people. However, the risk of botulism is greatly overestimated, while that from the smallpox vaccination is overestimated to a lesser extent. The same is true when two high probability events such as homicide and diabetes are compared. The frequency of both is underestimated but that of diabetes is underestimated to a greater extent than homicide.

A second effect, known as secondary bias, represents these deviations away from the line of best fit which captured the primary bias. Lichtenstein et al. observe that hazards with an upward secondary bias are "generally dramatic and sensational whereas [hazards with downward secondary bias] tend to be unspectacular events, which claim one victim at a time." Spectacular multifatality accidents receive extensive media coverage (Combs and Slovic, 1979), which Johnson and Tversky (1983) found affected peoples' "mood" and led to a heightened perception of risk.

Highway grade crossings were one of the hazards studied in Lichtenstein et al.'s work. At that time these accidents claimed about 1,500 fatalities a year. The study's respondents judged that these accidents caused between 600-800 fatalities per year, or about half of the real death toll. Not only did the primary bias lead to an underestimation of risk, but downward secondary bias was present as well because most grade crossing fatalities occur in events where a single life is lost and do not receive extensive media attention.

\section{Table 5.1: Biases in the Perceptions of Railroad Risk Probabilities}

\begin{tabular}{|c|c|c|c|}
\hline & \multicolumn{2}{|c|}{ Secondary Bias } \\
\hline & & Downward & Upward \\
\hline \multirow{3}{*}{ Primary Bias } & Downward & & \\
\hline & Neutral & $\begin{array}{c}\text { Highway Crossings, } \\
\text { Trespassers }\end{array}$ & \\
\hline & Upward & & $\begin{array}{l}\text { Passenger Trains, } \\
\text { Hazardous } \\
\text { Materials Releases }\end{array}$ \\
\hline
\end{tabular}

Table 5.1 shows the most likely biases applicable to contemporary railroad risks. Today the risk to grade crossing users would fall close to the crossover in primary bias, where we might expect perception of risk to match reality. The risk to 
trespassers falls in the same range. However, the risk to passengers on trains, and to third parties from hazardous materials spills, is much smaller so we would expect that people bias upwards their risk perceptions due to both primary bias and upward secondary bias caused by the extensive press reporting of any incidents.

\section{PUBLIC ACCEPTANCE OF RISK}

The accuracy of the perception of the true magnitude of risks is only part of the story. Even if risk was accurately known, the public would accept some hazards willingly, and express consternation about others. People recognize that there are risks associated with many activities in life, and are accepting of some risk in order to gain certain benefits. For example, people accept the risks of driving in order to gain mobility and freedom. However, not all hazards are accepted equally.

Psychologists have analyzed peoples' acceptance of different types of hazards. Fischhoff et al. (1978) asked respondents from the League of Women Voters to indicate the relative benefits and risks of thirty technological hazards which included railroading. Railroads were judged to have high benefits and relatively low risks. Benefits were judged to be comparable with those derived from driving, vaccinations, and the existence of fire and police departments; while the risks were comparable with those from food coloring and preservatives, college football, and lawn mowers. When asked to indicate which hazards required societal action to reduce the risks, the respondents did not give a high priority to railroads. Alcoholic beverages, handguns, motorcycles, automobiles, nuclear power, pesticides, and smoking were the hazards for which the respondents demanded action to reduce risk.

Fischhoff et al. then attempted to gain a further understanding of the attitudes to risk by asking respondents to rate each of the hazards using nine different characteristics: whether people are exposed to the hazard voluntarily or involuntarily; whether death is immediate or delayed; whether the hazard is known to the potential victim; whether scientists understand the risks; whether the victim could have mitigated an accident due to their personal skill or diligence; whether the hazard is new or old; whether the hazard claims multiple victims at one time; whether the hazard is a common one or a "dread" hazard; and whether the outcome is certain to be fatal or not. In general, railroads fell very close to the mean response in each category, except that it is regarded as an "old" hazard, and is perceived as claiming multiple victims at one time.

Of course, many of these characteristics are collinear with each other. Factor analysis has been used to conclude that attitudes to risk are dependent on two major factors. The first is whether the probability and consequences of an accident were known in advance. This factor is typically called the unknown factor. The second is that certain types of accidents engender dread. Dread is largely determined by the voluntariness of the exposure to the hazard, and whether potential victims can control the outcome of risky situations. Figure 5.2 shows a plot of the unknown and dread factor scores for the hazards investigated by Fischhoff et al. The higher the 
scores on both the unknown and dread scales, that is to say moving toward the top right of the graph, the less accepting the public is of the hazard. Railroads appear to fall right in the middle of the graph. Further studies by the same authors based on the responses of college students and professional risk assessors also placed railroads firmly in the center of the graph (Slovic, Fischhoff and Lichtenstein, 1980, 1985).

Figure 5.2: Location of Hazards in Unknown - Dread Factor Space

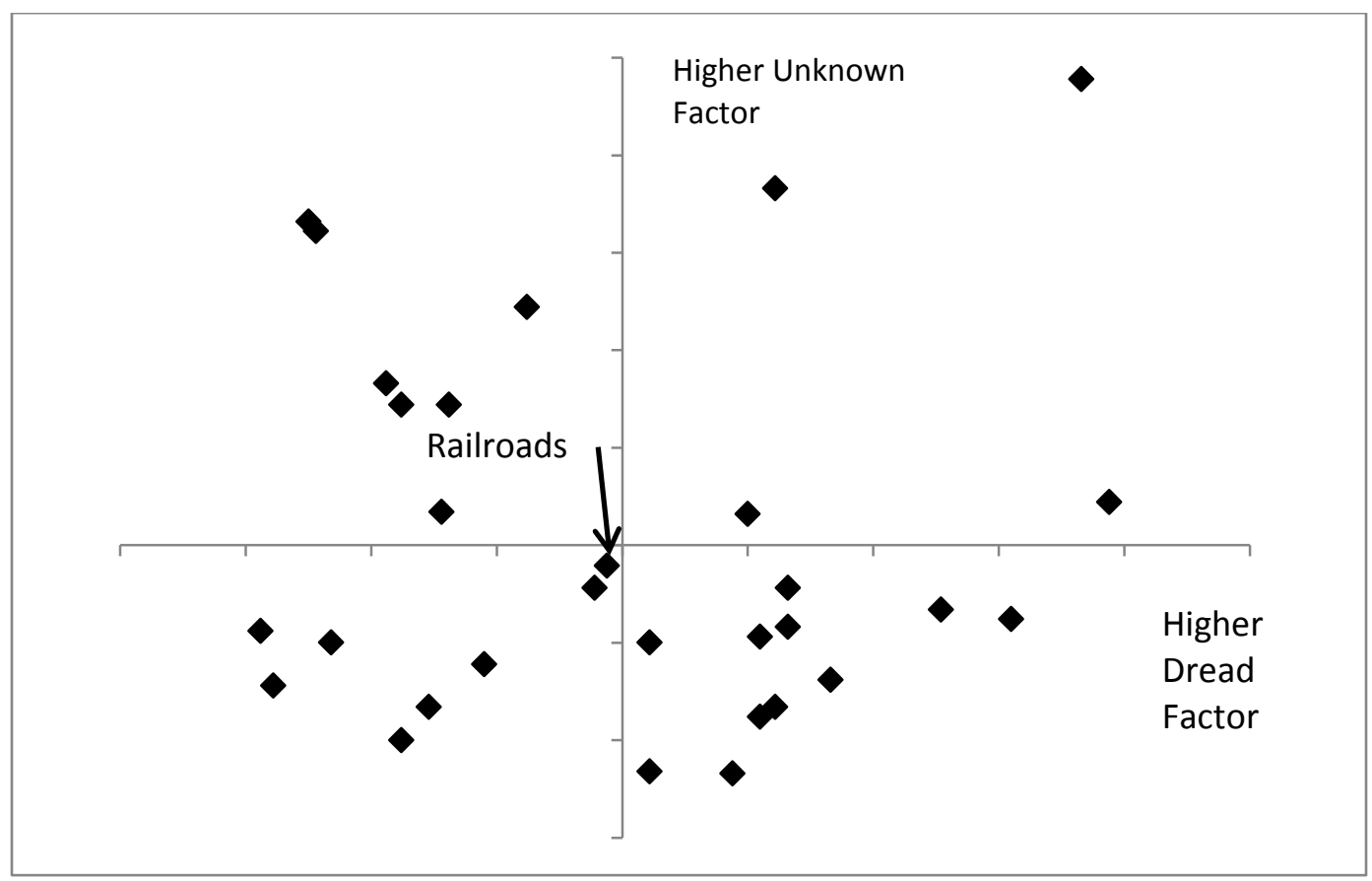

The above studies only considered the risks of railroads in general and did not consider the different components of the annual fatality toll. There is evidence that the respondents were not familiar with the risk of railroads. At the time the studies were undertaken annual railroad fatalities where about 1,900 whereas the respondents in Slovic et al. (1980) estimated that annual fatalities in a typical year were 200, which could rise to between 330 and 600 in a particularly "disastrous" year. Respondents were clearly unfamiliar with the fact that the vast majority of railroad fatalities are to trespassers and highway-crossing users, and that there is little year-to-year variation, outside of the overall downward trend over time, in fatalities to these groups.

Using the principles developed so far in this section, I have tried to classify in table 5.2, the most likely unknown and dread scores for five types of people exposed to railroad risks. As one moves toward the bottom right of the table, people become less accepting of risk. 
Table 5.2: Classification of Railroad Hazards by Acceptance Factors

\begin{tabular}{|l|c|c|c|}
\hline \multicolumn{2}{|c|}{} & \multicolumn{2}{c|}{ Dread } \\
\cline { 3 - 4 } & \multirow{4}{*}{ Low } & $\begin{array}{c}\text { Low } \\
\text { Trespassers, } \\
\text { Highway Crossings, } \\
\text { Employees }\end{array}$ & \\
\cline { 2 - 4 } & Medium & & Passenger Trains \\
\cline { 2 - 4 } & High & & $\begin{array}{c}\text { Hazardous } \\
\text { Materials Releases }\end{array}$ \\
\hline
\end{tabular}

\section{Acceptance by Trespassers and Highway-Crossing Users}

I have already argued that most people who trespass on the railroad, or are negligent at grade crossings, are well informed about the possible risks. They undertake these risks voluntarily, and are usually confident that their own diligence and skill can save them in the event that a train shows up. The consequent low dread and unknown scores would explain the lack of an outcry about fencing the railroad to discourage trespassers, and the general acceptance of most grade-crossing risks. This lack of an outcry is even more remarkable given the large number of annual fatalities to these two classes of people.

\section{Acceptance by Employees}

Employees are generally assumed to voluntarily choose their occupation, and would very quickly become familiar with the types of risks they are exposed to and the magnitudes of those risks. Moreover in a perfectly functioning job market, employers in risky occupations would have to pay a premium wage to attract staff, and would attract workers who are comfortable with the risks. Therefore, most risk analysts acknowledge that employees will accept more risk than consumers or third parties.

\section{Acceptance by Passengers on Trains}

Passengers on trains are, in a sense, riding voluntarily, but they are certainly not in control of the situation. People are less willing to accept risk when they put their lives in the hands of an airline pilot or locomotive engineer than when they are 
behind the wheel of their own automobile. Jones-Lee and Loomes (1995) found that subway travelers in London place a risk premium of fifty percent on subway travel compared with automobile travel.

The psychologists claim that hazards that claim multiple victims at one time engender more dread than hazards that claim their victims one at a time. This scale effect has been actively debated in the literature. Jones-Lee and Loomes (1995) dispute whether in practice such a scale effect exists based on survey work in London. However, I would claim that it does. By this I am not saying that the public is irrational in thinking that a single accident claiming twenty-five lives is worse than twenty-five separate accidents claiming one person each. Rather I am claiming that large accidents provoke different emotions than smaller, more routine, accidents. And these emotions affect both the unknown and dread factors.

Major passenger train disasters are usually caused by a combination of several contributing factors, which may be mechanical, human factors, environmental, managerial and public policy related. This is in contrast to most trespasser and grade crossing accidents where the "facts" are usually simple, straightforward and widely understood. Thus the reporting of most major railroad accidents will cause many people to reevaluate whether they know and understand the risks of railroads, and the resultant uncertainty will cause apprehension.

It is not surprising that the public reacts to railroad passenger accidents in a far more exaggerated way than the safety record would suggest. Indeed the railroads may consider it fortunate that the changing role of railroads away from passenger to freight transportation has decreased the frequency of passenger train accidents, and hence reduced the extent of the publicity and public concern.

\section{Acceptance by Third Parties}

Third Parties are people who live or work adjacent to the railroad line and might be affected by a collision or derailment, especially one that leads to a release of hazardous materials. Though the statistical probability of such an event is very small, the public is very fearful and unaccepting of the risks. A contributing cause to the fear is that people are generally unaware of the magnitudes of the risks resulting in a high unknown risk-acceptance factor. While local residents may have a reasonably accurate view of the probability that a derailment may occur, they are not aware of what exactly is in the tank cars, how volatile those contents might be, or what will happen if a release occurs. Given that neither the railroads nor shippers appear to be particularly keen on making such information generally available, the public can only fear the worst based on television pictures of fireballs, and news reports about small towns evacuated for weeks due to leaking liquid petroleum gas tank cars.

People are less accepting of risk if they cannot appreciate the benefits that the risky activity confers. Traditionally the railroad conferred many economic benefits

on the towns that it passed through. Nowadays the passenger station and public 
freight depot have closed, and the local residents perceive that there are few local economic benefits from the railroad. People are also less accepting of risk if they feel that they are exposed to the risk involuntarily. Traditionally only people living right next to a railroad would be affected by a derailment, and people could choose to live further away. The increased shipment of hazardous materials has meant that the consequences of derailments in the form of gas clouds and fireballs may affect people living some distance from the tracks. It is worth remembering that many small rural towns still have land-use patterns centered on the railroad tracks.

\section{PUBLIC POLICY ON RISK APPRAISAL}

The logical extension of the discussion in the previous two sections is to ask how public perceptions and reactions to various hazards are translated into public policy. While a public outcry about specific hazards can undoubtedly affect the agendas of elected officials, the power lies with government officials. If action is required in response to a risk, the legislature usually sets broad general goals for dealing with the hazard. The promulgation of the specific rules and regulations to implement public policy is then left with the various agencies of the administrative branch of government (Viscusi, Vernon and Harrington, 1995; Viscusi, 1996). The Federal Railroad Safety Act of 1970 is a good example. Congress laid down some general objectives and gave the FRA rulemaking powers over "all areas of railroad safety." The development of the specifics regulations was then left to the FRA.

The methodology by which the proposed regulations are evaluated is not clearly defined. The federal Office of Management and Budget is empowered by Executive Order 12291 of 1981 to review all regulations to show that the benefits exceed the costs, except in cases where any analysis would conflict with the legislative mandate of the agency promulgating the rules. This exemption primarily concerns regulations from the EPA and OSHA rather than the DOT (Viscusi, 1996).

A leading method for evaluating regulations is cost-benefit analysis. A major feature of cost-benefit analysis is the desire to express the valuation of non-pecuniary benefits and costs such as time savings and deaths and injuries avoided in dollar terms. This permits a strictly numerical comparison of benefits and costs. Transportation has been at the forefront of the development and application of cost-benefit analysis, and the DOT has a tradition of appraising investments and proposed regulations using it (Viscusi, 1996).

FRA manuals on conducting cost-benefit analysis have existed for some time. A manual for conducting a cost-benefit analysis of precautions for railroad safety in general dates from 1974 (Kennedy, Lloyd and Lowrey, 1974), and a manual for evaluating the provision of active warning devices at grade crossings dates from 1986 (Department of Transportation, 1986). However, cost-benefit analysis is hardly a panacea for determining the desirability of safety regulations. Any analysis requires knowledge of: the costs (both direct and indirect) of the proposed regulations; the anticipated effect on the number of accidents, fatalities, injuries and 
property damage; and a valuation methodology for fatalities and injuries. There are considerable uncertainties involved in all these aspects. These uncertainties result not only from deficiencies in the knowledge of economists, but also the inability of engineers to predict the effect of regulations on the probability and severity of accidents.

In these circumstances, simpler rules are needed. An alternative is Quantitative Risk Assessment where the statistical risks associated with an activity are enumerated, and some rules adopted to decide whether these risks are acceptable or not. Quantitative Risk Assessment is used in the United States, although the rules adopted are ridiculed by Viscusi (1996). For example, the EPA and the Food and Drug Administration have targets that no one should face a lifetime risk of more than 1 in 100,000 from an activity or hazard. On the basis of a seventy-year life this implies that no one should be exposed to an annual risk of more than one in seven million, which is smaller than the risk of being struck by lightning. These rules would clearly outlaw most things that we do in our daily lives.

Much more useful are the rules adopted by the British Health and Safety Executive, the equivalent of OSHA, and based on international experience and a study by the Royal Society (Evans, 1994). Risks are divided into three categories. The first category is for risks that have such small probabilities that no action is required. These risks are often called negligible risks, and have probabilities similar to that of being struck by lightning (i.e., about one in three million). At the other end of the scale is a second category of risks that are so large that nobody should be exposed to these risks and action should be taken without regard to the financial consequences. These risks are described as intolerable risks. Risks that fall in the zone between these two categories are often referred as falling in the as low as reasonably practicable or ALARP region. Risks in this category should be reduced if the cost of doing so can be justified. This would seem to support the economists' approach of conducting a cost-benefit analysis on individual policy initiatives.

Evans (1995) reports that it is commonly accepted that the boundary for the intolerable category is that no employee should face an annual fatality risk of more than 1 in 1,000 and no third party should face a risk of more than 1 in 10,000. The former figure is based on the risks accepted in the most hazardous occupations such as deep-sea fishing. The rationale for the risk to third parties is less clear, and I find the 1 in 10,000 figure unconvincing. Starr (1969) found that people were 1,000 times more unwilling to accept an involuntary risk than they were a voluntary risk. This would place the boundary of intolerable risk for true third parties, such as people living adjacent to the railroad, at about one in one million a year. The 1 in 10,000 risk may be more applicable for passengers or highway grade-crossing users where the person is exposed to the hazard voluntarily and derive some economic benefit from riding the train or undertaking car trips that require crossing a railroad.

These concerns are reflected in the definitions of intolerable risk adopted as policy by the British Railways Board (Evans, 1995). Their policies are shown in table 5.3. Risks are intolerable, and should be reduced without regard to cost, if employees and passengers face a risk of more than 1 in 10,000 each year, highway 
crossing users more than 1 in 100,000, and third parties not more than 1 in one million. British Rail therefore have set a stricter standard for employee safety than the British Health and Safety Executive, and have set the level of intolerable risk from grade crossings mid-way, in terms of exponential magnitude, between that of passengers and that of third parties.

\section{Table 5.3: British Rail's Definition of Intolerable Annual Risk Compared with Actual British and American Performance}

\begin{tabular}{|l|c|c|c|}
\hline \multicolumn{1}{|c|}{ Type of Person } & UK Guideline & UK Actual & USA Actual \\
\hline Employees & 1 in 10,000 & 1 in 18,500 & 1 in 6,000 \\
\hline Passengers per mile & 1 in 50 million & 1 in 1337 mil. & 1 in 1370 mil. \\
\hline Passengers per year* & 1 in 10,000 & 1 in 250,000 & 1 in 215,000 \\
\hline Grade crossings users & 1 in 100,000 & $?$ & 1 in 185,000 \\
\hline Trespassers & no guideline & 1 in 500,000 & 1 in 500,000 \\
\hline Third parties & 1 in 1 million & 1 in 25 mil & 1 in 6 mil \\
\hline
\end{tabular}

* My calculations for a commuter travelling 20 miles each workday

Source: Evans (1995), Health \& Safety Executive (1995), FRA (1997a,b)

Table 5.3 also contains my calculations of the current railroad risks in Britain and the United States. I have defined third parties as synonymous with the FRA's definition of non-trespassers, excluding those at grade crossings. The fatality rate for employees in the United States does not meet the British Rail policy, although it should be remembered that Britain's railroads are primarily oriented toward passenger travel so that there are many people undertaking station work who are not exposed to moving trains. Front line operating employees who are estimated to face an annual fatality risk of 1 in 1,500 in Britain (Evans, 1994) and 1 in 3,500 in the United States do not meet the British Rail guidelines but are not severe enough to be classed as intolerable by the Health and Safety Executive. For all other categories of people, actual risks in both Britain and the United States are lower than the British Rail definition of intolerable risk by a comfortable margin. Indeed the risks to third parties are so low that they would probably fall into the category of risks that are so negligible that no public policy response is required. 


\section{THE STORY SO FAR}

This chapter provides a summary of the major issues so far. It identifies the hazards posed by railroads, assesses the casualty rates, looks at trends in those rates, makes comparisons with comparable hazards in other industries or elsewhere in society, and reflects on how people react to the hazards. The five major railroad hazards considered are (in no particular order): fatalities to highway users at grade crossings; trespasser fatalities, fatalities to train crews in collisions and derailments and during coupling operations; occupational injuries to maintenance employees; and releases of hazardous materials.

\section{HIGHWAY CROSSINGS}

The geography of North America has presented the railroads with a legacy of a significant number of grade crossings, especially in the prairie states. Grade separation is not as common as it is in Europe. Despite the prevalence of grade crossings, the risks are quite low. A daily user of grade crossings with passive warning devices faces a much lower risk than that of drowning in their own bath or swimming pool. In addition, there is clear evidence that the risk has been diminishing over time. The annual risk per highway vehicle registered is only a fifth of that in 1970.

Highway user negligence is a factor in many grade crossing collisions. In a quarter of all collisions the road user drives into the side of the train. At crossings with gates, eighty-six percent of fatalities occur when the road user drive around or through closed gates.

\section{TRESPASSERS}

Trespassers can be characterized as single adult males under the influence of alcohol. Trespassing is primarily an urban problem with many trespassers killed close to their residences. It would appear that the railroad right of way is an attractive place for people to socialize and imbibe. Almost a third of the trespasser victims are sitting or lying in the right of way at the time of impact which clearly indicates considerable negligence on the trespasser's part or suicidal intentions. It would seem that the 
railroads can do very little to dissuade this type of trespass. In the past few decades the number of trespasser fatalities seems to be related to changes in the population of the country, rather than by changes in railroad operations. Remarkably the propensity for people to trespass on, and become victims of, the railroad is the same whether one looks at America, Canada or Great Britain.

Despite the fact they account for more than ninety percent of the annual fatality count, there is little public outcry concerning grade crossing or trespasser fatalities. The reason is that these incidents usually cause only one or two fatalities at a time and attract little press coverage. In addition, there is a general presumption on the public's part that the victims have voluntarily assumed the risks by trespassing on the railroad, or have been negligent in their use of a grade crossing. The general assumption by grade crossing users that they can safely cut across in front of a train because of their own superior driving skills also works to reduced risk perception and increase risk acceptance.

\section{TRAIN CREW FATALITIES}

Railroads require work outdoors and involving heavy moving machinery, which clearly pose a greater risk than working in an office. However, railroad workers face job risks which are at the lower end of the scale when a comparison is made with a peer group of other transportation modes such as trucking, aviation, and the maritime industry. There is also evidence of great improvements in worker safety. Fatality rates have fallen by a third, and injury rates by two-thirds since 1980 .

However, the risks vary by type of employee. Train crews, which represent about a third of the workforce, have higher casualty rates. The fatality risk of about 1 in 3,500 per year is higher than the average fatality risk in construction injuries, and approaching that in mining. The greatest risks to train crews are due to collisions and derailments, and coupling and uncoupling operations.

\section{OCCUPATIONAL INJURIES}

On average about one in eighteen employees each year will receive an injury, and about one in thirty will receive an injury that results in at least one lost workday. This injury rate is not much greater than that in wholesaling or retailing. More than eighty-five percent of injuries do not involve a moving train. Maintenance employees, both on the track and in the workshops, face the highest injury risks. There is also a prevalence of risks from falls by operations personnel.

While employees face the greatest statistical risk of any of the parties involved in railroad transportation, risk analysts have observed workers will tolerate greater risks than consumers or bystanders. This is because workers are assumed to quickly become familiar with workplace hazards, voluntarily choose their occupation, and 
derive direct economic benefits from exposure to the hazards in that risky occupations will have to pay wage premiums to attract staff.

\section{HAZARDOUS MATERIAL RELEASES}

Most collisions and derailments are of little concern to the general public as they involve freight trains and occur in sidings and on yard track. However, there seems to be a great fear of that small number of collisions and derailments that result in the release of hazardous materials. These materials can affect the communities surrounding the accident site due to contamination of ground water, explosion or release of poisonous gases.

The statistical risks are very low. Indeed, by the standards used by quantitative risk analysts they would be described as negligible and not require any public policy response. However, hazardous materials releases cannot be ignored by the railroad industry. The work of risk analysts has shown that people are very unwilling to accept risks to which they are involuntary third parties. The public is also less accepting of risks that they do not understand and cannot appraise true probabilities and severities. By analogy, the public is very skeptical about the risks posed by nuclear power stations despite a historical safety record that is very good.

It is a fact of risk appraisal and risk acceptance that the death of one person whose house is adjacent to the railroad may be regarded by the general public as worse than the deaths of 1,000 employees or passengers. The railroad manager, and the economist, may lament this fact and the effects that this may have on safety resource allocation. However, to the extent that the essence of free-market economics is that consumer preferences are paramount, the reality is that the public is willing to pay many times more to protect a third party than they are to protect an employee or other interested party. Moreover, these attitudes risk drive public opinion and hence the political economy in which railroads have to live.

\section{WHAT'S NEXT?}

The preceding paragraphs have given the reader an idea of the contemporary safety performance of the railroad industry, how it has changed over time, and how it compares with other hazards in society. However, the above comments do not permit the reader to conclude whether or not the railroad industry has a "safety problem" and whether it should invest more to improve its safety record. The public outcry about railroad safety over the years, which has led to considerable governmental rulemaking, might suggest that there is something unsatisfactory about the safety decisions that are made by railroad managers. But is there any substance to these concerns, or are they due to political posturing and pressure by special interests? How safe should the railroads be? What is the best way to tackle any 
"safety problem?" The remainder of this book is devoted to dealing with these questions.

The economist would argue that the root of answering these questions is to determine whether there is any failure in the market mechanisms that determine safety. The next ten chapters present the basic economic theory, indicate how market failure might occur, and use empirical evidence to ascertain the existence and magnitude of possible market failures in the railroad industry.

The theory can be divided into two distinct types. The first is the economics of bilateral accidents. These are accidents where the probability of an accident is influenced by the level of preventive effort undertaken by both the railroad and the other party involved in the accident. The prime examples of bilateral accidents are grade-crossing collisions, trespasser fatalities, and occupational injuries. Because the highway user, trespasser, or employee can affect the probability and severity of an accident by the level of care that they take, economic and legal theory has developed to provide all parties the correct incentives so as to minimize the societal cost of accidents. The theory of bilateral accidents is described in chapter 7 , and then is applied to grade crossings, trespassers and occupational safety in chapters 8, 9 and 10 respectively.

A different theory of safety is used when we look at operational safety. Here, safety is one of the attributes of the service offered by the railroad to its passenger and freight customers. It is an attribute of service that is desired by customers but costly to provide. There will be some economic equilibrium where desire and costs are matched. This equilibrium is described in chapter 11. However, this ideal equilibrium will only occur when five conditions hold: that the railroad has no market power; customers are well informed about the level of safety offered; customers are rational in making choices about safety; railroads are not myopic in their decision making; and that accident costs imposed on bystanders are borne by the railroad. A market failure will occur when one, or more, of these conditions does not hold in the actual marketplace. Chapters 12 through 16 consider whether each of these five conditions holds in practice.

Chapters 17 through 20 then consider the various ways in which society can respond to failures in the market for operational safety. Direct safety regulation by government is only one of the possible responses. Other policy responses include legal liability, insurance and public information campaigns. These chapters consider whether full advantage has been made of the non-regulatory responses, and whether the current system of safety regulations serves a useful function.

The final chapter draws together public policy recommendations on grade crossings, trespassers, occupational injuries and operational safety that should lead to improved railroad safety at a reduced cost to society. 


\section{ECONOMIC THEORY OF BILATERAL ACCIDENTS}

Rail-highway grade-crossing collisions, trespassing fatalities, and occupational injuries are called bilateral accidents because the level of care taken by both the railroad and the other party to the accident affects the probability of occurrence. The analysis of these accidents is a three-step process. The first step is to determine the level of care, called due care, that should be taken by both parties so as to minimize social costs. The second step is to observe whether the parties will, in practice, select the appropriate levels of care. If they do not, the third step suggests legal rules of liability that provide both parties with the incentives to take due care. This chapter reviews the theory. Applications to grade-crossing collisions, trespasser fatalities and occupational injuries are in the following three chapters.

\section{DUE CARE}

Accidents, and accident avoidance, impose two types of costs on society. Accidents cause personal injury and destruction of property. However, taking care to avoid accidents is also costly. For example, the installation of grade-crossing warning devices is costly to the railroad. Highway users incur costs of care because they have to slow down and observe for an approaching train before using a grade crossing. Economists argue that from a societal point of view the most preferable choice is for both parties to choose the level of care that minimizes the combination of the costs of care and expected accident costs.

The economic theory of bilateral accidents was developed in the early 1970s (Brown, 1973; Diamond, 1974a,b). The most comprehensive and readable review of the literature is given by Shavell (1987, pages 9-21). This chapter presents the relevant theory using simple fictitious examples concerning accidents involving the railroad (RR) and another party. The other party may be thought of as either a trespasser, a grade-crossing user, or an employee.

The first example, shown in table 7.1, concerns a bilateral accident between the railroad and Party A. Each party can choose either to take no care to avoid an accident or to take care. The effort of taking care imposes a cost of five on the party taking care. The probability of an accident occurring varies between 0.06 and 0.16 depending on the level of care taken by either or both parties. The more care taken 
by either or both of the parties, the lower the probability of an accident. If an accident occurs, both parties suffer 100 units of damage. The expected accident cost for each party will be 100 multiplied by the probability of an accident. The expected accident costs are shown in the sixth and seventh columns. The final column shows total societal cost which is the summation of both party's expected accident costs and costs of taking care. Total costs to society are minimized in this example at a value of twenty-two when both parties take care. The level of care that a party should adopt in order to minimize total social cost is called due care.

\section{Table 7.1: Example I}

\begin{tabular}{|c|c|c|c|c|c|c|c|}
\hline \multirow{2}{*}{ Level of Care } & \multicolumn{2}{|c|}{ Cost of Care } & \multirow{2}{*}{$\begin{array}{c}\text { Accident } \\
\text { Acrobability }\end{array}$} & \multicolumn{2}{|c|}{$\begin{array}{c}\text { Expected } \\
\text { Accident Cost }\end{array}$} & \multirow{2}{*}{$\begin{array}{c}\text { Total } \\
\text { Cost }\end{array}$} \\
\cline { 1 - 1 } RR & A & RR & A & & RR & A & \\
\hline None & None & 0 & 0 & 0.16 & 16 & 16 & 32 \\
\hline None & Care & 0 & 5 & 0.12 & 12 & 12 & 29 \\
\hline Care & None & 5 & 0 & 0.10 & 10 & 10 & 25 \\
\hline Care & Care & 5 & 5 & 0.06 & 6 & 6 & 22 \\
\hline
\end{tabular}

It will not always be the case that both parties must take care. Consider a second example shown in figure 7.2 involving the railroad and another party called B. Here the cost of the railroad taking care is ten, the cost of taking care for Party B is three, and the damages incurred by each party in an accident are fifty. The accident probabilities, conditional on the level of care taken, are the same as in the first example. The preferred societal outcome is where social costs are minimized at fifteen. Hence, due care for Party B is to take care, and due care for the railroad is not to take care. Note that while the probability of an accident would be lower if both parties took care, society's best interests are served when the railroad is not required to undertake the expense of taking care.

Table 7.2: Example II

\begin{tabular}{|c|c|c|c|c|c|c|c|}
\hline \multirow{2}{*}{ Level of Care } & \multicolumn{2}{|c|}{ Cost of Care } & \multirow{2}{*}{$\begin{array}{c}\text { Accident } \\
\text { Probability }\end{array}$} & \multicolumn{2}{|c|}{$\begin{array}{c}\text { Expected } \\
\text { Accident Cost }\end{array}$} & \multirow{2}{*}{$\begin{array}{c}\text { Total } \\
\text { Cost }\end{array}$} \\
RR & B & RR & B & & RR & B & \\
\hline None & None & 0 & 0 & 0.16 & 8 & 8 & 16 \\
\hline None & Care & 0 & 3 & 0.12 & 6 & 6 & 15 \\
\hline Care & None & 10 & 0 & 0.10 & 5 & 5 & 20 \\
\hline Care & Care & 10 & 3 & 0.06 & 3 & 3 & 19 \\
\hline
\end{tabular}


The reader will appreciate that by changing the costs of taking care, the effects of taking care on accident probabilities, and the amounts of accident damage sustained, additional examples could be provided where the optimal societal outcome is for either one, none or both parties to take care.

\section{THE POSSIBILITY OF MARKET FAILURE}

Determining due care is only half of the story. It is also necessary to see whether both parties will freely choose this level of care. Game theory is a powerful tool for investigating actual behavior. It uses a payoff matrix which indicates the total care and accident cost borne by each party conditional on the level of care by both parties. The payoff matrix for the first example is shown in table 7.3. Each cell of the matrix is defined by the level of care taken by the two parties. For example the upper-right cell represents the situation where the railroad takes care but Party A does not. Inside the cell in parentheses are shown the costs to the railroad and then, after the comma, to Party A. Because these are costs, they are shown as negative amounts. For example, in the upper-right cell the railroad incurs its expected accident costs of ten plus five which is the cost of taking care, and Party A only bears its expected accident costs of ten.

Table 7.3: Example I's Payoff Matrix with No Liability

\begin{tabular}{||c|c|c|c|}
\hline \multicolumn{2}{|c|}{} & \multicolumn{2}{|c|}{ Railroad } \\
\cline { 3 - 4 } \multicolumn{2}{|c|}{} & No care & Care \\
\hline \multirow{2}{*}{ Party A } & No Care & $(-16,-16)$ & $(-15,-10)$ \\
\cline { 2 - 4 } & Care & $(-12,-17)$ & $(-11,-11)$ \\
\hline
\end{tabular}

The matrix can be used to try to determine whether each party will act in a consistent way. In example I, the railroad will always choose to take care, irrespective of the decision of Party A, because it prefers -15 (at top right) to -16 (at top left), and -11 (bottom right) to -12 (bottom left). Party A will always choose not to take care, irrespective of what the railroad decides, because -16 (top left) is preferable to -17 (bottom left), and -10 (top right) is preferable to -11 (bottom right). Party A chooses to do this because the cost of taking care exceeds the resulting change in its expected accident damages. Therefore, in actuality the railroad takes care and Party A does not. A comparison of this equilibrium with table 7.1 indicates that such a choice of care will result in a total societal cost of twenty-five. Society is worse off than if both parties had chosen to take care and imposed a cost on society of only twenty-two. A market failure has occurred.

Market failure also occurs in example II. In actuality, as shown in table 7.4, the railroad will choose not to take care, irrespective of the actions of Party $\mathrm{B}$, because it prefers -8 to -15 , and -6 to -13 . Party B will choose not to take care because it 
prefers -8 to -9 , and -5 to -6 . The equilibrium will impose sixteen units of total costs on society. Had Party B chosen to take care, total social costs would have been fifteen. Party B does not take care because it weighs the three-unit cost of taking care against a reduction in its own expected accident cost of only two. Party B does not take into account in its decision that taking care will also save two units of expected accident cost to the railroad.

Table 7.4: Example II's Payoff Matrix with No Liability

\begin{tabular}{||c|c|c|c|}
\hline \multicolumn{2}{|c|}{} & \multicolumn{2}{|c|}{ Railroad } \\
\cline { 3 - 4 } \multicolumn{2}{|c|}{} & No care & Care \\
\hline \multirow{2}{*}{ Party A } & No Care & $(-8,-8)$ & $(-15,-5)$ \\
\cline { 2 - 4 } & Care & $(-6,-9)$ & $(-13,-6)$ \\
\hline
\end{tabular}

It would be inaccurate to claim that a market failure always occurs. For example, in situations where the costs of taking care are small compared with the accident costs that each party would incur, both the railroad and the other party would correctly choose to take care and societal costs will be minimized. However, there is a high likelihood of market failure in those cases where the consequences of one party's actions impose substantial accident costs on the other party.

\section{LEGAL RESPONSE TO MARKET FAILURE}

In response to the possibility of market failure, society has developed tort liability laws which aim to give both parties the incentives to select due care. Liability laws are based on a concept of negligence. At a very basic level a party is negligent when it takes less than due care, where due care is defined as that level of care consistent with minimizing total societal costs. A negligent party is open to be sued to pay damages for the harm incurred by the other party.

In the United States there are two sets of legal rules used in liability cases. In federal cases and most states the rule is that of comparative negligence. In Massachusetts, Virginia, North Carolina and the District of Columbia an older rule of negligence with a defense of contributory negligence is used. In economic theory, both rules will remove market failure and lead to optimal conduct by all parties (Shavell, 1987).

The practical application of these liability rules will be illustrated using the two examples from earlier in this chapter. In example I, social costs are minimized when both parties take care. Even if both parties take care, there is still a six-percent probability that an accident will take place. In the event of an accident, the liability rules preclude either party from claiming damages from the other because neither has acted negligently. However, if the railroad takes care but Party A does not, the railroad can seek damages from Party A when an accident occurs because Party A 
has been negligent while the railroad has not. The railroad can claim from Party A the 100 units of accident cost that it incurs. In these circumstances the railroad will now only bear the five units of care costs. Party A will bear the 100 units of accident damages that it sustains itself plus the 100 units that it has to pay to the railroad. Of course, an accident only occurs 10 percent of the time so Party A can expect to have to bear a combined cost of 20 units of accident damage. The reverse will happen if the railroad is negligent, and $\mathrm{A}$ is not.

When both parties have taken due care, or when one party takes due care and the other does not, the comparative negligence and negligence with a defense of contributory negligence rules operate in the same way. The two liability rules differ when both parties have been negligent. Under the rule of negligence with a defense of contributory negligence, each party is barred from recovering any damages from the other because it has itself been negligent. Even in situations where one party has been minimally negligent and the other party grossly negligent the former party cannot claim any damages from the latter.

Dissatisfaction with the bar that contributory negligence had on the collection of any damages led to the adoption of a rule of comparative negligence in most jurisdictions. Negligence by a party claiming damages against a negligent other party will reduce any award of damages but not necessarily eliminate it altogether. The reduction in any award will depend on comparing the extent to which both parties deviated from their levels of due care.

Table 7.5: Payoff Matrices with Negligence with a Defense of Contributory Negligence or Comparative Negligence

\begin{tabular}{|c|c|c|c|}
\hline \multirow{2}{*}{\multicolumn{2}{|c|}{ Example I }} & \multicolumn{2}{|c|}{ Railroad } \\
\hline & & \multirow{2}{*}{$\begin{array}{l}\text { No Care } \\
(-16,-16)\end{array}$} & \multirow{2}{*}{$\begin{array}{c}\text { Care } \\
(-5,-20)\end{array}$} \\
\hline \multirow{2}{*}{ Party A } & No Care & & \\
\hline & Care & $(-24,-5)$ & $(-11,-11)$ \\
\hline \multirow{2}{*}{\multicolumn{2}{|c|}{ Example II }} & \multicolumn{2}{|c|}{ Railroad } \\
\hline & & No Care & Care \\
\hline \multirow{2}{*}{ Party B } & No Care & $(0,-16)$ & $(-10,-10)$ \\
\hline & Care & $(-6,-9)$ & $(-13,-6)$ \\
\hline
\end{tabular}

The payoffs to both parties in example I under either system of liability are shown in the upper part of table 7.5. Now both parties will, correctly, choose to take care. The railroad prefers to take care irrespective of the actions of Party A because it prefers -5 to -16 , and -11 to -24 . Likewise Party A will always choose to take care because it prefers -5 to -16 and -11 to -20 .

In example II, society's preferred outcome is for the railroad not to take care, and Party B to take care. The railroad can never be found negligent as it is impossible to 
take less than due care. Party B can never recover any accident damages from the railroad. However, the railroad can recover damages from Party B if Party B did not take care. For example in the first and third lines of table 7.2, the railroad can recover its 50 units of accident costs that it incurs from Party B. Given that the probabilities of an accident are 0.16 and 0.10 respectively, the expected liability costs to Party $\mathrm{B}$ are eight in line one and five in line three. The resulting payoff matrix is shown in the lower part of table 7.5. The railroad, correctly, prefers not to take care because it prefers 0 to -6 and -10 to -13 . Party B will correctly choose to take care because it prefers -9 to -16 and -6 to -10 .

The examples are very simplified in that the parties can only choose between care and not taking care. In the real world there are gradations of care. Nevertheless, it will still be theoretically true that both liability rules will remove market failure (Shavell, 1987).

\section{LEGAL PROCEDURES}

The preceding section presented a theoretical discussion of liability law. In practice, things are less clear-cut and there is the possibility that the law may fail to correct market failure. As a prelude to a discussion of legal failures, it is useful to briefly review legal procedures and introduce some legal terminology.

The branch of law that deals with compensation in connection with bilateral accidents is called torts. Torts are legal actions taken by a plaintiff who has suffered harm to recover damages from a defendant. In some cases both parties have suffered harm and both feel that the other party has been negligent. In these circumstances, both parties will take legal action against the other in a countersuit or cross-suit.

The basis for tort law in the United States is the American Law Institute's 1965 Restatement (Second) of Torts, which follows from the first Restatement issued in the 1930s. One can regard the Restatement as a recommendation for "best" law practice, and a summary of what the law is in the majority of jurisdictions in the United States. But it should be recognized that the Restatement will be secondary to local statutes and cases in an actual trial.

The vast majority of torts are settled privately between the two parties, many without the intervention of a lawyer. Only a small minority of cases goes to trial, and many of the cases are heard without a jury so as to speed settlement. If a trial is necessary, the plaintiff issues a complaint which is "a short and plain statement of the claim showing the pleader is entitled to relief." Witnesses may be introduced by both parties to contest whether the defendant did in fact cause the harm, and the extent of the damages caused. The burden of proof is on the plaintiff.

The court needs to resolve two things. The first is the due care to expect from a defendant. This is referred to as a standard of law because it is broadly and vaguely defined in legal statues, and will be discussed in the following section. Judges, in a jury trial, specify in their instructions to the jury the legal standard of care. 
However, the jury has to interpret what that standard implies for the actions expected of the defendant. The second issue to be resolved is how the actual conduct of the defendant compares with the expected level of due care. This is a question of fact and is decided by the jury based on the evidence presented.

If the court finds for the plaintiff, it also decides on the level of damages to be paid. If the court finds for the defendant, the claim is dismissed. Courts can also decide to award damages in excess of the harm caused, called punitive damages, to penalize a defendant and to act as a warning to deter others from the same conduct. However, the award of punitive damages requires more than just negligence on the part of the defendant. The defendant must have engaged in "willful or wanton conduct."

Few tort cases are appealed because it is only possible to appeal on the basis that the trial judge made errors in decisions about the law or in the conduct of the trial. One cannot appeal based on the "facts" of the case. Appeals initially go to an appellate court. The appellate court bases its decision on a printed transcript of relevant parts of the trial, supplemented by oral argument by the lawyers involved. Appellate courts usually make written opinions explaining their findings, and their understanding of applicable law. Written opinions on appeals become part of society's case law. At best a person who appeals obtains a new trial.

\section{LEGAL DEFINITION OF DUE CARE}

Earlier in this chapter due care was defined in economic terms as conduct consistent with minimization of total societal costs. The legal definition of due care is the care exercised by a "reasonable man under like circumstances." On the face of it, the economic and legal definitions should be equivalent to each other if a reasonable person is assumed to balance the costs of taking care with the resultant changes in expected harm to both himself and other parties.

There is a history of distinguished lawyers who have used economic reasoning to define due care. In a landmark appellate court case, United States v. Carroll Towing Co. (159 F.2d 169 (2d Cir. 1947)), Judge Learned Hand used a cost-benefit calculation to determine the level of due care to be taken by the plaintiff who was appealing against a decision of a lower court for the defendant. The case involved the question of whether the federal government who owned a barge that had broken loose from its moorings while being moved by Carroll should have arranged for their own bargee to be in attendance twenty-four hours a day to prevent such a happening. Judge Hand said the plaintiff should have traded off the burden of adequate precautions (i.e., the costs of taking care) against the probability of an accident multiplied by the damages to all parties likely in an accident. Denoting these three factors as $\mathrm{B}, \mathrm{P}$ and $\mathrm{L}$ respectively, he devised a rule that is the level of due care is where $\mathrm{B}=\mathrm{PL}$.

However, it should be emphasized that the standard of law is very general and stated in the human, if somewhat sexist, terms of the "reasonable man." A purely 
computational "proof" of due care may not carry the day in court. The jury has wide latitude in interpreting how a reasonable man would have acted and the comparison with the actions of the defendant. The tort textbook by Henderson, Pearson and Silicano (1994) comments that "[i]t is only a slight exaggeration to assert that negligence in most cases is whatever the jury says it is." In many tort cases the major controversy does not center of the actual actions of the defendant, because the "facts" can easily be elicited, but rather on the level of care and conduct that should be expected of the defendant.

The defendant can claim that the plaintiff had also been negligent. The standard of care required of the plaintiff is similar to that required of the defendant. The Restatement section 463 defines negligence as "conduct on the part of the plaintiff which falls below the standard to which he should conform for his own protection, and which is a legally contributing cause co-operating with the negligence of the defendant in bringing about the plaintiff's harm." Section 464 sets that standard as that of "a reasonable man under like circumstances," although some courts take the plaintiff's mental and physical abilities into account in setting a standard.

\section{FAILURES IN THE LEGAL SYSTEM}

If the liability laws work as they should, both parties to bilateral accidents will be given the correct incentives to take the level of care that minimizes total societal cost. However, there are possible failures in the legal system that may lead to incorrect incentives.

The first possible failure is that the potential plaintiff is unable to claim damages because some types of harm are not legally recoverable. Plaintiffs have always been able to recover compensatory damages for: destruction of personal property, medical expenses incurred, lost earnings and impairment of earning capacity, and the loss of the consortium of a spouse or minor child. However, purely economic losses such as increased business expenses or lost revenue cannot be recovered in all jurisdictions. If plaintiffs are unable to recover certain types of harm then there will be less than optimal incentive for the defendant to take care.

A second possible failure occurs when the complaint is served on the wrong defendant. The most appropriate defendant is a party who has the economic and practical power to influence the level of care and hence the probability of an accident. In practice the defendant may be a party who acts as the agent for the decision maker and has no real say in the level of care taken. For example, chapter 8 will describe how in the case of grade-crossing collisions the railroad is the defendant as the owner of the train that is involved in a collision with a road vehicle, yet the decision of the type of warning devices to install at particular crossings is made by the highway authority.

The third, and probably the most important, possible failure is where the court makes an erroneous decision on the level of due care that should be taken by either the defendant or the plaintiff. Railroads frequently claim that "anti-corporate" 
feeling leads juries to hold railroads to a higher level of due care than would be warranted by economic calculations of the type advocated by Judge Learned Hand.

There is a distinct possibility that plaintiffs may be held to a lower standard of due care than is consistent with minimizing social costs. A careful reading of section 463 of the Restatement suggests that plaintiffs have to weigh the cost of taking care against the possible harm they might suffer. There would appear to be a limited duty to consider the harm that their carelessness imposes on the defendant. An extreme example would be where a negligent grade-crossing user collides with a train causing a derailment that damages the locomotive and track and results in a release of hazardous materials. Should the road user have foreseen the wider consequences in deciding on the level of care to take when crossing the tracks?

For example, consider what would happen in example I if the court only considers Party A's cost of taking care and expected harm received in deciding on the level of due care for Party A. This will be equivalent to the private choice made by Party A in table 7.3. The court would say that due care for Party A is not to take care, irrespective of the actions of the railroad. Party A would therefore be held to a lower level of due care than is optimal. The most obvious solution to the possibility for this legal failure would be for the railroad to issue a countersuit against Party A for the damages caused to railroad property. This would make the court aware of the accident damages that the railroad has sustained.

The fourth possible failure occurs if excessive or insufficient damages are awarded. The awarding of damages is a controversial topic. This is particularly the case with damages for non-pecuniary harm such as pain and suffering. The concern that some awards are excessive has prompted some states to limit the dollar damages that can be recovered for pain and suffering. Clearly, if the level of damages awarded is inconsistent with the harm caused then the wrong economic signals will be made to defendants. If damages are "too small" then defendants may take less-than-optimal care, and if damages are "too large" then the defendant may exercise too much care.

The fifth possible failure occurs when a party is unable to pay damages. If a defendant is unable to pay for the harm caused to another party, and does not carry insurance coverage to protect against a claim, then the defendant may be motivated to take less-than-optimal care. In practice this is not really a problem when the railroad is a defendant because a typical grade crossing, trespasser or occupational injury claim is for a small amount relative to the assets of the railroad. Most large railroads self-insure against such claims, and smaller railroads can and do obtain insurance coverage. The problem is most likely to emerge when the railroad files a countersuit. Consider the extreme example of the negligent grade-crossing user who collides with a train causing a derailment that damages the locomotive and track and results in a release of hazardous materials. Even if the railroad was successful in its suit, it is unlikely that it would be able to collect full damages.

The sixth and final possible legal failure concerns the transactions costs involved in the legal process. These are the costs incurred by plaintiffs and defendants in hiring legal counsel, and the time taken by the parties themselves in preparing their 
cases. There are also costs borne by the public in providing the judicial system. Transaction costs are an unproductive burden on society and can deter plaintiffs from filing some bona fide smaller torts.

\section{HUMAN FAILURES}

The existence of well-functioning liability process does not eliminate the concern about bilateral accidents. After all, more than ninety percent of railroad fatalities and the vast majority of injuries occur in bilateral accidents. The sad fact is that even with the correct economic incentives, many parties to bilateral accidents take much less care than they should.

Mostly the fault lies with the non-railroad party, especially in the cases of trespassers and highway users at grade crossings. Barring legal failures, these parties must either be ignorant of the tradeoffs between the level of care taken and the probability and consequences of an accident, or do not act in accordance with known economic incentives.

It is easily conceivable that many people are not fully informed. Trespassing and grade-crossing fatalities do not, in general, receive widespread publicity because they claim very few victims at a time. There seems to be a general underestimation by many people of the destructive force exerted by a heavy railroad locomotive and the distance required for a train to brake to a halt.

There is certainly evidence that people may not be thinking clearly when they trespass on the railroad or undertake risky behavior at grade crossings. A third of the grade-crossing victims and at least two-thirds of the trespasser fatalities had been drinking prior to the accident.

Table 7.6: Example III

\begin{tabular}{|c|c|c|c|c|c|c|c|}
\hline \multicolumn{2}{|c|}{ Level of Care } & \multicolumn{2}{|c|}{ Cost of Care } & \multirow{2}{*}{$\begin{array}{l}\text { Accident } \\
\text { Probability }\end{array}$} & \multicolumn{2}{|c|}{$\begin{array}{c}\text { Expected } \\
\text { Accident Cost }\end{array}$} & \multirow{2}{*}{$\begin{array}{l}\text { Total } \\
\text { Cost }\end{array}$} \\
\hline $\mathrm{RR}$ & $\mathrm{C}$ & $\mathrm{RR}$ & $\mathrm{C}$ & & $\mathrm{RR}$ & $\mathrm{C}$ & \\
\hline None & None & 0 & 0 & 0.20 & 20 & 20 & 40 \\
\hline None & Care & 0 & 6 & 0.12 & 12 & 12 & 30 \\
\hline Care & None & 12 & 0 & 0.10 & 10 & 10 & 32 \\
\hline Care & Care & 12 & 6 & 0.08 & 8 & 8 & 34 \\
\hline
\end{tabular}

It is a matter of semantics as to whether these problems should be described as "market failures." Whatever one chooses to call them, problems of realizing and acting on the correct incentives have market implications. Consider example III shown in table 7.6. In this example both the railroad and Party $\mathrm{C}$ would incur damages of 100 if an accident occurred, and the probability of an accident will vary between 0.2 and 0.08 depending on the level of care undertaken by either or both 
parties. It costs the railroad twelve units to take care, and it costs Party $\mathrm{C}$ six units. Society's total costs are minimized at thirty units when Party $\mathrm{C}$ takes care and the railroad does not take care.

Consider what happens when Party $\mathrm{C}$ ignores the expected accident costs. Party $\mathrm{C}$ only considers the costs of taking care and consequently refuses to take care so as to avoid incurring six units in care costs. What should society do? One option is to undertake a public information campaign to make Party $\mathrm{C}$ cognizant of the accident costs it might incur, the probability of such an accident and how preventive actions by Party $\mathrm{C}$ might lessen these probabilities. One can see evidence of this approach in the Operation Lifesaver campaign undertaken to inform the public about the dangers of grade crossings, and the presentations made by railroad employees in schools to inform students about the dangers of trespassing.

But what if Party $\mathrm{C}$ still will not respond to the information, or is under the influence of drugs or alcohol? If Party $\mathrm{C}$ refuses to take care, society only has the choice between lines one and three. In these circumstances it will be desirable to make the railroad take care so as minimize social costs at thirty-two. Society may have to compensate for the inappropriate actions of one party by requiring the other party to take more care than it otherwise would, a so-called second-best solution. For example, the government may require railroads to install active warning devices at grade crossings, or erect fencing along the right of way, so as to protect against persistently-negligent highway users and trespassers. 


\section{8 highWAY GRADE CROSSINGS}

Collisions between highway vehicles and trains are very costly. Calculations later in the chapter will suggest that a typical grade-crossing collision causes $\$ 450,000$ of harm. The physics of a heavy railroad locomotive colliding with an automobile means explains why highway users suffer more than ninety-five percent of the harm. The probability of a collision can be affected by the actions taken by both the highway user and the "railroad." The highway user affects the probability by their conduct in checking whether a train is approaching before using a crossing. The "railroad" affects the probability by deciding on the type of warning signs and devices that are installed at individual crossings.

To describe the party that decides on the provision of warning devices as the "railroad" is somewhat misleading. The railroad does not act alone in the provision of grade-crossing warning devices. This responsibility is shared between the railroads, municipalities, state highway authorities and the federal government. The latter provide ninety percent of the costs of providing upgraded warning devices under the 1974 Rail-Highway Crossing Program.

\section{SOCIALLY OPTIMAL LEVELS OF CARE}

The starting point for the analysis is the determination of the socially optimal levels of due care for the "railroad" (RR) and the highway user (HU). For expositional simplicity the shorthand term "railroad" will be used to represent the whole cast of characters involved in the decision to provide warning devices. Of necessity the analysis will be very simple, and make some very broad and sweeping assumptions about collision probabilities, prevention costs, and the harm caused by collisions.

Both the railroad and the highway user can choose between two levels of care. The railroad can choose between providing passive warning devices, such as crossbucks or stop signs, or a higher level of care involving active warning devices such as train-activated flashing lights or gates. Highway users can either adopt their current level of care, or take a higher level of care. Currently highway users are not as careful as they could be. Railroad lawyers comment that they rarely encounter a grade-crossing case in which the highway user has not been negligent in some way, either by reckless behavior or by inattention. A higher level of care will be defined 
as that necessary to reduce the number of collisions to only those where the highway user has inadvertently stalled on the crossing. Adopting this higher level of care would reduce the number of collisions by three-quarters at crossings with passive warning devices and by eighty percent at crossings with active warning devices (FRA, 1997b).

The first step is to estimate collision probabilities. Based on information on crossing usage in FRA (1997b), one can calculate that at crossings with passive warning devices and with highway users exercising their current level of care, the probability of a collision is 63.5 per billion vehicle crossings. Installing flashing lights at such crossing is estimated by the DOT to reduce collisions by seventy percent to 19.1 per billion vehicle crossings (DOT, 1986). Based on the discussion in the previous paragraph, these two rates would be reduced by seventy-five percent and eighty percent respectively if highway users exercised a higher level of care.

The second step involves an estimation of the costs both parties incur by taking care. Industry sources suggest that the cost of installing flashing lights at a crossing is about $\$ 80,000$. For simplicity, the initial installation costs will be amortized equally over the twenty-year life of the equipment. There are annual maintenance costs of $\$ 1,700$, calculated based on inflating figures given in DOT (1986) by a construction price index. Therefore, the cost of care is $\$ 15.60$ a day.

The cost to the highway user of taking a higher level care is more speculative. When passive warning devices are installed, drivers may have to slow down to observe if a train is coming. The word "may" is used because circumstances will vary from crossing to crossing. At some crossings in prairie states, drivers are able to observe a train approaching from a great distance away and do not need to slow down. At other crossings, curvatures of the highway or the railroad require vehicles to slow down on all occasions. Other crossings will be somewhere in between where vehicles only need to slow down at certain times of day or in certain climatic conditions. The proportion of traffic that needs to slow at a particular crossing in order for road users to take a higher level of care will be denoted by P.

The model assumes that currently nobody slows down, which is clearly an exaggeration. If a driver has to slow down in order to observe whether a train is approaching, the model assumes that the driver will brake from fifty miles per hour to twenty miles per hour when he or she encounters a crossbucks sign at 750 feet from a crossing. This slowing and the subsequent acceleration cause a time penalty of ten seconds. Transportation economists have a long history of estimating dollar valuation of time delays. More recently, researchers have shown that the valuation of time depends on the circumstances in which the time delay occurs. The time taken while driving on a congested highway has been found to be valued higher than the time taken while driving on an uncongested highway (Bein, Miller and Waters, 1994). Certainly time taken slowing for a railroad crossing or waiting at the crossing is as irritating as driving in heavy traffic. This research suggests the value of time in such circumstances is about $\$ 13$ an hour, which would translate into a time-delay cost of 3.6\$ for each driver who slows down. Therefore if highway users 
adopt a higher level of care, they would each incur a cost of 3.6P\$, where $\mathrm{P}$ is as defined in the previous paragraph.

If flashing lights are installed, taking a higher level of care requires some highway users, who previously cut across at the last moment, to incur a delay of three minutes while they wait for the train to pass. At least 1530 in every million highway users will incur this delay. This is the number of collisions that are avoided when the highway users take a higher level of care. For every one highway user that ignores flashing lights and gets struck by a train, there are probably nine others who ignore the lights but do not get struck. Even accounting for the ratio of "successful" to "unsuccessful" attempts to "beat the train," the average cost of taking care is negligible.

The final step is to estimate the harm caused by a collision. Each collision at a crossing with passive warning devices results in 0.12 highway user fatalities, 0.44 highway user injuries (FRA, 1997b), and \$4,000 damage to the highway vehicle. In addition the railroad bears the cost of 0.0003 fatalities and 0.03 injuries to its employees and passengers, and \$6,000 in damage to its property (FRA, 1997b). Recent research has estimated the social cost of a fatality at \$3.15 million, and that of an injury at $\$ 225,000$ at current prices (Miller et al, 1991). Each collision at a crossing with passive warning devices will therefore be expected to impose harms of $\$ 470,000$ on the highway user, and $\$ 13,000$ on the railroad. There will also be delays to railroad and highway traffic which are not quantified.

When active warning devices are installed, the severity of any resulting collisions changes to 0.1 highway user fatalities and 0.36 highway user injuries. Assuming that the consequences of a collision in terms of property damage or casualties to railroad employees and passengers remain unchanged, a collision at a crossing with active warning devices will impose harms of $\$ 380,000$ on the highway user, and $\$ 13,000$ on the railroad.

Table 8.1: Economic Model of a Highway Grade Crossing

\begin{tabular}{|c|c|c|c|c|c|c|c|}
\hline \multicolumn{2}{|c|}{ Level of Care } & \multicolumn{2}{c|}{$\begin{array}{c}\text { Cost of Care } \\
(\$)\end{array}$} & $\begin{array}{c}\text { Collision } \\
\text { Probability }\end{array}$ & \multicolumn{2}{c|}{$\begin{array}{c}\text { Expected } \\
\text { Collision Cost }(\mathbb{})\end{array}$} & Total Cost \\
\hline RR & HU & RR & HU & & RR & HU & \\
\hline Passive & Current & 0 & 0 & $6.35 \times 10-8$ & $0.08 \mathrm{~T}$ & $3.00 \mathrm{~T}$ & $3.08 \mathrm{~T}$ \\
\hline Passive & Higher & 0 & $3.6 \mathrm{PT}$ & $1.59 \times 10-8$ & $0.02 \mathrm{~T}$ & $0.75 \mathrm{~T}$ & $0.77 \mathrm{~T}+3.6 \mathrm{PT}$ \\
\hline Active & Current & 1560 & 0 & $1.91 \times 10-8$ & $0.02 \mathrm{~T}$ & $0.72 \mathrm{~T}$ & $0.75 \mathrm{~T}+1560$ \\
\hline Active & Higher & 1560 & $\approx 0$ & $3.81 \times 10-9$ & $0.01 \mathrm{~T}$ & $0.14 \mathrm{~T}$ & $0.14 \mathrm{~T}+1560$ \\
\hline
\end{tabular}

$\mathrm{T}=$ annual average daily highway traffic, $\mathrm{P}=$ proportion of traffic required to slow down

Table 8.1 brings together the information discussed above in a format similar to the analysis of chapter 7 . The table represents the total costs and benefits per day for an individual crossing, with monetary amounts expressed in cents. The total costs of care and the expected number of collisions depend on the annual average daily highway traffic using the crossing. Ceteris paribus, the greater the highway traffic, 
the greater will be the number of people who have to take care, and the greater the expected number of collisions. The amount of traffic is denoted by "T."

Society's ultimate goal is to encourage that combination of care that minimizes total social cost in the final column of table 8.1. The lowest-cost combination will depend on the values taken by $\mathrm{P}$ and $\mathrm{T}$. Table 8.2 shows the levels of due care that should be taken by the railroad and the highway user for different values of the levels of daily traffic, and the proportion of times that the highway user would have to slow down to exercise a higher level of care.

Table 8.2: Due Care by Crossing Characteristics

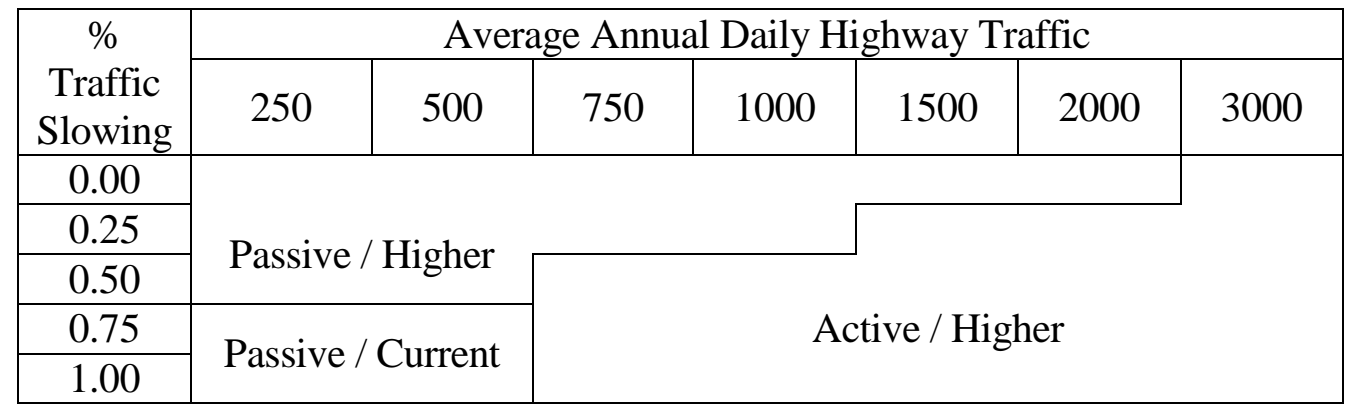

The current level of care taken by road users can only be condoned at crossings which are used by less than 550 vehicles a day and which require more than two-thirds of the traffic to slow down to properly observe for a train. If the careful highway user had to slow every time they used these crossing, it would actually be in society's interest to encourage the motorist to speed across the railroad without checking because the time delays are more costly than the resultant reductions in collision costs! In all other circumstances, society would wish that highway users exercise more care.

The decision whether to install active warning devices depends on the level of highway traffic. At crossings where sight lines are so limited that all prudent highway users would have to slow down, active warning devices are justified when daily traffic exceeds 550 vehicles a day. At the other extreme, where visibility is good that no prudent motorist is required to slow down, active warning devices should only be provided when daily traffic exceeds 2,600.

Even though they are based on some sweeping generalizations, these calculations are probably not too far away from the mark. Only twenty-four percent of public crossings with less than one thousand vehicles a day have active warning devices, whereas seventy-four percent of crossings with more than one thousand vehicles a day have such warning devices (FRA, 1997b).

Nevertheless there is evidence to suggest an insufficient deployment of active warning devices. Currently 3,000 of the 18,800 crossings with more than five thousand vehicles using them each day are not fitted with active warning devices. A 
third $(11,000)$ of the 34,500 crossings which carry between one thousand and five thousand daily highway vehicles lack active warning devices. The model suggests that all of the former and, perhaps, half of the latter crossings should receive upgrades. Consequently, about 8,500 grade crossings need upgrading.

In summary, the main conclusions that can be drawn from the model are twofold. Firstly, in most circumstances highway users should take more care that they currently do. Secondly, there is an insufficient deployment of active warning devices. The remainder of this chapter discusses why these problems have arisen and what policy initiatives can be taken to ameliorate the problems.

\section{INSUFFICIENT HIGHWAY USER CARE}

Highway users should have very strong incentives to take care when crossing the railroad. The highway user in a grade-crossing collision has a one in seven chance of being killed and a one in two chance of sustaining a major injury. Nevertheless some proportion of highway users take far less care than they should. There would appear to be a number of reasons why this is so.

The first is that highway users do not fully appreciate the dangers posed by grade crossings, and exaggerate their own abilities to extricate themselves from a close call. The second is that the standard of conduct required at crossings with passive warning devices is not clearly defined. The third is that the legal system may distort the economic incentives by displaying an anti-railroad bias.

\section{Poor Appreciation of the Dangers}

With the exception of few well-publicized cases, most grade crossing collisions are not widely reported. This will tend to make people bias downwards their perceived probability that a collision will occur. Also, most highway users also feel that their own skill and diligence can avert a possible collision which reduces their fear of this risk. In studies, most auto drivers rate their driving skills "above average."

There is also an "it will not happen to me" effect. Research by psychologists suggests that most people feel that they are less likely to be affected by a particular hazard than the "average" person (Slovic et al., 1980). In addition repeated encounters with a hazard without any untoward personal experiences have been found to reinforce that opinion (Slovic et al., 1978). Even the most careless grade-crossing user is likely to go decades without having a close encounter with a train.

Of course, the vast majority of highway users do exercise due care when encountering a grade crossing. There is just a small minority of drivers who indulge in risky behavior not only at grade crossings but also in other aspects of their driving. Sometimes this is due to ignorance of the risk, but more often it is because their senses have been dulled by alcohol or drugs. A NHTSA study (1994) found that a 
third of the grade-crossing victims had been drinking prior to the collision, and a quarter had a blood-alcohol content higher than the legal limit.

\section{Poor Definition of Appropriate Conduct}

When active warning devices are installed, most road users are well aware of prudent conduct. The law is quite clear that drivers must always stop when the lights start to flash and/or the gates are lowered. Society has made it quite clear that it is inappropriate to enter the crossing after the lights start flashing or to weave around lowered gates. Usually railroads can successfully defend themselves against suits when active warning devices are installed. Witnesses, such as motorists who are waiting at the crossing, can bring evidence that the highway user ignored the flashing lights or drove around the gates.

This is not true when passive warning devices are installed. The ambivalence about the standard of conduct expected has already been demonstrated in this chapter. At little-used crossings with poor sight lines, society would actually condone highway users who speed across the crossing rather than slowing down and reconnoitering.

The State of Illinois Rules of the Road book advises drivers approaching crossings with passive warning devices to "slow down, look and stop if necessary. Roll your vehicle windows down and listen to make certain other noises do not block out the sound of a train. If a train is approaching, stop and wait. Do not try to race the train to the crossing." Note that the advice indicates that the stopping and looking are only required "if necessary." Yet, later in the booklet drivers are given a stronger caution in that they must be "especially careful! Drive as though you expect a train on any track at any time" (emphasis in the original).

The ambiguity concerning exactly how a highway user should act has been debated all the way to the highest court in the land. In 1927 the United States Supreme Court in the case of the Baltimore and Ohio R.R. v. Goodman (275 U.S. 66, 70 S. Ct 24, 72 L. Ed. 167 (1927)) decided that a prudent motorist should always stop and reconnoiter and that this standard of conduct should be written into law. This decision lead to the passing of laws in some states requiring that highway users had to "stop, look and listen."

However seven years later the composition of the Supreme Court had changed, and the Court abandoned efforts to judicially codify standards of due care. In the case of Pokora v. Wabash Ry. (292 U.S. 98, 54 S. Ct. 580, 78 L. Ed 1149 (1934)) the Court overturned the specific conduct implied in the 1927 decision, and commented that "[s]tandards of prudent conduct are declared at times by courts, but they are taken over by the facts of life. To get out of a vehicle and reconnoiter is an uncommon precaution, as everyday experience informs us." The Court noted that the decision in the earlier case had caused confusion in federal courts, and had received "wavering support" in state courts. 
One would therefore conclude that the onus is very much on the individual highway user to decide on the most prudent action to take at a particular crossing. The law provides no specific guidance. Juries have to use their discretion in deciding whether the specific conduct of the highway user accords with that of the "reasonable man" when considering contributory negligence in a case brought against the railroad.

\section{Legal Bias against the Railroad}

It is difficult to draw definitive inferences on biases in the legal system. More than ninety percent of cases are settled out of court, and there is no public data on the negotiation of settlements. In jury trials under the comparative negligence rule the jury does not have to explicitly specify how negligent they feel the highway user has been. They just implicitly reduce the amount of the award of damages to the highway user to reflect the perceived negligence.

Railroad lawyers express the concern that courts have held highway users to a lower standard of care than is appropriate. Evidence that the highway driver had ignored a flashing light, drove around the lower gates, was exceeding the posted speed limit, was driving under the influence of alcohol or drugs, or drove into the side of the train is usually successful in indicating contributory negligence.

However, it is difficult to prove or disprove whether the highway user had properly "looked and listened" at crossings equipped with crossbucks signs. In these situations the law neither requires the highway user to come to a stop, nor specifies an appropriate speed that the highway user must slow down to. Therefore, plaintiffs' attorneys are successful in arguing that their client had taken due care. When the collision occurs at a little-used rural crossing, there are usually no independent witnesses to attest to the actions of the plaintiff. Railroad lawyers feel that anti-corporate bias by some juries gives the "benefit of the doubt" to the highway user.

Railroads feel particularly aggrieved when the highway casualty is a passenger in a road vehicle. Passengers cannot by law be held to be contributorily negligent to the collision. Therefore if an automobile passenger issues a complaint against the railroad, the railroad cannot make any defense to reduce the claim. One strategy by the railroad is to issue a countersuit against the driver of the highway vehicle to protect against judgments in favor of the automobile passenger. But because the railroad has more financial resources than the driver of the highway vehicle, it is frequently saddled with bearing the difference between the cost of the passenger's claim and whatever monies can be obtained from the insurance held by the automobile driver. Therefore, negligent drivers of multiple-occupant vehicles may not face the full costs of their actions.

There is no doubt in my mind that highway users are frequently held to a lower standard of due care than they should be, particularly for cases involving crossings

with passive warning devices. But does this legal failure account for the lack of due 
care exhibited by some road users? I think not. Even though the legal system may be biased in favor of the highway user, most of the harm from a collision falls on the highway user and rational drivers should realize that it is in their own self-interest to exercise more care at grade crossings.

\section{ENCOURAGING MORE HIGHWAY USER CARE}

There would appear to be three possible policy options available to respond to the insufficient care exercised by highway users. The first is to try to make highway users aware of the dangers posed by grade crossings. The second is to try to define appropriate conduct at crossings with passive warning devices. The third is a second-best solution which accepts the fact that some highway users will be negligent and compensates by installing active warning devices at many crossings.

\section{Informing the Public}

In recent times, federal and state governments and the railroads have been actively promoting Operation Lifesaver, a public relations campaign that highlights the dangers of grade crossings, and appropriate conduct when using a crossing. This worthwhile campaign coupled with the installation of active warning devices at many crossings has been credited with the substantial reduction in grade-crossing fatalities since 1974 .

\section{Defining Conduct at Crossings with Passive Warning Devices}

A second option which appears to be gaining some popularity is to try to resurrect "stop, look and listen" requirements by replacing crossbucks signs by stop signs. Currently about seven percent of crossings are fitted with stop signs, an increase from two percent two-decades ago. Railroad lawyers are typically in favor of this movement because it allows the railroad to introduce evidence that the highway user did not come to a full stop as a way to demonstrate contributory negligence.

To my mind this is a very worrying trend. For crossings with a lot of road traffic and little rail traffic, it is likely that any cost-benefit analysis would show that the delays caused to road traffic by decelerating, stopping and accelerating would outweigh any reductions in collisions. Making road users come to a halt when, for the most part, no train is likely to be approaching might encourage contempt for stop signs and encourage road users to ignore stop signs elsewhere on the highway network. I also suspect that there is a real possibility that the deployment of stop signs may lead to an increase in rear-end collisions between automobiles. There is also the consideration that a highway vehicle moving at speed is on the crossing for a 
shorter period that a vehicle that is accelerating from a stop which would tend to reduce the probability of collision.

\section{A Second-Best Approach}

The final option is to just accept that some highway users are incapable of displaying appropriate care at crossings, especially those with passive warning devices. In effect society would accept that the second and fourth lines of table 8.1 will not occur in practice. Left with the choice between lines one and three, society would choose to install active warning devices when $0.75 \mathrm{~T}+1560$ is less than 3.08T. Active warning devices will be justified at all crossings carrying more than 670 highway vehicles a day. This criterion would add another 11,500 to the list of 8,500 public crossings that were recommended earlier in the chapter for upgrading to active warning devices (FRA, 1997b).

\section{INSUFFICIENT DEPLOYMENT OF ACTIVE WARNING DEVICES}

The total number of public crossings that should be upgraded to active warning devices depends crucially on whether one feels that it is possible to educate drivers to exercise proper care at crossings with passive warning devices. If behavior can be improved there may be as few as 8,500 , if not there may be as many as 20,000 . In other words somewhere between five and twelve percent of public crossings still need to be upgraded to active warning devices. While this may sound like a large number of crossings, it needs to be put in the context of the large strides that have been made in the past quarter century.

\section{Table 8.3: Distribution of Warning Devices at Public Crossings}

\begin{tabular}{|c|c|c|c|c|c|c|}
\hline & \multicolumn{3}{|c|}{1978} & \multicolumn{3}{|c|}{1996} \\
\hline & Number & $\%$ & $\%$ & Number & $\%$ & $\%$ \\
\hline Gates and Lights & 13,959 & 6 & \multirow{2}{*}{27} & 30,813 & 19 & \multirow{2}{*}{40} \\
\hline Lights Only & 44,959 & 21 & & 34,854 & 21 & \\
\hline Crossbucks Signs & 138,472 & 64 & \multirow{3}{*}{66} & 79,376 & 49 & \multirow{3}{*}{56} \\
\hline Stop Signs & 3,525 & 2 & & 10,832 & 7 & \\
\hline Other Signs & 1,054 & 0 & & 501 & 0 & \\
\hline No Signs & 14,636 & 7 & 7 & 6,050 & 4 & 4 \\
\hline Total & \multicolumn{3}{|c|}{216,611} & \multicolumn{3}{|c|}{162,426} \\
\hline
\end{tabular}

Table 8.3 shows the distribution of warning devices at public crossings in 1978, the first year for which data are available, and 1996. Two things are immediately apparent. The first is that track abandonment and crossing consolidation have led to 
the disappearance of a quarter of the public crossings in two decades. The second is that there have been upgrades of all types: crossings that previously had no signs now have passive warning devices, crossings that used to have passive warning devices have been fitted with flashing lights, and gates have been installed at crossings that used to have only flashing lights. However, it is apparent there has been an emphasis on installing gates.

The big impetus for these changes has been the Rail-Highway Crossing Program of 1974, commonly referred to as the Section 130 Program. The federal government has spent almost $\$ 6$ billion, at current prices, to improve grade crossings. Typically federal money pays for ninety percent of the cost of improvements. The remaining ten percent comes from the railroad, the state highway authority, the municipality, or a combination of all three. Currently the annual federal appropriation is $\$ 155$ billion.

On the face of it, the combined federal and local funds of approximately $\$ 172$ million a year could pay for installing flashing lights at all crossings that deserve them in a five to ten-year period, at a cost of $\$ 80,000$ per crossing. The reality, of course, is that Section 130 funds are spent on other types of upgrades as well: adding gates, improving highway alignments, renewing existing warning devices, and closing little-used crossings and consolidating traffic onto neighboring crossings. Therefore, in recent times only about 500 crossings a year have been upgraded from passive to active warning devices. At this rate of progress, a realistic prediction of when all deserving crossings will be upgraded is somewhere between the years 2013 and 2036.

One might argue that the year 2036 is a long way away, and at that time the Section 130 Program will have been in existence for more than sixty years! One could clearly argue that Section 130 funding is currently insufficient, and that increased public expenditures would be justified on the basis of a cost-benefit analysis.

\section{LEGAL IMPEDIMENTS TO THE DEPLOYMENT OF APPROPRIATE WARNING DEVICES}

Some observers claim that the grade-crossing program has been hampered by a legal problem which places the railroad and not the highway authority as the defendant in suits brought by injured road users. The railroad has always had a common law duty to maintain safe crossings, including a duty to select and install appropriate warning systems at hazardous crossings. Prior to the 1970s the railroads were the appropriate legally responsible party as they determined the type of warning device to install at a particular crossing, and bore the costs of installation and maintenance.

The worsening financial condition of the railroads in the 1960s coupled with the rise in automobile traffic prompted the ICC and the DOT to recommend that the financial burden and the planning of crossing improvements should be transferred to the highway authorities. The ICC argued that the change would be equitable 
because "[h]ighway users are the principal recipients of the benefits" (ICC, 1962). The DOT concluded that it was anomalous that railroad grade crossings were "the only place along the highway where the state authorities do not have total control over the installation ... of traffic control devices" (DOT, 1972).

Consequently the Section 130 Program was established, and uniform national standards were developed to determine the need for, and provide for the installation of, warning devices. These were manifested in the addition of a chapter on "Traffic Control Systems for Railroad-Highway Crossings" to the FHWA's Manual on Uniform Traffic Control Devices (FHWA, 1988). A cost-benefit manual (DOT, 1986), an associated handbook (FHWA, 1986), and computer software were developed to permit highway authorities to set priorities so as to allocate their budgets toward the most needy crossings.

This fundamental change in the decision making was not balanced by a change in the courts. In nearly all grade-crossing cases the railroad is usually the sole defendant. This leads to two problems. The first problem is that state highway authorities who now make the decisions on the deployment of warning devices are not given the economic incentives to press for larger state and federal budgets to speed the installation of active warning devices. The second problem is that the priority order in which crossings are treated can be distorted by railroads that react to random collisions by pressing for installation of active warning devices at little-used crossings so as to avoid liability in the event that another collision occurs.

The first problem arises because the highway authority does not bear any financial repercussions from failing to upgrade deserving crossings. For example, if a road user involved in a collision at a crossing equipped with passive warning devices issues a tort arguing that "someone" was negligent in not installing flashing lights, that tort can only be served on the railroad. The state highway authority suffers no penalty for failing to act, and thereby has little incentive to press both its state legislature and the federal Congress for increased funding of the grade-crossing program.

The second problem requires more explanation. If a collision occurs at a crossing with passive warning devices, courts frequently look to the past history of the crossing when determining negligence. If another collision had occurred in recent memory, this can be used as evidence that the railroad had been negligent in failing to respond to the earlier collision by installing an active warning device. Moreover, the court may decide that the inaction of the railroad requires awarding punitive damages.

To avoid such judgments, railroads may press the highway authority for installation of active warning devices at any crossing where a collision occurs. The railroad may persuade the highway authority to do this by offering to pay the full ten-percent match funds, or even more, required to obtain federal Section 130 funding. Clearly this would not be a problem if that crossing deserved to receive active warning devices anyway, based on the objective rules described earlier in the chapter. However, collisions do occur at little-used crossings that may not deserve 
upgrades, and the installation of warning devices at these crossings would be a misallocation of resources.

An example will illustrate the problem. A railroad has 150 grade crossings fitted with passive warning devices. Fifty of these crossings are heavily used and carry 5,000 highway vehicles a day. The other 100 are less busy and only carry 1,000 vehicles a day. Assume that the objective standards developed earlier in the chapter indicate that all of the busier crossings should be equipped with active warning devices, but the less-busy ones should not. Based on a probability of a collision of 63.5 per billion highway-vehicles crossings, the Poisson distribution that is commonly used to explain collision occurrence predicts that twenty-one of the less-busy and thirty-four of the busier crossings will experience a collision over a ten-year period.

The railroad will push to have active warning devices installed at all of these fifty-five crossings because it knows that a second collision will occur at two of the less-busy and sixteen of the busier crossings in the ten-year period. Yet society would be better served if none of the less-busy crossings were fitted with active warning devices, and the money thus saved was used to upgrade all of the busier crossings.

An objective observer might think that this problem could be avoided if, in response to a suit brought after the second collision at a less-busy crossing, the railroad called a witness from the Federal Highway Administration or the state highway authority to testify that the level of traffic at the crossing did not merit an active warning device. While railroad lawyers say that this is a reasonable line of defense, it does not always carry the day for the railroad. Judges may rule that this evidence is inadmissible in that the railroad and not the highway authority is the defendant, and it is the railroad's and not the highway authority's conduct that is on trial. Plaintiffs' attorneys can also argue that while the highway authority may not have wanted to install active warning devices, the railroad could have acted independently and installed devices.

\section{A POSSIBLE SOLUTION?}

A United States Supreme Court decision in 1993 coupled with a 1995 proposal by the FRA provides some hope that there may be a change in the placing of legal responsibility. The Supreme Court case, CSX Transportation Inc. v. Easterwood (113 S. Ct. 1732), involved questions concerning the speed of a train that was in collision with a highway user at a grade crossing. The train was traveling at less than the speed limits contained in the track standards in the Federal Railroad Safety Act of 1970 but more than the speed limit specified in a local ordinance. The court ruled that federal law took precedence because the 1970 Act only allowed state and local governments to issue safety regulations if the FRA had not exercised its rulemaking powers in that area. 
This ruling has been used to suggest that the use of Section 130 funds to provide passive warning signs at a crossing is an indication that the federal government has concluded that active warning devices were not appropriate for that crossing (Hester v. CSX Transp., Inc. (61 F.3d 382 (5th Cir. 1995)), and Armijo v. Atchison, Topeka, and Santa Fe Ry. Co (87 F.3d 1188 (10th Cir. 1996))). As a result there would be a federal preemption of state common laws which place responsibility on the railroads for selecting appropriate warning devices. The practical implication is that railroads would no longer be held liable for decisions on the appropriate type of warning device installed at a particular crossing.

McFarland (1997) indicates that most cases follow the precedent of Easterwood, but preemption is still a controversial issue. In Shots v. CSX Transp., Inc. (38 F.3d 304 (7th Cir. 1994)) the plaintiff argued successfully that while the federal government had given the State of Indiana money to install crossbucks signs at 2,638 crossings, it had not investigated the most suitable warning device for the crossing at which the collision occurred.

To solidify the case for preemption, the federal government proposed in 1995 to introduce a rule that would remove the railroad entirely from decisions on installation of warning devices (FRA, 1995c). These decisions would be made solely by state and local highway authorities using uniform national FHWA guidelines. Under the proposed rules the railroads would only be required to provide information on current and forecasted rail traffic and provide technical expertise in the design and maintenance of warning systems. Railroads would not be allowed to initiate installation of warning devices. The FRA stated that it expected the proposed rules would "substantially subsume" the selection and installation of warning devices and as such "preempt state laws covering the same subject matter."

In general one should be favorable to the proposed rule. Decisions on appropriate warning devices are primarily driven by the amount and nature of highway traffic to which only the highway authority is privy. The highway user is the primary beneficiary of reduced collisions. While some people are critical of the algorithms used to decide on the priority list of crossings deserving upgrades, there are clearly longstanding uniform national methodologies to assist highway authorities in their tasks.

Unfortunately there is a downside. The federal government has sovereign immunity against claims for either things it does or things it fails to do. One cannot bring suit against the federal government. States also have sovereign immunity, although they can choose to waive it. However, even if sovereign immunity is waived, there are often limits on the dollar amounts of claims.

Discussions earlier in this chapter indicated that there are many crossings which deserve upgrades that will not be treated for many years due to budget limitations. Highway users killed or injured at these crossings will either be unable to seek damages or have the amount of damages severely limited despite the fact that they have a bona fide complaint. 
It is therefore not surprising that the proposed rule was vigorously opposed by plaintiffs' trial attorneys. Critics also feared that the removal of legal recourse for plaintiffs may reduce the pressure on the federal government to continue to support the Section 130 Program at its current level. While the motivation for the 1995 FRA proposal may have been an honest attempt to place decision making with the most appropriate body, the principal effect was to limit corporate liability at the expense of individual highway users. To my mind, a big flaw of the 1995 proposal was that highway authorities cannot be held legally accountable for the conduct of their crossing-improvement programs. A waiver of sovereign immunity should have been included.

The proposed rule was quietly dropped in 1997. Railroad lawyers suspect that it would only be resurrected when the mood of the country again turns toward tort reform and limitations on corporate liability. Of course, the Easterwood decision still stands, and courts can interpret the decision as a de facto case for preemption. 


\section{9 tRespassers}

Preliminary data for 1997 suggests that trespassing has become the leading source of death on the railroads. The number of annual trespassing victims is greater than the number of grade-crossing fatalities for the first time in over half a century. Trespassing is primarily a problem in built-up areas, and mostly involves single adult males who are under the influence of alcohol.

\section{SOCIALLY OPTIMAL LEVELS OF CARE}

It is difficult to construct a table, similar to those in the previous chapters, to calculate the optimal level of due care to be taken by both the railroad and the trespasser. There are no data on the magnitude of the trespassing problem. Hence it is impossible to calculate probabilities that a trespasser will be injured. It is also difficult to conceive of a notion of how to quantify the costs a potential trespasser would incur in taking care.

However it is possible to infer the standards that society has adopted for the level of due care to be shown by both parties. There is lengthy legal case law on the duties expected of trespassers and holders of land.

\section{Due Care by Trespassers}

There is a strong legal presumption that trespassers, and not the owners of land, bear the burden of taking appropriate care. Trespassers bear the entire risk of any natural hazards (such as quicksand) that they encounter, and can only claim damages if they are injured by an artificial hazard (i.e., something manmade or mechanical) if the landowner had not used reasonable care to post a "warning." However, courts have held that the mere existence of a railroad track is a sufficient warning of the dangers of trespass. The implication is that the law assumes that the public is well aware of the dangers of trespassing on the railroad.

The presumption that trespassers are fully accountable for their actions has been strengthened in the past ten years by the passage of Recreational Use of Land laws in many states. These laws were prompted by the increase in trespassing by users of all-terrain motor vehicles and bicycles. Under these laws people who enter onto 
land for recreational purposes assume all of the risks, even those caused by unmarked artificial hazards. Some, but not all, railroad lawyers feel that consequently the entire burden of taking care is placed on snowmobilers, hunters and fisherman, and perhaps even recreational drinkers, who trespass on the railroad.

A trespasser who is on the land to commit a crime is held to an even higher level of care. The landowner is only required to avoid intentionally injuring the trespasser. Therefore thieves, vandals, and transients who are attempting to ride a freight train without paying, bear the entire burden of taking care.

The only people who are expected to exercise a lower level of care are children who "because of their youth do not discover the condition or realize the risks involved in intermeddling with it or in coming within the area made dangerous by it" (Restatement Section 339). In general, there is a view that children under the age of six years old cannot be found contributorily negligent. Between the ages of six and twelve there is a presumption against contributory negligence.

\section{Due Care by the Railroads}

As can be inferred from the previous paragraphs, the level of reasonable care expected from the railroad is quite low. In general, there is no legal requirement that the railroad construct a fence on the edge of its property. In a perverse way the law actually discourages rather than encourages fencing. The railroad is much more liable if it is shown that a fence was provided but then was not maintained, that if a fence did not exist in the first place. There is not a general requirement that the railroad post warning signs, although they generally do so at places of limited clearances such as tunnels or trestles. There is also no duty to secure the doors of empty box cars to deter traveling transients.

A more contentious issue is how the railroad should act when it is aware that trespass takes place repeated at certain locations. A trespasser is defined in section 329 of the Restatement (Second) of Torts as "a person who enters or remains upon land in the possession of another without a privilege to do so created by the possessor's consent or otherwise." Some courts have taken the view that if trespass takes place repeatedly at a certain point, and the possessor of the land has tolerated the trespass, then the trespasser could be regarded as a licensee. Landowners have to show a higher level of care to a licensee than they do to a trespasser. Section 342 of the Restatement makes the possessor liable if it can be shown that the licensees were not aware of the risks involved, and that the possessor had not taken care to make the conditions safe or warn the licensee of the danger.

In legal proceedings the issue of whether a person is a trespasser or a licensee has traditionally been open to some debate. Therefore some states such as New York and New Jersey have done away with the distinction and hold a landowner to the higher standard when trespass is known. Therefore, there would appear to be a duty to "anticipate future trespass" at locations where trespass occurs regularly, and to react to a "well-worn path" crossing the railroad. In general the posting of signs by 
the railroad is regarded as sufficient action. Railroads do take further actions such as conducting patrols and working with local authorities and police departments. Where there appears to be a well-used informal foot crossing then the railroad might be expected to provide a regular crossing, a footbridge, or erect fencing to make people use nearby formal crossings.

Railroads have a duty to protect their property against children. This is partly because, as explained in the previous section, there is a presumption that young children are not aware of the consequences of their actions. In addition the law recognizes that children may be attracted to playing on the railroad. This is formally known as the attractive nuisance doctrine and more commonly referred to as the turntable doctrine as an early case involved a child injured while he was trespassing on a railroad turntable. The Restatement requires reasonable care to remove the danger or otherwise protect the children, but does recognize the economic tradeoffs between the "burden of eliminating the danger" compared with the "risk to the children involved." The actual conduct expected of the railroad is somewhat unclear. In areas where there may be very young children a fence may be required, whereas for older children presentations in neighboring schools warning of the dangers may be sufficient.

While there is a limited requirement to prevent trespass, the railroad is held to a higher level of care when trespassers are discovered. In most states there is a duty to "avoid injury" in protecting land against trespass and in expelling a trespasser. In a minority of states, a possessor of land only has to refrain from "wanton or willful conduct." The implications are illustrated by the case of Hines v. Denver \& Rio Grande Western Railroad Co. (829 P.2d 419 (Colo. App 1991)) where the railroad was found negligent because the train crew did not use reasonable care in keeping a proper lookout, and did not take appropriate action in applying the brakes and sounding the whistle when their train encountered the husband of the plaintiff walking along the rails in a canyon while on a fishing trip. While courts do expect the engineer to apply the brakes and sound the whistle, railroad lawyers point out the most courts are very sympathetic to the emotional distress that a trespassing death causes a locomotive engineer.

\section{COMPARISONS WITH ACTUAL LEVELS OF CARE}

In general, one can conclude that society places few requirements on a landowner to protect against trespass. Indeed railroad lawyers comment that, with the exception of cases involving children, railroads are rarely found by courts to have acted negligently in damage suits brought by trespassers or their relatives. Situations where the railroad might be liable, such as those involving "well-worn paths" or children are in the minority. Less than ten percent of fatally-injured trespassers were crossing the tracks, and a good proportion of these would be at random places rather than in high trespass areas. Less than fifteen percent are young people, and only a small proportion of these are under the age of twelve. 
Therefore in at least three-quarters of the cases of trespasser fatalities, society has placed the burden of taking precautions entirely on the trespasser. There is considerable evidence that trespassers take considerably less care than they should. A third of the trespassing victims were sitting or lying in the right of way. Alcohol is involved in somewhere between sixty and eighty percent of trespassing cases, and when alcohol is involved the level of consumption is very high. Trespasser fatalities occur disproportionately on summer weekend evenings. It would appear that the railroad right of way is a popular place for poorly-educated single adult males to socialize and drink. Courts have typically held drunks to the same level of care as would be required of a sober person. This is known in legal language as taking prior precautions. A drunk is not only held to be aware of the dangers of trespassing on the railroad, but also should have exercised due care in deciding whether to become intoxicated.

\section{THE ECONOMICS OF FENCING}

At various times Congress has raised the issue of imposing regulations to requiring railroads to erect a fence along sections of their right of way. In Britain and on most urban mass transit lines fencing is very common. In the case of mass transit this is primarily to protect the public against electrocution from the third rail. The publicly-owned Amtrak took a decision to fence its heavily-used North-East Corridor. But in many countries on the continent of Europe, in North America and in most other parts of the world fencing is not common.

Of course, American railroads like other owners of land already fence part of their property to protect against people with a criminal intent to steal or vandalize. They also fence in certain locations to protect against liability to children or to react to high-trespass areas. However, the NTSB (1978a) study indicated that 85 percent of trespasser fatalities occurred at unfenced locations.

Should railroads have a much more general requirement to fence? The argument for fencing is twofold. The first is that a fence discourages young children who do not appreciate the dangers of railroads. The second is that fencing might be seen as a second-best solution if it was felt that it was impossible to educate adults of the dangers of drinking and socializing on the right of way. Although, in a perverse way the existence of a fence can encourage trespass because it makes the right of way an even more private and desirable place for people to socialize, drink, have sex or sleep.

The desirability of fencing can be investigated using a cost-benefit analysis. There are good data on the costs of fencing. Trespassing is primarily an urban problem. Internal calculations by the AAR in 1987 suggested that approximately 10,000 miles of right of way pass through areas with population densities of greater than 800 persons per square mile. If all of these lines were fenced, the cost at approximately $\$ 300,000$ per mile at current prices would be about $\$ 3$ billion. Obviously some of this mileage is already fenced, but fencing does get destroyed and 
deteriorate and requires replacement. Assuming a ten-year life, an ongoing annual expenditure of about $\$ 300$ million would be required to fence the urban railroad.

The effect of fencing on the number of trespasser fatalities is unclear. In chapter 4, it was shown that the annual rate of trespasser fatalities per head of population in Britain, where fencing is common, is almost identical to those in the United States and Canada, at roughly two per million. Therefore, one might argue that fencing will have no effect on trespasser fatalities. This would be supported by a comparison between Amtrak, who operate many of their trains over the fenced North-East Corridor, with Conrail and CSX who operate freight trains over primarily unfenced lines in the northeastern United States. In table 9.1 the fatality rates of trespassers and non-trespasser per train mile are shown for the three companies for the period 1994-96. Amtrak has a fatality rate twice that of Conrail and CSX. Of course, there may be legitimate reasons for this including the higher speed and quieter electric traction of some Amtrak trains, and the fact that Amtrak tends to operate in areas of higher population density.

Table 9.1 Comparison of Trespasser and Non-Trespasser Fatality Rates

\begin{tabular}{|l|c|c|c|}
\hline \multicolumn{1}{|c|}{ 1994, 1995 and 1996 } & Amtrak & Conrail & CSX \\
\hline $\begin{array}{l}\text { Trespasser and non-trespasser } \\
\text { fatalities not at grade crossings }\end{array}$ & 196 & 108 & 176 \\
\hline Train miles (millions) & 115 & 139 & 247 \\
\hline Fatalities per million train miles & 1.70 & 0.78 & 0.71 \\
\hline
\end{tabular}

Data are included for both trespassers and non-trespassers for two reasons. The first is that it is necessary in order to net out those fatalities that occur at grade crossings. The second is that there appears to be a systematic bias in the way the three companies distinguish between trespassers and non-trespassers.

Source: FRA (1995a,b; 1996a,b; 1997a,b)

Therefore, at one extreme, it might be argued that fencing has a negligible effect on trespassing fatalities. But it is also worth considering a more favorable estimate of possible fatality reduction from fencing the right of way in urban areas. The best estimates from existing sources (NTSB, 1978a; Pelletier, 1997) suggest that about 350 trespassing victims a year are neither residents of rural areas, undocumented suicides who would likely kill themselves in other ways, or people who already had to climbed a fence to trespass. Of this 350 , a realistic estimate of the number of lives saved by fencing might be the ten percent of victims who are children, and the twenty percent of persons who so inebriated that their fence-climbing skills are diminished. This would give an estimate of 105 fatalities avoided each year.

General fencing of the railroad in urban areas would be justified if the value of an individual life saved is greater than $\$ 300$ million annual cost divided by the 105 lives saved. The resulting cost per life saved is approximately \$3 million. This number is in the range of figures cited in the literature, and used by the DOT as a valuation of 
human life (Miller et al, 1991). This would suggest that fencing is marginally justified in urban areas.

However, there are two notes of caution. The first is that both public and private safety budgets are limited. The cost per life saved by fencing is quite large. The $\$ 3$ billion that would be required over a ten-year period to install fences along the entire urban right of way would be sufficient to install active warning devices at each of the 20,000 public crossings identified in the previous chapter as deserving of an upgrade, and still leave enough money over to install active warning devices at the 15,000 busiest private crossings. On my calculations such an investment would reduce the annual death toll at public grade crossings by 160 with additional lives saved at upgraded private crossings. It is reasonable to suspect that one could get twice the return from using money in this way rather than on fencing. The second caution is that the analysis is very favorable to fencing. Comparison with the British experience or the comparison between Amtrak and neighboring freight railroads might suggest that fencing is a futile waste of money. 


\section{0 occupational injuries}

This chapter considers the economics of occupational injuries that do not occur during train operations. These comprise a quarter of employee fatalities and eighty-five percent of employee injuries. They typically occur during maintenance of track, in railroad workshops, and when employees slip and fall. Employee fatalities and injuries that result from operational accidents are considered later in the book.

\section{OCCUPATIONAL INJURIES AND THE LABOR MARKET}

Economic models of occupational injuries have similarities and differences from the models used in previous chapters. Workplace accidents are bilateral accidents in that the care taken by both the employee and the railroad affects the probability of an accident. However, employees do have a contractual relationship with the railroad, and can influence safety by normal bargaining concerning wages and employment conditions. Companies that offer a high risk of injury may not be able to hire any labor. In contrast, trespassers and grade-crossing users are strangers to the railroad and appropriate levels of care can only be assured when there are suitable legal liability rules.

The simplest model of the labor market interaction is shown in figure 10.1. The model represents a perfectly-competitive marketplace for workers with similar skills to those required for railroad work. On the vertical axis is the wage rate and on the horizontal axis is the occupational safety risk, measured by the rate of workplace injuries. Representative firms from two industries, I and II, compete to obtain labor services.

Break-even iso-profit curves for the two industries are shown as $\pi_{\mathrm{I}}$ and $\pi_{\mathrm{II}}$. A break-even iso-profit curve shows all of the combinations of wage levels and job risks that result zero industry profits. They slope upward because higher wages are only possible if the industry reduces its investment in equipment and practices that make the workplace safer.

In isolation, an industry would be indifferent as to which combination of risk and wages it offered. However, that is not the case when there are a number of industries competing for labor. For example, industry I could not choose the 
combination at point $\mathrm{C}$ because it would be unable to attract any labor. At this point, industry II offers workers better combinations of wage and risk.

Figure 10.1: Basic Labor Market Model

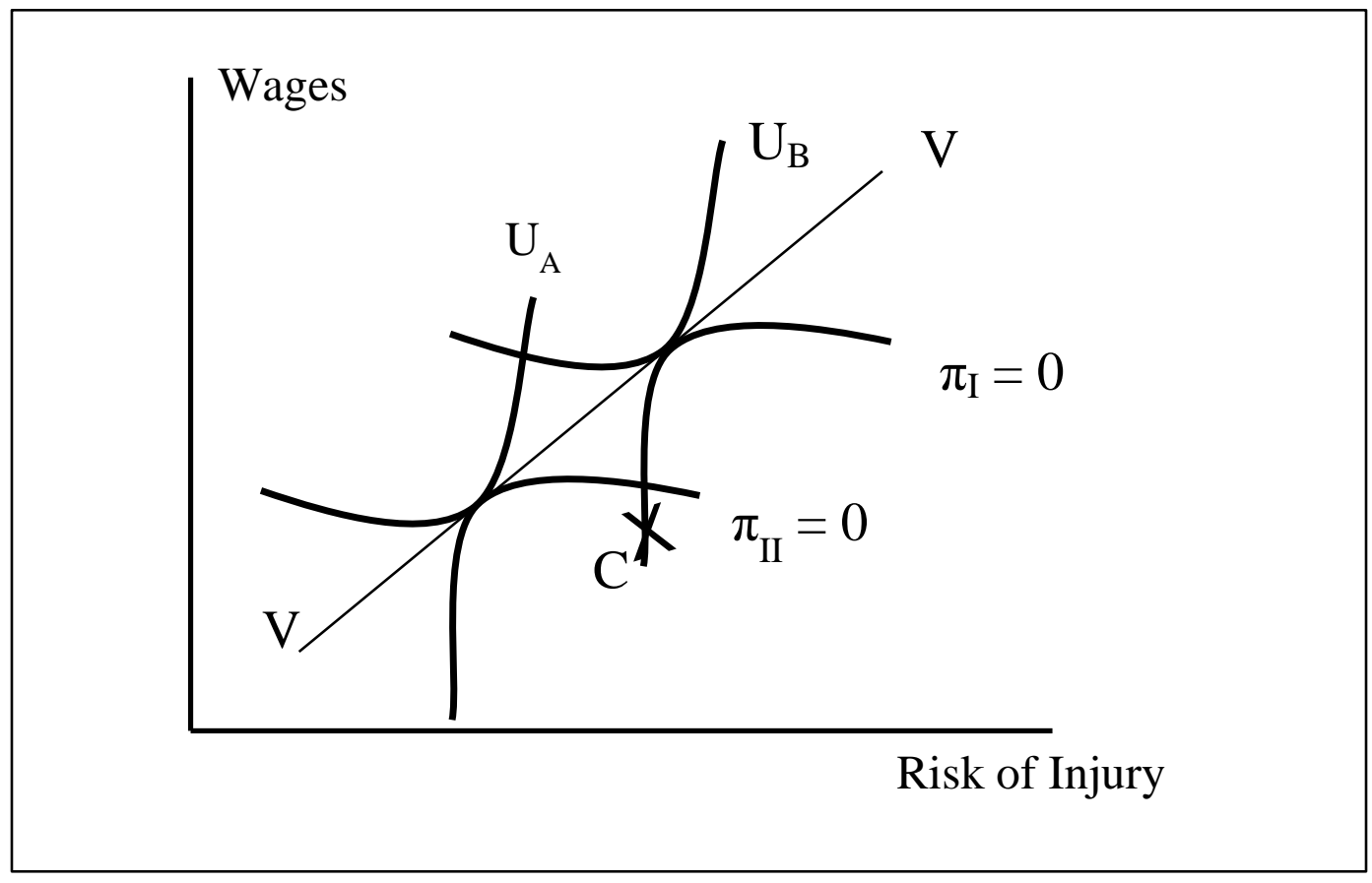

If the model is expanded to represent many industries, the choices for each industry would be narrowed to just one possible combination. That would be at a point where an envelope curve is tangential to an individual industry's iso-profit curve. In labor economics this is known as a market offer curve and is shown as line VV. Any industry offering a combination below this line would be unable to attract staff. The market offer curve will be upward sloping which means that industries that are inherently more risky must offer high wages in order to attract staff. This basic result in economics dates back to at least Adam Smith's Wealth of Nations published in 1776. He observed that occupations characterized by "hardship, disagreeableness, and dirtiness" commanded higher wages in order to attract people to work in these occupations. The wage premiums paid in these industries are known as a compensating wage differential.

The final element to introduce into the model is the preferences of individual workers. All workers prefer higher wages and safer working conditions, hence their preferences are toward the top left of the diagram. However, the relative valuation that individuals place on money and risk varies. In the diagram, individual A dislikes risk to a greater extent than individual B. Individual A may have a family and dependents while individual B may be single and greatly appreciates the material goods obtained from a high wage. The industries chosen by both individuals will be decided by the tangency of their indifference curves, $\mathrm{U}_{\mathrm{A}}$ and $\mathrm{U}_{\mathrm{B}}$, with the market 
offer curve. Individual A will therefore choose to work in the less risky industry II, and individual B will choose industry I.

In summary, the basic model predicts that inherently more dangerous occupations will have to offer higher wage rates to attract workers. High risk-high wage occupations will optimally coexist with low wage-low risk occupations. Workers will choose between occupations based on their preferences for risk and income. If workers correctly choose the industry that reflects their preferences then the labor market will have functioned correctly.

\section{WAGES AND RISK IN THE RAILROAD INDUSTRY}

The implication of the labor market theory is that a market failure would only occur if an industry was operating below the market offer curve, that is to say the wages offered did not adequately compensate for the risks vis-à-vis other industries. Whether there is a market failure in the railroad industry can be investigated using empirical data on fatality rates per 100,000 employees and average hourly wages for a variety of different industries (Bureau of Labor Statistics, 1996b,c).

A quick inspection of these data, shown in figure 10.2, seems to offer support for an upward sloping market offer curve. While the diagram is a simple two-variable plot, the positive association of fatal injury rates and wages across industries is robust even in more sophisticated regression models which incorporate other factors that influence wage rates (Ehrenberg, 1988).

Figure 10.2: Hourly Wages versus Fatality Risk for Different Industries 1995

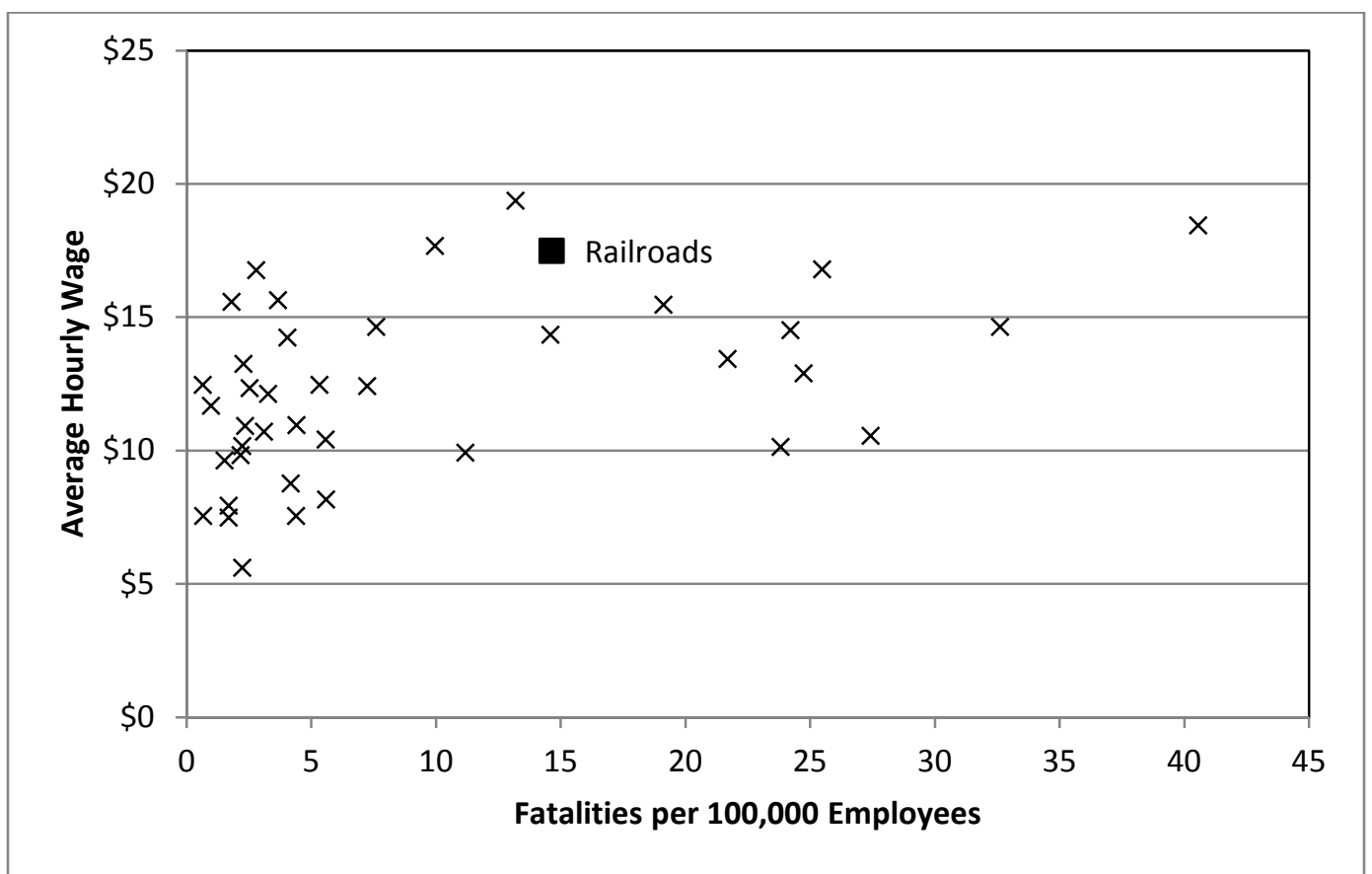


The railroads are identified by the square symbol. Railroads workers' are among the highest paid workers in the nation, while job risks are at the lower end of those for peer industries. This would suggest that there is not a failure in the railroad labor market. If anything, the railroads lie above rather than on the market offer curve. Industries that lie above the curve should have little trouble in attracting staff, and should have a very low staff turnover.

Morrow et al. (1997) found evidence to support the above observations in a survey of 1,000 union workers at four major railroads. They found that "safety was the most favorably perceived aspect of the work environment by employees and the only [job attribute] with a mean score above the [midpoint of a scale between "strongly disagree and "strongly agree"]." There was also little evidence of considerable staff turnover. More than eighty percent of railroad workers said that they intended to remain with their current employer.

The railroads may be above the market offer curve for two reasons. The first is that common labor market failures do not apply to the railroads, and the second is that the railroads are highly unionized.

\section{Absence of Market Failures}

The labor economics literature identifies two major market failures. The first is a lack of labor mobility. The basic model assumes that workers are free to select between occupations and employers based on their own preferences and the wages and conditions offered. If some people are constrained either by geography or by their level of skill and education, there is the possibility that unscrupulous employers may take advantage of a captive workforce by offering substandard wages and/or safety conditions. Arguments of this type are not really applicable to the railroad industry. The railroad industry requires skills that are readily transferable to other occupations, and employs a workforce who are, almost by definition, quite mobile.

The second possible market failure is that workers are not knowledgeable about the risks of working in a particular industry or firm and therefore cannot make an informed tradeoff between workplace safety risks and the wages and benefits offered. Viscusi $(1979,1983)$ found that workers tend to be very well informed about workplace physical injuries, and that concerns about injury were a major factor in decisions to quit jobs. However, the same is not true for industrial illnesses. A typical worker will not be able to appraise the toxicity of chemicals vapors or dust that they might breathe, or the dangers to their eyesight or hearing. The consequences of exposure of this type may take years to become apparent.

Most railroad injuries result from using maintenance equipment, falling, or being struck by a train. These are the types of accidents whose probability and severity employees can quickly appraise. Illnesses such as such as hearing loss, and inhalation of solvents or asbestos, are less prevalent. In 1996, only 157 of the more than 9,000 reports of employee casualties were industrial illnesses (FRA, 1997a). 


\section{Effect of Unions}

Railroad workers are highly unionized. Unions play an important role in keeping workers apprised of safety risks. Most unions have dedicated safety officials who are skilled in identifying dangerous situations and who report their findings to both their members and management. Market failure due to a lack of safety knowledge is less likely in a unionized setting.

Economic theory argues that unions are also have the effect of increasing safety in the workplace because the union will negotiate based on the safety desires of the average worker whereas the free market considers the economics of the marginal worker. Typically, the existing workforce will be older and desire less risk than the marginal new-hire employee who is likely to be young and single.

For example, consider two similar industries one of which is unionized and the other of which is not. If the wages were the same in the two industries, the union would argue for a higher level of job safety because it represents the interests of the inframarginal worker. Conversely if job risks are the same, the union will argue for a larger compensating wage differential. Moore and Viscusi (1990) found that workers in unionized settings received compensating wage differentials that are between ten and forty percent higher than in comparable non-union settings.

\section{COMPENSATION FOR WORKPLACE INJURIES}

Both theoretical and empirical labor economics analyses show that workers in relatively risky occupations receive higher wages. While all the workers benefit from the increased wages, only the comparatively few who suffer injuries bear the costs of the higher risks. Prior to the twentieth century, this asymmetry of benefits and costs meant that many seriously injured workers and their families faced poverty and hardship. Workers responded by establishing mutual-aid societies, often operated by trade unions, which collected subscriptions into a fund that would provide some support to the families of members who were killed or so seriously injured that they could not return to their former jobs.

Workers had to organize to support injured colleagues because the law was heavily biased against legal claims for compensation. In theory, there was a common-law requirement that employers provide a safe work place. However, in practice, there were a number of legal maneuvers that employers could use to protect themselves. The first was the rule of contributory negligence which at that time applied in most jurisdictions. This rule says that employers were not liable if the worker was also negligent in any way. The second was the fellow-servant doctrine, which said that the employer was not liable if the negligence of another employee had caused the unsafe condition. The third was the assumption of risk doctrine, which said that an employer was not liable if the worker had voluntarily continued to work despite knowledge about the existence of the hazards of the workplace. 
These pro-employer legal rules, coupled with dreadful tales of hardship for the families of injured workers, and the very high railroad injury rates at the turn of the twentieth century motivated Congress to implement legal reform. The Federal Employers' Liability Act (FELA) of 1908 dealt specifically with the railroads and eliminated the traditional defenses that employers could use. Contributory negligence was replaced by comparative negligence in most jurisdictions, which meant that even negligent employees could receive some damages if the railroad had also been negligent. The fellow-servant doctrine was eliminated, and the assumption of risk doctrine was limited and subsequently eliminated in 1939. Consequently, injured railroad workers could seek compensation by bringing legal suits against railroads.

At about the same time, reforms were introduced to provide for compensation of injured workers in other industries. This system, known as Workers' Compensation, had similar goals to the FELA but used a fundamentally different approach. It started as a scheme for federal employees in 1908, and expanded rapidly between 1911 and 1921 when it was adopted by all but six states as the primary method of compensating injured employees in both the private and government sectors. Workers' compensation is based on the legal principle of strict liability. Employers have to compensate injured employees regardless of who was at fault. Therefore, unlike FELA, courts do not have to decide on the comparative negligence of employer and employee. In effect, workers' compensation operates as social insurance scheme. To provide for settlements, employers can either self-insure or pay premiums to private or state-run insurance companies.

While workers' compensation may be more generous than FELA in that even negligent employees are compensated, the scale of benefits is much lower. Both workers' compensation and FELA compensate injured employees for medical expenses and provide broadly similar benefits to cover lost income due to time away from work. But workers' compensation prohibits employees from filing suit against employers to obtain compensation for pain and suffering, or to seek additional punitive damages against employers who are willfully or wantonly negligence. FELA does not prohibit railroad workers from seeking such compensation.

In 1910 both the House and the Senate voted to convert the railroads from FELA to workers' compensation but the bill failed in conference. Attempts in the following years to change to a no-fault system were defeated by labor interests. As a result 240,000 railroad workers are covered by an entirely different system of injury compensation than the ninety million Americans covered by workers' compensation. In New York City, employees of the Long Island Railroad and Metro-North are covered by FELA, while employees of the subway are covered by workers' compensation. Railroads are covered by FELA while competing trucking companies are subject to workers' compensation.

The debate about the relative merits of FELA and workers' compensation has continued unabated. Most railroad managers would prefer that the industry was covered by workers' compensation rather than FELA. Unions have strong opinions in the opposite direction. 


\section{INJURY COMPENSATION AND BILATERAL ACCIDENTS}

The most relevant question to ask in a book about railroad safety is which of FELA or workers' compensation better assures that both railroads and employees exercise due care in preventing workplace accidents. Employers can take precautions by providing good training, posting warning notices and installing machine guards. Employees also play their part by acting in a responsible manner. Nationally, at least fifty percent of industrial accidents are due to employee negligence (Viscusi, 1983). Almost twenty percent of railroad injuries are due to slipping or falling (FRA, 1997a), and one would imagine that falls can most easily be prevented by employees watching where they place their feet.

A model of bilateral accidents can be constructed to compare the two systems of compensation. In estimating the model, data are available on the costs of workplace accidents, and the legal and administrative fees associated with the two systems of compensation. One can also make some reasonable inferences on how the probability of an accident varies with the amount of care taken by both parties. Generally unknown is the costs that both parties incur in taking care.

\section{Table 10.1: Costs of Workers Compensation versus FELA}

\begin{tabular}{|l|l|c|c|}
\hline & \multicolumn{1}{|c|}{} & $\begin{array}{c}\text { Workers' } \\
\text { Compensation }\end{array}$ & FELA \\
\hline 1 & Covered employees $^{1}$ & 90 million & 240,000 \\
\hline 2 & Annual settlement payments & & $\$ 911$ million \\
\hline 3 & Average settlement per covered employee & $\$ 400$ & $\$ 3,800$ \\
\hline 4 & $\begin{array}{l}\text { Claims rejected or reduced due to } \\
\text { employee negligence per covered } \\
\text { employee (25\% }{ }^{1} \text { of line 3) }\end{array}$ & - & $\$ 950$ \\
\hline 5 & Proportion of payout in litigated cases & $30 \%{ }^{1}$ & $75 \%{ }^{4}$ \\
\hline 6 & $\begin{array}{l}\text { Plaintiff's legal expenses per employee } \\
\left(25 \%{ }^{3} \text { of line 3 multiplied by line 5) }\right.\end{array}$ & $\$ 30$ & $\$ 710$ \\
\hline 7 & $\begin{array}{l}\text { Net settlement per covered employee (line } \\
3 \text { less line 6) }\end{array}$ & $\$ 370$ & $\$ 3,100$ \\
\hline 8 & $\begin{array}{l}\text { Employers' administrative and legal } \\
\text { expenses }\end{array}$ & $\$ 27$ billion ${ }^{1}$ & $\$ 170$ million $^{2}$ \\
\hline 9 & $\begin{array}{l}\text { Employers' administrative and legal } \\
\text { expenses per covered employee }\end{array}$ & $\$ 300$ & $\$ 710$ \\
\hline
\end{tabular}


Data from recent research studies on compensation payments, and legal and administrative fees, for both workers' compensation and FELA are shown in table 10.1. Because injured railroad workers can sue for pain and suffering as well as medical expenses and lost wages, average settlements per covered employee, shown in line three, are almost ten times those under workers' compensation. This finding is in line with more detailed research studies (GAO, 1986; Transportation Research Board (TRB), 1994). Of course, settlements under FELA do not reflect total employee pain and suffering because courts can reduce or reject claims due to employee contributory negligence. Based on evidence from TRB (1994), one can estimate that employees are currently uncompensated for an amount equivalent to a quarter of the average FELA settlement.

Because FELA is an adversarial judicial system whereas workers' compensation is an administrative insurance system, the legal and administrative expenses incurred by railroads and injured employees (the combination of lines six and nine) are four times higher under FELA than under workers' compensation.

Currently, the probability that a railroad worker suffers an injury in a given year is one in twenty-five, or 0.04 (FRA, 1997a). What would happen to this probability if railroads and/or employees took less than their current level of care is unknown. One could argue that if neither party took care, the probability of a workplace accident would be the 0.25 , which is what it was in 1920 . A reasonable assumption is that care taken by employees can reduce the workplace accident rate by half (Viscusi, 1983). Therefore one could speculate that the probability of a workplace accident would be 0.125 if the railroad took less care and employees took their current level of care, and 0.08 if the railroad took their current level of care and the employees took less care.

The preceding information is incorporated into a bilateral accidents model shown in table 10.2. The model represents the expected costs of workplace accidents for a typical railroad worker in a given year. There are two changes from the model used in earlier chapters. The first one separates the injury costs to employees into costs associated with medical expenses and lost wages, and those due to pain and suffering. The second is the addition of the legal and administrative costs of adjudicating claims.

The last line of table 10.2 shows the current situation where both the railroad (RR) and the employee take their current level of care. The expected medical expenses and lost wages are approximated by the average workers' compensation settlement shown in line seven of table 10.1. An assumption will be made that the railroads bear equivalent costs to hire a replacement worker to cover the duties of the injured employee. The expected compensated cost of pain and suffering is approximated by the difference between average workers' compensation and FELA settlements, shown on line seven of table 10.1. The expected uncompensated cost of pain and suffering is approximated by the rejected or reduced FELA claims shown in line four of table 10.1 . 


\begin{tabular}{|c|c|c|c|c|c|c|}
\hline & & 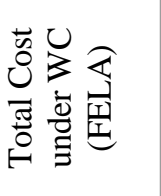 & 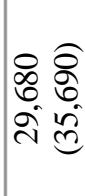 & 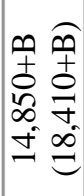 & $\begin{array}{ll}\varangle & \widehat{1} \\
1 & 1 \\
0 & 0 \\
0 & 0 \\
10 & 1 \\
\sigma & 0\end{array}$ & 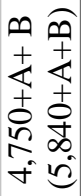 \\
\hline & & 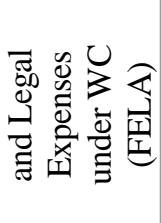 & $\begin{array}{ll} & \\
0 & 0 \\
0 & 0 \\
i & 0\end{array}$ & 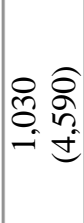 & o & 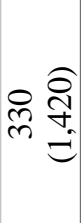 \\
\hline$\varangle$ & & 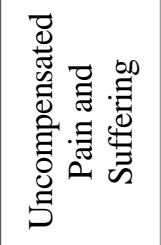 & $\begin{array}{l}\text { f } \\
\text { s. } \\
\text { ம) }\end{array}$ & 0 & $\begin{array}{l}\text { ठ্ } \\
\text { ñ }\end{array}$ & 으 \\
\hline 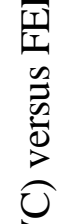 & 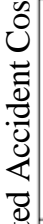 & 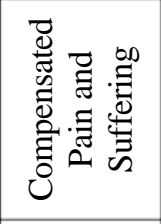 & 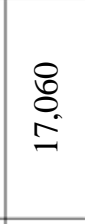 & 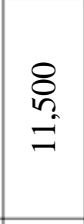 & 0 & 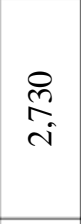 \\
\hline 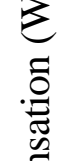 & 芯 & 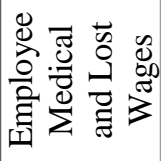 & 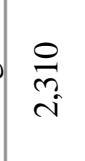 & $\begin{array}{l}\text { 号 } \\
\Rightarrow \\
=\end{array}$ & 옴 & $\stackrel{P}{\stackrel{R}{n}}$ \\
\hline త్రิ & & $\frac{\mathfrak{r}}{\sim 2}$ & $\begin{array}{l}\stackrel{0}{m} \\
\text { M. } \\
\text { N }\end{array}$ & 옴 & 옺 & 尽 \\
\hline $\begin{array}{l}\sum_{0}^{\circ} \\
3 \\
0\end{array}$ & & 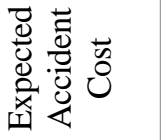 & $\begin{array}{l}\stackrel{\text { ڤn }}{0} \\
\text { On }\end{array}$ & 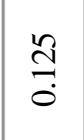 & $\begin{array}{l}\infty \\
\stackrel{0}{0} \\
0\end{array}$ & 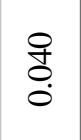 \\
\hline $\begin{array}{l}0 \\
0 \\
0 \\
0\end{array}$ & 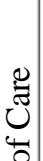 & 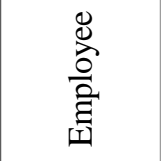 & 0 & 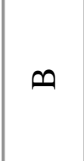 & 0 & 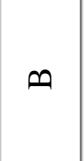 \\
\hline 娄 & ن & $\frac{a}{x}$ & 0 & 0 & $\varangle$ & $\varangle$ \\
\hline $\begin{array}{l}\frac{\mathscr{E}}{\pi} \\
\ddot{\oplus} \\
\dot{\sim}\end{array}$ & 总 & 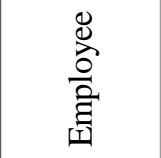 & 岕 & 苞 & 岕 & 泀 \\
\hline 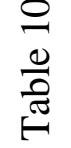 & 总 & $\stackrel{\mathfrak{r}}{\widetilde{\alpha}}$ & ్ֶత్త & ్ֶ & $\begin{array}{l}\text { 苞 } \\
\text { 罵 }\end{array}$ & 节 \\
\hline
\end{tabular}


If either or both of the parties do not take care, then the probability of an accident will increase, and the expected accident costs will increase proportionately. Of course, changes in the relative levels of care taken will affect FELA court decisions as to the level of pain and suffering that will be compensated. The model will assume that if railroads take less care, but employees continue to take their current care, then employees will be fully compensated for all of their pain and suffering. However, if employees take less care, and the railroad takes the current level of care, courts will not award any compensation for pain and suffering.

Currently, railroads incur FELA legal and administrative costs of $\$ 710$ per employee per year. This cost will increase proportionately with the probability of an accident if either party took less than their current level of care. Plaintiffs' attorneys are employed on a contingent fee basis. Therefore their costs are borne by the railroads as a percentage of gross settlements. Plaintiffs' legal costs are estimated at 18.75 percent of gross settlements. If FELA was replaced by workers' compensation, it is estimated to have a current legal and administrative cost of \$330 per employee. This cost will increase proportionately with the probability of an accident if either party took less than their current level of care.

The unknown costs of taking care by the railroad and the employee are represented by the letters A and B respectively. The range of plausible values that these variables can take can be determined by looking at the last column of table 10.2. In the context of this simple model, it is reasonable to suppose that all parties are best served when the railroad and the employees do not take less care than they current do. The maximum value of $\mathrm{A}$, the cost of the railroad taking care, can be found by comparing lines four and two. The value of A must be less than $\$ 10,100$ per employee per year. Likewise a comparison of lines four and three indicates that the maximum value of $B$, the employee's annual cost of taking care, is $\$ 4,420$.

The next step in the analysis is to construct payoff matrices for the railroad and employees under both workers' compensation and FELA. These are shown in table 10.3. The costs to the parties are shown as negative amounts, with the cost to the railroad shown first and the cost to the employee shown after the comma.

In the case of FELA, shown in the upper part of table 10.3, employees will receive no compensation if they take less than current care, but the railroads maintain their current level of care. However, if employees take the current level of care, but the railroads take less care, then employees will be fully compensated. Given that the value of $A$ is less than $\$ 10,100$, the railroad will always take the current level of care regardless of the actions of employees. And given that B is less than $\$ 4,420$, employees will always take the current of care regardless of the actions of the railroad. Therefore FELA will unambiguously discourage both parties from taking less than the current level of care.

In the case of workers' compensation, shown in the lower part of the table, employees always receive compensation from the railroad for their medical expenses and lost wages. However, they have to bear the costs of pain and suffering. Given that B is less than $\$ 4,420$, employees will always take the current level of care when railroads take less care. When railroads take their current level of care, employees 
will also take the current level of care provided that $B$ is less than $\$ 3,680$. This seems plausible. Therefore, it is reasonable to suppose that employees will always choose to take the current level of care regardless of the actions of the railroads. The actions of the railroads in response to this choice by employees are ambiguous. The railroads will choose to take the current level of care if their cost of care, A, is less than $\$ 2,280$ per employee per year. This is equivalent to $\$ 548$ million per year for the entire industry or about two percent of total operating expenses of the Class I railroad industry (AAR, 1997). It is therefore not clear whether railroads would or would not maintain their current level of care if FELA was replaced by a workers' compensation scheme.

Table 10.3: Payoff Matrices for FELA versus Workers' Compensation

\begin{tabular}{|c|c|c|c|}
\hline \multirow{2}{*}{\multicolumn{2}{|c|}{ FELA }} & \multicolumn{2}{|c|}{ Railroad Care } \\
\hline & & Less & Current \\
\hline \multirow{2}{*}{ Employee Care } & Less & $(-29750,-5940)$ & $(-2160-A,-8100)$ \\
\hline & Current & $(-18410,-B)$ & $(-4890-A,-950-B)$ \\
\hline \multirow{2}{*}{\multicolumn{2}{|c|}{ Workers' Compensation }} & \multicolumn{2}{|c|}{ Railroad Care } \\
\hline & & Less & Current \\
\hline \multirow{2}{*}{ Employee Care } & Less & $(-6680,-23000)$ & $(-2140-A,-7360)$ \\
\hline & Current & $(-3350,-11500-B)$ & $(-1070-A,-3680-B)$ \\
\hline
\end{tabular}

There are two somewhat contradictory conclusions from this analysis. The first conclusion comes from table 10.2. Society would prefer a system of workers' compensation to FELA because of the lower legal and administrative expenses. The second conclusion comes from table 10.3. FELA will guarantee that both employees and railroads do not deviate from their current level of care. If FELA was replaced by workers' compensation, it is highly likely that employees will continue to take their current level of care, yet it is possible that railroads may exercise less care. They would choose to do if the cost of care is more than $\$ 2,280$ per employee per year, which is quite plausible. If the railroads did deviate from their current level of care, society would be made worse off.

\section{INJURY COMPENSATION AND ACCIDENT INVESTIGATION}

The adversarial legalistic nature of FELA can work against a safe workplace. FELA requires injured employees prove negligence by the railroad. In addition, employees must defend themselves against arguments that they were contributorily negligent. If employees can show that the injury resulted from a violation by the railroad of federal safety laws, such as the requirements for car handholds under the 
Safety Appliance Act, then railroads become strictly liable and are unable to use a defense of contributory negligence.

In such circumstances, employees would genuinely not wish to compromise their legal cases by revealing too much information on the circumstances of injuries prior to a trial. The World Wide Web site of the Brotherhood of Railway Carmen's Fort Wayne Lodge 6760 advises their members "not [to] make any statements, either orally or in writing, and do not make out any reports of any kind, signed or unsigned, as to how the accident occurred, until you have been fully advised by your attorney." Part of the Union's concern is that "experience shows that the employee frequently signs a statement ... [that] ... includes weasel-words with which the claim agent intends to prove that the accident was not the fault of the railroad, or any of its employees, but was the fault of the injured person."

The unfortunate side effect is that there is no incentive for managers and employees to work together to objectively investigate the causes of workplace injuries and put in place changes that might mitigate injury occurrence and severity. This is in contrast to industries covered by workers' compensation where employees can freely admit errors they have made in the hope that fellow workers can learn from the mistake and act to mitigate future injuries. Some railroad managers that I have spoken to would be strongly in favor of replacing FELA by workers' compensation simply because workers' compensation fosters a more constructive attitude for investigating and mitigating workplace injuries.

\section{FELA VERSUS WORKERS' COMPENSATION}

The debate about FELA versus workers' compensation has many different facets, and continues to be very contentious. This book is primarily concerned with only the safety aspects of the debate. The main conclusions are that FELA would seem to offer the best incentives for both employees and railroads to exercise the current level of care, and that it is conceivable that if FELA was replaced by workers' compensation that railroads might take less care. These positive features of FELA come at a price. The price is the higher transaction costs and the inhibiting of open investigation of accidents.

There seem to be little prospect of any reform given that both sides of the issue are firmly entrenched. The general feeling of railroad management is that they cannot see why their industry, which is not unusually dangerous, continues to be treated differently from all occupations. The railroads claim that this puts them at a financial disadvantage compared with the trucking industry because under workers' compensation the costs of pain and suffering are transferred from the employer to the employee.

However, this is a simplistic argument, and one that is questioned by some thoughtful railroad managers. These managers recognize that FELA is seen as a major employee benefit, and that its replacement could only come at the cost of higher wages or improvements in other benefits or productivity agreements. It is 
even possible that the railroads have benefitted financially from FELA because workers are risk averse. Moore and Viscusi (1990) found that workers sacrifice 8⿷ in wages for each additional dollar of scheduled workers' compensation benefits, despite the fact that when the probability of having to claim benefits is considered, the expected payout to the worker is in the range of 4-5 $\$$. The employer benefits from an $8 \mathbb{C}$ reduction in wages but only has to pay out $4-5 \mathbb{\$}$ in injury compensation. The employer has benefitted, has have the employees because they freely traded off the wages for the injury benefits. Viscusi refers to this as a "free lunch."

There are other financial concerns that railroad managers have about FELA. In evidence to the TRB (1994) it was claimed that the higher benefits available under FELA induced workers to make claims for minor injuries, to stay away from work for longer when they are injured, and to make more spurious claims. There is certainly evidence to support some of these contentions. Meyer et al. (1995) found that the elasticity of injury duration with respect to the level of workers' compensation benefits was of the order of 0.3-0.4. But the interpretation of this result is open to debate. Unions claim that current workers' compensation rules do not adequately compensate workers with minor injuries, and thereby encourage workers to return to work too quickly and prior to full recuperation.

Perhaps the most notorious management grievance concerns the lack of incentives under FELA for injured workers to rehabilitation themselves. The most egregious issue concerns a clause of the Railroad Retirement Act which entitles disabled workers who have twenty or more years of service to full disability retirement pay irrespective of whether the worker could ultimately be rehabilitated or could undertake other types of employment either inside or outside of the railroad industry (GAO, 1996). Even for workers with less than twenty years' service, FELA discourages rehabilitation because it is beneficial for a claimant to abstain from rehabilitation prior to a judgment by a court on the size of an award. In contrast, workers' compensation is paid on a week-by-week basis during the period of injury and encourages workers to seek and be committed to a program of physical rehabilitation.

Railroad unions are firm supporters of FELA. Analysis earlier in this chapter provides some support for union arguments that replacement of FELA by workers' compensation might encourage railroads to take less care to avoid accidents. However, there are some aspects of FELA that are unfavorable to employees. There is the chance that workers who are injured due to their own negligence might receive no compensation under FELA while they would be entitled to some benefits under workers' compensation. While one might not have too much sympathy for negligent employees, one might feel sympathy for family members who suffer hardship. In addition, the litigious nature of FELA means that settlements occur a long time after the injury. In the interim, injured railroad employees and their families usually face some financial hardship and frequently have to take out loans from their employer (TRB, 1994). These two reasons prompted United States Supreme Court Justice Felix Frankfurter to call FELA "cruel and archaic" in 1954. 
So why are unions so unreservedly in favor in FELA? One explanation is rent sharing with plaintiffs' attorneys. The litigious nature of FELA, coupled with the large settlements awarded, ensures that representing injured railroad employees is a steady and profitable business. Quite understandably, railroad unions recommend to members a list of attorneys who are skilled in FELA law. They have a legal right to do so under a 1964 United States Supreme Court decision (Brotherhood of Railroad Trainmen v. Virginia State Bar (377 U.S. 1, 84 S. Ct 11113, 12 L. Ed 2d 89)). It commonly alleged that in return for inclusion on the list, many law firms provide benefits to union locals. Law firms pay for food at union meetings, support golf outings, and make contributions to the reelection campaign funds of union officials. Many union officials would lose personal benefits if FELA was replaced by a less litigious system. 


\section{1 eEnctumark LVELLSOF OPERATIONAL SAFETY}

The remainder of the book deals with operational safety. That is the prevention of collisions and derailments. This chapter discusses how much safety should be provided. It also introduces five possible market failures which may result in railroads providing non-optimal levels of safety. Subsequent chapters will investigate whether railroads are susceptible to these failures, and the possible public policy responses to the failures.

\section{HOW MUCH SAFETY SHOULD BE PROVIDED?}

Safety is an economic attribute of transportation service in that it is a characteristic of service that is valued by customers but costly to provide. This rather unobjectionable statement serves to take safety out of the realm of sacred cows and makes its determination an appropriate subject for economic analysis. Standard economic models can be used to provide some insight into how much safety should be provided. These will be called the benchmark level(s) of safety.

\section{The Social-Welfare Maximizing Monopolist}

The simplest economic model available is that of a monopoly railroad that does not have to compete with other railroads or rival modes of transportation, and prices in such a way so as to maximize social welfare. While this is not a realistic model, it serves two useful functions. The first is to introduce the terminology that will be used in more applicable models. The second is that it produces powerful insights that can be contrary to popular wisdom among lay people.

Economic models are based on structural equations that explain how customers and railroads will act. The quantity of railroad service demanded by shippers of goods or passengers will be measured in ton-miles or passenger-miles respectively. The factors influencing demand are described by a demand function:

$$
\mathrm{y}=\mathrm{q}(\mathrm{p}, \mathrm{x}, \mathrm{r})
$$


where: $\mathrm{y}$ is the quantity demanded;

$\mathrm{q}($.$) is the demand function;$

$\mathrm{p}$ is the price charged per ton-mile or per passenger-mile;

$\mathrm{x}$ is the preventive effort made by the railroad to avoid accidents; and

$r$ is a measure of other attributes of service that customers value such as speed and reliability of service.

The quantity demanded will be negatively related to price, but positively related to the preventive effort and other attributes of service.

The benefit that customers obtain from consuming transportation services is called consumer surplus. It is measured by the difference between how much customers would be willing to pay and how much they actually have to pay. The willingness-to-pay is measured by the height of the demand curve measured along the price axis. Demand curves have to be inverted to make this calculation. This means they have to be manipulated so that price rather than quantity demanded is on the left-hand side of the equation. This function will be denoted by $p($.$) . The$ inverse demand curve is then integrated to obtain the total willingness to pay. This integral function will be denoted by $\mathrm{u}($.$) , and is called utility. Total consumer$ surplus is therefore the area under the inverse demand curve less the price actually paid by all customers:

$$
\mathrm{u}(\mathrm{y}, \mathrm{x}, \mathrm{r})-\mathrm{yp}(\mathrm{y}, \mathrm{x}, \mathrm{r})
$$

On the supply side, railroads undertake preventive effort to avoid accidents. They do so by purchasing safety inputs, such as staff training and high-quality equipment, which are transformed into the number of accidents that occur by a safety production function. Of course, the actions of employees are an important feature of this function. Eighty percent of collisions and a quarter of derailments are caused by human error (FRA, 1997a). Employees do bear some personal responsibility in the prevention of accidents by, for example, abstaining from drinking prior to commencing duty. However, the model will take the view that the incidence of human-factors accidents is primarily determined by the railroad. If a railroad wished to reduce the number of human-factors accidents it could do so by raising wages rates to attract a more highly skilled workforce, and by making expenditures to provide better supervision and training. Employers have had a legal responsibility for the actions of their employees since Greek and Roman times. A party suffering harm in a railroad accident cannot bring suit against individual employees who caused the accident provided that the employees were "acting within the scope of their employment." Rather they have to direct torts toward the railroad on the basis of respondeat superior ("let the master answer"), because "a master is vicariously liable for the torts of his servants" (American Law Institute, 1965).

The railroad can also earn a surplus, often called producer surplus. This can be regarded as synonymous with profit $(\pi)$, which is to say total revenue minus total cost: 


$$
\pi=y p(y, x, r)-y[m+g(r)+c(x)]
$$

where: $\mathrm{m}$ is the basic marginal cost per ton-mile or passenger-mile for providing transportation services;

$\mathrm{g}(\mathrm{r})$ is the cost function for providing non-safety attributes of service per unit of demand. $g(r)$ will be a positive function, in that providing high quality service requires higher expenditures; and

$\mathrm{c}(\mathrm{x})$ is the cost function for safety per unit of demand.

The $\mathrm{c}(\mathrm{x})$ function is composed of two sub-parts. The first is the cost of purchasing the safety inputs. A cost function for safety inputs can be obtained by duality theory from the safety production function. The second is the cost of destruction to railroad property and injury to railroad employees when an accident occurs. Under FELA, railroads are strictly liable to employees who are injured in accidents resulting from violations of federal safety rules, which will be the case in most collisions and derailments.

One would expect that the total cost of safety inputs will rise with increased preventive effort, but the number of accidents and hence destruction to railroad property and injury to employees will fall. However, one should expect that overall $\mathrm{c}(\mathrm{x})$ will be a positive function of $\mathrm{x}$. If it were negative, one would obtain the rather uninteresting and unrealistic result that railroads would expend enough effort to totally eradicate all preventable accidents.

Of course, customers also bear some responsibility for taking precautions to prevent accidents. This is particularly the case for freight customers. Half of one percent of total collisions and 11/2 percent of total derailments are caused by improper loading of freight cars (FRA, 1997a). Improper loading can lead to goods falling from the car, or shifting during transit causing the car to derail. A more sophisticated model should incorporate a bilateral-accident component to investigate whether shippers and railroads are given correct incentives to take adequate precautions.

However for the moment the model will assume that accident causation and prevention is entirely within the control of the railroad. One justification is that railroads can and do affect the precautions taken by shippers. The AAR has conducted research and published manuals of rules and advice on loading all types of cars since at least the 1930s. Typical freight contracts specify that shippers must comply with these loading standards. Improper loading would be cause for the railroad to refuse to accept a shipment, albeit that the precautions taken by a shipper are difficult to determine when the load is shipped in a container or truck trailer.

The final party affected by operational accidents is bystanders who live or work next to railroad lines. These people are strangers to the railroad in that they do not have any contractual arrangements with the railroad and cannot directly influence the probability of an accident. Yet they can suffer externalities as a result of operational accidents. Typically one bystander is killed each year, and about 9,000 people a year have to be evacuated from areas surrounding accidents involving cars carrying hazardous materials. The costs to bystanders will be denoted by e(x) per unit of 
transportation. These costs will be a decreasing function of the level of preventive effort undertaken by the railroad. The benchmark model will assume that railroads are strictly liable for compensating bystanders for these costs. Therefore, $\mathrm{e}(\mathrm{x})$ will enter the cost function of the railroad.

Equilibrium in this model will be when social welfare (W), the combination of consumer and producer surplus, is maximized. Note that total revenue appears as a negative amount in equation (11.2) and a positive amount in equation (11.3). It therefore cancels out in the combined social welfare function:

$$
\mathrm{W}=\mathrm{u}(\mathrm{y}, \mathrm{x}, \mathrm{r})-\mathrm{y}[\mathrm{m}+\mathrm{g}(\mathrm{r})+\mathrm{c}(\mathrm{x})+\mathrm{e}(\mathrm{x})]
$$

There are three variables here: $y, x$ and $r$. Maximization of social welfare will be found by using first-order conditions. In these equations a subscript $\mathrm{y}, \mathrm{x}$ or $\mathrm{r}$ indicates the first derivative of the function with respect to output, preventive effort or other attributes respectively. The subscript * indicates that the variable is held at its social-welfare maximizing value, which would be determined by the other first-order conditions:

$$
\begin{gathered}
\mathrm{W}_{\mathrm{y}}=\mathrm{u}_{\mathrm{y}}\left(\mathrm{y}, \mathrm{x}^{*}, \mathrm{r}^{*}\right)-\mathrm{m}-\mathrm{g}\left(\mathrm{r}^{*}\right)-\mathrm{c}\left(\mathrm{x}^{*}\right)-\mathrm{e}\left(\mathrm{x}^{*}\right)=0 \\
\mathrm{~W}_{\mathrm{x}}=\mathrm{u}_{\mathrm{x}}\left(\mathrm{y}^{*}, \mathrm{x}, \mathrm{r}^{*}\right)-\mathrm{y}^{*} \mathrm{c}_{\mathrm{x}}(\mathrm{x})-\mathrm{y}^{*} \mathrm{e}_{\mathrm{x}}(\mathrm{x})=0 \\
\mathrm{~W}_{\mathrm{r}}=\mathrm{u}_{\mathrm{r}}\left(\mathrm{y}^{*}, \mathrm{x}^{*}, \mathrm{r}\right)-\mathrm{y}^{*} \mathrm{~g}_{\mathrm{r}}(\mathrm{r})=0
\end{gathered}
$$

The first term in equation (11.5) is the differential of the integrated inverse demand curve. This term is therefore $\mathrm{p}\left(\mathrm{y}, \mathrm{x}^{*}, \mathrm{r}^{*}\right)$ and, by definition, is price. Consequently equation (11.5) is the familiar equilibrium condition in economics that social welfare is maximized when price equals marginal cost. Equation (11.7) indicates that the other attributes of service should be increased until the marginal welfare gain to all customers equals the marginal cost of providing the other attributes.

Of course, equation (11.6) is the most relevant to this chapter. This equation indicates that the market is in equilibrium when the combined marginal change in the total cost of prevention and the harm to bystanders equals the marginal welfare gain to all customers from the increased safety.

This comparatively simple model produces the powerful result that the relationship between customers' willingness-to-pay, the externalities, and the costs of prevention determine the socially-optimal level of preventive effort and hence safety. It is therefore possible that the informed choices of customers and railroads can result in a level of safety that may be less than the amount technically possible. When this occurs "society" has chosen not to avoid some accidents. Professor Edwards describes the situation well:

"The risks of bodily harm are not unreasonable when consumers understand that risks exist, can appraise their probability and severity, know how to cope 
with them and voluntarily accept them to get benefits that could not be obtained in less risky ways." (National Commission on Product Safety, 1970)

\section{Social-Welfare Maximizing Competitive Markets}

When two railroads compete, or when there is intermodal competition, the equilibrium is less well-defined than in the monopoly case. If customers have identical tastes for safety, rival firms will all provide the same level of safety, and customers will be indifferent between firms in this regard (Hotelling, 1929). However, the more likely scenario is that customers have different tastes for safety.

In these models customer i derives a utility of $\theta_{\mathrm{i}}\left(\mathrm{x}_{\mathrm{j}}\right)$ from the safety aspects of the service provided by firm $\mathrm{j}$. $\theta_{\mathrm{i}}$ is a parameter indicating the customer's tastes for safety, and $\mathrm{x}_{\mathrm{j}}$ is the level of preventive effort undertaken by firm $\mathrm{j}$. A larger value of $\theta_{\mathrm{i}}$ indicates that the customer places a higher value on the preventive efforts undertaken by the firm. Some customers may value safety very highly because they might be married people with dependents or are shippers with delicate merchandise. Others may take a more cavalier attitude to safety.

Assume initially that there are two firms competing with each other. This can either be two railroads, or one railroad and a truck or barge line. Given the variation in tastes for safety, firm 1 might decide to offer a high level of safety. Firm 2 may decide to cater to the other end of the market. Firm 1 has to charge a higher price than firm 2 because of the higher costs of prevention. Each customer will compare the two firms and decide whether they wish to purchase transportation and, if so, which firm to patronize. Customer i will choose to patronize firm 1 if for his or her value of $\theta$ :

$$
\theta_{\mathrm{i}}\left(\mathrm{x}_{1}\right)-\mathrm{P}_{1}>\theta_{\mathrm{i}}\left(\mathrm{x}_{2}\right)-\mathrm{P}_{2}
$$

where $P_{j}$ is the price charged by firm $j$. Firm 2, the less-safe firm, will be chosen by customer $\mathrm{i}$ if the inequality is reversed.

This model produces the powerful result that if customers vary in their taste for safety then for a given set of firm preventive effort and prices, both firms will have demand for their vertically differentiated product (Shaked and Sutton, 1982). In a free-entry competitive model, entry of new firms occurs until prices are driven down to marginal cost. The nature of the marginal cost functions, the number of customers, and the distribution of their tastes will determine the socially-beneficial equilibrium number of firms, and hence levels of safety in the market.

Therefore, it will be optimal for a number of different safety levels to prevail in the market. Less-safe firms may optimally coexist with safer firms. Many lay people regard the fact that some firms are found to be less safe than other firms to be a market failure, but this is not the case. The customers of firm 2 decided of their own free will to patronize a less-safe firm in preference to safer alternatives. They do so because firm 2's service is offered at a discounted price, and compared with other customers they are less sensitive to the lower safety. 


\section{POSSIBLE MARKET FAILURES}

The models described in the previous section will produce equilibria that maximize social welfare. No amount of government intervention can lead to an improved combination of prices and levels of safety offered in the marketplace. However, the models are dependent on a series of assumptions:

(1) Railroads do not have market power to raise prices above marginal costs;

(2) Customers accurately perceive the preventive effort of railroads and other rival modes of transportation;

(3) Customers process information on safety, and act on their safety desires, in a rational way;

(4) Railroads are not myopic when considering the costs of prevention that occur in the present, and the consequent cost of accidents that occur at random times in the future; and

(5) Liability regimes are in place that ensures that railroads internalize into their costs the externalities caused to bystanders.

The reader may immediately object to some of these assumptions, and is right to do so. Indeed the determination of whether the railroads have a "safety problem" lies in the investigation of whether one or more of these five assumptions do not hold. The next five chapters deal with that determination. 


\section{MARKET POWER}

\section{THE THEORETICAL MARKET FAILURE}

The benchmark models assume that price equals marginal cost. In reality, this type of pricing is not commercially tenable. Railroads are characterized by economies of density at the route level because of high fixed costs of the infrastructure and relatively low marginal costs (Keeler, 1983). In 1996, the Class I railroads spent about $\$ 12$ billion on running the trains, $\$ 14.6$ billion on administration and maintaining track and equipment, and $\$ 6.1$ billion on capital investment (AAR, 1997). Therefore, perhaps only a third of the total costs vary in the short run with changes in levels of traffic. Pricing at marginal cost would lead to financial losses. Railroads have to price above marginal cost simply to stay in business. However, it is possible that railroads might be able to price above average cost, if they can erect barriers to entry to stop new firms entering the market in response to the earning of positive profits. Firms that are able to do so are said to have market power.

\section{Market Failure in the Monopoly Model}

The effect of market power on the monopoly model can be illustrated by considering a situation where the railroad prices to maximize profit $(\pi)$. Profit is, of course, defined as total revenue minus total costs:

$$
\pi=y p(y, x, r)-y[m+g(r)+c(x)+e(x)]
$$

The values of $y, x$ and $r$ which maximize profit are given by the following first-order conditions:

$$
\begin{gathered}
\pi_{\mathrm{y}}=\mathrm{yp} \mathrm{p}_{\mathrm{y}}\left(\mathrm{y}, \mathrm{x}^{\#}, \mathrm{r}^{\#}\right)+\mathrm{p}\left(\mathrm{y}, \mathrm{x}^{\#}, \mathrm{r}^{\#}\right)-\mathrm{m}-\mathrm{g}\left(\mathrm{r}^{\#}\right)-\mathrm{c}\left(\mathrm{x}^{\#}\right)-\mathrm{e}\left(\mathrm{x}^{\#}\right)=0 \\
\pi_{\mathrm{x}}=\mathrm{y}^{\#} \mathrm{p}_{\mathrm{x}}\left(\mathrm{y}^{\#}, \mathrm{x}, \mathrm{r}^{\#}\right)-\mathrm{y}^{\#} \mathrm{c}_{\mathrm{x}}(\mathrm{x})-\mathrm{y}^{\#} \mathrm{e}_{\mathrm{x}}(\mathrm{x})=0 \\
\pi_{\mathrm{r}}=\mathrm{y}^{\#} \mathrm{p}_{\mathrm{r}}\left(\mathrm{y}^{\#}, \mathrm{x}^{\#}, \mathrm{r}\right)-\mathrm{y}^{\#} \mathrm{~g}_{\mathrm{r}}(\mathrm{r})=0
\end{gathered}
$$


Where the \# superscript indicates the equilibrium level of a variable. Equation (12.3) is of primary interest to readers of this book. This equation says that the equilibrium level of preventive effort will be determined at the point where the marginal cost of prevention and the harm to bystanders is equated with the marginal valuation given to safety by marginal customer multiplied by the number of customers. Corresponding equation (11.6) of the benchmark model says something slightly different. Equilibrium in the benchmark model is at the point when these costs are equated with the marginal welfare gain by all customers. In other words, the valuation given to safety by the average customer multiplied by the number of customers.

In the normal good case where there is declining marginal valuation of safety as output expands, it is clear that profit maximization will lead to a lower level of safety than in the benchmark model. This is because the valuation given to a change in safety by the marginal customer will always be less than the average valuation by all of the customers.

However, this conclusion is dependent on the assumption that both market regimes produce the same level of output. This is clearly not true. Output in the profit-maximizing model is determined by equation (12.2) which gives the well-known result that a profit-maximizing firm sets marginal revenue equal to marginal cost. In the benchmark model, equation (11.5) shows that the welfare-maximizing firm will set price equal to marginal cost. When demand is inversely related to price, marginal revenue will be less than price. As a result, an unconstrained monopolist will produce a lower level of output than the socially-regulated monopolist.

As output falls, the valuation of improved prevention by the marginal customer will increase. It is impossible without knowing the parameters of the model to determine whether the average valuation of increased prevention at the social-welfare maximizing output will be higher, lower or the same as the marginal valuation at the profit-maximizing output. While one can conclude that monopoly power will result in a level of safety that will not in general correspond to that which would be socially desirable, it is impossible to say whether the level of safety will be greater than or less than that in the benchmark model (Spence, 1975).

It should be remembered that profit maximization unequivocally results in a lower level of output than the benchmark model. Market power leads to some customers being priced out of the market. Even those customers who do remain in the market will suffer reduced consumer surplus as the monopolist extracts this surplus in profit. Therefore the biggest outcry by customers will not be on the basis that safety has been affected, but rather because prices have risen and some of them have been priced out of the market. 


\section{Market Failure in the Competitive Model}

The benchmark competitive model is also affected by the existence of fixed costs. Economies of density result in a limited number of firms each of which must price above marginal cost to recoup fixed costs. Therefore not every customer will be able to purchase a product that exactly matches their tastes for safety. The number of firms in the market who can break-even will depend on the magnitude of the fixed costs, and the number of customers over whom the fixed costs can be spread (Spence, 1976).

If firms have market power and can price above average cost, some customers whose preferences for safety are not exactly matched by one of the existing firms, may decide it is too expensive to continue to consume transportation (Salop, 1979). Consequently, there would be an opening for new firms to enter and provide service specifically to those customers who were priced out of the market by existing firms. Because these firms will have to recoup their fixed costs from relatively few customers, prices will be quite high. Nevertheless they will have demand for their service because they are offering a level of safety that closely matches the desires of their customers.

The reader will recognize that there will be a trade off in such a market between the prices charged and the number of firms, and hence the number of safety choices. Theoretical models such as Dixit (1979) in the case of oligopoly, and Spence (1976), Dixit and Stiglitz (1977) and Koenker and Perry (1981) in the case of monopolistic competition show that the market can either produce a large number of safety choices at high prices, or a limited number at low prices.

In general, the levels of safety offered in all imperfectly competitive economic regimes will not correspond with that which would be socially desirable. However, without knowing the relative valuation that customers place on price and the availability of choices of safety levels, it is theoretically impossible to say whether customers will be better or worse off.

As with the profit-maximizing monopoly model, the main effect of market power in these models is that prices will rise, firms will appropriate some of the consumers' surplus in the form of profits, and some customers will be priced out of the market. The implications in terms of the range of safety choices offered might be regarded as somewhat secondary in importance.

\section{EVIDENCE OF MARKET POWER}

Railroads have to price above marginal costs to recoup the costs of infrastructure provision and maintenance. It is possible that they have the power to price above average cost and earn supernormal profits. Economists argue that supernormal profits can only be earned in the long run when there are barriers to stop new firms from entering the market and eroding away the profit. Substantial economies of 
density serve as such a barrier. The high cost of acquiring the land and building an infrastructure result in one, or at most two, railroads offering service in most markets.

Of course, much of the competition that railroads face is not from other railroads but from other modes of transportation. There is active competition from trucks, pipelines and barges. Intermodal competition is stronger for some commodities than others. Pipelines provide the strongest competition in the movement of oil and oil products. Barges are a significant threat along the Mississippi river for agricultural products. Trucks have a significant advantage for goods that need to be moved fast, over short distances, or have a low weight-to-volume ratio. Railroads face less competition for bulky, heavy products such as coal and other primary materials.

The railroads' market share for different commodities is shown in table 12.1. The data in the table suggest that railroads transport half of all coal shipments. Figures from other sources give an even higher rail market share. Both the AAR (1996a) and the National Mining Association (1996) put the figure at about sixty percent. Coal traffic is very important to the railroads. With the exception of the former Santa Fe Railroad, coal represented at least a quarter of the total tonnage moved by each of the nine largest railroads in 1995 (AAR, 1996a).

Table 12.1: Rail Market Share by Tons 1993

\begin{tabular}{|l|c|}
\hline \multicolumn{1}{|c|}{ Commodity } & Share \\
\hline Coal & $49.3 \%$ \\
\hline Metallic ores & $26.2 \%$ \\
\hline Waste or scrap materials & $24.6 \%$ \\
\hline Chemicals & $24.3 \%$ \\
\hline Farm products & $22.6 \%$ \\
\hline Primary metal products & $16.0 \%$ \\
\hline Pulp and paper & $15.5 \%$ \\
\hline Food and kindred products & $10.2 \%$ \\
\hline Lumber or wood products & $6.9 \%$ \\
\hline Nonmetallic minerals & $5.2 \%$ \\
\hline Clay, concrete, glass, stone & $5.1 \%$ \\
\hline Petroleum or coal products & $2.1 \%$ \\
\hline
\end{tabular}

Source: Tons carried by rail (AAR, 1996a) divided by total tonnage shipped by all modes reported in the 1993 Commodity Flow Survey (U.S. Bureau of the Census, 1995).

Railroads transport almost a quarter of all agricultural shipments. For certain specific agricultural commodities the market share is even higher. The AAR (1996a) reports that railroads carried forty percent of total domestic grain production. Railroads also have significant market shares for transporting ores, chemicals, and scrap materials.

For commodity flows in which the railroad is the dominant mode of transportation, there are usually only a limited number of railroads that can offer 
service to individual shippers. This market concentration in the rail industry has increased in recent years. Mergers have created large regional duopolies. As recently as 1960 there were more than one hundred large railroads. By the end of the twentieth century, the number will probably have fallen to seven.

Since 1994 the number of large railroads west of the Mississippi River has dwindled from five to two. In the East, the assets of Conrail are to be purchased and divided up between the two other major eastern railroads, Norfolk Southern and CSX Transportation. Albeit that the nature of the division of Conrail should increase the amount of competition in many markets in the northeastern United States. The two transcontinental Canadian railroads, Canadian Pacific and Canadian National, already own United States subsidiaries that provide them with access into Chicago. Canadian National is poised to purchase the Illinois Central, leaving the Kansas City Southern as the only independent medium-sized railroad. In the very near future, these seven companies will control three-quarters of the national route mileage and more than eighty percent of carloads moved (AAR, 1997).

But has the increased concentration within an industry that has a high market share for the transportation of certain commodities led to the charging of prices above average cost? Certain shippers, such as coal-burning electrical power generating companies, claim that railroads have exploited their market power. The government accepted that this was a possibility at the time of the Staggers Act of 1980. The Surface Transportation Board retains the right to regulate prices in markets where railroads are the dominant mode.

What can be said is that the financial position of the railroads has improved in recent years. Of course, this is in the context of poor financial returns and bankruptcies in the 1960s and 1970s. In 1996 the Class I railroads earned a 9.4 percent return on net investment compared with 4.6 percent in the mid-1980s (AAR, 1997). The question of whether the improved performance has come from an ability to exercise market power is hotly contested.

\section{SUMMARY}

The extensive fixed costs of providing and maintaining the right of way requires railroads to violate the marginal cost pricing assumption of the benchmark model in order to stay in business. Increased concentration in the rail industry, coupled with considerable comparative advantages in moving heavy, bulky products, raises the possibility that railroads might be able to price above average cost.

Departures from marginal cost pricing do distort the determination of safety. However, economists cannot be sure theoretically of the direction, let alone the magnitude, of the deviation. However, market power unequivocally leads to higher prices. Some customers will consequently be priced out of the market, and all customers will suffer a reduced consumer surplus. In both practical and political terms, the safety distortions might be regarded as somewhat secondary compared 
with the welfare loses associated with the restriction of output by railroads with market power. 


\section{IMPERFECT INFORMATION}

\section{THE THEORETICAL MARKET FAILURE}

A welfare-maximizing decision by individual customers as to whether to consume transportation, and which railroad or mode they wish to patronize presupposes that they are fully informed about the safety choices that are available. If customers misperceive the preventive efforts made by railroads and other transportation firms, they may make mistaken demand decisions. Some customers may be scared away from using rail transportation on the mistaken belief that it is less safe than it really is. Others may mistakenly patronize a firm or mode that is less safe than they would desire. Because customers do not accurately express their desires for safety preferences in their demand decisions, railroads will be sent the wrong signals about the preferences of customers. It is therefore likely that the "wrong" amount and variety of safety will be offered in the marketplace.

\section{Market Failure in the Monopoly Model}

The benchmark model will be modified by introducing a parameter $\alpha$ on the $\mathrm{x}$ variable in the customers' utility function. This parameter represents customers' perceptions of the preventive efforts undertaken by the railroad. If customers are perfectly informed, as in the benchmark model, the parameter will take the value of one. A value of $\alpha$ of greater than one indicates that customers perceive that railroads undertake more preventive effort than they really do. In other words, customers think that railroads are safer than they are in reality. Conversely, a value of $\alpha$ less than one means that customers underestimate the preventive efforts of railroads and think that railroads are less safe than they are in reality.

The social-welfare maximizing monopolist will decide on the level of output, preventive effort and other attributes of service by setting price, or the willingness-to-pay by customers, equal to marginal cost. The decision rule used in setting preventive effort is:

$$
\mathrm{u}_{\mathrm{x}}\left(\mathrm{y}^{\#}, \alpha \mathrm{x}, \mathrm{r}^{\#}\right)=\mathrm{y}^{\#}\left[\mathrm{c}_{\mathrm{x}}(\mathrm{x})+\mathrm{e}_{\mathrm{x}}(\mathrm{x})\right]
$$


When customers are perfectly informed, and $\alpha$ equals one, this decision rule is identical to the first-order condition (equation 11.6) in the benchmark model. The benchmark level of preventive effort will be provided. However, if $\alpha$ is greater than one, the marginal willingness-to-pay function will shift upward. It will now intersect the marginal cost of preventive effort curve at a higher level of $\mathrm{x}$. For a constant level of output, the perception that railroads are safer than they really are motivates railroads to produce more safety than in the benchmark model.

Conversely, a value of $\alpha$ of less than one shifts the marginal willingness-to-pay function with respect to safety downward, and for an unchanged level of output, less preventive effort will be undertaken than in the benchmark model (Spence, 1977). A belief by customers that railroads are less safe than they really are motivates the railroad to provide less safety. In the extreme if $\alpha$ equals zero, meaning that customers cannot form any perception about the amount of prevention, the railroad will not take any preventive efforts because customers will be unwilling to pay the higher price that it would entail.

A non-optimal choice of preventive effort has repercussions on the equilibrium level of output. The welfare-maximizing monopolist will decide on output based on the decision rule:

$$
u_{y}\left(y, \alpha x^{\#}, r^{\#}\right)=m+g\left(r^{\#}\right)+c\left(x^{\#}\right)+e\left(x^{\#}\right)
$$

If $\alpha$ is greater than one, and hence $x^{\#}$ is greater than $x^{*}$, the cost function will shift upward because the monopolist is now producing a safer service. The equilibrium level of output will be smaller than in the benchmark model. The converse conclusion will be drawn if the value of $\alpha$ is less than one.

\section{Market Failure in the Competitive Model}

There is an added twist in the competitive model. Not only do customers have to be knowledgeable about the general level of safety offered by railroads, but they also have to be able to distinguish between the safety levels offered by rival railroads or modes of transportation.

Consider the extreme case where customers have some general idea of the safety of railroads, but cannot distinguish between the safety performance of individual railroads. A profit-maximizing railroad would respond to this situation by electing not to take any safety precautions. It would do this because it could save the cost of taking precautions yet would not suffer a decline in demand because customers do not recognize that a lower-quality service is being provided. Other railroads would follow suit, and very soon all railroads would be providing the most minimal safety level possible (Akerlof, 1970).

For the socially-optimal vertically differentiated market for safety to exist, customers have to be able to recognize which firms are offering higher-quality service. Otherwise, no railroad would choose to supply a high-safety service 
because customers would not recognize the product and be unwilling to pay the higher price that has to be charged to recoup the costs of prevention.

\section{Liability to Customers}

An institutional arrangement exists that many people incorrectly believe ameliorates the problem of imperfect information. Railroads have a legal obligation to compensate customers for harm caused in accidents. The requirement is strongest for freight transportation. The 1906 Carmack Amendment to the Interstate Commerce Act of 1887 requires common carriers to compensate shippers for the "full actual loss and injury" caused by reasons of loss, damage or delay. While this requirement has been relaxed by the Staggers Act of 1980 in that shippers can declare the goods to be of a lower value in order to obtain a lower rate, railroads are strictly liable for damage to goods (Augello and Pezold, 1995; Sorkin, 1996).

The situation for passenger travel is a bit different in theory, but perhaps not in practice. The legal principle is that of comparative negligence in most jurisdictions, and negligence with a defense of contributory negligence in a minority of jurisdictions. Kenworthy (1989) argues that even limited evidence of negligence is enough to ensure a successful outcome for an injured passenger because courts have typically held common carriers to a higher standard of care than that applicable to an individual or a manufacturing firm. Indeed, some courts may interpret the simple fact that an accident has occurred to imply negligence, even though the plaintiff cannot bring witnesses who saw actual negligence. Kenworthy concludes that innocent passengers suffering harm in railroad accidents are almost certain to be compensated.

It is commonly argued that these legal arrangements will ensure that safety is provided at the appropriate levels even if customers are imperfectly informed. This is because the costs of harm suffered by customers are transferred to the railroad. The railroad will be knowledgeable about the amount of preventive effort it is taking, and the effects on the probability and severities of accidents. Because the railroad bears both the costs of preventing accidents and the financial consequences when accidents occur, the amount of preventive effort will be optimal. However, this happy outcome is dependent on an assumption that the customer's disutility associated with the possibility of an accident is identical to the expected harm suffered in an accident.

If this assumption holds, the decision rule used by the welfare-maximizing monopolist, equation (13.1), can be rewritten as:

$$
\mathrm{u}_{\mathrm{x}}\left(\mathrm{y}^{\#}, \mathrm{r}^{\#}\right)=\mathrm{y}^{\#}\left[\mathrm{c}_{\mathrm{x}}(\mathrm{x})+\mathrm{e}_{\mathrm{x}}(\mathrm{x})+\mathrm{l}_{\mathrm{x}}(\mathrm{x})\right]
$$

where $\mathrm{l}(\mathrm{x})$ is the liability payment. Because the railroad is fully aware of its preventive efforts, the parameter $\alpha$ no longer appears in this equation. Therefore, irrespective of the knowledge of customers, the benchmark level of safety will be 
produced. Note that the railroad recovers the costs of the liability payout in the form of higher prices charged to all customers. Liability has the effect of spreading risk by providing involuntary insurance to passengers or shippers. Absent liability, the accident costs would be borne by the unlucky few customers who are involved.

Another implication is that safety no longer enters the utility function of customers. They will be indifferent to the level of preventive effort taken by railroads. This is a strong and unrealistic assumption. Generally one expects that people will prefer more safety to less safety, even in the presence of strict liability for losses. The reasons are twofold. The first is that not all losses can be legally compensated for, and the second is that people are risk averse.

Liability typically only provides for restitution of a portion of the losses suffered in an accident. For example, freight customers are only compensated under the Carmack Amendment for the value of their goods that are damaged or destroyed. Shippers are not compensated for costs related to damage such as delays in their production schedules or costs of claim administration.

For passenger transportation, there is a high probability that people will be killed or seriously injured if an accident occurs. Victims, and their relatives, can recover pecuniary losses which include medical bills and time away from work. It is also possible to bring suit to obtain compensation for non-pecuniary losses such as pain and suffering, and the loss of the consortium of a spouse or child. However, even if such a suit is successful, it is unlikely that even the most cold-hearted would claim that they can be adequately compensated for their loss.

In addition, it is commonly accepted in economics that individuals place a higher disutility on risk than would be explained by their pecuniary and non-pecuniary losses. This is known as risk averse behavior. People feel this way because the consequences of a transportation accident are so serious and irrevocable. In contrast, it can be argued that freight shippers may be risk neutral, because the losses sustained in an accident are purely financial and will be small compared with the total assets of the corporation.

If some losses are not legally recoverable or if customers are risk averse, the decision rule facing the monopolist will be given by:

$$
\mathrm{u}_{\mathrm{x}}\left(\mathrm{y}^{\#}, \mathrm{r}^{\#}\right)-\left[\mathrm{d}_{\mathrm{x}}(\alpha \mathrm{x})-\mathrm{l}_{\mathrm{x}}(\mathrm{x})\right]=\mathrm{y}^{\#}\left[\mathrm{c}_{\mathrm{x}}(\mathrm{x})+\mathrm{e}_{\mathrm{x}}(\mathrm{x})+\mathrm{l}_{\mathrm{x}}(\mathrm{x})\right]
$$

where $d(\alpha x)$ is the perceived disutility occasioned by accidents per unit of output. Because there is still an $\alpha$ term in the equation, a market failure will occur if customers are not perfectly informed (Spence, 1977).

The liability-as-a-cure-for-imperfect-information argument is even more dubious when applied to the benchmark competitive model. The competitive model is grounded in the fact that customers have different tastes for safety. In some cases the difference in tastes will be a reflection of variations in the level of pecuniary damages a customer would suffer in the event of an accident. For example, shippers of delicate goods would suffer more pecuniary harm in an accident and consequently have a greater taste for safety. However people who suffer similar harms will have 
different tastes when risk aversion varies across individuals. Very cautious individuals may suffer considerable anxiety in contemplating risk and be very risk averse, while other individuals may be less troubled by risk.

\section{KNOWLEDGE OF FREIGHT SHIPPERS}

In general, one would expect freight shippers to be well informed. Even first-time shippers have a range of sources from which to obtain information. Trade associations, such as the Chemical Manufacturers' Association, act as both formal and informal forums for sharing of experiences between shipping managers. Potential shippers on a small railroad can consult with a neighbor who already uses the railroad. Railroads with poor quality of service will tend to have more dissatisfied customers than good railroads. This is because some novice shippers may sample the service of rival railroads, and will be disappointed with poor railroads. The dissatisfaction will be disseminated throughout the local community by word of mouth, and the story may be picked up by trade publications whose journalists write on railroad issues, and highlight railroads that are experiencing safety problems.

Table 13.1: Loss and Damage Payments by Cause 1995

\begin{tabular}{|l|c|c|}
\hline \multicolumn{1}{|c|}{ Cause } & Carload & Intermodal \\
\hline Train accidents & $32 \%$ & $38 \%$ \\
\hline Theft & $4 \%$ & $29 \%$ \\
\hline Other causes & $38 \%$ & $17 \%$ \\
\hline Defective equipment & $6 \%$ & $9 \%$ \\
\hline Temperature failure & $7 \%$ & $2 \%$ \\
\hline Employee error & $5 \%$ & $2 \%$ \\
\hline Shortage & $3 \%$ & $1 \%$ \\
\hline Vandalism & $2 \%$ & $1 \%$ \\
\hline Fire & $2 \%$ & $1 \%$ \\
\hline Source: AAR (1996b) & \multicolumn{2}{|l}{} \\
\hline
\end{tabular}

There are also published data that shippers can use. One source of information is the annual Freight Loss and Damage Report published by the AAR. This report provides a wealth of information on the fourteen largest American and Canadian Railroads. Data for 1995 show that railroads paid out one-third of one percent of their revenues in compensation for loss and damage. The leading causes of loss and damage, shown as a percentage of total compensation paid, are in table 13.1 for both carload and intermodal traffic. Accidents account for about a third of all compensation payments for both carload and intermodal shipments. Robbery, theft and pilferage represent a significant proportion of the losses for the higher-value intermodal shipments. 
The AAR publication also provides analysis by commodity. Loss and damage as a percentage of the revenue from that commodity can be as high as ten percent as it is for flat glass and electrical transmission equipment. Fresh fruits and vegetables suffer loss and damage equal to three-and-one-half percent of revenue. At the other extreme, loss and damage to minerals and chemicals is equal to a tenth-of-one-percent of revenue, while that for coal is only one-fiftieth-of-one-percent. The publication also presents data for individual railroads. The former Southern Pacific Railroad and the Florida East Coast Railroad had the worst claim records at half-of-one-percent of revenue, although this is likely explained by the prevalence of fresh fruit and vegetable shipments originating in southern California and Florida. At the other end of the spectrum, the coal-oriented Norfolk Southern Railway had very low claims at a sixth-of-one-percent of revenue.

Any shipper with access to this report would clearly have a wealth of information on which to make reasonable calculations of possible loss and damage to their goods. While this report is technically a public document, it appears that few shippers are privy to it. The total circulation is about 500 and it is primarily mailed by the AAR to damage prevention officers of member railroads. While any railroad is free to share the information with shippers, this rarely happens. The data is also not picked up by shippers' organizations such as the National Industrial Transportation League who could possibly publish it in the trade press. The data are not available on the Internet.

Another source of published data is the annual FRA Accident / Incident Bulletin which provides individual information for the largest forty-four railroads. The data on collisions and derailments per million train miles in 1996 are shown in table 13.2. As can be seen, collision and derailment rates do vary markedly between the large, Class I, railroads. Shippers could draw some conclusions from these data, although they would have to build in allowances for differences in the nature of operation of individual railroads, such as the amount of switching, that affect accident rates.

It is more difficult, but not impossible as explained in a later chapter, to draw meaningful comparisons between the accident rates of the smaller Class II freight railroads. These twenty-four railroads average eight-and-one-half collisions and derailments each a year, and accident rates will vary markedly from year to year due to statistical fluctuations explained by the Poisson distribution. For the small, Class III, railroads meaningful statistical inference is impossible, even if the data were published individually by railroad by the FRA. The 275 different corporate entities average only 0.7 collisions and derailments each a year.

Of course, the largest source of information available to a shipper is personal experience. Major corporations represent the vast majority of the railroads' business, and their shipping and logistics managers are repeat customers who have dealings with railroads almost every day. While destruction of their freight in accidents will occur infrequently, they will be familiar with routine claims for minor loss and damage in transit. As indicated in table 13.1, two-thirds of the claims are for causes other than accidents. This claim experience, and any changes in it over 
time, gives shippers considerable insights into preventive efforts made by the railroads. Railroads that take care to avoid in-transit damage are also likely to take care to prevent collisions and derailments.

Table 13.2: Collisions and Derailments per Million Train Miles 1996

\begin{tabular}{|l|c|c|c|}
\hline & $\#$ & MTM & Rate \\
\hline Union Pacific & 383 & 115 & 3.3 \\
\hline BNSF & 383 & 146 & 2.6 \\
\hline CSX & 150 & 84 & 1.8 \\
\hline Southern Pacific & 226 & 64 & 3.5 \\
\hline Norfolk Southern & 128 & 64 & 2.0 \\
\hline Conrail & 171 & 46 & 3.7 \\
\hline Soo Line & 77 & 10 & 7.8 \\
\hline KCS & 56 & 8 & 6.9 \\
\hline Illinois Central & 52 & 8 & 6.5 \\
\hline GTW & 30 & 5 & 5.5 \\
\hline & & & \\
\hline Class I Freight & 1656 & 550 & 3.0 \\
\hline Class II Freight & 210 & 28 & 7.6 \\
\hline Class III & 184 & 22 & 8.5 \\
\hline
\end{tabular}

Source: FRA (1997a)

\section{KNOWLEDGE OF PASSENGERS}

For passenger transportation, the situation may be somewhat different. There is not the equivalent of the AAR's Freight Loss and Damage Report which passengers can use to evaluate accident risks. While all the necessary information would be available from the annual FRA Accident / Incident Bulletin and from NTSB accident reports, this information does not circulate widely among the general public.

The press does provide extensive reporting of passenger train accidents. However, because accidents occur rarely, the number of recent column inches of reporting in the press will be an unreliable indicator of risk. An additional source of information is the NTSB that conducts investigations into major railroad accidents. Even though final NTSB reports often only appear years after an accident, officials of the NTSB frequently give news conferences in the immediate aftermath of an accident which provide technical information to underpin an informed public debate and enquiry into the causes of an accident. Of course, many major accidents result from bizarre sets of circumstances which make passengers uncertain as to whether to infer that the railroad was at fault, rather than blaming the weather, an "act of god," or pure bad luck. 
First-hand experience can improve the information for some groups of passengers. About sixty percent of national passenger miles are by commutation passengers (FRA, 1997a). Regular commuters will board trains almost 500 times a year and hence can absorb considerable information that might indicate the amount of preventive effort undertaken by the railroad.

Of course, even a low level of preventive effort by a railroad will not mean that an accident occurs during every trip. A regular commuter will go many years, or even decades, before they are involved in an accident. (In the event that the commuter suffers a fatal injury, this new information may come too late to affect their travel-demand behavior!) Nevertheless, accident probabilities may be inferred from more readily observable attributes of service such as operating practices, minor operating problems, the condition of equipment, on-time performance, and the demeanor of employees.

Infrequent users of commuter railroads and most users of Amtrak will not have this wealth of experience. These passengers will therefore have to form some perception of the safety offered by railroads. Chapter 5 discussed how people form perceptions of risk. Spectacular derailments and collisions are low probability events which attract substantial press reporting. The primary and secondary biases identified by the risk psychologists will tend to make passengers believe that accidents occur more frequently than they really do. In other words, people assume that railroads are less safe than they really are. In terms of the models used in this chapter, $\alpha$ will be less than one. In equilibrium this will result in a non-Pareto optimum outcome where too little safety is produced by the railroad.

\section{SUMMARY}

In general, imperfect information is less of a problem for railroads than for other modes of transportation. Railroad commuters and shipping managers of large corporations are repeat and knowledgeable customers. This is in marked contrast to airlines, charter buses, and small trucking lines, where imperfect information on safety is common. These customers should have an accurate opinion of the average safety of railroads, and be able to distinguish between the safety offered by rival railroads or modes.

There are some groups of users who are less well informed. Examples are infrequent users of Amtrak, infrequent shippers, and customers of newly-formed railroads. Given the biases in the way in which people form opinions about risks, one would expect these users to believe that railroads are less safe than they really are. As a result, customers underestimate the preventive efforts made by railroads and the railroad will be motivated to provide less-than-optimal safety. Contrary to popular opinion, liability by the railroad to compensate customers for losses will not remove this market failure because liability payments are typically less than the disutility that customers associate with train accidents. 


\section{4 customer Rationality}

The benchmark models assume that fully-informed customers will make rational choices consistent with their desires and economic incentives. For freight transportation, it is reasonable to suppose that shipping managers will act in a rational way. They will compare the prices quoted by the various railroads and different modes of transportation, assess the probability that their goods will be lost or damaged in transit, and make an informed and calculating choice. They will be making decisions in a calm and dispassionate way because the consequences of accidents, to the shipper at least, are just financial in the form of property damage and disrupted production schedules.

For passenger transportation this may not be true. The high speeds and heavy machinery involved in rail transportation mean that there is a high probability that fatalities and serious injuries will occur in any accident. Given the unpleasant nature of the outcome, passengers may try to reduce their anxiety by assuming that an accident will occur to someone else. Psychologists have found plenty of evidence that most people consider themselves less likely than the average person to be affected by a hazard (Slovic et al., 1980). This opinion is reinforced because most trips are completed without any untoward personal experience due to the fact that accidents occur rarely (Slovic et al., 1978). In effect, familiarity breeds contempt for the possibility of risk.

The process by which people delude themselves by ignoring some facet of a good or service is known as cognitive dissonance (Akerlof and Dickens, 1982). A formal explanation for this psychological behavior is advanced by Calabresi (1970). He refers to it as the "Faust" attitude, and argues that people are myopic when it comes to choosing between a lower price now and increased probability of damage or injury later. He says "in such cases, people tend to choose the immediate good life only to regret it later." Oi (1973) explains the phenomenon as customers with a very high time preference in favor of current gain against future losses, yet who in retrospect regret their choices because their retrospective time preference is different.

There is no empirical literature that I am aware of that provides insights into the cognitive processes of railroad passengers, and whether Calabresi's Faust attitude makes them ignore or downplay safety concerns when deciding to travel.

Whether cognitive dissonance would be described as a "market failure" is a matter of semantics, given that the failure is in the minds of the passengers rather than in the information flow between railroads and customers. The failure comes 
from the difficulty that passengers have in identifying and acting on their own desires and preferences. It is possible, therefore, that intervention in the market may be justified to protect passengers from themselves rather than to protect them from imperfect information provision by railroads! 


\section{RALRoAD MYOPIA}

\section{THE THEORETICAL MARKET FAILURE}

The nature of the market for safety makes myopic behavior possible. The costs of preventive effort are borne in the present, whereas accident costs including liability to customers and bystanders occur at random times in the future.

An unscrupulous railroad may decide to improve short-run profits by reducing preventive efforts. It might do so if it is close to bankruptcy, and feels that it can escape accident cost in the future. It might also do so if it feels that customers will fail to recognize that an inferior product is now offered and will continue to pay a high price for the service. These railroads value the short-run profits more that the possible repercussions when customers recognize that they have been cheated and decide to shun the railroad.

Newly-formed railroads may provide too little preventive effort due to inexperience rather than avaricious intent. They might not be aware of the accident cost consequences of decisions they make on the amount of preventive effort.

\section{Unscrupulous Railroads}

There are two situations in which there are incentives for railroads to cheat in the short run. The first is when they are close to bankruptcy. Stockholders of an almost bankrupt railroad can reap the benefits of reduced prevention costs in short-run profit, but avoid the downside risk of accidents by declaring bankruptcy (Bulow and Shoven, 1978; Golbe, 1981, 1988). A railroad that reduces its preventive efforts today can reap the benefits of reduced costs for some time because a catastrophic accident may not happen immediately due to the random nature of when accidents occur.

The second situation is where even a financially-solvent railroad thinks it can deceive its customers. The customers will continue to pay the same price that they have always paid because they believe that quality of service has not changed. While revenues remain unchanged, the railroad gains from reduced prevention costs (Shapiro, 1982). Customers may ultimately become aware of the change in the railroad's reputation, and may then adjust their demands or lobby for a lower price given that quality has declined. However, by this point the railroad has already 
benefitted from the short-term boost in profits (Klein and Leffler, 1981). A railroad might be susceptible to use this short-sighted behavior if it wants to make a stock market offering more attractive, or if it wants to increase the value of the company in the eyes of a potential purchaser or lending institutions.

Both of these situations are predicated on imperfect information. If customers were perfectly informed they would quickly become aware of any changes in preventive effort and railroads would not be able to financially benefit from cheating. At the very least, cheating requires that previously well-informed customers can only update their knowledge of the reputation of individual railroads at discrete points in time.

\section{Inexperienced New Railroads}

Inexperienced railroads may not be familiar with the accident cost consequences of decisions they make concerning the level of preventive effort. It is difficult, even for safety professionals, to predict the frequency and magnitude of accidents. It is even more difficult to infer how levels of preventive effort ameliorate the frequency and severity of accidents. New railroads face considerable uncertainty about accident costs, yet are very well aware of the costs of prevention which they incur in the present. It is intuitive that a railroad that ignores or downplays future accident costs when deciding on the level of preventive effort will supply too little safety. This situation also presupposes imperfect information. Customers who recognize that an inferior service is being provided will signal their desires to the new railroad.

\section{EVIDENCE OF UNSCRUPULOUS BEHAVIOR}

From the perspective of a quarter of a century later, there is considerable evidence that some sectors of the railroad industry engaged in cheating in the 1960s. This was a period of very poor financial returns for the railroad industry, and bankruptcies particularly in the East and Midwest. Railroads deferred track maintenance, which eventually resulted in the well-documented increase in the number of derailments and employee injuries. This form of cheating is quite insidious in that it takes some time for the effects to become apparent to shippers. The ultimately recognition by shippers and government of this cheating, coupled with mounting public concern, was probably a major motivation for the passage of the Federal Railroad Safety Act of 1970.

Econometric support for these observations is presented by Golbe (1983). The study looked at the rate of derailments and collisions per gross ton-mile for ninety larger railroads over the period between 1963 and 1967, and related it to the financial condition of the railroad, measured as net income per gross ton-mile. Loss-making railroads had accident rates that were two-thirds higher than profitable railroads. 
Among the unprofitable roads, large losses were strongly related to a higher level of accidents.

The bankruptcy-leading-to-cheating model has been subject to some criticism in that many bankrupt firms are purchased by other firms. A run-down infrastructure or outstanding claims for compensation to accident victims will reduce the price at which assets can be sold. This should reduce the incentives to cheat. However, this does not seem to have constrained the behavior of the managers and shareholders of several railroads in the 1960s.

The improved financial health of the industry has reduced, but not eliminated, concerns about myopic behavior. In the mid-1990s the Union Pacific Railroad acquired the Chicago and North Western Railway and the Southern Pacific System. The railroad grew in size by eighty percent. In an effort to recoup some of the costs of acquisition, and to demonstrate to shareholders that the acquisitions had improved profitability, the railroad took several cost-saving actions. Some of these actions, such as a reduction in the number of dispatchers and supervisors, had safety implications. Fortunately, from a societal point of view, this attempt to cheat backfired because the reduction in preventive effort quickly led to a visible increase in service delays and accidents. Shippers and the government became aware of the change in quality, and demanded that the railroad take action to remedy the situation.

\section{INEXPERIENCED NEW RAILROADS}

The Staggers Act of 1980 which liberalized economic regulation of the industry also made it easier for large railroads to abandon operation of secondary and branch lines. While some lines were closed, many were sold to newly-formed companies. Many of these companies were non-union, and therefore could provide service at a lower cost primarily due to more liberal work rules.

Some of these companies were quite large. Substantial regional railroads, such as the Montana Rail Link and the Wisconsin Central Railway, were formed to operate secondary mainlines that were spun off by the major companies. However, most of the new companies were short-line railroads, formed to operate switching and branch lines. There is a popular misconception that these short-line railroads are all small $\mathrm{Ma}$ and $\mathrm{Pa}$ operations. While there are many examples of such family-run railroads, there has been an emergence of large holding companies that own many, geographically separated, short-lines railroads. Examples include RailTex, Rail Management and Consulting Corporation, OmniTRAX, and Kyle Railways.

The AAR (1997) estimates that there about 550 railroads in the United States. However, there are far fewer different corporate entities are involved in railroading. It is reasonable to suppose that a parent corporation will impose the same safety policies on all of its subsidiaries. Some small switching railroads are, and always have been, individually or jointly owned by the major railroads. Some of the newer 
short-line railroads are subsidiaries of other short-line railroads, or have been purchased by the aforementioned large holding companies.

I estimate that there are 319 different corporate entities offering freight service. These firms are classified in two ways in table 15.1. First by size, as measured by the number of carloads moved per year. Second, by type of railroad: public common-carrier railroads, railroads within port facilities, and shipper-owned railroads. The focus of this chapter is primarily on the public common-carrier railroads because railroads in the other two categories have typically been established for many years, and were not formed by the recent spinning off of branch lines.

Table 15.1: Freight Railroad Companies by Carloads per Year 1995

\begin{tabular}{|c|c|c|c|c|}
\hline & \multicolumn{3}{|c|}{ Number of Railroads } & \multirow{2}{*}{$\begin{array}{l}\text { Percentage } \\
\text { of Market }\end{array}$} \\
\hline & Public & Port & Shipper & \\
\hline 1 million + & 5 & & 1 & 80.86 \\
\hline 500,000-1 million & 2 & & 0 & 4.18 \\
\hline $100,000-499,000$ & 9 & & 3 & 6.90 \\
\hline $50,000-99,000$ & 10 & 1 & 3 & 2.50 \\
\hline $25,000-49,000$ & 20 & 1 & 6 & 2.46 \\
\hline $10,000-24,000$ & 32 & 0 & 9 & 1.72 \\
\hline $5,000-9,000$ & 24 & 4 & 5 & 0.62 \\
\hline $1,000-4,000$ & 71 & 6 & 18 & 0.65 \\
\hline less than 1,000 & 72 & 5 & 12 & 0.10 \\
\hline Total & 245 & 17 & 57 & \\
\hline
\end{tabular}

Data reflects subsequent mergers of large railroads. Switching lines that are owned, individually or jointly, by the major railroad companies are included in with their parent corporation(s).

Short-lines owned by a common holding company are shown as one "railroad." Commuter passenger railroads and Amtrak are not included.

Sources: AAR (1996c), Lewis (1995).

There are a substantial number of very small independent railroads. Ninety percent of the 245 common-carrier public railroads move less than 25,000 car loads a year. However, these railroads collectively represent only about $2 \frac{1}{2} 2$ percent of carloads moved nationwide, and an even lower proportion of industry ton-miles. Not only are many short-line railroads reasonably small, but many are reasonably inexperienced. Table 15.2 shows the dates of incorporation of the public common-carrier railroads. Over half of the railroads have been founded since 1985. The movement to spin off these lines continues unabated. The large eastern railroads continue to rationalize their networks, while the two large western railroads spin off lines subsequent to the recent mergers. 
Table 15.2: Distribution of Date of Incorporation

\begin{tabular}{|l|l|}
\hline \multicolumn{1}{|c|}{ Year } & Number \\
\hline Before 1970 & 61 \\
\hline $1970-1979$ & 21 \\
\hline $1980-1984$ & 34 \\
\hline $1985-1989$ & 71 \\
\hline $1990-1995$ & 58 \\
\hline
\end{tabular}

Source: Lewis (1995)

The safety record of the smaller railroads can be investigated using FRA data. Table 15.3 shows accident and fatality-rate data for the years 1994-96 for three different sizes of railroads: the large Class I railroads, the medium-size Class II railroads, and the small Class III railroads that are defined as having less than 400,000 employee-hours per year. In rough terms, Class III would be equivalent to those railroads shown in table 15.1 as moving less than 40,000 carloads a year.

Table 15.3: Accident Rates by Railroad Size 1994-1996

\begin{tabular}{|l|c|c|c|}
\hline \multicolumn{1}{|c|}{ Accident Measure } & Class I & Class II & Class III \\
\hline $\begin{array}{l}\text { Employee fatalities per billion } \\
\text { employee hours }\end{array}$ & 63.9 & 62.2 & 83.6 \\
\hline $\begin{array}{l}\text { Non-trespasser fatalities per million } \\
\text { train miles }\end{array}$ & 0.1 & 0.3 & 0.5 \\
\hline $\begin{array}{l}\text { Trespasser fatalities per million train } \\
\text { miles }\end{array}$ & 0.7 & 1.2 & 0.6 \\
\hline $\begin{array}{l}\text { Crossing user fatalities per million } \\
\text { train miles }\end{array}$ & 0.9 & 0.5 & 0.7 \\
\hline Collisions per million train miles & 0.3 & 0.8 & 0.7 \\
\hline Derailments per million train miles & 2.4 & 3.7 & 8.8 \\
\hline Source: FRA (1995a, 1996a, 1997a). & & & \\
\hline
\end{tabular}

By certain measures the accident record of the small railroads is good. Rates of trespasser and crossing-user fatalities per train mile are comparable with large railroads. Employee fatalities per employee-hour are thirty percent above those of larger railroads. However, these data are misleading in that half of the Class III employee fatalities occurred in a collision involving a train owned by one of the smaller commuter-railroad agencies at Silver Spring, Maryland in 1996. This agency is not representative of the characteristics of the short-line railroad industry.

The most notable difference is in the rate of collisions and derailments. The rate of collisions is similar to that of class II railroads, but twice that of the Class I railroads. Derailments occur almost four times as frequently as on Class I railroads and over twice as frequently as on Class II railroads. Of course part of the 
explanation is that the smaller railroads are engaged in switching operations, which is highly susceptible to collisions and derailments in comparison with line-haul operations. Another explanation is poor track condition, occasioned by years of low investment prior to the sale by the large railroads. Fortunately, the consequences are mitigated by low operating speeds.

So why don't small, inexperienced railroads have outrageously poor safety records? The first reason is that most of the managers and the workforce of the new railroads are not new to the industry. Most were victims of downsizing of the major railroads. New railroad companies looking to purchase branch lines from major railroads seek out experienced managers to satisfy the loan requirements of lending institutions. As the number of short-line railroads has grown, the amount and quality of training programs have improved. The American Short Line and Regional Railroad Association (ASLRRA), an industry association, runs seminars for its members on issues such as qualifications for locomotive engineers, drug and alcohol programs and track maintenance. Courses and seminars are also run by the large railroads and universities and colleges. The Burlington Northern Santa Fe Railroad runs training courses which are open to managers of small railroads. The University of Tennessee runs courses on track and bridge maintenance.

The second, and perhaps most important, reason is that short-line railroads are not in competition with the major railroads but are providing a complementary service. The major railroads rely on the short-line railroads to provide connections to and from shippers' premises. The major railroads have considerable incentives to ensure the competence of the companies to whom they sell their branch lines. There are direct financial incentives. Often when goods are damaged in transit, shippers often cannot identify when and where the damaged occurred. The cost of any Carmack Amendment claim is split between participating railroads on the basis of the mileage the car traveled on the various railroads. Consequently, a large share is borne by the major line-haul railroad.

The cooperative nature of railroading imposes another discipline on the short-line railroads. Cars have to be interchanged between short-line and major railroads. This interchange is governed by formal interchange rules agreements that are signed by both parties. The major railroads can claim restitution if their equipment is damaged while on a short-line railroad. In addition, the major railroads can withdraw from service and repair, at the short-line railroads expense, any poorly maintained cars owned by a short-line railroad. Short-line railroads have an incentive to avoid this happening because the major railroads have higher, union, rates for undertaking repairs as compared with the cost of undertaking the repairs in its own shops. In the extreme, major railroads can refuse to accept cars owned by short-line railroads with chronic maintenance problems, and threaten to cancel the interchange agreement. This would effectively remove the life blood of a small railroad.

The final reason is that many short-line railroads serve only a handful of shippers. These shippers will have personal contact with the railroad management, and can exert considerable influence to ensure that high-quality service is provided. They 
have leverage because each represents a high proportion of the railroad's business. Indeed shippers will have far more power to express their safety desires than in the former days when the branch line was run by a major railroad whose headquarters was many hundreds of miles away.

\section{SUMMARY}

Myopia is probably the most threatening and most likely type of market failure. Financially-distressed railroads have been tempted to skimp on safety in the past. This has primarily happened by the deferring of track maintenance, which is a particularly insidious form of cheating. It may take some years for a previously well-maintained right of way to deteriorate, and shippers have difficulties in monitoring any deferment of maintenance. Although the financial condition of the railroad industry is much healthier than in the 1960s, the concerns of myopia are still with us. The rapid expansion of the Union Pacific Railroad in the mid-1990s lead to safety problems as the railroad attempted to reduce costs and improve its short-run financial performance.

There are also genuine concerns that some small new railroads may be myopic due to inexperience. Albeit, that there is little empirical evidence that they pose a serious safety threat. Small railroads represent 3.2 percent of national train miles, and account for 3.8 percent of total railroad fatalities. While they do have higher rates of collisions and derailments, these are not translated into higher fatality rates. Low speeds of operation mitigate the consequences of many accidents. While some individual small railroads might give cause for concern, it is likely that the inexperience of new short-line railroads would be far down the priority list of railroad safety problems that need to be attended to. 


\section{6 externalities}

\section{THE THEORETICAL MARKET FAILURE}

The benchmark model requires the railroad to be legally liable to compensate bystanders for harm caused by railroad accidents. The market failure, when this does not occur can be easily shown. Absent compensation, the social-welfare maximizing monopolist will set the level of preventive effort using the rule:

$$
\mathrm{u}_{\mathrm{x}}\left(\mathrm{y}^{\#}, \mathrm{x}, \mathrm{r}^{\#}\right)=\mathrm{y}^{\#}\left[\mathrm{c}_{\mathrm{x}}(\mathrm{x})\right]
$$

The marginal cost of preventive effort is greater than in the benchmark model. This is because the railroad no longer bears the negative marginal cost of compensation to bystanders. This marginal function is negative because an increase in preventive efforts will reduce the number of accidents and hence the compensation payments to bystanders. Consequently, for a constant level of output, the railroad will undersupply preventive effort.

There will also be consequences for the quantity of output. The railroad will now set output using the decision rule:

$$
\mathrm{u}_{\mathrm{y}}\left(\mathrm{y}, \mathrm{x}^{\#}, \mathrm{r}^{\#}\right)=\mathrm{m}+\mathrm{g}\left(\mathrm{r}^{\#}\right)+\mathrm{c}\left(\mathrm{x}^{\#}\right)
$$

Compared with the benchmark model, the railroad will charge a lower price because it does not have to pay out compensation to bystanders. As a result, customers will purchase too much output. Bystanders therefore suffer double harm. Railroads provide less-safe service and bystanders have an increased exposure to the risk.

\section{THE LEGAL LIABILITY FOR EXTERNALITIES}

Injured bystanders can bring claims for damages against a railroad under state common laws of negligence. In order to claim compensation, the bystander has the burden of proof to show negligence on the part of the railroad. There is a departure from the normal negligence rule for "abnormal or ultrahazardous activities" (American Law Institute, 1965, Section 520). In these circumstances, defendants are strictly liable. It is unclear whether shipments of hazardous materials by rail fall 
into this category. On one hand the major piece of case law is based on the explosion of a gasoline road tanker (Siegler v. Kuhlman (81 Wash. 2d 448, 502 P.2d 1181, 1972)). On the other hand, the court in the case Indiana Harbor Belt Co. v. American Cyanamid Co. (916 F.2d 1174 (7th Cir. 1990)) ruled that "there was no reason ... for believing that a negligence regime is not perfectly adequate to remedy and deter at reasonable cost, the accidental spillage of acrylonitrile from railroad cars." Acrylonitrile is one of the nastier substances moved by rail. The AAR's Emergency Action Guide gives it a risk factor of four on a scale of one to four for health risks, and a three for flammability risk.

If railroads are subject to strict liability to bystanders then the benchmark model would apply. This optimal result will not necessarily occur under a regime of negligence. Courts will define due care as consistent with the social-welfare maximizing level of preventive effort $\left(x^{*}\right)$. If the railroad provides this level of preventive effort or a higher level it will not be liable to compensate third parties. If it provides less preventive effort it will be liable. Therefore, the decision rule on the level of preventive effort is:

$$
\begin{array}{cc}
\mathrm{u}_{\mathrm{x}}\left(\mathrm{y}^{\#}, \mathrm{x}, \mathrm{r}^{\#}\right)=\mathrm{y}^{\#}\left[\mathrm{c}_{\mathrm{x}}(\mathrm{x})\right] & \text { if } \mathrm{x} \geq \mathrm{x}^{*} \\
\mathrm{u}_{\mathrm{x}}\left(\mathrm{y}^{\#}, \mathrm{x}, \mathrm{r}^{\#}\right)=\mathrm{y}^{\#}\left[\mathrm{c}_{\mathrm{x}}(\mathrm{x})+\mathrm{e}_{\mathrm{x}}(\mathrm{x})\right] & \text { if } \mathrm{x}<\mathrm{x}^{*}
\end{array}
$$

Shavell (1987) shows that the cost-minimizing railroad will select $x^{*}$, the optimum level of preventive effort. The railroad will escape liability and will set output according to:

$$
\mathrm{u}_{\mathrm{y}}\left(\mathrm{y}, \mathrm{x}^{*}, \mathrm{r}^{*}\right)=\mathrm{m}+\mathrm{g}\left(\mathrm{r}^{*}\right)+\mathrm{c}\left(\mathrm{x}^{*}\right)
$$

As in equation (16.2), too much output will be produced because the railroad does not have to pass along the harm to bystanders in its pricing to customers. A market failure will result as bystanders will face increased exposure to possible harm.

However, I would advance the notion that in practice legal settlements with bystanders approximate strict liability. The standards of proof of negligence are probably quite low. Evidence that a train derailed and spilled cargo on your property is likely to be sufficient to prove negligence on the basis of the legal principle of res ipsa loquitur ("the facts speak for themselves"). Even if injured bystanders are required to show evidence of negligence, this should be relatively easy to obtain. Most railroad accidents are "caused" because someone had done something wrong: an employee has deviated from operating rules; a piece of equipment was not inspected properly; or a particular safety device had not been installed or was not working. 


\section{THE MAGNITUDE OF EXTERNALITIES}

How important is the harm to bystanders as compared with harm borne by the railroad, its customers and employees? An estimate of the annual social costs of collisions and derailments is made in table 16.1. The costs have been classified according to the party who suffers the harm: customers (passengers and freight shippers), the railroad, employees, trespassers and bystanders. Total social cost is in excess of $\$ 400$ million or about $\$ 200,000$ for each of the 2,100 collisions and derailments in 1996.

Table 16.1: Annual Cost of Collisions and Derailments

\begin{tabular}{|l|c|c|c|c|c|}
\hline & Fatalities $^{1}$ & Injuries $^{1}$ & $\begin{array}{c}\text { Property } \\
\text { Damage }\end{array}$ & Total & $\%$ \\
\hline Customers & 8 & 180 & $\$ 42 \mathrm{~m}^{2}$ & $\$ 108 \mathrm{~m}$ & $26 \%$ \\
\hline Railroad property & - & - & $\$ 173 \mathrm{~m}^{1}$ & $\$ 173 \mathrm{~m}$ & $42 \%$ \\
\hline Employees & 12 & 236 & - & $\$ 91 \mathrm{~m}$ & $22 \%$ \\
\hline Trespassers & 1 & 22 & - & $\$ 8 \mathrm{~m}$ & $2 \%$ \\
\hline Bystanders & 1 & 6 & $\$ 31 \mathrm{~m}^{3}$ & $\$ 35 \mathrm{~m}$ & $8 \%$ \\
\hline \multicolumn{7}{|l|}{} & & $\$ 415 \mathrm{~m}$ & - \\
\hline
\end{tabular}

Fatalities are valued at $\$ 3.15 \mathrm{~m}$ and injuries at $\$ 0.225 \mathrm{~m}$ (Miller et al., 1991). Not included are railroad administrative and managerial costs in dealing with the aftermath of an accident, the administration of tort claims, and the costs and possible lost revenue associated with the disruption of operations.

Sources: ${ }^{1}$ FRA (1997a and earlier editions); ${ }^{2}$ AAR (1996b); ${ }^{3}$ Dennis (1996) based on the consequences of major hazardous materials releases over the period 1982 to 1992.

The full cost of property damage to bystanders is not known. The only available data concern accidents involving hazardous materials. Dennis (1996) calculates that major releases of hazardous materials following collisions or derailments result in annual costs of \$11 million in environmental clean-up costs; \$18 million in legal settlements; and \$2 million in wreck clearance and payments to local fire departments and other emergency and disaster services who were in attendance. Releases of hazardous materials only occur in just over one percent of accidents. While accidents not involving the release of hazardous materials are more numerous, the consequences are much less severe. The derailment of a coal train may only require the payment of compensation to a farmer for damaged crops in a neighboring field. Most of the consequences of collisions and derailments which do not involve hazardous materials will be contained within the \$173 million damage to railroad property, which includes the cost of wreck clearance.

Dennis' estimate of \$31 million will underestimate the total property damage to bystanders, but it should not be a substantial underestimate. Based on these figures, the harm suffered by bystanders amounts to about eight percent of the social cost of collisions and derailments. 


\section{ARE ALL EXTERNALITIES INTERNALIZED?}

Most of the harm suffered by bystanders is transferred to the railroad. However, there are two circumstances where this might not happen. The first is where the usual rules of law invalidate compensation for certain victims or certain types of harm. The second is when the expenses incurred by emergency services are not recovered from the railroad.

Claims are only permissible if the bystander is both proximate to the accident site, and is also a foreseeable victim of the accident. Juries have to find an uninterrupted sequence of events from the railroad's actions to the bystander's harm. Major disputes occur when an intermediate event occurs between the initial negligent act by the railroad and the bystander. For example a railroad is probably not liable if a motorist collides with another motorist whilst visibility on a road is adversely affected by smoke from a burning railroad tank car.

Not all types of harm are recoverable. For many years, plaintiffs were unable to recover purely economic losses such as increased business expenses or lost revenue. However, there is a trend to allow such claims with the major case involving a railroad. In the case of People Express Airlines, Inc. v. Consolidated Rail Corp. (100 N.J. 246, 495 A.2d 107 (1985)), the court ruled that the airline was able to recover damages caused by an interruption of its business caused by the release of hazardous chemicals from a Conrail tank car. The court allowed the claim because it was felt that Conrail should have foreseen the harm that a chemical spill would have on businesses adjacent to the railroad. Despite the judgment in the above case, railroad lawyers have expressed the opinion that the majority of legal sentiment is still unfavorable to the recovery of economic losses.

That said, railroads are motivated to settle possible claims quickly to avoid costly law suits and adverse local publicity. Conversations I have had with railroad lawyers suggest that railroads will offer to pay for costs incurred by businesses such as clean up and damage to inventory. Railroads would probably not pay for profits foregone due to the interruption of business. Individuals will be offered compensation, based on their actual hourly wages, if they are unable to go to work due to evacuation of their homes or workplace. People displaced from their homes are usually offered compensation for actual out-of-pocket expenses, but not for any emotional costs they may incur.

Collisions and derailments, especially those involving hazardous materials usually require the attendance of emergency services. At the very least, ambulances and the fire department will attend. If an evacuation is necessary, police will be called to help in the evacuation and provide security for the affected area. Assistance of the state police or the National Guard may be necessary in major incidents. Local schools may have to be opened to provide temporary accommodations for those displaced, and the Red Cross may be called to provide bedding and food service for the residents and emergency workers.

There is no legal liability for railroads to compensate emergency services. Some fire departments do have schemes whereby industrial concerns contribute after 
a major incident, while other fire departments pride themselves that no charge is made for their services. Railroads often make payments in order to preserve their local image, and there is a trend for more local authorities to charge for attendance by emergency services.

\section{PRICING OF HAZARDOUS MATERIALS SHIPMENTS}

Shippers who have placed their goods in the hands of a common carrier are not legally responsible for any subsequent accidents, except in circumstances where they had taken inadequate precautions in packaging and loading their merchandise. However, shippers play a vital role in determining the risk to bystanders because they determine the quantity of transportation produced, and hence the number of accidents that occur.

Railroads carry many different commodities. Most are very benign and can be cleaned up quite easily, but others cause considerable damage and are difficult to clean up. Therefore in the benchmark model, the $\mathrm{e}(\mathrm{x})$ function will vary depending on the product transported. Indicating individual products by the superscript $\mathrm{k}$, the social-welfare maximizing monopoly railroad should set output on the basis of:

$$
\mathrm{u}_{\mathrm{y}}\left(\mathrm{y}, \mathrm{x}^{*}, \mathrm{r}^{*}\right)=\mathrm{m}+\mathrm{g}\left(\mathrm{r}^{*}\right)+\mathrm{c}\left(\mathrm{x}^{*}\right)+\mathrm{e}^{\mathrm{k}}\left(\mathrm{x}^{*}\right)
$$

The railroad should charge different prices depending on the externalities associated with that particular product.

When shipments are priced in this way, manufacturers can make sensible decisions on the quantities of hazardous materials to be shipped and the location of manufacturing plants relative to where the users of the hazardous material are located. If a particularly hazardous material is charged a high price for transportation, then the manufacturer may decide to locate its manufacturing facilities close to the ultimate users of the product.

Until the early 1990s most railroads did not have the information necessary to price in this way. There were a few exceptions. The Union Pacific Railroad had a crude system of risk-based pricing, and CSX Transportation had tried to enumerate the costs of cleanup and liability specific to particular commodities. But most railroads charged a standard price mark-up to reflect total accident costs incurred and the liability claims settled. Such a pricing scheme will result in the transportation of too much extremely-hazardous materials, and too little less-hazardous or non-hazardous materials.

A study commissioned by the railroads, and conducted by the AAR, in the early 1990s attempted to rectify this lack of information (Dennis, 1996). The study looked at major hazardous-materials releases in the previous ten years, and estimated the environment and liability costs associated with specific types of hazardous materials. The results of the study are shown in table 16.2. The figures represent 
the risk premium that should be charged on top of a pure transportation cost of $\$ 1,660$ for an 800 -mile movement of one car load for a variety of different products.

Table 16.2 Risk Premiums for a 800-Mile Carload Movement

\begin{tabular}{|l|l|c|}
\hline \multicolumn{1}{|c|}{ Sample Product } & \multicolumn{1}{|c|}{ Type of Hazard } & Risk Premium \\
\hline Gravel & None & $\$ 0.00$ \\
\hline Asphalt & Low environmental hazard & $\$ 1.36$ \\
\hline Sulfuric Acid & Medium environmental hazard & $\$ 5.52$ \\
\hline Chlorine & Poison inhalation hazard & $\$ 8.24$ \\
\hline Liquid Petroleum Gas & $\begin{array}{l}\text { Flammable or combustible \& low } \\
\text { environmental hazard }\end{array}$ & $\$ 10.64$ \\
\hline Fuel Oil & $\begin{array}{l}\text { Flammable or combustible \& } \\
\text { medium environmental hazard }\end{array}$ & $\$ 20.88$ \\
\hline Phosphorus & $\begin{array}{l}\text { Flammable or combustible \& high } \\
\text { environmental hazard }\end{array}$ & $\$ 87.04$ \\
\hline Chloroform & High environmental hazard & $\$ 226.00$ \\
\hline
\end{tabular}

Currently, the average risk-premium charged to all types of traffic is $\$ 1.31$. If pricing reflected the externalities caused, some products such as gravel would pay no risk premium. However, flammable or combustible products which have a low environmental hazard such as liquid petroleum gas would pay \$10.64. Chloroform, which poses a high environmental hazard, would pay a premium of $\$ 226$. In the latter case, the risk premium would add fourteen percent to the pure transportation cost.

Currently the eastern railroads have incorporated elements of the AAR study into their pricing. This should be encouraged. Otherwise the prices charged to hazardous materials shippers would be too low, and give the wrong signals when they decide where, and in what quantities, to manufacture and ship their goods.

\section{SUMMARY}

Bystanders can obtain compensation from railroads for most of the harm suffered as a result of railroad accidents through state common laws of negligence. In most cases, the standard of proof required is quite low. The mere fact that an accident occurred is usually sufficient to establish negligence. The law will therefore act in a similar fashion to strict liability, and hence removes any market failure.

There are some types of harm that cannot be legally recovered. Businesses have difficulty in recovering harm such as lost profitability. The public sector may not be fully compensated for emergency response. To the extent that there are such costs that are not internalized by the railroad, a market failure will result. However, the magnitude of these costs will be very small relative to the accident costs borne, 
directly or indirectly, by the railroad. Hence, any resulting market failure will be small.

A more serious problem is that railroads have had great difficulty in identifying the externality costs associated with the different types of products they carry. As a result, a uniform surcharge was often collected on all kinds of shipments to recover the costs incurred in clean up and settling claims from bystanders. Consequently, railroads carry too much extremely-hazardous materials, and too little low- or non-hazardous products. Recent work has identified that the cost of externalities varies markedly by the type of product shipped, with some products causing more than one hundred and fifty times more damage per carload than other products. Railroads are making moves to incorporate such information into their pricing, although people in the industry have suggested that full implementation is still far off. 


\section{NON-REGULATORY RESPONSES}

There are a variety of policy responses that might be deployed to ameliorate the five market failures. One of these responses, legal liability, has already been introduced. There are other responses that have yet to be described: anti-trust powers, information provision, insurance requirements and safety regulation. These responses are shown on the vertical axis of the matrix in Table 17.1. Along the horizontal axis are the five market failures. An " $\mathrm{X}$ " in a cell of the matrix indicates which market failures can be ameliorated with each policy response.

\section{Table 17.1: Matrix of Market Failures and Policy Responses}

\begin{tabular}{|c|c|c|c|c|c|c|}
\hline & $\begin{array}{l}\text { Market } \\
\text { Power }\end{array}$ & $\begin{array}{l}\text { Imperfect } \\
\text { Information }\end{array}$ & $\begin{array}{l}\text { Customer } \\
\text { Rationality }\end{array}$ & $\begin{array}{l}\text { Railroad } \\
\text { Myopia }\end{array}$ & $\begin{array}{c}\text { External } \\
\text { Harm }\end{array}$ \\
\hline \multicolumn{2}{|c|}{ Anti-Trust Powers } & $\mathrm{X}$ & & & & \\
\hline \multicolumn{2}{|c|}{ Liability } & & $\mathrm{X}$ & & & $\mathrm{X}$ \\
\hline \multirow{2}{*}{$\begin{array}{l}\text { Information } \\
\text { on Safety .. }\end{array}$} & Output & & $\mathrm{X}$ & & & \\
\hline & Inputs & & $\mathrm{X}$ & & $X$ & \\
\hline \multicolumn{2}{|l|}{$\begin{array}{l}\text { Insurance } \\
\text { Requirement }\end{array}$} & & & & $X$ & \\
\hline \multicolumn{2}{|c|}{ Safety Regulation } & & $\mathrm{X}$ & $\mathrm{X}$ & $X$ & $\mathrm{X}$ \\
\hline
\end{tabular}

As can be seen, more than one response may be appropriate for dealing with each failure, and some responses may act to ameliorate several failures. In particular, safety regulation can be an appropriate response to most market failures. For those market failures where more than one response could be deployed, the various responses should be regarded as complementary in nature rather than direct substitutes. This is because all of the responses have their own drawbacks and may not totally ameliorate the market failure.

The next four chapters discuss the various policy responses in some detail. The advantages and disadvantages of the various responses will be discussed and recommendations will be made on how they might be improved. This initial chapter will deal with the non-regulatory responses. The following three chapters 
will describe, evaluate and suggest improvements to the extensive safety regulations that government has placed on the railroads.

\section{ANTI-TRUST POWERS}

Market power by railroads can result in pricing above cost, restriction of output and a loss of consumer surplus. The level(s) of preventive effort may not be optimal, although it is unclear whether higher or lower levels of safety will result. Not surprisingly, the motivation for the deployment of anti-trust powers has usually come from dissatisfaction with the level of output rather than from safety concerns.

The railroads are no strangers to anti-trust considerations. The Surface Transportation Board retains the rights, inherited from the ICC, to review all railroad merger proposals. Proposed mergers have been refused in the past. When mergers of competing railroads have been allowed, the government can impose conditions such as granting of track-access rights for other company's trains over the lines of the merged railroad. The government also retains the right to impose price controls on rates charged for commodities that are captive to the railroads.

The safety analyst can rightly feel somewhat "out of the loop" in these issues. Non-optimal levels of preventive effort are not the motivating force for initiation of anti-trust powers. The safety analyst cannot even say whether a more competitive atmosphere will result in more than or less than optimal safety.

\section{LIABILITY}

Legal liability has already been discussed in some detail in the chapters dealing the market failures due to imperfect information and externalities. In the chapter on imperfect information, it was shown that liability will be insufficient to completely remove the market failure for passengers. This is because passengers will be risk averse. This is not to say that liability is bad and should not be deployed. Liability is a mechanism for spreading risk, and will reduce but not eliminate the market failure. The issue is less relevant for freight shippers, as they tend to be better informed than passengers.

In contrast, liability is an effective response to the market failure due to externalities. There are some limitations. Injured third parties cannot always obtain compensation for purely economic losses such as reduced profits from disruption to their businesses. It is also unclear whether railroads fully compensate public agencies for costs incurred in emergency response, relief efforts and clean-up services. However, it would generally appear that the railroads do bear most of the costs for externalities that they cause.

For all of the benefits that it confers, there are some disadvantages of liability. The first are the costs of litigation. In an earlier chapter it was shown that the adversarial FELA method of compensating injured employees has far high 
transaction costs that the no-fault workers' compensation applicable to other industries. Of course, the strict liability nature of the Carmack Amendment does reduce the transaction cost of settling freight loss and damage claims considerably. Most claims are settled quickly, and only in rare circumstances are they referred to an arbitrator, and they almost never end up in the courts. Railroads are also motivated to settle claims with bystanders and injured passengers quickly before litigation is necessary. The incontrovertible fact that an accident had occurred, and that in most cases the passenger or bystander had not been contributorily negligent, reduces the possibility of courtroom conflict.

Railroads complain that introduction of courts and juries can lead to liability awards that are too great. Generally the issue concerns awards made for non-pecuniary losses, such as pain and suffering, or when punitive damages are awarded in excess of compensatory damages. The latter type of award can only be made when a railroad was found by the court to have engaged in "willful or wanton conduct." Railroads can appeal awards that they feel are excessive to appellate courts. Excessive damage awards should motivate railroads to undertake too much preventive effort.

\section{INFORMATION ON SAFETY OUTPUTS}

An obvious response to the problem of uninformed customers making incorrect decisions is to mount a public-information campaign. In general, all the public needs to know are historical data on the accident performance, or safety output, of individual railroads. Much of this information is already available. The FRA's Accident / Incident Bulletin for a calendar year is available with a delay of about nine months. Midyear data are available with a delay of a couple of month. The information is available in hardcopy and on the FRA's World Wide Web site. An interested customer can quite quickly obtain information on the rate of collisions and derailments for the largest Class I and II railroads, and can observe recent trends in these rates for individual railroads.

For freight shippers using the largest railroads, a copy of the AAR's Freight Loss and Damage Report would provide almost every conceivable piece of information they would need. It is published with a delay of about four months after the end of the calendar year. The major drawback of this source of information is its limited circulation. It is received by about 500 people and these people are within the railroad industry. Shippers are not on the circulation list, although they are not deliberately excluded.

In the current information era, the costs of disseminating this information have considerably reduced. One would imagine that inventive use of the Internet could be used by both the FRA and AAR to disseminate its accident data in an informative and user-friendly way. A lesson could be learned from the Federal Aviation Administration which has attempted to disseminate aviation safety data to a wide audience on the Internet since 1997. 


\section{INFORMATION ON SAFETY INPUTS}

Both the FRA and AAR data are not very useful to customers of small railroads. Of course, the best source of information for these customers would probably be from speaking to neighboring businesses. The FRA data does not show specific data for individual Class III railroads, and the AAR data are confined to the largest railroads. Even if the data were available, they would have to be treated with some caution due to the usual problems associated with the random nature of accident occurrence. An average-size Class III railroad can expect to have one reportable derailment every 18 months and a reportable collision every fifteen years. A small railroad will therefore have no accidents in most years, yet in the year it does have an accident the resulting accident rate will be exceptionally large.

An alternative for customers of small railroads is information on safety inputs. Examples might be the average experience of the staff, the age and condition of equipment, and the level of safety-related expenditures. Information of this type will be especially useful in ameliorating the market failure due to myopia. Myopic railroads will tend to be inexperienced firms who do not have a long safety output track record to report on, or unscrupulous railroads who are cheating by deviating from their past safety performance.

Currently, this type of information is not collected and disseminated. The traditional objection has been that it is unclear which, if any, measures of safety inputs provide readily-interpretable information to customers. This is in contrast to information on safety outputs where it is quite straightforward to specify the data that should be collected, and customers can readily interpret their meaning: a higher accident rate is worse than a lower accident rate.

In general, physical measures of inputs would be more useful than financial measures. As input prices and efficiency vary between railroads, comparison of safety-related expenditures may be misleading. Higher levels of expenditures may not signify a greater level of preventive effort. Higher expenditures on maintenance may, perversely, imply that older and less-reliable equipment is in use.

Meaningful provision of safety-input data does require that users of the information have the skill and knowledge to relate input measures to the expected effect on safety outputs. This is a task which is difficult even for professionals in the safety field. Are older locomotives more of a safety risk than newer locomotives? At what point does age become critical?

However, such difficulties should not discourage a wider dissemination of safety input data. One should remember that the major role of providing information on safety inputs is to alert customers to possible myopic behavior. Customers are therefore not really trying to compare one railroad with another railroad, but rather trying to observe how the preventive efforts of a specific railroad are changing over time. Has this railroad reduced its track maintenance expenditures? Has it stopped purchasing new rolling stock? Such time-series comparisons can be quite easy for customers to make and to interpret, and permit some insights into the safety management practices of a railroad. 
The FRA can facilitate such a market disciplining of myopic railroads by collecting, analyzing and publicizing information on safety inputs. The first step would be to consult with the ultimate users of the information to identify which measures of safety inputs would be most useful. Railroads would then have to provide the required information to the FRA on a regular basis. The FRA would need to have powers to verify the information because unscrupulous myopic railroads will cover up the cheating by falsifying reports on their safety inputs. The data would then need to be tabulated and given wide dissemination. Ideally, the FRA would also perform statistical calculations to determine if there are any statistically significant deviations from historical data for each individual firm, and highlight any such deviations in its publications.

The recommended FRA action described in the preceding paragraph will be complementary to actions that the FRA takes to enforce safety regulations. By making safety-input data available, the FRA is strengthening its enforcement role by enlisting the support of railroad customers. A railroad that is discovered to be cheating will also be disciplined by its customers who may turn to other transportation alternatives or demanding lower prices commensurate with the lower quality of service on offer.

\section{HOLDING OF INSURANCE BY UNSCRUPULOUS RAILROADS}

A possible consequence of unscrupulous myopic behavior is that railroads may use the cover of bankruptcy protection to avoid paying compensation to injured employees, customers and bystanders. A possible solution to this problem is to ensure that railroads have enough assets to provide for such payment or hold liability insurance. Insurance companies pool risk across various railroads and the other kinds of risks that they insure against, and therefore can pay out even if one of their clients is forced in bankruptcy.

In practice, this may not be a major concern in the railroad industry. Typical accident claims are small compared with the assets of large railroads. Consequently, large railroads do not hold insurance against most accident risks. They do hold catastrophe insurance, but the deductibles are typically in the range of \$5 million to \$25 million. To put these numbers in context, one of the most serious accidents in recent years, the derailment of liquid petroleum gas tank cars at Weyauwga, Wisconsin in March 1996, resulted in compensation settlements of "only" \$26 million.

\section{HOLDING OF INSURANCE BY INEXPERIENCED RAILROADS}

The main benefit of insurance is that by charging premiums to cover future losses, insurance companies make new railroads aware of future accident costs. Railroads can then decide on appropriate levels of safety by trading off between the insurance 
premiums they might be charged and the levels of preventive effort they undertake. Of course, such an optimal trade-off requires that insurance companies have enough information to set premiums appropriate to the preventive efforts undertaken by individual railroads.

While there is no legal requirement that railroads hold insurance, most small railroads do so. The primary reason is that it is a requirement of financial institutions that lend them money. ASLRRA reports that most small railroads carry insurance against damage to their own equipment and against third-party liability claims. Typically policies also provide coverage against employee-injury claims under FELA. Railroads may elect to take coverage against loss and damage to freight, although not all do as such claims tend to be small, routine and predictable.

A GAO (1996) survey that was primarily concerned with FELA settlements found that eighty-eight percent of small railroads had taken out insurance packages that included protection against FELA claims. A small proportion of railroads self-insure against FELA claims because these claims, like freight loss and damage, are generally small and predictable. Indeed, the GAO's survey found that ninety percent of FELA claims were small enough that they were less than the standard deductible on most insurance policies. It is likely that even the railroads that decline FELA coverage will hold insurance on their own equipment and against third-party claims.

In the early-days of the spinning off of secondary and branch lines to small railroad companies, it was quite difficult for a short-line railroad to obtain insurance. The GAO (1996) reports that there was only one company writing such policies in the late-1980s, and was doing so at premiums they were double what they are today. As a result, ASLRRA even considered setting up its own insurance company. In contrast, insurance is now available and affordable. By 1995 there were eight companies offering insurance. A typical policy for a small railroad provides \$5 million in coverage with a $\$ 50,000$ deductible for an annual premium of about $\$ 50,000$.

It would be incorrect to claim that the almost universal holding of insurance totally ameliorates the market failure due to inexperienced new railroads. Insurance companies do not and cannot perfectly observe the amount of preventive effort undertaken by individual railroads. Consequently, they may have to charge standard premiums to a whole range of railroads. If they do so there will be no incentive for any railroad to undertake a higher-than-average level of preventive effort.

ASLRRA reports that there are general industry-wide premium rates that apply to railroads who are first-time customers of an insurance company. However, railroads can then try to negotiate a lower premium based on their experience of claims, and the safety management practices that they have put in place. Insurance companies employ their own assessors to validate such arguments. This process of setting individual premiums is aided by the practice that railroads tend to purchase their own insurance and do not seek group purchase in cooperation with other railroads (GAO, 1996). 
The general feeling is that insurance companies should be even more discriminating in the setting of premiums. This would encourage railroads that put in place good safety management practice, and penalize those who do not. One might argue that the insurance companies have avoided fulfilling this role because of the extensive direct safety regulation by the FRA. Insurance companies can free ride on the enforcement activities of the FRA in the identification of railroads that are bad risks. In a world without direct regulation, it is likely that insurance companies will have to use their own staff to assess risks prior to writing policies. To do so, insurance companies would have to set down the criteria for setting premiums, and establish forms of surveillance to ensure that railroads do not shirk in their preventive efforts.

There is one drawback to the holding of insurance. Insurance dulls the incentives for safe operation. Payments to injured parties are made indirectly through the insurance company rather than directly by the railroad. The distancing of the actual payout from the persons making decisions on preventive effort may lead to less care being taken than would occur otherwise. The holding of insurance may have the perverse effect of increasing the possibility of myopic behavior rather than reducing it. In the insurance literature this is referred to as moral hazard (Shavell, 1979).

\section{THE NEED FOR SAFETY REGULATION}

There would appear to be three main reasons for wanting to have direct safety regulation as part of the armory of policy responses. The first concerns customer irrationality. This will primarily affect passenger transportation, because it is likely that freight shippers will make decisions in a calculating rational way. Passengers may ignore the safety aspects of service simply to reduce their anxiety about unpleasant events. Consequently, railroads may be motivated to provide too little safety. The only possible response to this market failure is for the government to second-guess what the preferences of passengers should be, and impose safety regulations to achieve the preferred level of safety. This is obviously a very paternalistic reason for regulating safety, and one that is dependent on strong evidence that passengers cannot and do not make sensible choices by themselves.

The other two reasons for direct safety regulation are less speculative. There is reason to believe that insurance companies are neither motivated, nor able, to monitor the preventive efforts of inexperienced firms. Hence premiums are not tailored to the preventive efforts taken. Inexperienced railroads will therefore not be motivated to make the correct trade-off between preventive efforts and future accident costs. There may be a role for government intervention to specify minimum acceptable safety standards so that inexperienced railroads do not act myopically.

The final reason for possible direct safety regulation is the prevention of cheating by unscrupulous railroads. The government might have to be involved if it is felt 
that customers are unable to quickly detect cheating. Even previously well-informed customers may not immediately recognize that a lower quality service is offered, especially if the cheating takes the form of deterred maintenance of track or other capital equipment.

The theoretical literature has recognized that drawbacks to legal, insurance and informational policy responses make it desirable to simultaneously deploy governmental safety regulation (Hansson and Skogh, 1987; Kolstad, Ulen and Johnson, 1990; Shavell, 1984a,b). The best way to respond to market failures will be a mix of the different responses. Hence, the reality of railroad safety control is a combination of exposure of railroads to liability torts from customers, employees and bystanders; the holding of insurance by smaller railroads to cover all or part of such claims; extensive data on accidents which is not widely disseminated; and considerable direct safety regulation by the government.

The next three chapters investigate the effectiveness of current safety regulations. Three questions will be asked. What are the current safety regulations? How effective are they? And, can the regulatory system be improved? 


\section{8 federal safety REGULATIONS}

This chapter provides a summary of the federal safety regulations. The interested reader is also directed to appendix A which provides more detail. To facilitate the discussion, the regulations are divided into five general categories: those supportive of other policy responses to safety regulation, those that deal with minimizing externalities, those that are necessary to deal with civil liberties issues, those that contain specifications for equipment design or operating practices, and those that deal with monitoring and enforcement. A matrix showing a division of the current regulations into the five categories is shown in table 18.1. In parentheses after the name of each area of regulation is its relevant part number within Title 49 of the United States Code of Federal Regulations (CFR).

\section{REGULATIONS SUPPORTIVE OF OTHER POLICY RESPONSES}

Prior to 1970 most governmental actions were supportive of informational or liability responses to market failure. The Carmack Amendment of 1906 made railroad strictly liable for loss and damage to freight. The Federal Employers' Liability Act of 1908 established liability for occupational injuries. The Accident Reports Act of 1910 required railroads to provide information on accidents. The same act allowed the ICC to investigate railroad accidents. These powers were transferred to the NTSB in 1974. Signal failures have had to be reported to the government since the Signal Inspection Act of 1920.

\section{REGULATIONS DEALING WITH EXTERNALITIES}

Regulations concerning externalities have a long history. Controls on the transportation of explosives date back to the civil war. Until the 1960s, and to some extent continuing to the present day, the detailed implementation of rules concerning hazardous materials has been delegated to the railroads. The AAR Bureau on Explosives set standards for carriage of hazardous materials for most of the twentieth century, and even today the AAR Committee on Tank Cars has delegated responsibility under 49 CFR 179 for the specification of tank cars. 


\begin{tabular}{|c|c|}
\hline $\begin{array}{l}\text { Supportive of } \\
\text { other policy } \\
\text { responses }\end{array}$ & $\begin{array}{l}\text { Carmack Amendment } \\
\text { Federal Employers' Liability Act } \\
\text { Accident reporting (49 CFR 225) } \\
\text { Signal failure reporting (49 CFR 233) } \\
\text { NTSB investigations (49 CFR 840) }\end{array}$ \\
\hline $\begin{array}{l}\text { Minimizing } \\
\text { externalities }\end{array}$ & $\begin{array}{l}\text { Carriage of hazardous materials (49 CFR 174) } \\
\text { Hazardous materials packaging ( } 49 \text { CFR } 178 \text { \& 180) } \\
\text { Tank car specifications ( } 49 \text { CFR 179) }\end{array}$ \\
\hline Civil liberties & Drug \& alcohol testing (49 CFR 40 \& 219) \\
\hline \multirow[t]{2}{*}{$\begin{array}{l}\text { Specification } \\
\text { standards }\end{array}$} & $\begin{array}{l}\text { Equipment Design } \\
\text { Track standards (49 CFR 213) } \\
\text { Freight car standards (49 CFR 215) } \\
\text { Rear-end marking devices (49 CFR 221) } \\
\text { Glazing standards (49 CFR 223) } \\
\text { Locomotive safety standards (49 CFR 229) } \\
\text { Safety appliance standards (49 CFR 231) } \\
\text { Power brakes \& drawbars (49 CFR 232) } \\
\text { Grade crossing systems (49 CFR 234) } \\
\text { Installation \& repair of signals (49 CFR } 235 \text { \& 236) }\end{array}$ \\
\hline & $\begin{array}{l}\text { Operating Practices } \\
\text { Workplace safety (49 CFR 214) } \\
\text { Operating rules required (49 CFR 217) } \\
\text { Operating practices (49 CFR 218) } \\
\text { Radio procedures (49 CFR 220) } \\
\text { Hours of service (49 CFR 228) } \\
\text { Certification of locomotive engineers (49 CFR 240) }\end{array}$ \\
\hline $\begin{array}{l}\text { Monitoring and } \\
\text { enforcement }\end{array}$ & $\begin{array}{l}\text { Enforcement procedures (49 CFR } 209 \text { \& 212) } \\
\text { Special Notices \& Emergency Orders (49 CFR 216) } \\
\text { User fees (49 CFR 245) }\end{array}$ \\
\hline
\end{tabular}

The delegation of rulemaking powers to the industry being regulated is not without its problems. NTSB reports $(1978 b, 1981)$ that followed a series of serious accidents in 1978 were very critical of the railroads, saying that they had tried to obstruct the introduction of safety devices on tank cars, and had designed some tank cars without regard to public safety. There are two basic safety design considerations in a tank car. The first is to avoid punctures to the tank, and the second is to insulate the tank so that in the event of an external fire the contents will not heat up and explode. Punctures were primarily caused by the couplers of neighboring cars following a derailment or collision. Effective preventive measures include the use of "shelf" couplers, and the installation of protective steel "head shields" on the end of tank cars to protect the tank. Despite the proven technology, 
the railroads had fought the installation of head shields in the courts. The 1978 NTSB report observed that while the AAR was favorable to shelf couplers, it lacked the necessary power over its members to require their installation.

Regulations on the packaging of hazardous materials are widely regarded as one of the more progressive parts of the federal regulations with an emphasis of regulating how the packaging performs rather than giving detailed engineering specifications of how to construct the packaging. This permits the use of innovative materials and construction techniques. A possible reason why these regulations differ from the design bias of other regulations is that packaging of hazardous materials is increasing determined by international regulations and treaties.

Other regulations place requirements on shippers to properly identify the goods that they are shipping, to provide placarding showing the contents of cars, and to provide contact phone numbers and information materials for firefighters who are called to the scene of an accident. These rules are particularly important in that shippers whose goods are in packages or road trailers may have incentives to disguise the true nature of their product so as to obtain a lower price from the railroad. Shippers also have little economic motivation to cooperate with railroads given that the railroad and not the shipper is legally responsible for any externalities caused to third parties while in transit.

\section{REGULATIONS DEALING WITH CIVIL LIBERTIES}

The consumption of drugs and alcohol by employees prior to commencing duty can have serious safety consequences. Federal law prohibits railroad employees from taking drugs and specifies a maximum blood-alcohol content which is much lower than that for legally driving an automobile. Since 1989, railroads have had the right to test employees as part of pre-employment screening, on a random basis, with cause, and after accidents. Federal regulations are vital in this area. Otherwise railroads would be vulnerable to charges that they were interfering with civil liberties by specifying the off-duty conduct of employees, and infringing constitutional rights by conducting drug tests.

\section{SPECIFICATION STANDARDS FOR EQUIPMENT DESIGN}

Some of the design specifications are long standing. The safety-appliance regulations date from 1893 and the signaling regulations from 1920. However, most specification standards have been introduced since 1970. In chronological order these more recent specification standards concern: track (1971), freight cars (1974), rear-end marking devices (1976), radio standards (1977), glazing (1979), locomotives (1980), grade crossings (1988), and certification of locomotive engineers (1988). Some of the regulations are quite general but most are quite 
specific, and describe in great detail how equipment should be designed and maintained.

There are only two exceptions where the written standards are expressed in terms of performance rather than design. The first are the signaling regulations which are quite general and mainly specify where different types of signals should be used rather than giving detailed engineering specifications of the design of systems. Block signaling is required on lines which passenger trains move at more than sixty miles per hour or freight trains move at more than fifty miles per hour. Automatic train control is required on track where trains operate at more than eighty miles per hour. While there is currently a debate about how to deal with new technology such as the use of satellite positioning systems for locating trains, the general impression is that the signaling regulations are somewhat more flexible than other aspects of the federal regulations.

The second exception is the glazing standard adopted in 1979. Following a problem with bullets and other projectile being thrown at trains, a joint labor-management-government committee was formed to specify the impact standards for glazing applied to locomotives, cabooses and passenger cars windows. The regulations specify the impact-resistant performance that glazing should have, but does not specify materials.

In contrast the safety appliance and drawbar regulations are very detailed. Cars and locomotives are required to have steps, ladders, running boards, and handholds in specific locations. To illustrate the level of detail given, here are the requirements for the dimension and location of steps:

\section{(d) Sill steps -}

(1) Number. Four (4).

(2) Dimensions. Minimum cross sectional area one-half ( $1 / 2)$ by one and one-half (11/2) inches, or equivalent, of wrought iron, steel or other material of equivalent strength. Minimum length of tread, ten (10), preferably twelve (12), inches. Minimum clear depth, eight (8) inches.

(3) Location.

(i) One (1) near each end of the car, so that there shall be not more than eighteen (18) inches from end of car to center of tread of sill step.

(ii) Outside edge of tread of step shall be not more than four (4) inches inside of face of side of car, preferably flush with side of car.

(iii) Tread shall be not more than twenty-four, preferably not more than twenty-two (22), inches above the top of the rail. (49 CFR 231.27(d))

The regulations also require that semi-automatic drawbars are installed at a standard height. This reduces the need for employees to go between cars during coupling and uncoupling operations. There are regulations that require marking devices to signify the end of a train. Specifications are given for the design of such devices, and the federal regulations even contain a list of approved manufacturers. 
Handbrakes must be fitted that can be operated from specific locations on the car. Handbrake design is specified down to the smallest detail:

(2) Dimensions.

(i) The brake wheel may be deep or shallow, of malleable iron, wrought iron, steel or other materials of equivalent strength.

(ii) Overall diameter of brake wheel nominally twenty-two (22) inches.

(iii) Depth of brake wheel shall be two and five-eights (2-5/8) inches with square taper shaft fit, taper two (2) inches in twelve (12) inches with the small end of taper fit seven-eighths (7/8) inches.

(iv) Brake wheel and drum shall be arranged so that both will revolve when applying or gradually releasing the handbrake. Handbrake shall be provided with means to prevent application of the rake by winding in a counterclockwise direction.

(v) Brake shaft shall be arranged with a square fit at its outer end to secure the handbrake wheel; said square fit shall not be less than seven-eighths (7/8) of an inch square. Square fit taper: Nominally two (2) in twelve (12) inches (see Plate A).

(vi) All chains shall not be less than nine-sixteenths (9/16) inch BBB coil chain.

(vii) All brake rods shall be not less than three-fourths (3/4) inch diameter.

(49 CFR 231.27(a)(2))

More recently the federal regulations have contained regulations defining defects on cars and inspections for defects. The regulations define defects in wheels, axles, bearings, trucks, bodywork, couplers and cushioning systems. Up until the early 1970s, the industry had self-regulated using its interchange rules. These rules give railroads the right to refuse to accept cars that are in poor condition, and allowed for the repair of these cars at a set schedule of fees that are then billed to the owning railroad. By necessity, these regulations had to specify the circumstances in which a car can be refused and/or withdrawn from service for repairs. The Federal Railroad Safety Act of 1970 motivated the FRA to take the interchange rules that were current in 1974/75 and write those parts dealing with safety into the federal regulations. For example, the law specifies that railroads must withdraw from service cars whose wheels have the following defects: 
(a) A wheel flange on the car is worn to a thickness of $7 / 8$ of an inch, or less, at a point 3/8 of an inch above the tread of the wheel;

(b) The height of a wheel flange on the car, from the tread to the top of the flange, is $1 \frac{1}{2}$ inches, or more;

(c) The thickness of the rim of a wheel on the car is 11/16 of an inch, or less;

(d) A wheel rim, flange, plate, or hub area on the car has a crack or break;

(e) A wheel on the car has a chip or gouge in the flange that is $1 \frac{1}{2}$ inches in length or $1 / 2$ inch in width, or more;

(f) A wheel on the car has -

(1) A slid flat or shell spot that is more than $2 \frac{1}{2}$ inches in length; or

(2) Two adjoining flat or shelled spots each of which is more than two inches in length;

(g) A wheel on a car shows evidence of being loose such as oil seepage on the back hub or back plate;

(h) A wheel on the car shows signs of having been overheated as evidenced by a reddish brown discoloration, to a substantially equal extent on both the front and back face of the rim, that extends on either face more than four inches into the plate area measured from the inner edge of the front or back face of the rim; or,

(i) A wheel on the car has been welded unless the car is being moved for repair in accordance with section 215.9 of this part.

(49 CFR 215.103)

Federal regulations had long dealt with the problems of steam locomotive boilers. However the requirements for diesel and electric locomotives are more recent and are very detailed. The regulations require the fitting of fuel cut offs, slip/slide alarms, speed indicators, snowplows, headlights and other lights (strobes, ditch lights), and from 1995 event recorders on locomotives of trains that exceed thirty miles per hour. The regulations set design requirements for cab noise limits, and specify reinforcement of cabs and the provision of anti-climb devices to avoid locomotives riding up over each other and crushing the train crew. Safety rules are defined for electrical collectors and steam generators. Specific definitions are given for deciding if brake systems, couplers, suspension, wheels or tires are defective. Inspection cycles are defined for specific components. Many components have to be inspected every ninety-two days.

Requirements for fitting of continuous air brakes on cars and locomotives date back to the 1890s. The federal regulations not only require that at least eighty-five percent of cars in any trains must have their air brakes in use, but also specify piston travel in the brake cylinder, brake pressure, and where and when brakes must be inspected. Federal regulation of brake inspection dates from 1958 when the existing AAR rules were adopted in an amendment to the Safety Appliance Act. Train brakes have to be examined before a train leaves its initial terminal, when there is a change in the consist of the train, and at intermediate points en route. For many years, intermediate inspections were required every 500 miles. This distance was 
relaxed to 1,000 miles in 1982, although there is an active debate concerning reimposition of the 500 -mile limit.

Prior to 1970, the industry had managed to survive for more than 130 years without the need for any standards for track. The first order of business for the FRA under the 1970 Act was to establish such standards. The regulations specify six different levels of track construction and prescribed maximum speeds for each class. These maximum speeds are shown in table 18.2. In 1982, an exemption to these regulations was introduced for track not used for passengers and with limited amounts of hazardous materials providing the speed is less than ten miles per hour. The definition of track class is based on engineering specifications of gauge, alignment, elevation, the number of crossties, and the mismatch of railends. For example, Class 6 track requires at least fourteen crossties per thirty-nine-foot segment of track, Class 4 and 5 needs a least twelve, Class 2 and 3 needs eight, and Class 1 only five. There are also specified design criterions for frogs and switches. Maximum speeds for curves are specified based on curvature and elevation. The regulations also specify how frequently track should be inspected, and sets minimum experience that track inspectors should have.

\section{Table 18.2: Track Classification}

\begin{tabular}{|c|c|c|}
\hline \multirow{2}{*}{ Track Class } & \multicolumn{2}{|c|}{ Maximum Speed (mph) } \\
\cline { 2 - 3 } & Freight & Passenger \\
\hline Exempt & 10 & - \\
\hline 1 & 10 & 15 \\
\hline 2 & 25 & 30 \\
\hline 3 & 40 & 60 \\
\hline 4 & 60 & 80 \\
\hline 5 & 80 & 90 \\
\hline 6 & 110 & 110 \\
\hline
\end{tabular}

Federal regulations lay down some engineering guidelines for highway grade crossings. The regulations specify how quickly lights and barriers have to be activated on the approach of a train, and also require that the equipment be inspected. As discussed in an earlier chapter, federal regulations do not deal with the types of warning devices that are required at specific crossings. However, there are federal manuals (DOT, 1986; FHWA, 1986, 1988) that can assist engineers in deciding on priorities for installing active warning devices, and in designing an appropriate system for an individual crossing. 


\section{SPECIFICATION STANDARDS FOR OPERATING PRACTICES}

There is a very general requirement that railroads must have a written set of operating rules, and that records must be kept that employees have been tested on their knowledge of the rules. The larger railroads must file a copy with the FRA, while the smaller railroads are only required to have a copy available at their main offices. The operating rules of many railroads are based on the AAR's recommended Uniform Code of Railroad Operating Rules which has its origins in 1887. These recommended rules have not been written into federal law.

More specific regulations deal with the hours that operating employees can work. These rules have existed since 1907 . Operating employees can only work twelve hours in twenty-four, must take at least ten hours rest after twelve hours of duty, and must rest for at least eight hours in twenty-four. The law also specifies records and recordkeeping requirements that railroads must keep substantiating compliance with the law.

Three new regulations dealing with the operating practices have been introduced since 1970. The first designates a blue signal to protect non-train crews when they go underneath or between cars, and when working on the track. The regulations also specify the protection required for stopped or stalled trains. The second regulation, adopted in 1977, dealt with procedures for making radio transmissions, with the objective of reducing the possibilities of misunderstandings between train crews and dispatchers.

Until 1988 there were no regulations concerning who could or could not be a locomotive engineer. In part the new regulations were supportive of other initiatives that were introduced to bar people with drug or alcohol problems from driving trains. Under the new regulations, railroads must take into account an applicant's motor vehicle driving record in previous three years, and whether the applicant is enrolled in a substance abuse program. However, the rules also proscribe more general requirements including whether the employee has committed any railroad rules violations in the previous five years, has certain minimum sight and hearing abilities, has taken a written rules test, and has had his or her skills examined either on an actual locomotive or on a simulator.

\section{MONITORING AND ENFORCEMENT}

An appendix to 49 CFR 209 of the federal regulations contains a statement in commendably clear and straightforward language of the FRA's policy on monitoring and enforcement of safety laws. The frontline for the enforcement of federal laws is 270 inspectors employed by the FRA who work jointly with a further 130 inspectors who are employed by individual states. These inspectors conduct routine inspections of track, rolling stock and signaling, and monitor the operations of individual railroads. Some of the inspections are routine, others are random and others are in response to unsolicited complaints. Most inspections are of individual 
equipment or sections of track, but others are more-coordinated "Safety Assurance and Compliance Program" (SACP) assessments where teams of inspectors undertake comprehensive evaluations of particular railroads or divisions of particular railroads.

This latter program was introduced in 1994 to "identify and solve the root causes of systemic problems facing the railroads" and is aimed at the larger railroads and the holding companies for multiple smaller railroads (GAO, 1997). The program involves the FRA developing "safety profiles" of the railroads which highlight the major safety strengths and weaknesses. This process takes between two and six months. The FRA then meets with management and unions to discuss the important findings. Railroads are then asked to provide a plan of action to respond to specific problems that are found. Typically railroads are then given one year to implement measures to ameliorate the risks. During that time the FRA will not levy fines for violations connected with specific safety problems provided that the railroad is making a good faith effort to implement an action plan. Thirty-three railroads were subject to SACP inspections in 1996, and a further twenty-one in 1997. As a result of the introduction of the SACP, the FRA scaled back its traditional inspections of track and equipment by more than twenty percent in 1995 as compared with 1994.

When an inspector discovers noncompliance during a "traditional" inspection, each violation of federal law is listed on an inspection report. Decisions are then made on how best to ensure compliance with federal regulations. In some cases compliance can be obtained simply by bringing the deficiency to the attention of railroad management by issuing warning letters. Inspectors can recommend civil penalties if they feel that the deficiency is serious, if serious actual harm has already been caused or is likely to occur, or if the railroad has a record of non-compliance. The scale of maximum civil penalties for individual infractions is listed in the federal regulations. These maximum penalties were raised considerably by the Rail Safety Improvement Act of 1988 and range from $\$ 500$ to $\$ 1,000$ for each violation of the hours-of-service regulations, and from $\$ 2,500$ to $\$ 10,000$ for each violation of other regulations. Typically the maximum penalties are doubled if the violation is made "willfully" or "where a grossly negligent violation or pattern of repeated violations has created an imminent hazard of death or injury to persons, or has caused death or injury."

Since 1988 civil penalties can be assessed not only against the railroad but also against individual managers and employees. However, such individual penalties can only be assessed if the employee has acted willfully and was not acting under orders of a supervisor. The standard of proof is that the employee acted with a level of culpability higher than negligence, although the government does not have to show evil intent or that the employee was aware of the regulations. Inspectors have the right under any circumstances to request that an individual be removed from a safety-sensitive position.

Since 1983, railroads are strictly liable for paying any civil penalties that are assessed. It is assumed that railroads are aware of all applicable safety regulations and the existence of the violation. Evidence of a violation is sufficient for the government's case. It does not have to show evidence of specific negligence in 
failing to comply with the regulations. If the inspector recommends civil penalties then these are reviewed by regional supervisors and the FRA Office of the Chief Counsel. A penalty demand letter is then issued. Railroads and individuals can then confer informally with the FRA, and possibly an adjustment to the penalty can be made. Typically small railroads and individuals discuss individual violations by letter or over the phone, while large railroads usually hold a conference with the FRA covering multiple violations. When a final penalty is agreed, it is put in writing and the offending party writes a check for the agreed amount. Only in a very few cases have the FRA had to ask the United States Attorney General to bring suit to collect from railroads that have refused to pay. In fiscal year 1994 the FRA collected \$6 million in civil penalties from railroads for violations of safety regulations, and a further $\$ 2$ million for violations of hazardous materials regulations. Penalties against individuals totaled only $\$ 5,600$.

There are few criminal felonies. The Federal Railroad Safety Act of 1970 has criminal penalties for destroying, falsifying or failing to keep records, and there are criminal penalties for willful violations of parts of the Hazardous Materials Transportation Act of 1975. It is possible that individuals may be cited for criminal penalties in certain egregious circumstances, although very few individuals have been successfully prosecuted for manslaughter. Shaw (1978) reports that even when prosecutions are brought, most juries are sympathetic to railroad employees and acquit. One of the few exceptions in recent times was that the engineer of a train involved an accident at Dickerson, Maryland in 1942 who was sentenced to two-and-one-half years in prison.

The FRA's statement on enforcement notes that "[w]hile civil penalties are the primary enforcement tool under the federal railroad safety laws, more extreme measures are available under certain circumstances." Part 216 of the federal regulations provides legal powers for federal inspectors to require immediate rectification of defects with freight cars and locomotives, or the lowering of the maximum speed over a piece of track by means of issuance of Special Notices. Inspectors can require discontinuation of service over section of track by issuing of an Emergency Order. A 1980 amendment permitted very broad and sweeping powers over "conditions or practices" which need not be confined to a specific "facility or piece of equipment" which had been the original 1970 wording. It might therefore be possible for the FRA to suspend operations of an entire railroad, or a subdivision of a railroad, by means of an Emergency Order if it had grounds for doing so. The FRA may seek, through the United States Attorney General, injunctions in federal district court to either restrain the committing of violations, or support FRA initiatives to enforce rules. 


\section{Evaluation OF REGULATIONS}

How does one evaluate the "success" of a safety regulation? There would seem to be three criteria. The first is that the regulation tackles a genuine market failure. The second is that the written standards are set at appropriate levels to achieve the minimum acceptable benchmark level of safety. The term "minimum" is used here to recognize that in a vertically-differentiated marketplace, some firms will elect to supply a higher quality service to appeal to customers who have a high taste for safety. The regulations will need to be written to be consistent with the tastes of those customers who prefer a lower level of safety. The third criterion is that the monitoring and enforcement strategy achieves compliance at the minimum cost to the government and the firms that are regulated. A regulation will be a "failure" if there are deficiencies in any or all of these three criteria.

Economists argue that a cost-benefit analysis should be used to measure success. The analyst would observe whether the regulation has led to a decline in the accident rate. Reductions in accidents would then be valued by attaching dollar values to the deaths averted, the reduced number of injuries, and the reduction in property damage. These "benefits" are then compared with the "costs" of the regulation. These costs should include any additional money that railroads have to expend on preventive effort to comply with the regulation, the cost of government inspectors, and inspection costs borne by the railroad.

In the event that the costs outweigh the benefits, one would then look to determine why the regulation had failed. In other words, one would try to determine which of the three criteria had not been met. Did the regulation address a genuine problem? Were the standards set right? Was an appropriate monitoring and enforcement strategy adopted? By answering these questions, the analyst would be able to tell whether it is possible to improve the design or implementation of the regulation.

In practice, cost-benefit calculations are fraught with difficulty. Discerning whether the introduction of regulations has any effect on accident rates is quite difficult. While there are consistent time-series accident data for the railroad industry going back to 1975, changes in regulations have occurred at the same time as other changes in the industry that affect accident rates. The "costs" of many of the regulations are typically hard to define and estimate. The costs of most safety precautions are lumped in with other maintenance, capital, and operating 
expenditures in railroad accounts. While it may be possible to identify the specific capital costs of certain mandated safety equipment, changes in work practices are near impossible to either identify or value.

The late-Office of Technology Assessment (OTA, 1978) commented that many of the regulations introduced in the 1970s were not subjected to a formal cost-benefit analysis. Twenty years later it is now possible with the benefit of hindsight to form some opinion as to which, if any, of these regulations were beneficial. This book is not able to undertake any original cost-benefit calculations, but will draw inferences based on analyses of accident rates and other pertinent data.

\section{THE MOST "CONTROVERSIAL" REGULATIONS}

What are the most controversial regulations? This can be determined by a process of elimination from the full listing in table 18.1. For the purposes of this chapter, one can pass over those regulations supportive of other policy responses because their merits have been discussed earlier in the book. For a similar reason the grade-crossing regulations will not be discussed in this chapter.

Next, one can eliminate the alcohol and drug testing regulations. They appear to be very beneficial. The railroad industry has been perceived as a bastion of men working away from home who might frequent bars, and there has been a growing concern about drug use throughout the economy. The issue of conducting drug tests, and consequently what employees do in their private time, clearly requires government intervention to deal with legal and constitutional issues.

Table 19.1: The Most "Controversial" Federal Regulations

\begin{tabular}{|l|l|}
\hline Track standards & 49 CFR 213 - 1970 \\
\hline $\begin{array}{l}\text { Freight car and } \\
\text { locomotive } \\
\text { standards }\end{array}$ & $\begin{array}{l}\text { Freight car standards (49 CFR 215 - 1974) } \\
\text { Rear-end marking devices (49 CFR 221 - 1976) } \\
\text { Locomotive safety standards (49 CFR 229 - 1980) } \\
\text { Safety appliance standards (49 CFR 231 - 1893) } \\
\text { Power brakes \& drawbars (49 CFR 232 - 1958) }\end{array}$ \\
\hline $\begin{array}{l}\text { Operating } \\
\text { practices }\end{array}$ & $\begin{array}{l}\text { Operating practices (49 CFR 218 - 1976) } \\
\text { Radio procedures (49 CFR 220 - 1977) } \\
\text { Hours of service (49 CFR 228 - 1907) } \\
\text { Power brakes \& drawbars (49 CFR 232 - 1958) } \\
\text { Certification of engineers (49 CFR 240 - 1988) }\end{array}$ \\
\hline $\begin{array}{l}\text { Monitoring and } \\
\text { enforcement }\end{array}$ & 49 CFR 209, 212, 216 \& 245 - 1970 \\
\hline
\end{tabular}

One can also pass over those regulations concerning hazardous materials, glazing, signal installation and repair, and the requirement for operating rules 
because these regulations are very general, and leave the rulemaking powers to the railroads themselves.

This leaves the subset of the federal regulations which are shown in table 19.1. These regulations fall into four categories: track standards, freight car and locomotive standards, operating practices, and monitoring and enforcement. Each of these categories will now be analyzed in detail. The table includes the relevant citations in the Code of Federal Regulations and the date of first introduction. With the exception of safety appliance and hours-of-service regulations, most of these regulations are quite recent.

\section{TRACK STANDARDS}

In retrospect it is easy to see why the first order of business for the FRA under the 1970 Act was to establish track standards. It is now generally accepted that the increase in derailments that started in the 1960s was due to deferred track maintenance by cash-strapped railroads coupled with the introduction of larger and heavier freight cars.

An AAR committee was specially constituted in 1970 to define best practice. At that time the industry did not have any nationally accepted guidelines. The committee submitted a recommended code of track standards, but was disappointed that their attempts to define best practice were taken by the FRA as an input to legislated minima. In some cases the FRA made the design standards more stringent than those proposed by the AAR committee. The industry therefore felt that the minimum standard had been set too high.

The OTA (1978) was very critical of the lack of analytical methods used by the FRA in deciding on the new regulations:

"... the rulemaking docket is devoid of any substantive treatment by FRA of most major issues. Changes were made from proposed to final rule on the basis of their being 'necessary (or unnecessary) for safety.' This conclusory treatment seemed to be primarily a result of a lack of empirical data to support particular standards. ... the rules were developed without any formal use of accident or other safety statistics, at least as reflected in the public record. ... while various parties submitted at FRA's request some rather simple cost-benefit analyses, there is no indication that FRA used that information, or any such data that it developed, in arriving at the final track standards." (OTA, 1978, page 101)

A possible side effect is that today's younger engineers may decide on proper construction and maintenance by deference to the federal regulations rather than by using their own professional judgment. This has allegedly built up a culture where the objective is to meet the federal rules and not to develop best practice in track design, types of maintenance, and the allocation of resources to maintenance on different sections of track. It is said that innovation and professional judgment are no longer job requirements if you are a track engineer. By comparison, bridge 
engineers have never been constrained by federal design regulations, yet excluding floods and collisions, there has not been a major bridge collapse since the 1940s.

But perhaps the most virulent criticism has been directed to the methods of monitoring and enforcement. The regulations are written in such a way that enforcement is based on identifying individual defects rather than evaluating the overall maintenance policies of a railroad. Railroad managers contend that resources have to be diverted from planned maintenance operations to respond to defects uncovered by FRA inspectors. These managers ask: What is better for safety, having a gang of workers undertake scheduled maintenance and renewal, or have them follow a FRA inspector around replacing missing spikes? Moreover, the GAO (1982) found that individual violations attracted relatively small penalties and there is a lag of up to two years in assessing the penalties. Therefore, violations were rarely brought to the attention of senior management who would have powers to review maintenance programs. The GAO comments:

"... the Railroad Administration's limited inspection force, and the questionable deterrent value of the FRA's violations process have not encouraged broad-based railroad compliance with safety standards. In fact, the program's primary effect has been to get individual defects corrected and not to motivate railroads to improve their overall safety programs." (GAO, 1982, page i)

The GAO (1982) found that more than ninety percent of the FRA inspectors used to be employed in similar capacities by railroads and still functioned like railroad inspectors. They inspected individual sections of track and did not "employ management analysis or statistical techniques to evaluate railroad operations or support an overall conclusion on the adequacy of a railroad's safety program" (page 9). Also, it is commonly alleged that inspectors can create work for their union ex-brothers and can step up inspections to penalize a railroad when there is a labor dispute.

The way in which the regulations are written encourages labor-intensive visual inspections that count the number of spikes per length of rail. The regulations are not written in terms of the maximum lateral deflection of the rail, which would permit wider use of mechanical inspections using Gauge Restraint Measuring System equipment. The railroads naturally follow the lead of the FRA in retaining traditional inspection methods to ensure that individual defects do not occur. For labor unions wishing to preserve jobs in the face of new inspection technology, the track standards as they are written are very desirable.

A quarter of a century later, it is possible to assess effectiveness by looking at the time-series of the rate of collisions and derailments due to track defects and of variables that might affect this rate. These data series are shown in figure 19.1 in the form of an index with the value in 1975 set equal to 100 . The accident rate per track mile is shown by the line with the squares. The rate increased by two-thirds between 1975 and 1978 and then began to decline and is now only a quarter of the level in the peak year. Some of the reduction in track-caused collisions and derailments can be explained by changes in railroad operating practices. Railroads 
conduct less switching which is inherently more likely to cause an accident and is usually conducted over poorer-quality track. The ratio of yard train miles to total train miles is shown as the line with the triangles. Since 1975 this ratio has declined continuously and is now less than half what it was twenty years ago. While this factor is clearly important, it does not entirely explain the change in accident rates. Accidents were increasing in the mid-1970s when the ratio of yard miles to train miles was stable and starting to decrease. In addition during the 1980s the accident rate fell quicker than the decline in switching.

Figure 19.1: Analysis of Track-Caused Collisions and Derailments

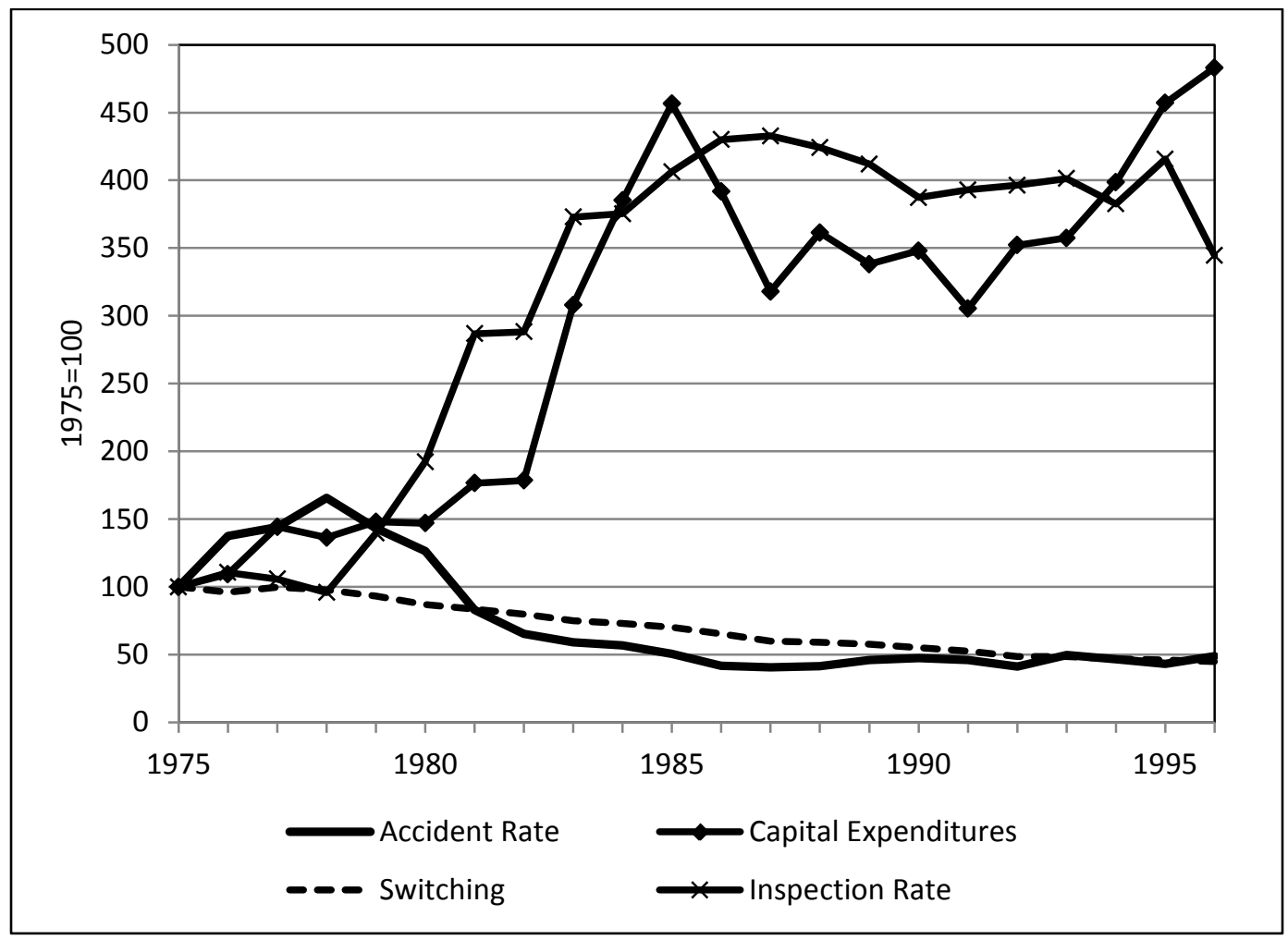

Given that the decline in railroad finances in the 1960s is credited with causing the increase in track-related accidents, it is logical that the improvement in railroad finances may have led to the solution to the problem. Capital expenditures per mile of track, in constant 1996 dollars for the Class I railroads, are shown as the line with the diamonds. With the deregulation of the industry, capital expenditures increased considerably starting in 1982. Clearly, this was the proximate cause of the decline in track-caused accidents in the 1980s. But what caused this increase in expenditures? The railroads would argue that the increased track expenditures are due to the financial health of the railroads, and that it was inevitable that the relative prosperity subsequent to deregulation allowed firms to invest in their capital stock. The safety regulators, on the other hand, would argue that the "railroads simply had 
the money [after deregulation] to respond more effectively to FRA's promptings" (U.S. Congress, 1995).

This latter argument has some statistical merits in that the index of miles inspected per track mile, shown as the line with the crosses, started to increase dramatically in the period after 1978, which is the same time that the accident rate started to fall. Since the early 1980s, track capital expenditures and government inspections have tracked each other closely, making any econometric untangling of their relative contribution to the decline in accident rates difficult. Critics of track standards point out that the standards were developed in the early 1970s some six years before accident rates reversed their upward movement. However, the hiring of federal inspections lagged some years behind the writing of the new regulations, and it was not until 1978 that the number of inspections increased dramatically. The FRA is clear about the inference that should be drawn:

"It is obvious that the Federal Railroad Safety Program contributed significantly to that dramatic safety improvement, though the split between the contributions of the safety program and railroad investment is difficult for anyone to prove to a statistical certainty" (U.S. Congress, 1995, page 58, emphasis added).

It is certainly true that there is statistical uncertainty, but it is less clear whether it is "obvious" that the FRA track standards contributed significantly to the decline.

\section{FREIGHT CAR AND LOCOMOTIVE STANDARDS}

Unlike track standards, the freight car standards are long standing. Rules on handholds, steps and grabirons date back to the nineteenth century. Requirements for brakes date back to the same era and were updated in the 1950s. Even the rules on car inspection and the definition of defects with wheels, axles and bodywork while written into law in the mid-1970s were derived from the industry's century-old interchange agreements.

There is no doubt that the safety appliance, and brake standards are directed at real problems that in the past were the cause of many injuries each year. The origins of the regulation were that standardization of grabirons was necessary so that employees working "always in haste, and often in darkness and storm" could instinctively know of their location (Illinois Cent. R.R. v Williams 242 U.S. 462 (1917)). The air-brake regulations hastened the widespread adoption of the Westinghouse brake system to prevent run-away accidents in mountainous areas, the separation of trains, and reduced stopping distances which was vital in the days before the telegraph when rear-end and head-on meeting of trains was common. The requirement for semi-automatic couplers at a standard drawbar height led to a substantial reduction in the fatality rate among switching-yard employees.

The regulations are still relevant today, as can be seen in table 19.2. In 1996, four of the twenty-two operating employee casualties, and forty-eight percent of the 4,087 injuries, were associated with causes that may be affected by equipment design 
and maintenance and are partly covered by the safety appliance, freight car and locomotive standards. The injuries were sustained in three circumstances of roughly equal magnitude: while getting on or off equipment, during coupling or handbrake operations, and while on a locomotive. One cannot determine from the FRA data what proportion of these injuries are caused by non-compliance with the appropriate safety appliance, freight car or locomotive regulations, or might be prevented by tightening the regulations.

Table 19.2: Operating Employee Casualties due to Equipment Failures 1996

\begin{tabular}{|l|c|c|}
\hline & Fatalities & Injuries \\
\hline $\begin{array}{l}\text { Collisions and derailments due to equipment } \\
\text { failures }\end{array}$ & 0 & 19 \\
\hline Coupling, uncoupling and handbrake operations & 3 & 630 \\
\hline Getting on or off locomotives or cars & 1 & 724 \\
\hline While on a locomotive & 0 & 604 \\
\hline $\begin{array}{l}\text { As percentage of total operating employee } \\
\text { casualties }\end{array}$ & $18 \%$ & $48 \%$ \\
\hline Source: FRA (1997a) & \\
\hline
\end{tabular}

The main drawback of writing particular designs, maintenance schedules and inspection periods into law is that the regulations are inflexible and cannot respond to changes in technology. A prime example is the braking-design standards. One would imagine that the government's sole concern is that a train should be able to stop from x miles per hour in y hundred yards, and it should not be too concerned about the technology that leads to this performance. However, the regulations are written in terms of specific design, brake-cylinder stroke length, cylinder pressure and the like. Recently a vastly superior form of braking, known as electronically-controlled pneumatic brakes, has become available which can reduce stopping distances by up to forty percent. Such a technological advance has not been reflected in the regulations, and the use of such brakes is currently authorized only under a waiver to the regulations issued by the FRA. The railroad industry laments that rewriting of the freight car regulations to reflect modern braking conditions has been in the works since the late 1980s.

The industry points to other areas where the regulations have not kept pace with changes in technology. Roller bearings have improved over time. However, the regulations concerning design tolerances lead to them being reconditioned or thrown away even though technically they do not need to be replaced. Changes in technology have also made regulations dealing with slackless drawbars and the use of lubricants outdated. The industry argues that if design and maintenance requirements had been left with the industry's own interchange agreements, rather than written into federal law, then the rules would be more flexible to new technology. 
Another example deals with whether a wheel is defective if it has a discoloration that might indicate heat damage. This regulation, 49 CFR 215.103(h), which was quoted in full in the previous chapter, was written into law in 1974. It aimed at dealing with failure-prone high-carbon, straight-plate wheels. At that time it was felt that there was a connection between discoloration and the heat damage that was believed to cause the failures. Initially the rule required a wheel to be taken out of service if there was discoloration on both the front and back surfaces of the wheel that extended half way from the rim to the axle, a distance of about eight inches. In 1980 the rule was tightened up to read that a wheel was defective if the discoloration was greater than four inches on either the front or the back surface. This change had the effect of requiring railroads to spend $\$ 100$ million a year to replace supposedly-defective discolored wheels. In 1982 the railroads asked for relief from this rule citing evidence obtained from sawed cross-sections of wheels that showed that there was no connection between wheel discoloration and heat damage. It took until 1995 for the FRA to grant the industry a waiver from the discolored wheel regulations. Nevertheless the regulation still remains on the books, with the understanding that it will not be enforced.

A similar story of regulations responding years after technology has changed can be found in diesel-locomotive inspection rules. In the early 1960s, locomotives were required to have several safety-related components checked every thirty days. This frequency had its origin in the necessity of locomotives to visit maintenance facilities on a monthly basis for changing oil filters. In the mid- to late-1960s, ninety-day oil filters become available. However it was not until 1975 that the FRA extended the inspection period to its current ninety-two days. In the 1990s, six-month oil filters have become more common, and advances in locomotive technology have made the locomotives more reliable. The FRA has yet to make any moves to expand the inspection period.

There is some concern that more recent regulations have dealt with design matters that do not directly address a market failure. A good example is a knee-jerk political reaction to a commuter train accident in Chicago in 1972, which led to the promulgation of federal regulations for lights marking the ends of trains. Curiously, while this accident did involve a rear-end collision, the circumstances leading up to it did not hinge on the adequacy of rear marker lights on the front train. The accident resulted when one train was struck in the rear as it reversed back into a station platform that it had overshot. One might question why the government felt that it needed to intervene in an area that the industry had taken care of by itself for over a century with apparently relatively little controversy. Even more questionable is why the federal regulations give detailed design requirements and even list the names and addresses of FRA approved manufacturers. Should the FRA be in the business of approving manufacturers? 
In addition to the prevention of injuries, the locomotive and car standards are supposed to prevent serious collisions and derailments caused by defective equipment and inadequate braking. The effectiveness of these regulations can be investigated by a time-series analysis of data relating to collisions and derailments due to equipment defects since 1981. A graph of relevant data is shown in figure 19.2, with all data shown as an index with the value in 1981 set equal to 100 . The collision and derailment rate per train mile is shown as the line with the squares. The rate has declined continuously and is now a third of what it was in 1981. Some of the decline may be explained by the move away from switching toward unit trains. The coupling and uncoupling of cars provide considerable opportunity for defects to transform themselves into accidents. However switching, indicated by the line with the triangles, has only declined by forty-five percent over the period, so there must be other contributing causes.

Figure 19.2: Analysis of Equipment-Caused Collisions and Derailments

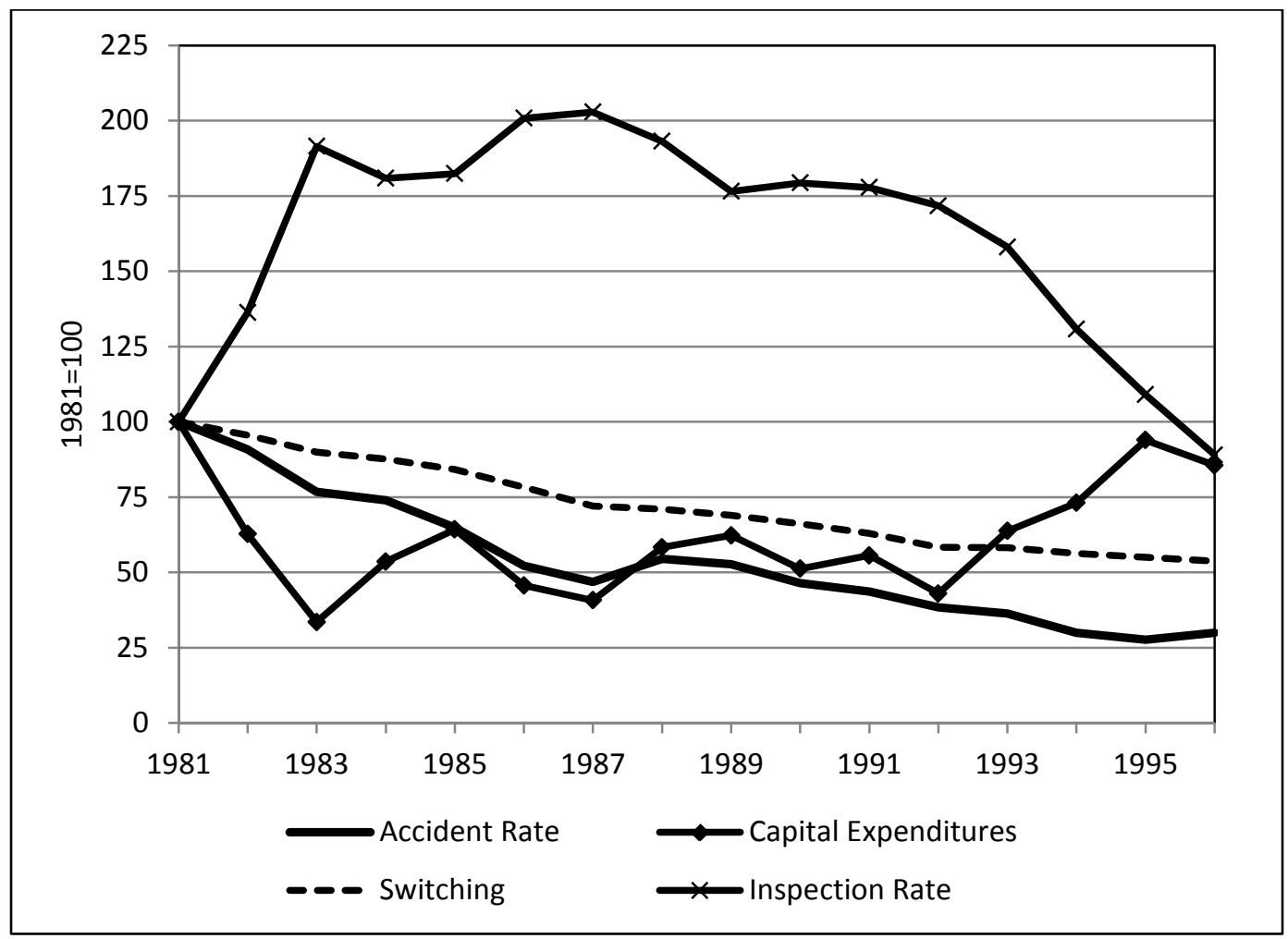

Unlike track, there has not been a big increase in capital expenditures on equipment deregulation. Capital expenditures per train mile in constant dollars for Class I railroads, are shown as the line with the diamonds. These expenditures declined during the 1980s and increased in the early 1990s. In some ways these figures are misleading in that part of the freight-car fleet is provided by shippers and leasing companies, and the proportion of such cars has increased from about a 
quarter of the fleet in 1980 to almost a half in 1996 (AAR, 1997). Consequently there have been considerable capital expenditures made that are not reflected in the data.

Equipment inspections per train mile, shown as the line with the crosses, almost doubled between 1981 and 1983 but then started a gradual decline, so that now they are barely more than they were in 1981. The steady decline in the accident rate has continued despite the fluctuating number of inspections. Why does the inspection rate have so little effect on the accident rate? A likely explanation is that FRA inspectors look for and write up many minor offenses of the Safety Appliance Acts specifying the position of handholds, handbrakes and coupling levers that have little to do with operational safety. Support for this statement can be found in a FRA Region 5 campaign in Texas, Arkansas, New Mexico, Oklahoma and Louisiana in 1994 (FRA, 1994). The FRA found that 10.4 percent of 16,088 cars inspected in a twelve-week period had defects. Most of the defective cars (6.4 percent of cars inspected) had violations of the safety-appliance regulations (49 CFR 231). A much smaller proportion of cars were found to have mechanical defects. Defective wheels, axles, body and couplers in violation of the freight-car standards (49 CFR 215) were found on 3.1 percent of cars, and brake defects in contravention of the power brake regulations (49 CFR 232) were found on 2.9 percent of cars. The defect rate of 10.4 percent was found to be three times higher than the defect rate found by railroad inspectors at the same locations who found defects in 3.1 percent of 648,089 cars inspected.

This raises the question of whether the writing up of so many defects in grabirons and steps is worthwhile. I think the FRA would be hard pressed to show that the writing up of these defects has had any effect on the number of injuries sustained in getting on or off equipment. One might suspect that it would be merely sufficient for the FRA or the AAR to oversee original equipment manufacturers to ensure they properly install such uniform appliances, but not to check on their condition while in service. Writing up a bent grabiron is likely to have a negligible implication for safety, is a waste of the inspector's time, and is counterproductive in souring the relationship between the FRA and the railroads.

\section{OPERATING PRACTICES}

These regulations primarily specify hiring standards for locomotive engineers, hours of service of operating employees, and to a more limited extent specify how they perform their duties. The hours-of-service rules are longstanding, but regulations in the other areas are more recent.

The major criticism of the hours-of-service rules centers on two issues: are they needed and what should they be? Evidence presented earlier in the book suggested that they were effective early in the twentieth century in reducing the average hours worked by employees. But are they still necessary in an industry which is 
characterized by strong labor unions? In Canada they are a matter for collective bargaining between railroads and their employees (OTA, 1979).

Critics of the details of the regulations point out that they were developed at a time when less was known about circadian rhythms and consequently may not only be outdated but may also be counterproductive. For example the rules allow a person to work twelve hours then take ten-hours rest and be back at work two hours earlier than on the previous day. More modern thinking suggests that day-to-day variations in the body clock can be as important in contributing to fatigue as the actual amount of time spent at work (Vignau et al., 1993; Wehr, 1996). There are also medical suggestions that quick "napping" may be more effective at combating fatigue that longer breaks, yet this is not allowed under the present rules. As with the freight-car standards the fear is that the inflexibility of formal legal regulations prevents the incorporation of new scientific knowledge that might improve work scheduling to the benefit of both the railroads and their employees.

The railroad industry was able to survive a century and a half before it was felt necessary to write rules on who can and who could not be a locomotive engineer. Part of the new rules is supportive of other efforts to prevent people with drink or drug problems from driving trains. However, there are additional qualifications in terms of tests of rules knowledge and the testing of skills on the road or in a simulator. There are conflicting views on why rulemaking was necessary in 1988. The management view is that the rulemaking was suggested by the Brotherhood of Locomotive Engineers to limit the use of management personnel to drive trains during labor disputes. The other side points to two Amtrak accidents on North-East Corridor in the mid-1980s that were caused by ill-qualified and impaired engineers.

The industry developed its own recommended set of operating rules back in 1887. In general, the Uniform Code of Railroad Operating Rules has not been written into a federal statute. The exception is rule 26, dealing with the protection of employees working on track or equipment. These are known as the "blue signal" rules. The FRA wrote this into federal law in 1976 because it was felt that there had been uneven application of this rule. Yet, the OTA criticized the FRA for not giving any "statistical or safety data basis for undertaking this rule," and that:

"there has never been any attempt to assess whether the net benefits provided by the rule, particularly the requirement for locking and lining of switches [to protect workers working on a particular track], are in reasonable proportion to the costs of compliance." (OTA, 1978, page 102)

Perhaps the most famous examples of the regulation of operating practices are those dealing with the inspection of air brakes. These rules date from 1958. Since that time railroads have repeatedly asked the FRA to amend some of the rules. The railroads were successful in 1982 in having the distance between intermediate inspections increased from 500 to 1,000 miles. Any amendments to the regulations require public hearings. Typically, any changes have been opposed by organized labor. In the view of labor, changes are proposed by railroads to save money at the expense of safety, while railroads view the actions of the unions as a means of protecting outdated work practices and preserving jobs. The union position was 
strengthened by a judgment in United States District Court, United Transportation Union, et al. v. United States et al. [337 F. Supp. 410 U.S. 964 (1972)], which ruled that changes in power-brake laws can only be made if the FRA can show clear evidence that the proposed rulemaking will not negatively affect safety. Consequently, the brake regulations have in the words of the OTA:

"been saddled with such inflexibility, and elimination of this statutory limitation would offer a valuable opportunity for FRA to reassess these rules in the light of current safety hazards and operating practices" (OTA, 1978, page 102).

The current regulations require inspections to be conducted by "qualified personnel." The Carmen's Union proposed a revision to the regulations in 1997 which read, in part, that "Carriers will designate Carmen to perform all initial terminal tests and inspections under 49 CFR Part 232 and all mechanical inspections under 49 CFR Part 215 in accordance with the provisions set out below and subject to the exceptions as outline below" (letter from Thomas P. McDermott to the FRA, April 18, 1997). The Carmen's Union was clearly hoping that federal regulation could be used to stem further losses of Carmen's jobs as railroads made greater use of train crews to inspect their own trains (see GAO, 1997 at page 29).

Figure 19.3: Analysis of Human Factors-Caused Collisions and Derailments

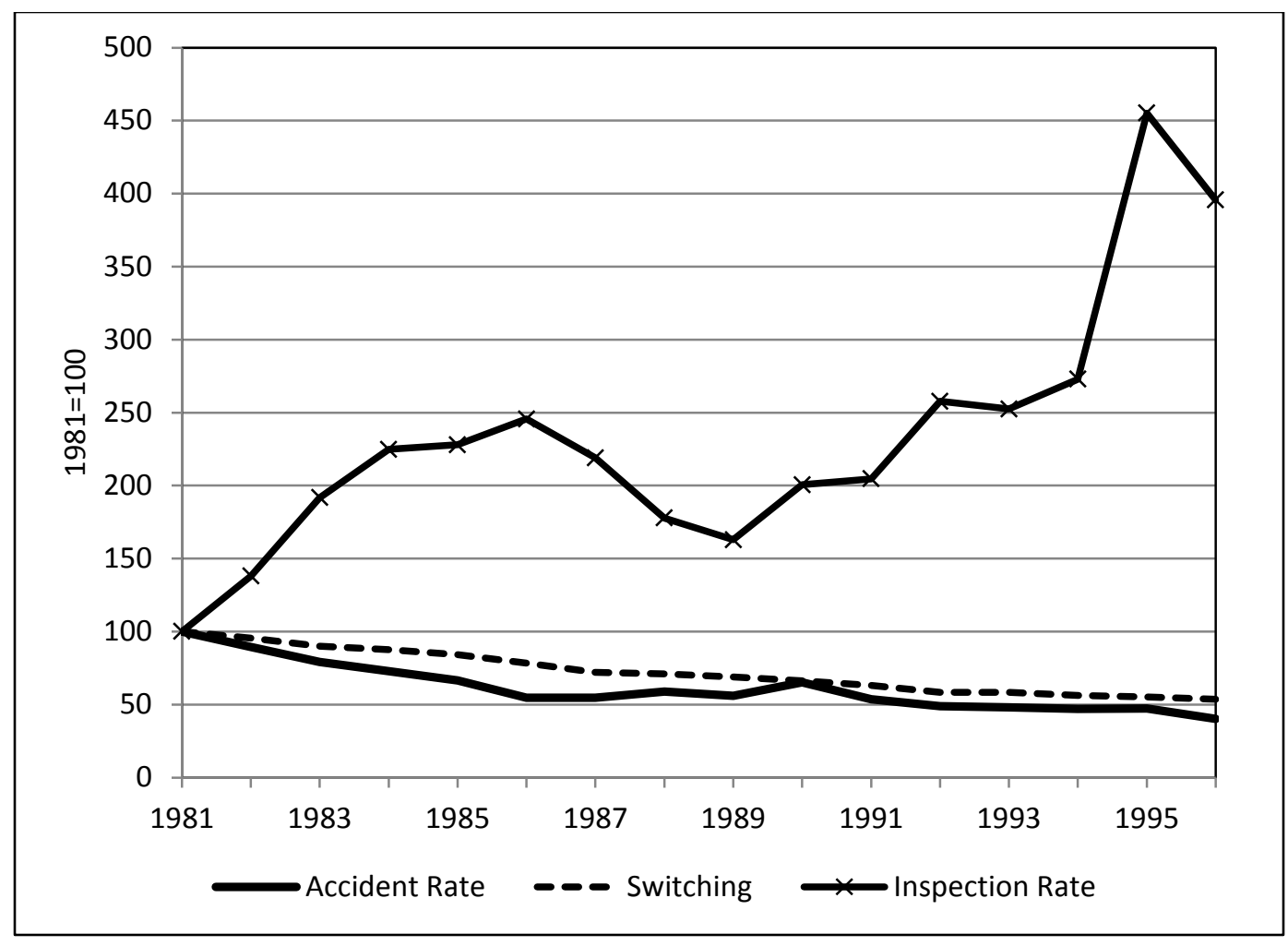


The effectiveness of regulations dealing with operating practices is investigated in figure 19.3 which looks at the period since 1981. The rate of collisions and derailments due to human factors per train mile is shown as the line with the squares. These, and all other data, are shown as an index with the value in 1981 set equal to 100. The accident rate has declined continuously and is now only half of what it was in 1981. A major explanation for this decline has been the reduced amount of switching, which is indicated by the line with the triangles. The possibility of collisions and derailments due to employee lapses in switching yards is much greater than while a train is on the mainline. Not surprising, the declining accident rate closely tracks the reduction in the amount of switching.

Set against the close relationship between switching and accidents are data on FRA inspections of "operating practices." The rate of inspections per train mile, shown as the line with the crosses, has quadrupled since 1981. There is seemly little relation between changes in the number of inspections and the accident rate.

\section{MONITORING AND ENFORCEMENT}

A common thread through the previous discussions has been criticism of the methods adopted for monitoring and enforcement. The most comprehensive analysis of this subject was a 1982 report by the GAO. The title of the report summarizes the contents: The Federal Approach to Rail Safety Inspection and Enforcement: Time for Change. The two-paragraph summary on the front cover of this report is worth quoting in full:

"The Railroad Administration's safety enforcement program mainly involves making individual, routine inspections of track and railcars. These inspections often result in identifying defects or recommending enforcement actions. Although the inspections have identified many defects and violations, their narrow focus does not encourage broad-based railroad compliance with safety standards.

The Railroad Administration could more effectively fulfill its enforcement responsibilities if it would reduce the number of individual, routine inspections performed and shift its emphasis to broad-based system assessments, comprehensive evaluations of railroads' entire systems and operations. Through these assessments, the Railroad Administration could determine the overall adequacy of railroads' safety programs and bring deficiencies to the attention of railroads' top management." (GAO, 1982, cover)

The GAO recommended that the FRA move toward a system of broad-based system assessments, but noted that the FRA lacked criteria for selecting railroads for such evaluations.

As described in the previous chapter, the FRA has changed to some extent the focus of its inspections. However, the criteria for selection of railroads or divisions of railroads for broad-based assessments have been the subject of debate. The 
predecessor of the current SACP, known as the National Inspection Plan, was based on analytical models which were supposed to direct the activities of the inspectors. The computer model was based on information on past inspections, accidents and the nature and quantity of traffic. Yet the GAO (1994) in an investigation of inspection of track called the data in the model "questionable."

Earlier GAO reports (1989a, 1990) were equally critical of the FRA's inspection and enforcement of hazardous materials regulations. The 1989 report concluded that the hazardous materials inspections program was not effectively implemented because of: inadequate central guidance, an outdated 1983 procedures manual, the lack of a systematic approach to targeting the highest risks, the inspection of individual tank cars rather than monitoring the safety policies of the railroad, and an insufficiency of inspectors. The 1990 report also commented that there were insufficient inspectors to cover all the places at which hazardous materials are loaded and unloaded. Indeed, the FRA was criticized for not having an up-to-date list of such locations.

The trade journal Railway Age conducted some investigative journalism into the inspection of short-line railroads (Miller, 1993, 1996). The 1993 article highlighted scathing criticism of the writing up of minor violations by some inspectors which "divert very scarce management time and attention from the real safety issue" in the words of one railroad president. Some ex-union inspectors are criticized because they seem to "want to get even with management. They want to write new work rules that they were never able to win at the bargaining table." Most of the people interviewed requested anonymity for themselves and their companies because they feared retribution from the FRA. The president of the ASLRRA recommended that the focus of the FRA change to a more educational role by holding seminars on safe practice for inexperienced railroad managements.

The follow-up 1996 article suggested (not immodestly) that the earlier article had provoked changes at the FRA with a modification in the "attitude and ferocity of inspections" and a "more friendly and cooperative attitude" by inspectors. Company presidents praised the safety seminars organized jointly by the FRA and ASLRRA, and said that they were looking for advice and cooperation and did not want inspectors who are "belligerent to the point that both the employees and the company are afraid of them." However, there was a feeling that the change of heart in Washington toward a policy of "instruct rather than fine" had not filtered down to the local inspectors, particularly those inspectors employed by the states. In short, there was a preference for inspectors who discussed company safety procedures with management rather than randomly looked for violations in track and equipment. The article did note that the fault may not always lie with the FRA inspectorate. One company president said that "[i]f a short line makes an honest effort and is upfront and courteous to FRA inspectors it should never have problems, as the kindred spirit will surface. Unfortunately some short-line operators have a chip on their shoulder." 


\section{LESSONS}

One might be tempted to conclude that while most of the early regulations were worthwhile, those adopted since 1970 have been of questionable value. Chapters 2 and 3 have shown that the regulation introduced between 1893 and 1911 coupled with the rise of the "Safety First" movement lead to substantial reductions in fatalities and injuries, particularly those sustained by employees. It would be difficult to make the same argument for the Federal Railroad Safety Act of 1970. While the upward trend in accidents that started in the 1960s was subsequently reversed in the late 1970s, the causation of this reversal is open to question. The Staggers Act of 1980, coupled with the public subsidies to Conrail, gave the industry a new prosperity which resulted in renewed investment for the first time in thirty years.

There are some lessons that can be learned. The first is that the most controversial regulations are those which specify detailed design. While the government may have a legitimate interest in the engineering of certain critical components of railroad equipment and infrastructure, it is surely only interested in how the equipment or infrastructure performs and not how it is designed. There are two consequent problems. The first is that a government committee has to decide on what the design specifications are. The clear indication is that cost-benefit analysis is not one of the tools used by the FRA in making such a determination. The second problem is that there is clear evidence that once written into law, specification standards become so inflexible and so politicized that changes in technology and engineering knowledge are held back. This is particularly the case when engineering advances have repercussions on labor and work rules.

Those regulations that are perceived as more useful are typically those where they are written in terms of performance standards rather than specification standards, such as the glazing, signaling and hazardous materials regulations. In contrast, the Canadians have not adopted any track and freight car standards or rules on the inspection of power brakes. The OTA (1979) commented that when Canada does set rules, such as the placement of blue flag protection, and the design of locomotive cabs, they are much more general in nature than in the United States.

In response to the suggestions that regulation had fossilized outdated technology and working practices, the FRA formed a Railroad Safety Advisory Committee in 1996 (GAO, 1997). The forty-eight committee members are drawn from twenty-seven organizations representing government, management and labor unions. The objective of the Committee is to review proposed new rules, and proposed revisions to existing rules, to ensure that they are practical, effective, and cost-efficient. The Committee was charged with tackling some of the most controversial regulations such as the design requirements for crashworthiness of locomotive cabs, the qualifications required to be a locomotive engineer, the track standards, the braking regulations, and rules for radio communications. It is too early to see whether the size of the Committee and the possibly conflicting viewpoints of management and labor can produce meaningful and constructive input to the making of new and revised rules. 
The second lesson is that one should not underestimate the ability of the industry to self-regulate. Arguably one of the most important prerequisites for safe operation is the operating rules, and these have remained largely outside of government interference. The industry has promoted its own recommended uniform code of rules for over a century. Likewise the very basis of railroad operations is interchange of cars and locomotives. For over a century until the mid-1970s the industry had its own set of rules that member railroads had to abide by at the risk of being disqualified from interchange rights. It is likely that the freight car standards as well as substantial parts of the Safety Appliance Act would be promulgated and enforced by the industry itself in the absence of government intervention.

The third lesson is that one should not underestimate the power of organized labor in two ways. The first is that unions have long campaigned for safety on the job, and one might argue that safety precautions and hours of service are a legitimate subject for collective bargaining between strong unions and management. The second is that the unions have used government interest in regulating the railroads to attempt to obtain advantages that they could not have achieved in negotiation with management or could only have achieved by sacrificing in other areas. The most notable example is efforts by the Carmen's Union to retain intermediate inspection of train brakes, and attempt to mandate that inspections are conducted by Carmen.

The final lesson is that the strategy for monitoring and enforcement is as crucial to the success and value of regulations as is the actual wording of the regulations. One might argue that the FRA's strategy since 1970 has not only been pointless but actually may have been counterproductive in that it has alienated the industry rather than helped to enroll management in improving safety. I would suspect that random writing of violations of track standards on individual sections of track or finding defects with the Safety Appliance Act would not pass a cost-benefit analysis test. Part of the problem is that the FRA employs ex-railroad track and car inspectors who have been conditioned to look for individual problems. Finding such problems is the proper role for railroad employees but probably is not the role of the FRA. The FRA should be identifying railroads, or districts of large railroads, that have inadequate programs of inspection, maintenance and renewal and then should make senior management commit to reform. While the FRA does conduct task force or special assessment exercises, such as those conducted against the Union Pacific Railroad in the summer of 1997, these are the exception rather than the rule.

Support for this last lesson comes from several sources. Independent review of FRA operations by the GAO has repeatedly drawn attention to the ineffectiveness of pursuing individual defects and has recommended that the FRA move toward conducting more in-depth investigations of the safety-management practices of railroads that appear to offer deficient levels of safety. Interviews with managers of short-line railroads in Railway Age suggest that they find the educational seminars and advice offered by the FRA in cooperation with ASLRRA to be more informative and useful than a stack of violation notices written by a FRA inspector during a random visit. 


\section{ANEWERAFor SAFETY REGULATION}

This chapter proposes a new and improved strategy for safety regulation. One that could overcome the problems with the current method of regulation. In defining a new strategy, one must first define the ultimate objective. Excluding concerns about customer rationality, the main objective for deploying safety regulation in the railroad industry is to counter myopia. Myopia may stem from inexperience or from unscrupulous intent. The two causes of myopia call for quite different responses by the government. Safety regulations will therefore have to comprise both an educational system to ensure that new inexperienced railroads do not select lower levels of safety than they should, and a delinquency system to identify and punish railroads that are engaging in unscrupulous myopic behavior.

\section{DESIGNING AN EDUCATIONAL SYSTEM}

The objective of the educational role of the FRA would be to ensure that new railroads are aware of the future accident-cost consequences of decisions made concerning maintenance, training and operating practices. This can be done by holding seminars and by personal visits by FRA inspectors.

The FRA has some natural allies in this process. Enrolling the insurance industry will be critical to giving some "teeth" to the educational programming. Insurance company assessors would explain how premiums are set and how these premiums will vary depending on the preventive efforts made by the railroad company. The trade associations are also natural allies. The ASLRRA is naturally concerned about the good name of both itself and the portion of the industry that it represents and would not wish companies with little commitment to safety to enter the industry. The AAR has a strong interest as well because small railroads act as feeder lines to the larger railroads. New small railroads are interested in signing onto interchange agreements and the large railroads are interested in ensuring that the cars they receive from the small railroads are well maintained, and conversely that their own cars are not damaged when running on the short-line railroad.

To a certain extent this recommendation is already in place. The FRA in cooperation with ASLRRA does run seminars. In addition, ASLRRA and the major railroads run courses and seminars aimed at discussing best engineering and 
operating practice. FRA inspectors already work with the managers of new railroads to produce written policies and procedures. The comments of short-line railroad managers reported in Railway Age (Miller, 1996) suggest that the FRA has already changed to an "instruct rather than fine" policy. Albeit that the change may be more evident in Washington than in the field.

The natural follow-up question is whether there should be an accreditation system to indicate those companies who "pass" the educational process. In effect this is questioning whether railroads should be required to obtain a government "Certificate of Fitness" in order to operate. The actual form of the certification process is open to debate. For example, it might be a simple system whereby railroads are either approved or not approved. Alternatively it might be a graded system whereby railroads receiving less than top grade may have to pay higher premiums to obtain insurance. It is also open to debate whether there should be a formal examination taken by managers of newly formed railroads, or whether there should be an audit undertaken by FRA officials. There is probably a need for some type of formalized system which could be used as legal support by the FRA to deny operating authority to companies that are clearly unprepared to provide a minimal level of safety. Whatever system is adopted, there is no doubt that it would be quite feasible in the railroad industry. This is an industry with fewer than four hundred separate corporate entities, and the number of newly formed railroads is less than twenty a year.

Traditionalists would doubtless argue that the FRA should not act as a "free" consultant to newly-formed railroads. The response to this objection draws from an analogy to crime and law enforcement. It may be cheaper to deal with the causes of crime rather than detecting offenders after crimes have been committed, and trying to deter recidivism by handing out punishments.

\section{POSSIBLE EDUCATIONAL MODELS}

Assuming that one wishes to have a formal system of certification to ensure that new railroads have sufficient educational knowledge, there are a couple of possible models. One is from the United States trucking industry, and the other from the newly-privatized railways in Britain.

The Office of Motor Carriers of the FHWA uses a system of audits to rate truck and bus companies. Technically this is not a system of prequalification for entry to the industry. It would be impossible for the FHWA to visit each carrier who is contemplating entering the truck industry. However, the FHWA does try to audit as many carriers as it can. "Safety Review" audits of motor carriers involve visits by federal inspectors to the operating bases of firms to question managers about safety-related procedures and policies such as those governing maintenance, and employee hiring and training. The federal inspector does not actually inspect any equipment or test employees. The FHWA views the initial visit to a carrier as mainly educational, and has a policy of not initiating citations for violations found. 
The FHWA has a standard list of fifty-seven questions, grouped in five categories, which are asked of all carriers. Trucking firms who carry hazardous materials are asked a further eighteen questions in two categories. FHWA inspectors mark a "yes" or "no" answer to each question, but can append comments and supporting documentation. To give a flavor of the type of information that is solicited, examples are listed for each of the different headings. The inspectors ask thirteen general questions such as "Does the individual in charge of safety have authority to terminate drivers?" There is then one question on whether the carrier has been certified by the government as having a minimum level of financial responsibility; five on reporting of accidents ("Can the carrier explain the meaning of a reportable accident?"); thirteen on driver qualifications ("Can the carrier list the documents required to be in a driver qualification file?"); five on driving ("Does the carrier have a policy for monitoring speed?"); eight on maintenance ("Can the carrier produce the prior three months inspection reports on a vehicle selected at random?"); and twelve on hours of service ("Can the carrier produce the prior six months' records of duty status for a driver selected at random?"). If the carrier hauls hazardous materials, it can also be asked seven questions on driving and parking rules ("Is the carrier aware of the marking of vehicles requirement?"); and eleven more general questions ("Can the carrier explain the accessibility requirements for shipping papers?").

An algorithm is then used to producing a rating for the carrier. Each question is assigned a severity weighting between zero and ten. Within each category, the FHWA tallies the number of penalty points derived by multiplying "no" answers by the severity weighting. Carriers are then rated as satisfactory, conditional or unsatisfactory in each category depending on the number of penalty points received. A carrier that receives an unsatisfactory rating in two categories, or one unsatisfactory rating and two or more conditional ratings, is assigned an overall unsatisfactory rating. The accident rate also plays a part in the rating determination, but it is only used in rating the largest carriers. This is because smaller carriers run so few miles each year that the accident rate in any one year is an unreliable guide to the risks the carrier poses.

An unsatisfactory rating does not mean that the carrier is barred from operating. Indeed the FHWA's policy is not to issue citations at that stage. An unsatisfactory rating triggers educational action and also a second, more detailed, audit. Carriers can only be barred from operating if they fail to respond to the educational action, and that an unsatisfactory rating is also given in the second audit.

Moses and Savage (1992) were somewhat critical of many of the individual questions asked as part of the audit. Limited correlations were found between the "no" answers recorded by the inspector for many of the questions, and the accident rate of the carrier. Questions about maintenance procedures and checking the qualifications of employees were not strong predictors of the accident rate of the carrier. Nevertheless there was a subset of the questions that did have a good predictive value. Moses and Savage $(1992,1994)$ found that the questions that were the best predictors of a carrier's accident rate were: whether a carrier had a procedure 
for the reporting of accidents to the government and investigating and disciplining drivers involved in "preventable" accidents, and whether the carrier was familiar with and enforced the hours-of-service regulations. Despite the fact that many of the seventy-five questions were of dubious value, Moses and Savage (1996) found that taken as a whole the audit questions and rating algorithm did provide useful information to identify the worst carriers.

There are a number of lessons that can be learnt from the experience of the FHWA that may be useful if an accreditation system is used for new railroads. The first is that only a minority of the questions asked are designed to find out whether the carrier is familiar with, and complies with, formal government regulations. Many of the questions asked deal with safety-related policies and procedures such as hiring and firing of employees, information systems so that supervisors can ensure that employees are scheduled in compliance with hours-of-service rules, and the investigation of accidents. Questions should therefore not just be oriented to rules familiarity and compliance. Some of the questions that are the most successful in identifying poor carriers are quite general in nature, such as whether the director of safety has the authority to fire offending employees.

The second lesson follows on from the first. There is a strong inference from the most successful, in terms of predicting accident rate, questions in the FHWA audits that the safest carriers are those whose senior management is seen to be concerned with safety, and communicate that concern to employees. Any certification procedure of new railroads by the FRA might be well advised to look for evidence of such a commitment by senior management.

The third lesson is that the FHWA maintains an education overtone to their initial contact with the carrier. Violations will not be written up during the first visit. However, one should not consider the safety audits to be totally a velvet glove experience. The second visit to carriers who have unsatisfactory ratings is the FHWA's primary legal method by which they can close a carrier down.

The second possible model is the Railway Safety Cases (RSC) that bidders for the operations of the privatized railways in Britain were asked to complete (Health and Safety Executive (HSE), 1994). New regulations were required because the previously nationalized vertically-integrated railway system was broken up and passed to the private sector. Track and signaling is now vested in a privately-held infrastructure company, the shares of which are traded on the London stock market. The freight operations were sold to the Wisconsin Central Railroad. Passenger operations were divided into twenty-five regional operations, and franchises were let for periods varying from five to fifteen years. The successful bidders commenced operations between February 1996 and March 1997.

Both the infrastructure company, the buyers of the freight companies, companies that operate stations, and the passenger franchisees all had to prepare an RSC. The purpose of these Cases as explained by the HSE - the British equivalent of OSHA who had assumed the railway safety responsibilities from the British Department of Transport in 1990 - is twofold: 
"(a) to give confidence that the operator has the ability, commitment and resources to properly assess and effectively control risks to health and safety of staff and the general public; and

(b) to provide a comprehensive working document against which management, and also the acceptor and HSE, can check that the accepted risk control measures and safety systems have been properly put into place and continue to operate in the way in which they are intended." (HSE, 1994, paragraph 11)

Table 20.1: Required Contents of British Railway Safety Cases

1. Name and address of operator.

2. A description of the operation.

3. A description of the premises or plant which is intended to be used.

4. Particulars of any technical specifications, and of operating and maintenance procedures.

5. A statement of the operator's general health and safety policy.

6. A statement of significant findings of the operator's risk assessment.

7. Particulars of the operator's safety management system.

8. Particulars to demonstrate that the operator has adequate arrangements for implementing its safety policy, and for ensuring the competence of staff.

9. Arrangements for disseminating safety information both within the organization and to other affected organizations.

10. Arrangements for consulting with employees on health and safety.

11. Arrangements for investigating accidents, if necessary in cooperating with other operators.

12. Arrangements for ensuring the work done by contractors.

13. Arrangements for dealing with accidents and emergencies.

14. For station operators, arrangements for dealing with overcrowding, and for emergency evacuation.

15. Particulars of safety procedures in the design and procurement of premises and plant.

16. Arrangements for safety audits.

17. Arrangements for cooperation on safety matters with other operators.

Source: Heath and Safety Executive (1994) Schedule 1.

An RSC is a series of self-prepared documents which are required to contain a number of items. The required contents are listed in table 20.1. One will immediately note the similarities with the safety audits for trucking firms in that RSCs require operators to demonstrate that they have the safety management structure in place. One interesting difference is item number 6 which requires reporting of the significant findings of a risk-assessment exercise. Actually, this requirement dates from 1992 and applies to all British companies who employ more 
than five people. In general, this item has been found to occupy about a fifth of the total submitted RSC documentation.

To comply with item 6, operators have to identify the major hazards they face, estimate the frequency and consequences of each risk, combine the frequency and the consequences in some kind of risk-ranking matrix, and finally set some criteria for determining which are the high-priority risks. Some operators chose to identify the risks by the outcomes, such as a derailment or a collision, while other operators chose to identify the root cause of the risk, such as brake failures, defective vehicles or track-circuit failures.

Evans and Horbury (1997) examined many of the RSCs and found that few of the operators made actual calculations of the frequency and severity of different types of accidents. However, most did try to rank the risks by categorizing the various risks by broad categories of severity and relative frequency of occurrence. For example, frequency of occurrence might be estimated roughly in five bands such as: less than one occurrence in ten years, once in five to ten years, once in two to five years, once in one to two years, and at least one occurrence a year. Consequences might be categorized as involving: no lost-time injury, a lost-time injury, a major injury, a single fatality, and multiple fatalities. Evans and Horbury observe that the categorization of the various risks was mainly done by judgment, although some statistical sources for the judgments were occasionally quoted. Some RSCs then assigned some weighting system to both the frequency and severity measures, and took either the sum or the product of these weightings to produce a ranking of the various risks they faced, and used this to establish a priority listing.

Evans and Horbury note that the rankings given to common risks by different operators in their RSCs do not always match. However, they argue that the important part of the exercise was not the actual list of risk ranking but rather that the operator had been through a risk-assessment process. Given that the whole objective of the exercise is to prevent myopia by inexperienced companies, this exercise makes the new operators very much aware of the accident risk that they face, and how these risks may be related to preventive action that can be taken.

Preparation of a RSC is a statutory requirement in Britain before a company can start to operate. The RSCs are subject to "acceptance," which implies some degree of approval to the contents of the Case. The RSCs by the operating companies are "accepted" by Railtrack, the track and signaling infrastructure management company, while Railtrack's own RSC is "accepted" by the HSE. While there were certainly instances during the privatization process where a RSC was referred back to the operator because it was "incomplete," there are no examples where Railtrack or the HSE has rejected an RSC. While the legal authority for a rejection, along with an appeals procedure to the Secretary of State for Transport, is in place, there is as yet no precedent for the grounds for rejection.

Some of the similarities to the trucking audits have already been mentioned. The RSCs put an emphasis on management process rather than micro-management of staff training and maintenance procedures. But there are some differences. The first is that RSCs are required prior to operation, and thus fit in with a concept of 
accreditation. The second is that RSCs rely more on self-assessment rather than external evaluation by an inspector. As a result, preparation of a RSC is a lot more time-consuming for the operator than merely spending part of a day with a government inspector. The third is that the RSC is an ongoing process. Operators are required by law to fully review and revise their risk assessment and the documentation of the RSC every three years.

The big difference is pedagogical. The RSC requires a self-assessment of the nature, severity and frequency of possible risks, and an effort by the operator to think about how it will respond to these risks. There is a strong element of encouraging deep thinking and learning by the operator. Some would conclude that a new operator would be less inexperienced and thus is less likely to be myopic about risk after completing the risk assessment exercise than after responding to a series of questions from an inspector.

One problem that might be encountered in transferring the British experience to the United States is the size of the railroads that are involved. The regional British passenger operations are huge in comparison with the typical Class III railroad. However it is worth noting that the requirement for a risk assessment, surely the most interesting aspect of the RSC, applies to all firms in Britain with more than five employees. Perhaps a scaled-down version could be used for Class III railroads. Possibly the risk assessment exercise could be incorporated into the educational programs mounted by the FRA. In such a system, managers of newly-formed railroads would complete the self-assessment exercise as part of their preparation for the seminar. Their submissions would then be discussed in the seminar, and suggestions would be made for improvements as they work with FRA instructors and their fellow course participants.

\section{DESIGNING A DELINQUENCY SYSTEM}

The objective of a delinquency system is to alert the FRA to incumbent railroads who are providing substandard safety performance. In a steady-state world the only railroads that a delinquency system would have to catch are those railroads that are cheating by offering a lower level of safety than they used to. While that might be the role of a delinquency system in the long term, in the short term the delinquency system may also have to detect those railroads who have always offered unacceptable levels of safety.

To a certain extent, the delinquency system is not much different in intent from the FRA's current monitoring and enforcement role. The big difference is the strategy adopted to detect delinquent railroads. The current strategy is to conduct many, semi-random, inspections of track and equipment and then levy fines based on violations found. As discussed in the previous chapter, the effectiveness of this strategy can be questioned, and there are negative side-effects caused by specifying in law equipment design and operating practices. The proposed delinquency system takes an entirely different approach. Under the proposed system FRA staff will 
monitor the performance of individual railroads, and make decisions as to which railroads they suspect may be delinquent. Quite how they might do this will be discussed a little later in this chapter.

So what should the FRA do about railroads that they suspect are delinquent? Obviously the first action is to confirm their suspicions. The FRA already has such a procedure in place in the form of "task force or special assessments" where large teams of FRA inspectors descend on a railroad and conduct inspections of track and equipment, and investigate management policies on hiring, training and scheduling of employees. The findings of such an assessment will clearly determine what action should be taken.

Assuming that the suspicions are grounded, the first thing the FRA should do is to publicize their findings widely. The FRA's enforcement role will be aided considerably if large customers of the railroad under investigation also start to pressure railroad managers to continue to provide the quality of service that they were used to.

The next step will depend on whether the decline in the railroad's quality has been so precipitous that it has fallen below the minimum standards adopted by the FRA. If a railroad has had a decline in safety, but safety is still above the federal minima, the only action that the FRA should take is to ensure that the customers of the railroad are informed so that they can renegotiate their contracts. The FRA only needs to take enforcement actions if they believe that the level of safety is less than the federal minima.

Assuming that enforcement is justified, it would appear that the FRA already has the powers that it needs. Under the 1994 Safety Assurance and Compliance Program the FRA has established a procedure where the FRA's concerns are reported to management and unions. Railroads then have to prepare a one-year plan of action, a remediation plan, to correct the alleged deficiencies. The FRA withholds imposing any fines or penalties for violations found while the railroad is making a good-faith effort to implement their remediation plan.

The "stick" that the FRA wields to ensure compliance is the possibility of imposing penalties if the railroad does not carry out its remediation plan. In the event that an accreditation system is adopted as part of the FRA's educational mission, another possible sanction is that accreditation might be withdrawn. To substantiate penalties, and to provide the legal basis for any removal of accreditation, there would still be a need for a background system of specification standards. The FRA inspectors would use these standards to prepare documentation that can be used in a court of law. The big difference from the current strategy is that inspections of specific equipment and operating practices are used to support the remediation process, rather than as the primary means of identifying delinquent firms.

In extreme cases where imminent danger is discovered, the FRA already has the sanctions of Special Notices and Emergency Orders that can be used to limit operations of certain pieces or equipment or sections of track, or can even be used to close down all or part of a railroad. 


\section{POSSIBLE DELINQUENCY MODELS}

There are two possible models that the FRA might look to. The first is the system that is used by the Office of Motor Carriers of the FHWA to monitor truck and bus companies. The second is a relatively new enforcement system used by OSHA.

The problems facing the FHWA are much more difficult than those faced by the FRA. There are at least 250,000 carriers engaged in interstate commerce, and probably a similar number engaged in intrastate operations. Many of these carriers are owner-operators for whom it may be impossible to schedule visits. Indeed, the FHWA is also not entirely sure how many trucking firms there are in the United States. Officials of the FHWA are only half joking when they say that the Internal Revenue Service has a better idea of how many trucking firms there are than they do. The FRA has a much easier task. There are about 550 railroads in the United States, all of whom are by definition in a fixed location. That number reduces to less than 400 entities when one considers railroads under common management or who are subsidiaries or joint-subsidiaries of larger railroads.

As discussed earlier in this chapter the FHWA does not prequalify carriers to entry into the industry. Therefore, the FHWA is not looking for carriers that are deviating from past performance because it does not know any past performance. Rather, they wish to detect those carriers with poor safety performance per se. One might imagine that the knowledge of accident rates would be the only piece of information the FHWA needs to identify the most dangerous carriers. Those carriers with the highest accident rates must be the worst carriers. Unfortunately, there are severe data and methodological problems with such an approach.

Truck accidents occur relatively infrequently. A trucking firm with an accident rate three times the industry average has a reportable accident rate of one-and-a-half accidents per million miles. An accident is "reportable" if it involves a death, a serious injury, or property damage severe enough that a tow truck has to be called. Seventy percent of trucking firms operate less than 100,000 miles a year, so it is obvious that even very dangerous carriers could be in business for many years without an accident. The FHWA's problem is compounded in that they only know the number of miles operated by forty percent of the carriers. Another forty percent of carriers self-report the number of trucks they own. The FHWA doesn't have any information on the remaining twenty percent of carriers. Consequently, the FHWA cannot calculate accident rates for most carriers.

The FHWA therefore has to rely on a variety of sources of information. First, they have data on accidents obtained from reports filed by attending police officers. Second, they have access to traffic violations written by police officers. Third they have complaints submitted by members of the public. Fourth they have local "intelligence" from their own inspectorate. Fifth, they have some idea of the "profile" of poor carriers such as size, corporate structure, and the type of work they are engaged in. Sixth they have the Safety Audits described earlier in the chapter. Finally there is a system of uniform inspections of vehicles and drivers which are 
conducted at the roadside. Over one-and-a-half million trucks are inspected each year. Many are conducted at existing weigh stations where all trucks are required to stop when stations are open. Other vehicles are pulled over by specialist officers who patrol in cars.

Moses and Savage (1996) found that carriers that do poorly in both the roadside inspections and the Safety Review audits have accident rates significantly above those of other carriers. The research also found that the roadside inspections and the audits are complements and not substitutes. Information from both programs is needed to isolate the worst carriers.

The FHWA has a system called the Motor Carrier Management Information System (MCMIS) which should contain the various items of intelligence about individual carriers. Starting in early 1997, the FHWA produced an algorithm called the Safety Status Measurement System, or SafeStat. The algorithm contains information on safety audits, accident reports, and the results of roadside inspections of drivers and vehicles. Information from this system directs the monitoring and enforcement activities of the FHWA. The FHWA is making real-time information available to roadside inspectors to guide them to the trucks from companies that have not been inspected frequently, if at all, or have poor records in audits. Trucks from companies with good records, who can signal ahead that information by a transponder, can bypass safety checkpoints. Carriers who are in good standing with the FHWA are also allowed flexibility from more of the mundane record keeping requirements under the Motor Carrier Relief Demonstration Program. To be eligible for this program, a carrier has to receive a favorable safety audit and maintain an accident rate that would put it in the top quarter of the industry for a period of three years.

Importantly a suspicion that a carrier is delinquent can trigger a Safety Review audit if the carrier has not already had one. An unsatisfactory rating in a Safety Review triggers the enrolling of the carrier in the FHWA's "Selective Compliance and Enforcement" program. This program is partly educational and partly enforcement. The enforcement part is by the scheduling of a second audit termed a "Compliance Review." These second audits are much more detailed than the "Safety Review" and involve twenty-eight FHWA staff hours compared with the two to three hours for the initial audit. In addition to reexamining the carrier on the same questions as the first audit, inspectors also determine whether legal enforcement action is necessary, and can collect evidence to support any citations. In the extreme, evidence collected at a Compliance Review can be used to support legal action by the FHWA to close down dangerous carriers.

There are a number of lessons that would be useful in a railroad setting. The first is the contrast in the scale of the problem that the FRA faces compared with that of the FHWA. In the case of railroads it would be perfectly feasible to conduct the equivalent of a Safety Review audit on every railroad in the country each year.

The second is that the FRA like the FHWA faces the problem that even bad small carriers have accidents so infrequently that annual accident rates are not a useful guide for evaluating safety performance. This would be the case for all Class III and 
some of the Class II railroads. The FRA would have to rely on other pieces of information.

Another possible model is the Cooperative Compliance Program of OSHA. This program, barring successful legal challenges, will be applied nationwide in 1998, following pilot programs since 1993 in Maine and eight other states. The "Maine 200" program, is it was colloquially known, offered the 200 firms with the highest number of workplace injuries a choice between traditional OSHA inspections and a new approach. The program focused on the largest employers. The firms in the Maine program represented a third of the total employment in the state and originally almost half of the annual injuries. Smaller firms in Maine were subject to traditional methods of OSHA inspection.

The new approach required self-inspections and the taking of responsibility for planning and implementing health and safety improvements. To a certain extent there are strong similarities with the Railway Safety Cases required in Britain. Firms have to show plans of how they deal with injuries occurring in the workplace, conduct a self-examination based on existing OSHA standards, develop within thirty days a plan to abate hazards that are found, eliminate the hazards in twelve months, and report quarterly to OSHA on progress made. Failure to make a good-faith effort to improve would precipitate the firm's removal from the program and subject it to traditional OSHA inspection-citation-fine strategies. There are no numerical targets for injury reduction. Therefore, it is not entirely clear how OSHA would deem that a firm was making a good faith effort to improve.

An evaluation of the effects of the pilot program in Maine found that firms had uncovered more violations during their self-examinations that OSHA inspectors had been able to in previous inspections. Subsequently these firms corrected seventy percent of the violations and were able to reduce workers' compensation claims by forty-seven percent. This compared with a decrease of ten percent for other Maine firms that were not in the program.

The OSHA system is not strictly a pure delinquency system. The system does not aim to prevent cheating per se. Rather it takes a snapshot of the largest firms, determines which firms have the worst safety records, and attempts to enjoin the management of those firms in self-assessment and correction of safety problems. The Maine 200 program won an Innovation in American Government Award from the Ford Foundation in 1995. There are clearly some parallels to the FRA's Safety Assurance and Compliance Program. The difference is that OSHA's system is far more radical. If the OSHA system was applied to the railroads, it is likely that all of the Class I and Class II railroads would conduct their own self-examinations, all traditional FRA inspections of track and equipment would cease, and the FRA inspectorate would spend their time monitoring progress of the railroads in their plans to abate hazards. 


\section{IDENTIFYING DELINQUENT RAILROADS}

The proposed delinquency system incorporates elements of both of the FHWA and OSHA systems. The proposed system has an information phase that identifies those railroads with poor and/or declining safety records, and a remediation phase into which offending railroads would be enrolled which would be similar to the FRA's current Safety Assurance and Compliance Program.

The novel aspect is designing an information system. Of course, the most obvious question is whether this needs to be a formal system. After all, FRA inspectors are intelligent people with considerable local knowledge. It is almost certain that any FRA inspector could list which railroads in his or her area have the most dubious safety records. Unlike the trucking industry, there are relatively few companies in the railroad industry, and it would not be beyond the bounds of reason that local FRA offices could make simple judgment calls.

However, there are flaws in such a system. Railroad managements can rightly demand that the FRA has an objective system that is divorced from possible biases by FRA inspectors. The vital question is identifying a series of measures of safety performance that are useful and practical.

\section{Input Measures versus Output Measures}

The traditional objection to use of measures of accidents to identify delinquent railroads is that it is inherently an ex-post identification of myopic firms. The FRA can only observe which railroads are myopic after the accident rate has increased. Ideally one would wish to detect myopic railroads prior to the point at which the number of accidents increases. Myopia is caused when a railroad starts to weight current costs more heavily than future costs. This is mainly occasioned by short-term financial expediency by the railroad which might be caused by a decline in revenues, possible bankruptcy, or the wish to look attractive for stock offerings or if they are a takeover target. The FRA would probably want to have a system which alerts them to changes in financial conditions of individual railroads. In addition, the FRA might develop an information system on safety inputs that might be used to alert them to railroads that do not seem to be spending as much on track maintenance as they used to or who are allowing the average age of their locomotives to increase. Information on staff turnover might be used as an indication of railroads whose working conditions have deteriorated so that employees wish to resign. A legacy of the many years of regulation is that the largest firms in the industry are already required to submit much of this information to the government.

Of course, the link between financial condition or measures of safety inputs and the number of accidents is tentative, and not well understood. It is possible that financial measures and safety-input measures could decline without affecting safety performance. Conversely, safety performance can decline for reasons that are not captured by financial and input measures. For this reason the FRA would also wish to have measures of accident performance in its information system. 
There is an additional benefit from defining minimum acceptable accident-performance measures. Responsible firms will be deterred from myopic behavior if there are clearly stated minimum performance standards that they can meet that would obviate scrutiny by the FRA. From a societal point of view it is much more beneficial to state these minimal objectives in terms of safety outputs rather than by the existing system where acceptable performance is stated in terms of the minimum quality and quantity of safety inputs. The benefit comes from the ability of railroads to use their managerial ability to achieve at least the minimum level of safety by using the most efficient combination of safety inputs.

\section{Defining Measures of Safety Performance}

What accident measures should be used? There are a number of considerations that will help define the best measures.

Timeliness: One cannot escape the fact that accident data is an ex-post identification of myopia. This problem can be minimized if one measures accidents that occur relatively frequently. It is pointless to use the occurrence of a major catastrophe as the catalyst for identifying delinquent railroads. These events occur rarely, and to react only after such an event can certainly be described as "closing the stable door after the horse has bolted." The measures of safety performance should use a wider definition of accidents. Currently a collision or derailment is reportable to the FRA if it results in a fatality, or an injury or more than $\$ 6,300$ in damage to railroad property. The average Class I railroad has more than 130 reportable collisions and derailments a year. With this frequency of accidents, the FRA should be able to identify an upward trend for any railroad relatively quickly and hopefully prior to the incidence of major catastrophes.

Measuring different risks: Separate measures should be developed for each of the major risks associated with railroading. It would seem sensible to separate out the risks of collisions and derailments from those of employee injuries or grade-crossing accidents or trespasser fatalities. Each of these different types of risk have different causal factors and demand different responses.

Data Integrity: To make the analyses meaningful, one needs measures of safety that are reported consistently, and cannot easily be falsified. Consequently, measures need to be relatively simple, and not require judgment on the part of the railroad as to whether to report an accident. A GAO audit (1989b) of five railroads found serious underestimating of the number of lost workdays by injured employees and inaccurately estimating of the property damage from train accidents. All but one of the railroads was found to lack a system for tracked the number of days that an employee was away from work following an injury. The magnitude of the underreporting was large. The railroads reported 2,176 lost workdays by injured employees, whereas the GAO determined that in actuality the figure was 8,023. The GAO also looked at unreported cases of injured employees, and found that twelve percent of cases were serious enough to need to be reported. The moral is 
that it is more reliable to measure the number of injured employees rather than to try to use the more sophisticated measure of total workdays lost.

A similar problem was found with the estimates of property damage in accidents. With the exception of one of the railroads, the GAO found that estimates of property damage were made at the scene of an accident and the degree of understating of property damage was in the range of fifty to sixty percent. As a result, some property-damage-only accidents were not reported even though they should have been had property damage been estimated properly. Again this emphasizes that measures should be based on criteria that do not require too much judgment from the officials completing accident reports.

Of course, a railroad that decides to cheat will be predisposed to cover up that cheating by deliberately underreporting accidents. This is obviously undesirable from two points of view. The first is that the FRA might be misled into not noticing that the railroad is cheating. The second is that a railroad management that communicates to its employees that they should be "careful" in deciding whether to report accidents is implicitly communicating that senior management does not take safety very serious, and that may cause employees to be less diligent than they might otherwise be. Moses and Savage (1994) found that the truck carriers that did not comply with government regulations on accident reporting had a worse accident rate even on the records of accidents found by federal inspectors during safety audits. The magnitude of the effect was large. Carriers who were deficient in reporting had an accident rate nine times higher than those that did report. Accident measures should be chosen in such a way that it is difficult for railroads to falsify reports, and the FRA as part of its delinquency system will have to audit railroads to ensure that there is not deliberate underreporting. It may be necessary to increase the penalties for false reporting.

Changes in exposure to risk: The FRA will need to be sensitive to changes in exposure to risk. Railroads vary in size, and even an individual railroad can change its size from year to year. During economic upturns, more train miles will be run and the number of accidents will increase. Therefore, for each measure of adverse safety occurrences there needs to be an appropriate measure of the exposure of the railroad to that risk.

Data variability: To be able to draw meaningful comparisons between one year and the next, the FRA should choose measures that do not suffer from wide fluctuations. For example, it might be intuitively appealing to define measures that combine severity of accidents with frequency of occurrence. Accidents that cause fatalities or evacuation of many people from an accident involving hazardous materials might be given greater weight than one that only involves property damage. However, such measures are also problematic. The problem is that accidents with serious consequences occur rarely. Hence the annual data will be skewed by the years with large catastrophes and consequently the calculated variance of the data will be large. As described by elementary statistical theory, the larger the variance in the data, the more difficult it is to determine whether the number of accidents in a given year is statistically significantly different from the 
historical average for that railroad. It may be more statistically powerful to use a simple measure such as the number of collisions and derailments rather than attempt to use a more sophisticated measure that incorporates the severity of the accident.

\section{Analyzing Measures of Safety Performance}

Of course, there will still be some variability in the data from year to year because while one can anticipate that a certain amount of preventive effort will result in a certain average number of accidents a year, one cannot define exactly when an accident will occur. Pure chance plays a role. A railroad may be "lucky" in not having very many accidents one year, but consequently have more accidents in a subsequent year. The FRA would clearly wish to be intelligent enough to incorporate these natural year-to-year fluctuations into their analytical process.

Fortunately statistical theory provides the necessary tools. Statisticians usually claim that accident occurrence is explained by the Poisson distribution. The probability that a railroad will have $x$ adverse safety occurrences in a given year is given by the formula:

$$
\text { Probability }(x \text { occurrences })=\frac{e^{-\lambda M}(\lambda M)^{x}}{x !}
$$

where $\lambda$ is the probability of an occurrence (e.g., the derailment and collision probability per train mile), and $M$ is the exposure to occurrences (e.g., annual train miles). The expected number of occurrences in a given year is obviously $\lambda M$. The value of $\lambda$ is determined by the preventive efforts made by the railroad. The more preventive efforts undertaken, the less will be the value of $\lambda$.

The actual number of occurrences observed is unlikely to be exactly $\lambda M$, but rather will be distributed around $\lambda M$ as described by the Poisson distribution. The problem facing the FRA is to determine whether the number of occurrences observed for a particular railroad in a particular year has deviated upward from the mean number expected for that railroad. Statisticians make that determination by using a one-tailed significance test. Statisticians look to see how far the observed value is from the mean. It is called a one-tailed test because the FRA is only interested in railroads whose safety performance is declining, that is to say that the observed number of occurrences is greater than the mean.

Of course, almost any level of observed number of occurrences is possible, and is consistent with the mean given the inherent variability in the Poisson process. However, the further the observed number is from the mean, the less likely it is to occur. For example, consider a railroad that averages 100 collisions and derailments a year? Equation (20.1) determines that this railroad will have more than 107 accidents one year in every four, will have more than 117 accidents one year in every twenty, and more than 120 accidents one year in every forty.

How many accidents does this railroad need to have in a given year before the FRA suspects that the preventive efforts of the railroad have declined and the 
expected number of accidents is greater than 100 ? There is not a clear-cut answer to this question. Clearly one increases the chance of detecting a myopic railroad if the critical value of the number of accidents was set at 107. This is technically known as minimizing the chance of a type II error. However, one also stands a one in four chance of falsely accusing a responsible railroad. This is known as a type I error. The reader will appreciate that there is a tradeoff between the sizes of the type I and type II errors. For this reason, statisticians typically use the five-percent significance level, which is to say that critical value above which the count of occurrences would only fall outside by pure chance once every twenty years.

Table 20.2: Critical Values for One-Tailed Statistical Significance (with percentage variation above the mean)

\begin{tabular}{|c|c|c|c|}
\hline \multirow{2}{*}{$\begin{array}{c}\text { Mean Number of } \\
\text { Annual } \\
\text { Occurrences }\end{array}$} & \multicolumn{3}{|c|}{ One-Tailed Significance Level } \\
\cline { 2 - 4 } & $25 \%$ & $5 \%$ & $2 \frac{1}{1 / 2} \%$ \\
\hline 1 & $2(+100 \%)$ & $2(+100 \%)$ & $3(+200 \%)$ \\
\hline 2 & $3(+50 \%)$ & $5(+150 \%)$ & $5( \pm 150 \%)$ \\
\hline 3 & $4(+33 \%)$ & $6(+100 \%)$ & $7(+133 \%)$ \\
\hline 4 & $5(+25 \%)$ & $8(+100 \%)$ & $8(+100 \%)$ \\
\hline 5 & $6(+20 \%)$ & $9(+80 \%)$ & $10(+100 \%)$ \\
\hline 10 & $12(+20 \%)$ & $15(+50 \%)$ & $17(+70 \%)$ \\
\hline 20 & $23(+15 \%)$ & $28(+40 \%)$ & $29(+45 \%)$ \\
\hline 30 & $34(+13 \%)$ & $39(+30 \%)$ & $41(+37 \%)$ \\
\hline 50 & $55(+10 \%)$ & $62(+24 \%)$ & $64(+28 \%)$ \\
\hline 100 & $107(+7 \%)$ & $117(+17 \%)$ & $120(+20 \%)$ \\
\hline 200 & $209(+5 \%)$ & $223(+12 \%)$ & $228(+14 \%)$ \\
\hline 300 & $312(+4 \%)$ & $329(+10 \%)$ & $334(+11 \%)$ \\
\hline 500 & $515(+3 \%)$ & $537(+7 \%)$ & $544(+9 \%)$ \\
\hline 1000 & $1021(+2 \%)$ & $1052(+5 \%)$ & $1062(+6 \%)$ \\
\hline \multicolumn{3}{|l}{} \\
\hline
\end{tabular}

The critical values for three levels of significance are shown in table 20.2 for differing levels of the expected number of occurrences (i.e., $\lambda M$ ) between one and 1,000 per year. The critical value is also expressed as the percentage variation above the mean. Focusing on the middle column representing the five-percent significance level, one can observe an important implication. For a railroad that only averages three occurrences a year, one would need to observe six occurrences before one can be statistically confident that the railroad is offering reduced safety. This implies that the accident rate has doubled. Yet for a larger railroad that averages 200 occurrences a year, the number only has to increase by twelve percent before one is statistically confident that safety has declined. Clearly, statistical tests 
based on the Poisson distribution are more powerful, and more likely to detect myopia for the larger railroads.

It is probably fair to say that for measures of safety performance that occur less than fifty times a year, the size of the year-to-year variation is so large in percentage terms that it may be difficult in practice to draw meaningful statistical conclusions. Fortunately, the situation is less discouraging if a railroad is observed over multiple years. Consider the twenty-five-percent significance level. A railroad would have an occurrence count above this level by pure chance one year in every four. However, if the railroad falls above the critical value for two years in a row, then the probability that this event will occur purely by chance, and not due to poor safety precautions by the railroad will be $1 / 4^{2}$ or one chance in sixteen. The probability that the railroad would fall above the critical value by pure chance for three years in a row is $1 / 4^{3}$ or year in sixty-four, a very small probability. On this basis it is possible that meaningful statistical inference can be drawn on railroads that average as few as five or six occurrences a year.

Table 20.3: Average Number (and Range) of Accidents 1995

\begin{tabular}{|l|c|c|c|c|}
\hline & $\begin{array}{c}\text { Collisions } \\
\text { and } \\
\text { Derailments }\end{array}$ & $\begin{array}{c}\text { Employee } \\
\text { Fatalities and } \\
\text { Injuries }\end{array}$ & $\begin{array}{c}\text { Trespasser } \\
\text { Fatalities }\end{array}$ & $\begin{array}{c}\text { Grade } \\
\text { Crossing } \\
\text { Accidents }\end{array}$ \\
\hline Class I & $\begin{array}{c}137 \\
(41-353)\end{array}$ & $\begin{array}{c}579 \\
(84-1273)\end{array}$ & $\begin{array}{c}39 \\
(1-85)\end{array}$ & $\begin{array}{c}304^{1} \\
(47-621)\end{array}$ \\
\hline Class II & 10 & 31 & 1 & 10 \\
Freight & $(1-39)$ & $(5-139)$ & $(0-12)$ & $(0-78)$ \\
\hline Class II & 5 & 236 & 9 & 7 \\
Passenger & $(0-17)$ & $(51-558)$ & $(1-27)$ & $(0-15)$ \\
\hline Class III ${ }^{2}$ & 0.13 & 4.37 & 0.05 & 1.28 \\
\hline \\
Sourcludes Amtrak who operate over other company's lines ${ }^{2}$ Range is not reported \\
Sourced (1996a)
\end{tabular}

To consider the practical implications of the above statistical reasoning, consider the frequency with which four major types of safety problems occur. The four types are: collisions and derailments, employee injuries and fatalities, trespasser fatalities away from grade crossings, and accidents at grade crossings. Table 20.3 shows the average annual number of these safety occurrences in 1995 for four different categories of railroads: Class I, Class II freight, Class II commuter passenger, and Class III. Also shown is the range of the number of these occurrences for the first three categories of railroads. The published FRA data does not break down the number of occurrences by individual railroads for Class III railroads.

Statistical analyses of occurrence rates could certainly be possible for looking at collisions and derailments, employee casualties and grade crossing accidents of Class I railroads. Trespasser fatalities on individual Class I railroads could be analyzed if looked at over several years. The same is likely to be true for collisions 
and derailments, employee casualties and grade crossing accidents for the Class II railroads. However, it is unlikely that statistical techniques will be suitable for Class III railroads. An average-sized Class III railroad injures four employees a year, has one grade-crossing accident a year, kills a trespasser once every twenty years and has a collision or derailment once every seven-and-a-half years.

\section{TIME-SERIES ANALYSIS OF ACCIDENT RATES}

This section takes the theoretical discussion of the previous section and applies it to data on Class I and II railroads in the early 1990s. The objective of the analysis is to observe whether the performance of individual railroads was worse in 1994 and 1995 than it was in the earlier part of the decade. Analysis of this type will permit identification of those railroads which the FRA might suspect are indulging in reduced prevention.

Two measures of safety performance are used: the number of collisions and derailments and the number of employee fatalities and injuries. These are aspects of safety which one might assume are under the control of railroad management, unlike trespasser and grade-crossing accidents which are affected by the geographic location of the railroad.

The first step in the analysis is to estimate the expected number of occurrences that each railroad would have in 1994 or 1995, based on its performance in 1991-93. This is calculated in such a way to take into consideration changes in the exposure of the railroad to risk, and changes in the general rate of collisions and derailments or employee casualties in the industry that might indicate changes in technology or working practices that are common to all railroads. For example, the formula that is used for predicting the occurrences on railroad $i$ in 1994 is:

$$
\text { Expected number of occurrences }{ }_{i, 94}=\lambda_{i, 94} * M_{i, 94} * \frac{\lambda_{k, 94}}{\lambda_{k, 91-93}}
$$

where $\lambda_{i, 91-93}$ is the occurrence rate for railroad $\mathrm{i}$ in the years 1991-93;

$M_{i, 94}$ is the amount of exposure to the risk in year 1994;

$\lambda_{k, 94}$ is the overall occurrence rate for that subsection of the industry to which railroad i belongs in 1994. For this purpose the industry was split into three segments: Class I railroads, Class II freight railroads, and Class II commuter railroads; and

$\lambda_{k, 91-93}$ is the overall occurrence rate for that subsection of the industry to which railroad i belongs in 1991-93.

One problem was encountered during the analysis. The Burlington Northern Railroad managed to improve its employee fatality and injury rate significantly from 1991-93 to 1994 and 1995. Because this railroad is so large, it reduced the Class I average employee casualty rate so much that it made it appear that all of the other Class I railroads were getting worse. In actuality, the employee casualty rates of most of the other Class I railroads were also declining, and were doing so from a 
much lower level. Therefore expected employee casualties for the Class I railroads were not adjusted by the final term in equation (20.2).

The actual number of occurrences in 1994 and 1995 is then compared with the relevant predicted number. The ratio of the actual number of occurrences to the predicted number is shown in table 20.4. A value of greater than 100 indicates that the actual number of occurrences was greater than that predicted. Table 20.2 is then used to see if the observed number is above the critical value based on the assumption that the predicted value is the mean value shown on the first column. If the actual number of occurrences was greater than the twenty-five percent critical value, an "*" is placed next to the ratio. If it exceeded the five-percent critical value, a "**" is placed next to the ratio.

A decision rule is then necessary to decide which railroads had significantly worse performance. One rule might be that a railroad is suspected of deteriorating safety if it has either (a) one year in which the observed number of occurrences falls above the five-percent critical value, or (b) the observed number of occurrences falls outside the twenty-five-percent critical value in both years. The probability of a Type I error, which is to say that a railroad that is not deviating from past performance is falsely accused is one in twenty for the first criteria and one in sixteen for the second criteria.

Among the Class I railroads the Kansas City Southern shows the worst deterioration in the number of collisions and derailments, with the Burlington Northern, Conrail, and the Grand Trunk Western also showing statistically significant declines. Only Amtrak appears to have significantly worse employee fatalities and injuries compared with earlier in the decade.

Among the Class II freight railroads the Belt Railroad of Chicago; the Duluth Missabe and Iron Range; the Elgin, Joliet and Eastern; the Union Railroad of Pittsburgh; and the Wisconsin Central had statistically higher numbers of collisions and derailments than earlier in the decade. Worsening employee casualties are found at the: Belt Railway of Chicago; Bessemer and Lake Erie; Chicago, Central and Pacific; Florida East Coast; Indiana Harbor Belt; Texas Mexican; and Wisconsin Central.

Among the Class II commuter passenger railroads the Long Island Railroad had an increasing number of collisions and derailments and increased employee casualties were at the Northeast Illinois, Northern Indiana, and Southeastern Pennsylvania systems. 
Table 20.4 Time-series Analysis of Individual Railroads

\begin{tabular}{|c|c|c|c|c|}
\hline & \multicolumn{4}{|c|}{ Ratio of Actual to Predicted Occurrences } \\
\hline & \multicolumn{2}{|c|}{$\begin{array}{l}\text { Collisions \& } \\
\text { Derailments }\end{array}$} & \multicolumn{2}{|c|}{ Employee Casualties } \\
\hline & 1994 & 1995 & 1994 & 1995 \\
\hline \multicolumn{5}{|l|}{ Class I Railroads } \\
\hline Amtrak & $118 *$ & 103 & $110 * *$ & $112 * *$ \\
\hline Atchison, Topeka and Santa Fe & 85 & $110 *$ & 48 & 31 \\
\hline Burlington Northern & $113^{*}$ & $127 *$ & 38 & 28 \\
\hline Chicago and North Western & 107 & - & 79 & - \\
\hline Consolidated Rail Corp. & $112^{*}$ & $106^{*}$ & 88 & 64 \\
\hline CSX Transportation & 80 & 79 & 73 & 52 \\
\hline Grand Trunk Western & $122 *$ & $111^{*}$ & 87 & 79 \\
\hline Illinois Central & 88 & 66 & 73 & 58 \\
\hline Kansas City Southern & $301 * *$ & $286 * *$ & 82 & 67 \\
\hline Norfolk Southern & 101 & 85 & 77 & 65 \\
\hline Soo Line & 99 & 95 & 93 & 89 \\
\hline Southern Pacific & 91 & 97 & 80 & 63 \\
\hline Union Pacific & 89 & 81 & 67 & 54 \\
\hline Class I average & 85 & 83 & - & - \\
\hline \multicolumn{5}{|l|}{ Class II Freight Railroads } \\
\hline Alaska & 49 & 119 & 84 & 103 \\
\hline Alton and Southern & 96 & 61 & 105 & $164 *$ \\
\hline Bangor and Aroostook & 44 & 45 & 80 & 99 \\
\hline Belt Railway of Chicago & $225 * *$ & $141 * *$ & $191 * *$ & 53 \\
\hline Bessemer and Lake Erie & 314 & 398 & 101 & $211 * *$ \\
\hline Birmingham Southern & 0 & 147 & 65 & 80 \\
\hline Chicago, Central and Pacific & 77 & 66 & $139 * *$ & $112 *$ \\
\hline Cuyahoga Valley & - & - & 84 & - \\
\hline Dakota, Minnesota and Eastern & 109 & 93 & 67 & 96 \\
\hline Delaware and Hudson & 115 & $163^{*}$ & 91 & $126^{*}$ \\
\hline Duluth, Missabe and Iron Range & $148 *$ & $185 *$ & 83 & 102 \\
\hline Elgin, Joliet \& Eastern & $137 *$ & $236 * *$ & 106 & 59 \\
\hline Florida East Coast & 51 & $150 *$ & $180^{* *}$ & $212 * *$ \\
\hline Gateway Western & 112 & 67 & 73 & 95 \\
\hline Houston Belt \& Terminal & 71 & 62 & $132 *$ & 101 \\
\hline Indiana Harbor Belt & 80 & $115^{*}$ & $134 * *$ & $151 * *$ \\
\hline Montana Rail Link & 82 & 86 & 56 & 71 \\
\hline Paducah and Louisville & 0 & 93 & 91 & 103 \\
\hline Port Terminal (Houston, TX) & 65 & 21 & 79 & 74 \\
\hline
\end{tabular}


Table 20.4 (continued)

\begin{tabular}{|l|c|c|c|c|}
\hline \multirow{2}{*}{} & \multicolumn{4}{|c|}{ Ratio of Actual to Predicted Occurrences } \\
\cline { 2 - 5 } & \multicolumn{2}{|c|}{$\begin{array}{c}\text { Collisions \& } \\
\text { Derailments }\end{array}$} & \multicolumn{2}{c|}{ Employee Casualties } \\
\cline { 2 - 5 } & 1994 & 1995 & 1994 & 1995 \\
\hline Springfield Terminal & 36 & 8 & 56 & 69 \\
\hline Terminal Railroad of State Dock & 110 & 101 & 42 & 99 \\
\hline Texas Mexican & 65 & - & $151^{* *}$ & - \\
\hline Union Railroad (Pittsburgh) & $190^{*}$ & $223^{* *}$ & 105 & 87 \\
\hline Wheeling and Lake Erie & 75 & $136^{*}$ & 50 & 56 \\
\hline Wisconsin Central & $117^{*}$ & $115^{*}$ & $131^{* *}$ & $141^{* *}$ \\
\hline Class II freight average & $\mathbf{1 0 0}$ & $\mathbf{8 9}$ & $\mathbf{9 6}$ & $\mathbf{8 7}$ \\
\hline Class II Commuter Railroads & \multicolumn{5}{|l}{} \\
\hline Long Island & $184^{* *}$ & $135^{*}$ & 89 & 78 \\
\hline Metro North & 114 & 86 & $104^{*}$ & 92 \\
\hline New Jersey Transit & 68 & 48 & 107 & 41 \\
\hline Northeast Illinois Regional & 67 & $241^{*}$ & $110^{*}$ & $113^{*}$ \\
\hline Northern Indiana Commuter & 137 & 0 & $118^{*}$ & $129^{*}$ \\
\hline Port Authority Trans Hudson & 0 & 148 & 87 & 85 \\
\hline Southeastern Pennsylvania & 27 & 40 & $142^{* *}$ & $128^{* *}$ \\
\hline Class II commuter average & $\mathbf{1 0 8}$ & $\mathbf{9 9}$ & $\mathbf{9 3}$ & $\mathbf{7 9}$ \\
\hline
\end{tabular}

\section{CROSS-SECTIONAL ANALYSIS OF ACCIDENT RATES}

In the long run the FRA would only be interested in identifying railroads that are deviating from their, presumably satisfactory, past safety performance. However, at least in the short run, the FRA might also wish to identify which railroads have the worst safety performance per se. While the FRA should clearly be interested in any railroad whose performance is deteriorating, it should give high priority for further investigations to those railroads that have poor records to start with.

Prior to a formal analysis, it is instructive to look at some graphical plots for Class I and II railroads in 1995. Figures 20.1 through 20.4 plot the accident rates for four measures of safety against exposure. The four measures are: collisions and derailments per million train miles, employee fatalities and injuries per million employee-hours, trespasser fatalities per train mile, and crossing accidents per crossing. The Class I railroads are shown as the squares, the Class II freight railroads as the triangles and the Class II commuter passenger railroads as the crosses. The horizontal lines represent the average accident rate for each of the three types of railroads. 
Figure 20.1: Collisions and Derailments per Million Train Miles 1995

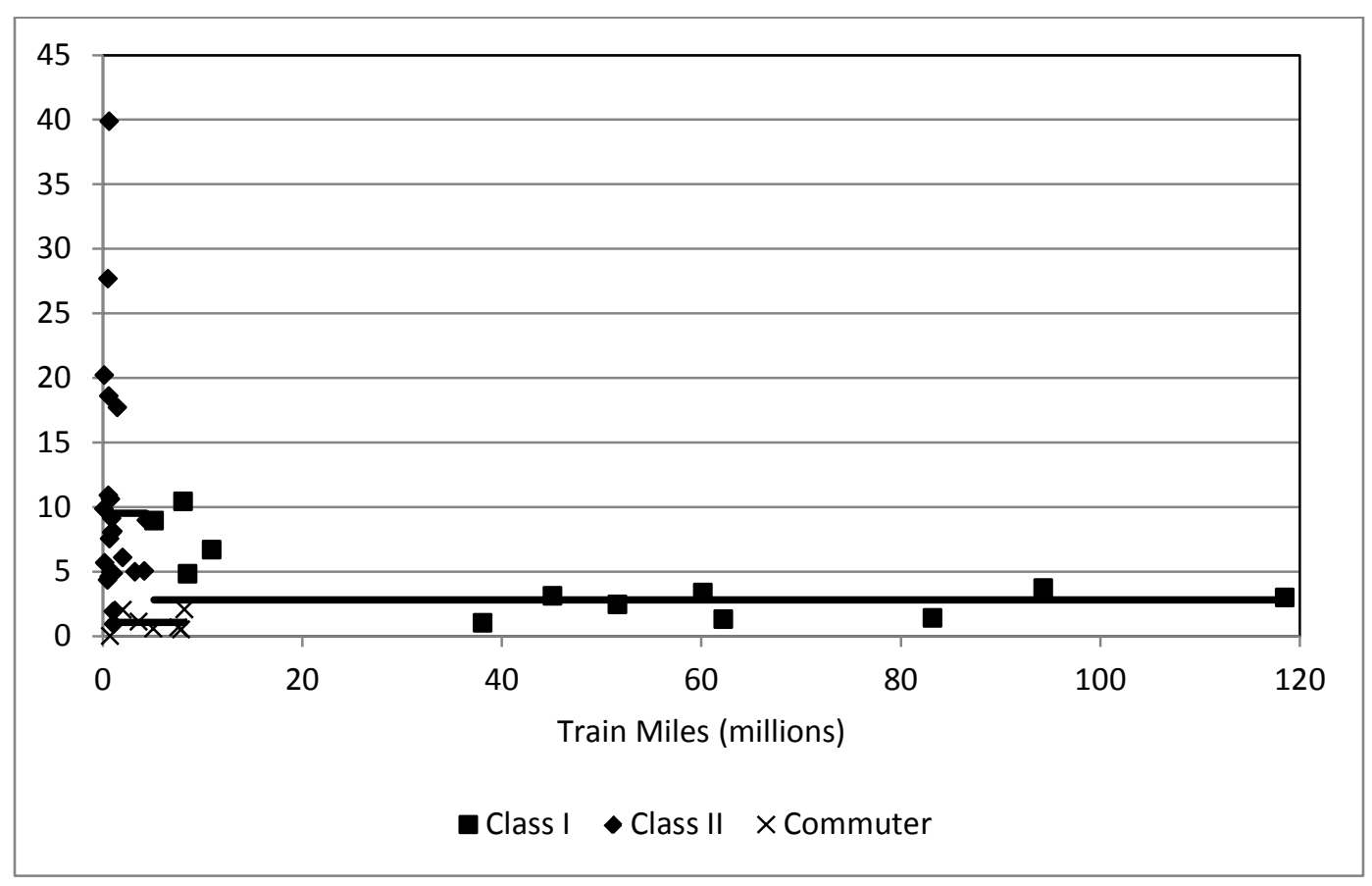

Figure 20.2: Employee Casualties per Million Employee Hours 1995

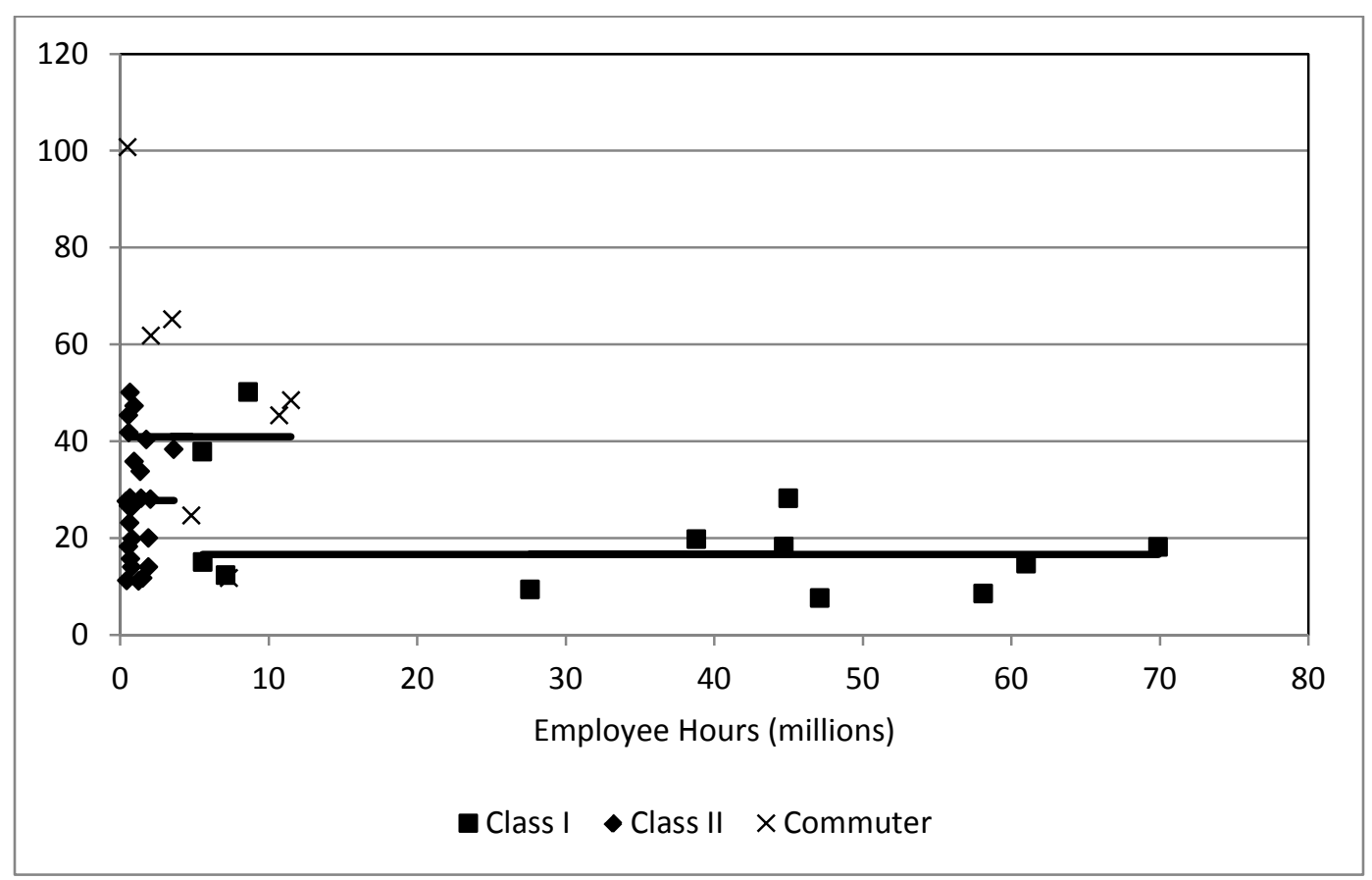


Figure 20.3: Trespasser Fatalities per Million Train Miles 1995

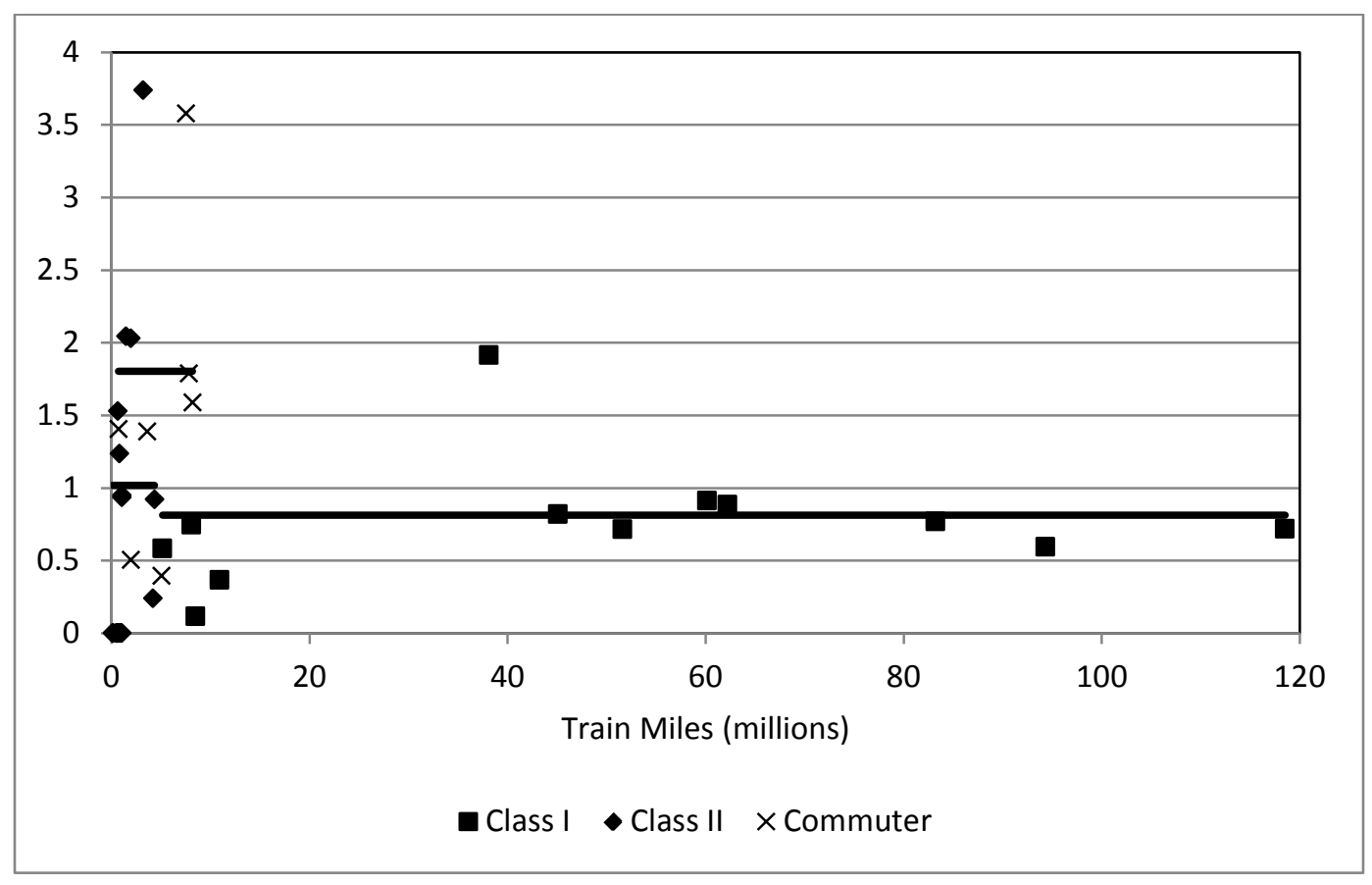

Figure 20.4: Crossing Collisions per Crossing 1995

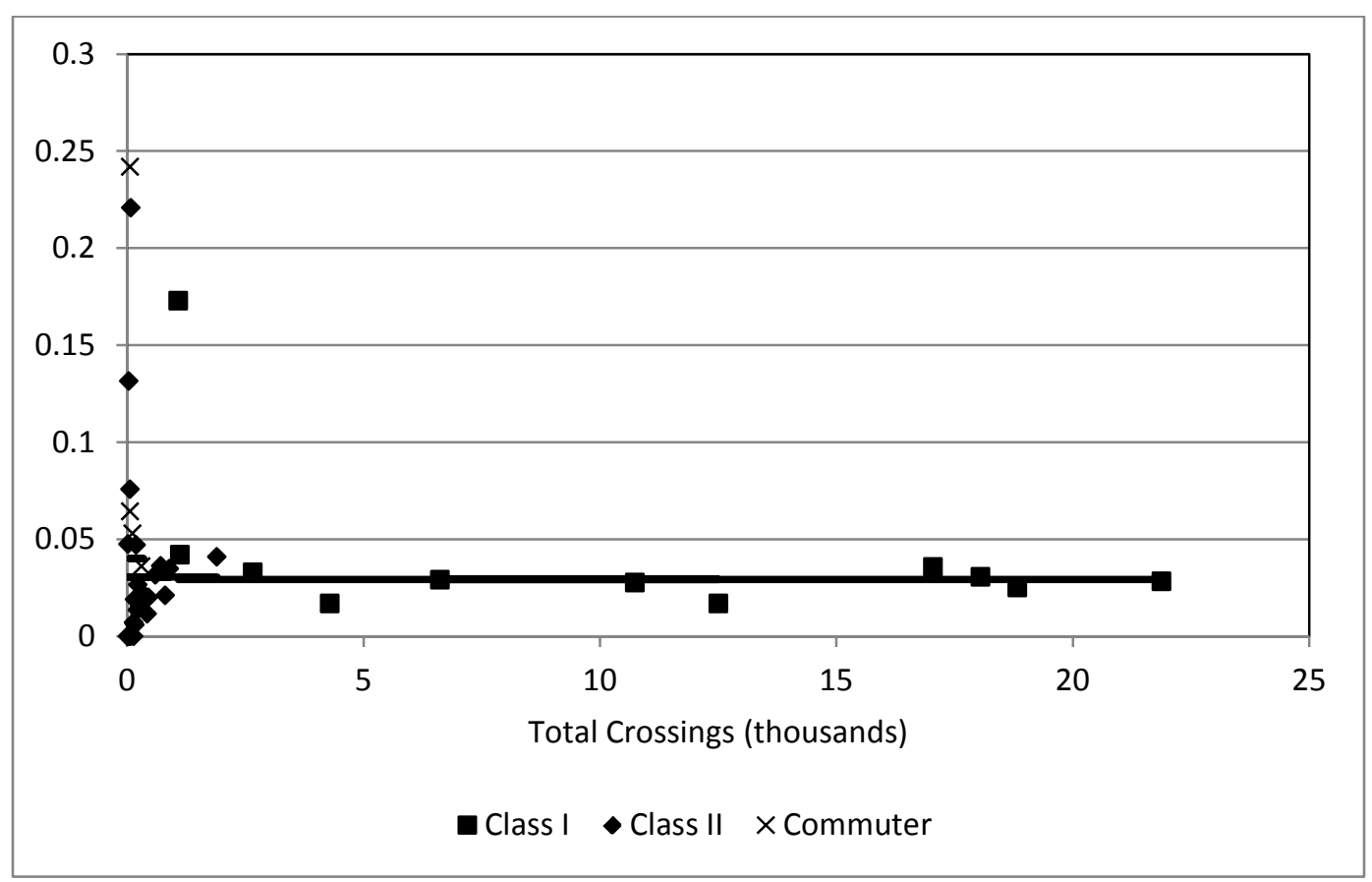


Turning first to the rate of collisions and derailments, the commuter railroads have the lowest rate, at only forty percent of that of the Class I railroads. The Class II railroads have an average collision and derailment rate equivalent to the worst of the Class I railroads. Of course, a major explanation is that these railroads are involved in relatively more switching. Three Class II freight railroads have a collision and derailment rate more than three times the average. One of these, the Belt Railway of Chicago has a rate of almost nine times the average and is not shown in figure 20.1.

Employee fatalities and injuries per million employee hours are shown in figure 20.2. The Class I railroads have the lowest rate at 9.5 fatalities and injuries per million employee hours. Class II freight railroads have injury rates about seventy percent higher than the Class I railroads. In general the injury rates for the various Class II railroads are closely grouped around the mean with no railroad having an injury rate of more than twice the mean. Commuter railroads have an injury rate two-and-a-half times that of the Class I railroads.

The rate of trespassing fatalities per train mile, shown in figure 20.3, confirms earlier analyses of the trespassing problem. Trespassing is primarily an urban problem and the fatality rate for commuter railroads is twice that for the freight railroads. Among the Class I railroads, Amtrak has a trespassing fatality rate equal to that of the commuter railroads. The only other railroad that stands out is the Florida East Coast which has a fatality rate three times higher than average.

Calculating of the rate of grade crossing accidents is problematic. The measure used in figure 20.4 is grade-crossing accidents per crossing. Problems can emerge in cases where a railroad operates extensively over other companies' tracks. A good example is Amtrak which has many grade-crossing accidents involving their trains, but has relatively few crossings on the stretches of lines that they own. Amtrak is not shown in figure 20.4. Another example is the commuter-passenger company in Chicago, and also the Indiana Harbor Belt Railroad. The rate of accidents is remarkably consistent across the three types of railroads at about three to four accidents per 100 crossings per year. The only railroads that really seem to stand out with unusually high accident rates are the Kansas City Southern, the Belt Railway of Chicago, and the Port Terminal Railroad Association of Houston, Texas.

A more formal analysis can be conducted using regression techniques. The analysis is confined to collisions and derailments, and employee fatalities and injuries. From the previous discussion it is clear that there would be very little to be gained, vis-à-vis a purely graphic analysis, from conducting any regressions on the rates of trespassing fatalities or crossing accidents.

The cross-sectional analysis was conducted for 1995 . The predicted number of collisions and derailments and employee fatalities and injuries were obtained by estimating regressions on the occurrence rates for the forty-two Class I and II railroads. The regression predicting collisions and derailment contained a variable representing the proportion of train miles represented by switching, and the equation predicting employee casualties contained a dummy variable indicating whether the railroad was a commuter passenger railroad or Amtrak. These variables were 
chosen because they are exogenous characteristics of the railroads. They cannot be chosen or altered by the railroad's management. One variable that is deliberate not in the regressions is railroad size. The whole purpose of the analysis is to identify the worst railroads, and one would therefore not wish to explain away the fact that small railroads have a higher occurrence rate.

Table 20.5: Regression Estimates of Predicted Safety Performance 1995

\begin{tabular}{|l|c|c|c|c|}
\hline & \multicolumn{2}{|c|}{$\begin{array}{c}\text { Collisions and } \\
\text { Derailments per Million } \\
\text { Train Miles }\end{array}$} & $\begin{array}{l}\text { Employee Casualties per } \\
\text { Million Employee Hours }\end{array}$ \\
\hline & Coeff. & t statistic & Coeff. & t statistic \\
\hline Intercept & 4.12 & 1.63 & 25.25 & 2.83 \\
\hline Yard miles/train miles & 19.80 & 3.10 & - & 3.55 \\
\hline Passenger dummy & - & & 23.05 & 0.22 \\
\hline Adjusted R ${ }^{2}$ & \multicolumn{2}{|c|}{0.17} & \multicolumn{2}{c|}{42} \\
\hline Observations & \multicolumn{2}{|c|}{42} & \multicolumn{3}{|c|}{} \\
\hline
\end{tabular}

The results of the regressions are shown in table 20.5. The variables are strong, statistically-significant predictors of the occurrence rate. However, the regressions only explain about a fifth of the variation in the occurrence rates, which implies that there are other factors at work. The regression results are used to predict the number of accidents that a railroad should expect to have. For example, the expected number of collisions and derailments for railroad $i$ is given by:

$$
\left(4.12+\left(19.80 * \frac{\text { Yard Miles }_{i}}{\text { Train Miles }_{i}}\right)\right) * \text { Train Miles }_{i}
$$

The actual number of occurrences for each railroad is then compared with the predicted number. This is shown as a ratio in table 20.6. A ratio of greater than 100 indicates that the railroad has a greater number of accidents than that predicted. Of course, a railroad might have a higher than expected number of accidents in 1995 simply because of the random year-to-year fluctuations explained by the Poisson distribution. For that reason a five-percent significance test was applied using the data from table 20.2. The predicted number of occurrences was taken to be the mean number in the first column of table 20.2. Railroads who had a higher number of occurrences in 1995 than the five-percent critical value have "**" placed next to their data in table 20.6. 
Table 20.6: Cross-Sectional Comparison 1995

\begin{tabular}{|c|c|c|}
\hline & \multicolumn{2}{|c|}{ Ratio of Actual to Predicted Occurrences } \\
\hline & $\begin{array}{l}\text { Collisions \& } \\
\text { Derailments }\end{array}$ & $\begin{array}{l}\text { Employee } \\
\text { casualties }\end{array}$ \\
\hline \multicolumn{3}{|l|}{ Class I railroads } \\
\hline Amtrak & 20 & 59 \\
\hline Atchison, Topeka and Santa Fe & 42 & 37 \\
\hline Burlington Northern & 52 & 58 \\
\hline Consolidated Rail Corp. & 39 & 72 \\
\hline CSX Transportation & 20 & 34 \\
\hline Grand Trunk Western & 90 & $150 * *$ \\
\hline Illinois Central & 83 & 49 \\
\hline Kansas City Southern & $145 * *$ & 60 \\
\hline Norfolk Southern & 18 & 30 \\
\hline Soo Line & 82 & $199 * *$ \\
\hline Southern Pacific & 52 & 78 \\
\hline Union Pacific & 48 & 72 \\
\hline \multicolumn{3}{|l|}{ Class II Freight Railroads } \\
\hline Alaska & 64 & $142 * *$ \\
\hline Alton and Southern & 44 & 112 \\
\hline Bangor and Aroostook & 65 & $199 * *$ \\
\hline Belt Railway of Chicago & $389 * *$ & 44 \\
\hline Bessemer and Lake Erie & 100 & 92 \\
\hline Birmingham Southern & 130 & 110 \\
\hline Chicago, Central and Pacific & 168 & $188 * *$ \\
\hline Dakota, Minnesota and Eastern & $967 * *$ & $180 * *$ \\
\hline Delaware and Hudson & 134 & 112 \\
\hline Duluth, Missabe and Iron Range & 132 & 134 \\
\hline Elgin, Joliet \& Eastern & 141 & 47 \\
\hline Florida East Coast & 65 & 79 \\
\hline Gateway Western & 55 & 106 \\
\hline Houston Belt \& Terminal & 34 & 79 \\
\hline Indiana Harbor Belt & $429 * *$ & $160 * *$ \\
\hline Montana Rail Link & 105 & 111 \\
\hline Paducah and Louisville & 56 & $166 * *$ \\
\hline Port Terminal (Houston, TX) & 8 & 62 \\
\hline Springfield Terminal & 15 & 56 \\
\hline Terminal Railroad of State Dock & 116 & 72 \\
\hline
\end{tabular}


Table 20.6 (continued)

\begin{tabular}{|l|c|c|}
\hline \multirow{2}{*}{} & \multicolumn{2}{|c|}{ Ratio of Actual to Predicted Occurrences } \\
\cline { 2 - 3 } & $\begin{array}{c}\text { Collisions \& } \\
\text { Derailments }\end{array}$ & Employee casualties \\
\hline Terminal Railroad of State Dock & 116 & 72 \\
\hline Union Railroad (Pittsburgh) & 84 & 104 \\
\hline Wheeling and Lake Erie & 152 & 56 \\
\hline Wisconsin Central & 117 & $152^{* *}$ \\
\hline
\end{tabular}

Class II Commuter Railroads

Long Island

\begin{tabular}{|l|c|c|}
\hline Metro North & 12 & 100 \\
\hline New Jersey Transit & 12 & 94 \\
\hline
\end{tabular}

\begin{tabular}{|l|l} 
Northeast Illinois Regional & 24 \\
\hline
\end{tabular}

Northern Indiana Commuter

Port Authority Trans Hudson

Southeastern Pennsylvania

\begin{tabular}{|c|c|}
\hline 24 & 51 \\
\hline 0 & $209^{* *}$ \\
\hline 30 & $128^{* *}$ \\
\hline 14 & $135^{* *}$ \\
\hline
\end{tabular}

There are four railroads whose collisions and derailments are statistically significantly greater than would be expected. They are the Kansas City Southern, the Belt Railroad of Chicago, the Dakota, Minnesota and Eastern, and the Indiana Harbor Belt. The latter three railroads have actual numbers of collisions and derailments many times the predicted number. The two Chicago area switching railroads have four times more collisions and derailments than would be expected. The Dakota, Minnesota and Eastern, a ten-year-old company, has a rate almost ten times that which would be expected. Twenty-two of the twenty-six collisions and derailments for this company were derailments caused by defective track.

There are more railroads whose number of employee fatalities and injuries are statistically greater than the predicted value. In part the greater number of railroads thus identified is explained by the fact that employee casualties are more numerous than collisions and derailments and thus the critical value is proportionately closer to the predicted value. Also, the equation used for prediction is much simpler than that used for predicting collisions and derailments in that it only contains an intercept term and a dummy variable. Among the Class I railroads, the Grand Trunk Western and the Soo Line have higher than predicted employee casualties. Among the Class II freight railroads the Alaska, Bangor and Aroostook; Chicago, Central and Pacific; Dakota, Minnesota and Eastern; Indiana Harbor Belt; Paducah and Louisville; and the Wisconsin Central have statistically-significant elevated employee casualties. The same is also true of the Northern Indiana, Port Authority Trans Hudson, and Southeastern Pennsylvania commuter passenger systems.

This, albeit very simple, type of analysis has identified two railroads that do poorly on both measures of safety, and a further twelve railroads that do poorly on 
one of the measures. This information would allow the FRA to set priorities for the work of their inspectorate to determine whether it is necessary for the FRA to set in motion the remediation phase of the delinquency system.

\section{INFORMATION ON SMALL RAILROADS}

Statistical analysis of accident rates or employee injury rates would only be possible for the largest forty or so railroads. Statistical analysis would be impossible for very small Class II and all of the Class III railroads. For these railroads other sources of information might have to be collected to allow the FRA to make judgments on which railroads deserve closer inspection. A parallel can be drawn here to the problems faced by the FHWA's Office of Motor Carriers who have to control safety in an industry dominated by small carriers. Clearly, the FRA can review individual accident reports from these smaller railroads to see if the accidents had causal factors that might suggest lax safety precautions. It is also likely that traditional random inspections of track and equipment may be necessary for smaller railroads so as to provide information on the safety practices of these railroads. An alternative strategy is to conduct an annual audit of each small railroad. This is not an unrealistic suggestion given that there are only three hundred different corporate entities involved. During the annual inspection, management could be questioned on safety issues that have arisen during the year, the responses by management, and information could be obtained on financial conditions which might suggest whether myopic behavior is expect. If an accreditation system is adopted as part of the educational role for new railroads, it may be convenient to have a formal system of annual re-accreditation.

\section{ALL CHANGE AT THE FRA}

There needs to be fundamental change at the FRA. The old way of doing business with the employment of ex-railroad inspectors to inspect track and equipment is wasteful and ineffective. As summarized in table 20.7, the "new" FRA will be somewhat schizophrenic in that it must be both a teacher and a police officer. In its role as an educator it would work with other interested parties to ensure that managers of inexperienced railroads are fully aware of the choices they have to make to provide a safe service. There would be a fundamental switch to formalized education and away from inspections.

In preventing and punishing myopic railroads, there would be a fundamental change from employing inspectors to employing risk analysts. It only makes sense that the FRA uses statistical analysis of the safety performance of Class I and most Class II railroads to direct the activities of those in its workforce who are involved in enforcement and remediation duties. In this new world, written regulations governing the design of track and equipment and operating practices would take a 
"back seat" unless they need to be used to support any legal penalties or sanctions to support the enforcement and remediation process.

Table 20.7: Features of an Improved Safety Regulation System

\begin{tabular}{|l|l|l|}
\hline Objective & Educational System & Delinquency System \\
\hline Target railroads & $\begin{array}{l}\text { Prevent myopia by } \\
\text { inexperienced railroads }\end{array}$ & $\begin{array}{l}\text { Prevent myopia by } \\
\text { unscrupulous railroads }\end{array}$ \\
\hline $\begin{array}{l}\text { railroads } \\
\text { strategy }\end{array}$ & $\begin{array}{l}\text { Educational seminars and } \\
\text { visits. }\end{array}$ & $\begin{array}{l}\text { Incumbent small and large } \\
\text { railroads }\end{array}$ \\
\hline $\begin{array}{l}\text { Information system to } \\
\text { identify delinquent } \\
\text { railroads. }\end{array}$ \\
\hline $\begin{array}{l}\text { specification } \\
\text { regulations }\end{array}$ & $\begin{array}{l}\text { Used only to confirm } \\
\text { delinquency, and as a threat } \\
\text { to ensure remediation. }\end{array}$ \\
\hline Enforcement & $\begin{array}{l}\text { Issuing of Certificate of } \\
\text { Fitness }\end{array}$ & $\begin{array}{l}\text { Fines, rescinding of } \\
\text { Certificate of Fitness, } \\
\text { informing shippers }\end{array}$ \\
\hline
\end{tabular}

These comments should not be taken as a justification for a larger FRA. It is not unrealistic to expect that by working in a smarter way the FRA's staffing may actually fall. 


\section{THE WAY FoRMaro}

\section{RECOMMENDATIONS ON HIGHWAY GRADE CROSSINGS}

Grade crossing collisions cause almost half of all railroad fatalities. While there have been great improvements in safety at grade crossings subsequent to a government funding initiative in 1974, there are still considerable problems.

The first is that some highway users do not exercise enough care. At crossings with flashing lights or gates, so called active warning devices, more than eighty percent of collisions are caused by the highway user ignoring the lights and/or driving around the gates. At crossings with passive warning devices such as crossbucks signs many drivers do not properly look and listen for a train. Because the conduct of highway users at crossings with passive warning signs is not explicitly defined in the law, there is some suggestion that courts hold drivers to a lower level of due care than they should.

The root of this problem is that some road users do not fully appreciate the dangers of grade crossings: trains approach a crossing much faster than might be assumed, and cannot stop quickly. The government and the railroads should be commended for their "Operation Lifesaver" campaign that attempts to educate the public of the dangers. There is a growing trend to specify conduct at crossings with passive warning devices by replacing crossbucks signs by stop signs. This is certainly not a panacea. While there may be advantages in encouraging drivers to take care, there are considerable problems including the fact that slow-moving vehicles are more likely to be hit by a train than a vehicle moving quickly across a crossing. There is an increased chance of rear-end collisions between highway vehicles at the stop sign, and the possibility that stopping for nonexistent trains may diminish the regard that drivers have for stop signs. I think that empirical research is necessary before one should support installing more stop signs.

The second problem is that there are a large number of crossings that deserve upgrading from passive to active warning devices. My estimation is that there are at least 8,500 , and maybe as many as 20,000, crossings deserving upgrades. At the current rate of progress, a realistic prediction of when all deserving crossings will be upgraded is somewhere between the years 2013 and 2036. One beneficial initiative to speed up deployment of warning devices has been a program to consolidate together little-used crossings into one crossing provided with active warning devices. 
The consequent delays to road traffic from closing some crossings are minimal. In many locations the large number of adjacent crossings is a legacy of the era of the horse and buggy when nearly every intersecting highway was provided with a crossing.

A proactive systematic program to upgrade crossings has been hampered by the legal system which places the duty to prove safe crossings on the railroad, even though funding of and decisions on upgrades are largely in the hands of state highway authorities. The current legal system encourages railroads to respond to random collisions by pressing for installation of active warning devices at little-used crossings so as to avoid liability in the event that another collision occurs in the coming decades. Because the railroad and not the highway authority is the defendant in suits brought by highway users, evidence that the crossing did not "deserve" upgraded warning devices is not always admissible as a defense.

A 1993 Supreme Court ruling promises to change the system. Some courts have held that the involvement of federal money means that federal standards for when to install active warning devices preempt state common laws that hold railroads liable for this decision. In 1995 the federal government proposed to clarify this preemption by placing the decision to install warning devices entirely in the hands of highway authorities, who would use Federal Highway Administration rules in deciding which crossings to upgrade. The role of railroads would be reduced to just providing information on the level of train traffic, and supplying technical expertise.

Unfortunately, there is a downside in that most States have sovereign immunity against claims for damages from injured highway users. Even if they decide to waive sovereign immunity, there are often limits on the dollar amounts of claims. There are many crossings that deserve upgrades that will still not be treated in the foreseeable future because of budget limitations. Highway users killed or injured at these crossings will either be unable to seek damages or have the amount of damages severely limited under the proposed rules. Critics of the proposal correctly observed that the principal effect of the 1995 proposal would have been to limit corporate liability at the expense of individual road users.

The proposal was quiet dropped in 1997. Railroad lawyers suspect that it would only be resurrected when the mood of the country again turns toward tort reform and limitations on corporate liability.

I am supportive of the concept that the highway authority and not the railroad should be the legally responsible party. The highway authority is clearly in the best position to judge the most appropriate type of warning device as only it is privy to forecasts of road traffic and land-use changes. However, this authority must be tempered with financial responsibility for the conduct of its crossing improvement program. A waiver of sovereign immunity must be incorporated into any resurrected proposal. 


\section{RECOMMENDATIONS ON TRESPASSER FATALITIES}

Trespassing fatalities have been increasing in recent years, at a time when safety at grade crossings has been improving considerable. Consequently, preliminary data for 1997 suggest that trespasser fatalities will become the largest category of railroad fatalities. It is common to think that most trespasser fatalities are children and people taking a shortcut by crossing the railroad. However, these fatalities represent less than a fifth of victims. The typical trespasser is a single adult male who is under the influence of considerable amounts of alcohol. While many are poorly educated, very few are homeless people. Most live reasonably close to the point of trespass. The railroad right of way has become a popular place to socialize, drink and rest. In general one must conclude that most trespassing victims take considerably less care than they should. This is reflected in the courts where trespassers or their relatives are usually not successful in any damage claims against railroads.

In contrast to the essentially rural grade-crossing problem, trespassing is primarily an urban phenomenon. This raises the question of whether the railroad should fence most or all of its urban right of way. Unlike some other countries, the railroads in North America are primarily unfenced. Calculations suggest that fencing the urban rights of way would cost about $\$ 3$ billion or about $\$ 3$ million per life saved. This puts fencing on the borderline of desirability based on standard values of life used in the transportation industry. However, the amount required to fence the urban right of way could be used to provide active warning devices at the 20,000 public highway grade crossings that deserve them, and still leave enough money over to provide active warning devices at the 15,000 busiest private crossings. Money spent in this way would save up to twice as many lives than if it was spent on fencing.

The above calculation was based on assumptions that are very favorable to fencing. There is considerable uncertainty about the effectiveness of fencing to reduce trespasser fatalities. The annual North-American rate of trespasser fatalities at two per million population is the same as it is in Britain where the railway is generally fenced. Closer to home, the rate of trespasser fatalities per train mile for Amtrak who run many of their trains over a fenced right of way in the North-East Corridor is higher and not lower than that on neighboring freight railroads with few fences. The general conclusion is that a general requirement to fence the urban right of way would come a long way down the priority list for cost-effectively improving safety on the railroad, and may even be a futile waste of money.

\section{RECOMMENDATIONS ON OCCUPATIONAL INJURIES}

Economic theory, dating back to Adam Smith, indicates that if workers are knowledgeable about job risks, market mechanisms will compensate workers for working in industries that are particularly risky. Workers with a greater tolerance of physical risk will tend to gravitate towards riskier occupations. A market failure 
will only exist if wages are insufficient to compensate for the risks. Railroad workers are among the highest paid workers in the nation whereas injury and fatality rates are low in comparison to peer industries that involve heavy, moving machinery and work outdoors. Construction, maritime, trucking and warehousing jobs have far higher casualty rates.

There are two reasons why there does not appear to be a market failure for employee safety. The first is that railroad risks are primarily physical injuries about which workers should be well informed. The second is that the high rate of unionization in the railroad industry should provide for higher-than-average levels of safety as unions are typically thought of as representing the inframarginal worker who will be less tolerant of risk than the marginal worker who determines safety in a competitive market.

While the higher wages paid by railroads benefit all workers, the costs fall on the minority of workers who suffer injuries. In the past ninety years, employers have been required to provide insurance schemes whereby injured workers are provided with compensation. The railroad industry has a different form of compensation system than that applicable to the competing trucking industry, and indeed to all other sectors of American industry. The Federal Employers' Liability Act (FELA) applicable to the railroads gives a higher level of benefits to injured workers than does the system of workers' compensation applicable to other industries, primarily because workers' compensation does not permit injured workers to claim compensation for non-monetary losses. However, awards to injured railroad workers can be reduced or eliminated if the worker was negligent, whereas awards are guaranteed under workers' compensation. Because of its judicial rather than administrative nature, FELA involves higher transactions costs than workers compensation.

My analysis indicates that FELA is more likely to ensure that both employees and railroads take care to avoid workplace accidents. If the costs to the railroad of taking care to prevent occupational injuries are more than \$2,280 per employee per year, there is the possibility that railroads may take less care if FELA was replaced by workers compensation. If this happened society will be worse off. The incentives to employees to take care are similar under both systems. While negligent employees will receive compensation under workers' compensation, the non-monetary losses which they have to bear themselves act as an incentive for taking care.

However, there is a way in which the adversarial nature of FELA increases workplace risks. Injured employees correctly respond to FELA by not wanting to reveal details of the nature of their cases to railroad managers prior to legal proceedings. Employees also have incentives to claim that the injury resulted from a violation of federal safety laws as this removes the railroad's defense of comparative negligence. This clearly works against informal sharing of information between employees and management on ways to learn from experience in mitigating injuries. Under workers' compensation the employee is guaranteed compensation, 
and will therefore be able to honestly admit to the circumstances of the injury and ways in which it might be avoided in the future.

There seems to be little prospect of any reform in that both management and labor are firmly entrenched. Management tends to believe that a switch to workers' compensation will save the industry considerable money. I regard that argument as spurious. FELA benefits are highly valued by railroad workers, and railroads should expect that substitution of workers' compensation for FELA will be at the expense of wages or other concessions valued by labor. However, management does have valid concerns about aspects of the Railroad Retirement Act which gives longer-serving workers no incentives to rehabilitate themselves following an injury and return to work. Much of the financial concern about the cost of injury compensation could be dealt with by changes to the Railroad Retirement Act rather than the replacement of FELA.

\section{RECOMMENDATIONS ON OPERATIONAL SAFETY}

Operational accidents, which are primarily collisions and derailments, result in about twenty-two deaths, 450 injuries and about \$250 million in property damage each year. Seventy percent of the collisions and sixty percent of the derailments occur in yards and sidings during switching operations. Half of all derailments are caused by the state of the track, while eighty percent of collisions are caused by incorrect or inappropriate operating practices.

Operational safety is only one of the attributes of service that railroads offer to their customers. Other attributes include price, speed, and reliability. Relatively elementary economic models suggest that there will be a socially-optimal level of each of these attributes. This benchmark level arises because safety and other attributes are valued by customers but are also costly to provide. The socially optimal level of safety may not be at the point where all accidents are eliminated. It may not be cost efficient to mitigate all accident risk.

Therefore the fact that we observe over 2,000 collisions and derailments a year is not necessary an indication that there is a "safety problem" on the railroads. There is only a problem if this level of accidents is different from the socially optimal levels. The theoretical causes for such a market failure are fivefold. There will be a market failure if:

(1) railroads do not price in a competitive fashion;

(2) customers cannot accurately perceive the level of safety on offer;

(3) customers do not act rationally;

(4) railroads do not compensate bystanders for damage; and

(5) railroads are myopic in trading off the cost of preventing accidents in the present against accident costs in the future.

Let us review these five possible market failures. There is evidence that railroads do have the necessity and the ability to price above marginal cost. The necessity comes from the fact that railroads are characterized by large fixed costs of 
track and relatively low marginal cost of operating individual trains. This natural monopoly characteristic requires pricing above marginal cost so as to recover costs. The ability to price above cost results from the high market share they have for certain bulky commodities such as coal, ores and grain. It cannot be denied that certain railroads have become increasingly profitable in recent years. However, economic theory cannot unambiguously conclude that market power leads to lower provision of safety. Even if it did, the safety distortions might be regarded as rather minor compared with the welfare losses associated with restriction of output and higher prices.

For many passenger modes of transportation the major justification for requiring safety regulation is that the customer is not a knowledgeable purchaser. If customers cannot determine the safety of the carrier they select, they will be unable to signal their desires for safety. In the railroad industry most customers are well-informed. This is because they are repeat customers. Commutation passengers and shipping managers are almost daily users of the railroad system. They are able to observe the level of safety on offer. Shipping managers are continually settling claims for minor loss and damage and are well aware of the safety risks. A legacy of the many years of economic regulation is that extensive information is collected on safety, loss, and damage. The AAR's Freight Loss and Damage Report provides a wealth of information on the amount of damage and loss sub-divided by cause, railroad and commodity. Unfortunately this report does not circulate widely outside of a select few in the railroad industry. Wider circulation of this information would certainly reduce calls for safety regulation based on the premise that the customer is not aware of the quality of the service that is being purchased.

Socially-optimal behavior will only occur if fully-informed customers make rational choices consistent with their desires and economic incentives. In general, we can expect freight shippers to make calm and rational decisions based on the prices and safety records of different railroads and available modes of transportation. The situation with regard to passengers is less clear. Psychologists have found evidence that people might ignore safety information in their decision- making so as to avoid thinking about very unpleasant consequences. Whether this is a "market failure" is a matter of semantics, as the failure is within the customer and not in the trade between customers and railroads. It is possible that intervention in the market may be necessary to protect customers from themselves rather than from avaricious railroads.

A traditional cause of market failure in economics is if there are uncompensated externalities on other parties. Bystanders, such as those adjacent to the railroad, can bring suit under the laws of negligence for any losses caused. If the damage is caused by a release of ultra-hazardous materials the railroad is strictly liable to pay compensation. My investigations suggest that in the vast majority of cases railroads bear the entire cost of damage caused.

However, socially-optimal exposure of third parties to risk only results if shippers are charged prices that incorporate the externality costs that a release of their 
product may cause. That is to say shippers of extremely hazardous materials should pay a high price for shipment so as to allow for compensation to bystanders who are affected by a release caused by a collision or derailment. Shippers of commodities which do not cause extensive externalities should be charged lower prices. Unfortunately the railroads have done a very poor job in identifying the costs associated with individual commodities.

In many cases a standard surcharge is collect on all freight movement to cover liability costs to bystanders. As a result too much extremely hazardous materials are shipped, and too little low- or non-hazardous are shipped. Shippers of extremely-hazardous materials are therefore not given the correct incentives to reevaluate where to locate their manufacturing plants or whether to develop safer alternative products. Recent research work has identified that the amount of externalities varies considerably between commodities. Some commodities cause over one hundred and fifty times as much damage per unit shipped than other commodities. While some railroads have made some moves to incorporate these findings into their pricing, there is still a long way to go. A desirable response by the railroads to the public's concern about the transportation of hazardous materials is to ensure that pricing of railroad service fully incorporates the cost of externalities appropriate to that particular commodity.

The market failure that is most threatening and most likely in the railroad industry is that of myopia. The costs of preventing railroad accidents, such as capital expenditures and training, occur in the present whereas the costs of accidents occur at some undefined point in the future. A myopic railroad can save money on prevention in the present while either not appreciating or not caring about the consequent rise in accident costs in the future. Two types of railroads may be susceptible to such myopia. The first are newly-formed railroads who make myopic decisions due to inexperience rather than unscrupulous intent. They simply do not understand that saving on training costs now will result in higher accidents in the future. The proliferation of short-line railroads since the Staggers Act of 1980 has given some prominence to this concern. Albeit that there is little evidence that these small railroads pose an unreasonable safety threat. While these railroads do have a higher rate of collisions and derailments than larger railroads, they do not have higher fatality rates. Low speeds of operation mitigate the consequences of many accidents.

The second type of railroad susceptible to myopic behavior is those who intend to "cheat" on their customers. These railroads hope to save money in the short term by reducing expenditures on accident prevention, yet hope that their customers do not notice and react by taking their business elsewhere or demanding lower prices. There is ample evidence that this behavior has occurred in the railroad industry. Indeed, the reason that extensive safety regulation was introduced in the 1970s was due to myopic behavior by certain financially-distressed railroads in the 1960s. These railroads indulged in a particularly insidious form of cheating in that they reduced their expenditures on track maintenance. It takes some time for a 
previously well-maintained right of way to deteriorate, and it was therefore some years before shippers could detect that safety was declining.

The market failure caused by myopia does not necessarily imply that safety regulations are necessary. For example, a concern about myopia by inexperienced railroads might suggest that there is a wider role for the insurance industry. Insurance assessors need to make a determination of the precautions taken by a new railroad and charge an appropriate premium to reflect the probability that accident claims will result in the future. Railroad management would be able to trade off the size of the insurance premium against the costs of preventive effort in determining the appropriate level of safety to provide. While there is no requirement for small railroads to hold insurance, most elect to do so. Unfortunately premium schedules are relatively coarse, and insurance companies do not routinely tailor the premium to the specific preventive efforts made by individual railroads.

A concern about myopia by unscrupulous railroads could be mitigated if customers could readily detect the cheating. Customers would immediately express their concern to railroad management and demand a lower price because they are receiving a lower quality of service. There is extensive data already available on railroad accidents. Unfortunately this information is not widely understood or disseminated. The government in the form of the FRA and the NTSB as well as the industry through the AAR or ASLRRA would be well advised to make current information more widely available to railroad customers in readily understood formats. Recent advances in electronic dissemination of information have substantially reduced the cost of doing so.

Of course, provision of accident data is not a panacea for removing incentives for cheating. Reductions in maintenance can occur long before they are reflected in accident rates. A purely informational response to a market failure due to myopia would therefore need to provide information on safety inputs such as maintenance activities, training and the age and condition of capital equipment. These are much more difficult metrics to measure and to convey to customers than are accident data. For smaller railroads, information on accidents in a given year is unlikely to provide useful information on whether the safety precautions undertaken by that railroad are deteriorating. Accidents are rare events and it may be difficult to determine from year to year whether the occurrence of an accident is due to myopic behavior or simply due to statistical chance.

While one should support the provision of greater information and encourage insurance companies to be more discriminating in setting premiums, there is probably some role for direct regulation by the government to reduce the chance of myopia. The big question is whether the traditional forms of regulation practiced by the FRA are appropriate for this role, and whether new and improved regulatory strategies could lead to more effective and more cost-efficient ways to prevent myopia.

Some safety regulations date back a long time. These older regulations tend to be supportive of informational and legal response to market failures. The liability of railroads to employees, shippers, and bystanders affected by munitions explosions 
dates back to the earliest part of the twentieth century. Railroads have had a requirement to report accidents to the government, and to submit to independent investigation of major accidents, since the same period.

The regulations that have drawn the most criticism are those that date from relatively recent times. This is not to say that railroads have not had their own self-enforced regulations for many years. The very necessity for railroads to exchange cars and locomotives between themselves to provide customers with through service has required standardization. Railroads devised interchange standards for equipment as far back as 1867 and have a recommended code of operating rules dating from 1887. Prior to 1970 these rules were self-administered and not written into federal regulations. The Federal Railroad Safety Act of 1970 provided the newly-formed FRA with the powers to "promote safety in all areas of railroad operations." Subsequently regulations were promulgated that wrote freight-car interchange standards into law, devised new standards for railroad track, specified locomotive standards, provided for certification of locomotive engineers and codified certain operating rules into law. Enforcement of these regulations is provided for by the employment of four hundred federal and state inspectors who conduct semi-random inspections of railroads and bring citations and fines for violations found. The FRA also conducts "task force or special assessments" where teams of inspectors undertake comprehensive evaluations of particular railroads. The FRA has the power to issue notifications to require immediate rectification of defects and in the extreme can forbid operation by a railroad.

The regulations of the 1970s have drawn criticism not only from railroads but also from independent government agencies such as the GAO and the late OTA. The criticisms focus on both how the regulations are written and how they are enforced. The regulations concerning track standards and brakes in particular have been criticized because of a lack of cost-benefit analysis in setting of the standards. It is possible that organized labor has been able to coerce Congress so as to write rules that preserve existing working rules. There is an additional concern that even when appropriate standards are written into law, the rulemaking process necessary to update these standards in the face of technical change or modern requirements is so lengthy and stifling that regulation can impede progress. The main cause of this problem is the penchant of Congress and the FRA to express standards in terms of the design of equipment rather than the performance of it. One would imagine that the FRA is really only interested in how quickly a train can stop or whether there is excessive lateral deviation in track, and not in the specific design of the braking equipment or the number of spikes per section of track.

The enforcement of the regulations has been subject to much criticism. There is considerable feeling, not only in the railroad industry, that semi-random inspections resulting in violation notices and fines are ineffective in improving safety. There is evidence that this is true in the trucking industry, and even OSHA has recognized that there must be a better way of obtaining a safe workplace. Reports by the GAO suggest that the FRA does not have adequate models to determine which railroads pose the greatest safety threat and therefore cannot reasonably set priorities for 
targeted or special assessments of individual railroads. There is also evidence that the tactics of FRA inspectors have antagonized rather than enrolled railroad managements in the cause of safety. Resolution of violations and the payment of fines by large railroads does not normally involve senior officers of the railroads, and there is little evidence that the fines influence corporate policy.

Perhaps the most damning criticism of the 1970s regulations is lack of any strong empirical evidence that these regulations have led to improvements in safety. It is certainly true that railroad safety was declining from the 1960s through the late-1970s, and has improved substantially since. However, other changes have occurred that may explain the decline in accident rates. The railroad industry was deregulated in 1980 and the improved financial viability of individual railroads has allowed increased expenditures on track and equipment. The railroad industry has also changed away from individual-car service towards block trains which reduce the amount of switching and hence the potential for collisions and derailments.

So how can we improve on this rather dismal performance by the legislators who write railroad regulations and the FRA who enforce them? The answer to this question comes from reflecting on the market failures that the government is hoping to prevent. My analysis suggests that the major role for the FRA is to prevent myopia by inexperienced railroads or unscrupulous railroads. Dealing with these two types of myopic firms calls for two different approaches. An educational system is needed to prevent myopia by inexperienced railroads, while a delinquency system is need to detect and punish unscrupulous myopic railroads who are trying to cheat their customers. The FRA needs to be both a teacher and a police officer.

To a certain extent the FRA already serves as a teacher. Seminars are held jointly with ASLRRA for managers of newly-formed railroads. Press reports suggest that people attending such sessions have found them to be very useful. The objective, of course, is to ensure that managers are made fully aware of the safety consequences of the decisions they are making on training, maintenance, and capital purchases. The FRA should expand its role in cooperation with ASLRRA, the AAR and the insurance companies. All of these organizations have interest in ensuring that new railroads do not pose unreasonable safety risks and also have considerable expertise to pass on. The question arises whether new railroads should be accredited before they are allowed to operate. This accreditation may be based on attendance at these seminars or on other factors.

There are two possible models that the FRA might look to. The first is the system of safety audits undertaken by the FHWA of trucking companies. A questionnaire is completed by a federal inspector which is used to rate the firm on the basis of the safety management practices that it has put in place. Perhaps a better educational tool is the "Railway Safety Cases" which had to be completed by private operators who wished to take over the services formerly provided by the state-owned railways in Great Britain. In addition to requiring details of the safety management systems put in place, operators had to complete a risk-assessment exercise in which they had to identify the major safety risks they faced, appraise the probability and severity of these risks, rate the risks and provide plans for ameliorating those risks 
that were too high. While data on risk probability and severity may be limited and rating of risks is judgmental, the important role of the risk assessment is to require railroad managers to think deeply about the risk faced and the ways in which the railroad can reduce the risks. It is unlikely that a new railroad that has to undertake a risk-assessment exercise will be myopic due to inexperience.

A delinquency system is not much different in intent from the current activities of the FRA. The objective is to identify those railroads providing sub-standard service or those whose safety record is precipitously declining. The FRA's enforcement role is aided considerably if customers are made aware of declines in the safety offered by an individual railroad. Customers will then pressure railroad managers to restore the previous level of quality or demand a discounted price. The FRA should be encouraged to make the findings of its monitoring and enforcement efforts well known.

These comments should not be taken as an endorsement of the FRA's current methods of monitoring safety performance. Far from it. Semi-random inspections to find violations with federal requirements that may or may not be related to safety performance is a bankrupt method of safety control. The system that I am proposing is a four stage process. The first stage requires the FRA to adopt the role of risk analyst. The FRA would analyze data on safety performance for individual railroads to determine which railroads might be delinquent. The second stage involves inspections and evaluations of railroads that the first stage has flagged as potentially delinquent so as to confirm or disprove the FRA's suspicions.

The third stage requires a delinquent railroad to prepare a remediation plan to correct its delinquent behavior. The FRA would also wish to involve the customers of the railroad at this stage so that they can also put pressure on the railroad. The fourth and final stage requires the FRA to monitor whether the railroad is making a good-faith effort to implement its remediation plan. Failure at this stage would trigger traditional methods of inspections, citations and fines. Of course, the FRA retains the powers to issue Special Notices or Emergency Orders to limit operations of specific equipment or stretches of track if it detects extremely dangerous conditions.

Such a system is in use in the trucking industry. The FHWA uses information on the accident rates of carriers, and other information it has, to set priorities for the work of its inspectorate. OSHA conducted an experiment in the state of Maine in 1993 whereby the largest firms where exempted from the traditional OSHA inspections if they made self-assessments of workplace risks, prepared a plan to ameliorate the risks, and made good-faith efforts to implement their plans.

The hardest part of the proposed system is to design an information system that can be used by the FRA to provide an early warning of railroads that may be cheating. An obvious input to such a system is the information that is currently collected on accidents and workplace injuries. While accidents are random events which lead to some natural variation in the number of accidents a firm will have from year-to-year, there are well-understood statistical rules that explain the nature of this variation. Providing the measures of safety that are used occur at least about ten 
times a year for individual railroads, it is realistic to expect that the FRA can define statistical rules that effectively identify those railroads whose accident performance is deteriorating or is worse than peer railroads. Candidates for such measures of accident performance are the number of collisions and derailments, and the number of employee fatalities and injuries. The very simple analyses conducted in chapter 20 provide the basis for identifying those railroads whose safety performance is wanting.

However, this is essentially an ex-post identification of myopic railroads. It is clearly preferable if the FRA could identify railroads who are acting myopically before their reductions in preventive efforts are reflected in increased accidents. The FRA might develop a system of warning flags for railroads whose circumstances might suggest myopic behavior, such as financial distress, declines in revenue, financial restructuring, stock offerings or being a takeover target. The FRA might also wish to develop information on safety inputs to alert them to railroads that do not appear to be spending sufficient amounts on track maintenance or who are allowing the average age of their fleets to increase, or who have inordinately high staff turnover. Such warning flags could trigger inspections or a special assessment of the railroad.

Such a statistical risk-analysis approach to analyzing data on safety inputs and outputs is only really applicable to the largest forty or so railroads. The smallest Class II and all of the Class III railroads have accidents so infrequently that any statistical inference would be impossible. The average-sized Class III railroad injures four employees a year, has one grade-crossing accident a year, kills a trespasser once every twenty years and has a collision or derailment once every seven-and-a-half years. It would also be infeasible to collect extensive financial or safety input data on these railroads.

Does this mean that traditional random inspections of track and equipment will have to be retained for smaller railroads? That is certainly a possibility. A more productive method may be an annual audit of each small railroad. This is not an unrealistic suggestion as many small railroads are either owned by larger railroads or are subsidiaries of larger holding companies that own many short-line railroads. There are perhaps only three hundred different corporate entities among the small railroads. During an annual audit the FRA inspector would be able to question management on safety challenges encountered in the past year, the response made by management, future safety plans and possible changes in financial conditions that might suggest myopic cheating. The inspector could also randomly inspect maintenance records, employee qualification files and also track and equipment to ensure that the physical condition of the railroad squares with the report given by management. 


\section{IN CONCLUSION}

The railroad industry has really only got itself to blame for the current mess it is in with regard to safety regulation. In the 1960s certain managers responded to financial distress by a disregard for safety. Accidents rates, which had been improving for many decades, started to increase. Quite appropriately the public demanded that Congress take action. The Federal Railroad Safety Act of 1970 is an understandable response to the circumstances. While the industry had long-standing systems of self-regulation, these had failed to exercise discipline over certain railroads.

Unfortunately the new-found public interest in railroad safety was hijacked by two forces. The first was empire building by the FRA which at that time was only three-years old and looking for a mission in life. Albeit, that there is some evidence that the FRA made a preemptive strike so as avoid the railroads falling under the rulemaking powers of the newly-formed OSHA. The second was the labor unions who attempted to prevent certain long-overdue reforms of working practices by trying to write these practices into law under the guise of safety regulation.

Perhaps the biggest mistake was the enforcement strategy adopted by the FRA. The FRA hired existing inspectors from the railroads as its own inspectors. This is not to criticize the professional abilities of the people involved but merely a reflection that the enforcement stance of the FRA became to go out, inspect things and write citations. Never mind the fact that these inspections were somewhat pointless and did not encourage railroads to change their practices. If anything they did the reverse, they antagonized railroad management and did not foster a cooperative spirit of mutually trying to tackle real safety problems.

In this book I have tried to chart a way forward for the "new" FRA. An FRA that is staffed by people with the outlook of teachers and risk analysts rather than that of police officers. By doing so the FRA can target the real causes of the "railroad safety problem" and do so at reduced cost. 


\section{APPENDIX A: FEDERAL REGULATIONS}

This appendix provides the reader with a sense of the federal safety regulations. The various regulations have been grouped into nine broad types: standards for locomotives and cars, track standards, operating procedures, signaling, grade crossings, employee regulations, carriage of hazardous materials, federal oversight, and accident reporting.

Railroad-safety legislation is within Title 49 of the United States Code of Federal Regulations, and occupies parts 40, 174-180, 209-245 and 840. Each of the regulations summarized starts with its part number, and also an indication of the date and the legislation by which the regulations were introduced. The following abbreviations are used for certain Acts: FRSA 1970 is the Federal Railroad Safety Act of 1970, HMTA 1975 is the Hazardous Materials Transportation Act of 1975, FRSAA 1976 is the Federal Railroad Safety Authorization Act of 1976, and RSIA 1988 is the Rail Safety Improvement Act of 1988.

\section{LOCOMOTIVE AND CAR STANDARDS}

49 CFR 215 Freight Car Standards (FRSA 1970)

Defines car defects with regard to wheels, axles and boxes, body and couplers. Freight cars must be inspected for defects before a train departs and also when cars are interchanged between railroads. While cars are often owned by shippers and third parties, the requirement for compliance with the Act is with the railroad. A railroad should refuse to accept such a defective car, or just haul it to a place of repair. Three Supreme Court cases going back to 1895 indicate railroad has an absolute duty to inspect cars it receives from another railroad, and hence is liable from harms caused by a defective car (Kenworthy, 1989).

\section{CFR 223 Glazing Standards (1979)}

Specification of impact standards to be applied to locomotives, cabooses and passenger cars windows. 
49 CFR 229 Locomotive Safety Standards (1980)

Defines defects in brake systems, couplers, suspension, wheels and tires. Sets requirements for fuel cut offs, electrical collectors, steam generators, slip/slide alarms, speed indicators, snowplows, headlights and other lights (strobes, ditch lights), and from 1995 event recorders on locomotives of trains that exceed thirty miles per hour. The regulations set design requirements for cab noise limits, and specifies reinforcement of cabs and the provision of anti-climb devices to avoid locomotives riding up over each other and crushing the train crew. The regulations specify that locomotives are visually inspected daily. Every three months brake gauges, electrical devices, jumpers, steam generators and event recorders must be inspected. Air brake filters and brake relays and valves need to be tested each year, and air brakes systems and main reservoirs every two years.

49 CFR 230 Locomotive Inspections (Locomotive Inspection Act 1911)

Applies to steam locomotives, and has not be shown in full in the federal regulations since 1980 .

49 CFR 231 Safety Appliance Standards (Safety Appliance Acts 1893, 1903, 1910, 1958)

Requires the fitting, and specifies the standards, for handbrakes, running boards (on roofs), sill steps, ladders, handholds and uncoupling levers. These are shown in detail for different types of equipment: box cars, hoppers \& high sided gondolas, low sided and drop end gondolas, flat cars, tank cars, cabooses, passenger cars and steam locomotives.

49 CFR 232 Power Brakes and Drawbars (Safety Appliance Act Amendment 1958)

Since 1910 continuous air brakes have to be fitted throughout a train with the engineer able to operate the brakes of eighty-five percent of cars. The regulations specify the piston travel and air pressure in the systems. Air brakes must be tested at terminals, when the consist changes and every 1,000 miles. Since cabooses were removed, radio-controlled one-way "end of train devices" have been substituted allow the engineer to determine brake pressure at the end of the train. The regulations set specifications for these devices. The regulations have since 1893 required drawbars to be at a standard height.

\section{TRACK STANDARDS}

49 CFR 213 Track Safety Standards (FRSA 1970, 1982)

Track is divided into seven categories depending on written engineering specifications of gauge, alignment, elevation, number of cross-ties, and mismatch of railends. The maximum allowable speed of trains depends on the 
classification of the track and is shown in table 18.2. In 1982, an exemption to these regulations was introduced for track not used for hazardous materials or passengers with a maximum speed of ten miles per hour. There are specified design criterions for frogs and switches. Maximum speeds for curves are specified based on curvature and elevation. The regulations also specify how frequently track should be inspected, and sets minimum experience for track inspectors.

\section{OPERATING PROCEDURES}

49 CFR 217 Operating Rules (1974 revised 1994)

The larger Class I and II and passenger railroads must submit copies of their operating rules to the FRA. The smaller Class III railroads must have them available at their main offices. Records of testing and inspection of track and equipment must be kept for one year, and there must be tests of employees to ensure that they are familiar with the operating rules.

49 CFR 218 Operating Practices (FRSAA 1976)

Designates a blue signal to protect non-train crew when they go underneath or between cars. They can also be placed on switches to protect people working on track. Speed limits are required within yard limits. Flag protection is required of stopped or stalled trains. Tampering with safety devices is prohibited.

49 CFR 220 Radio Standards (rulemaking 1977)

Contains details on radio procedures, and how to make radio transmissions.

49 CFR 221 Rear-End Marking Devices (FRSAA 1976)

Requires and details marking devices to signify the end of a train, and provides a list of approved manufacturers.

\section{SIGNALING}

49 CFR 236 Installation and Repair of Signals (Signal Inspection Act 1920, 1937, 1968)

Block signaling, whereby trains running in the same direction are kept a certain distance apart, is required on lines with passenger trains moving at more than sixty miles per hour or freight trains at more than fifty miles per hour. This system also prevents trains running in opposite directions from entering the same section of track. Automatic train control, whereby electrical or mechanical devices are deployed to prevent trains running past signals at danger, is required where trains operate at more than eighty miles per hour. There are requirements for track circuits which are used by signal systems to detect if a certain stretch of 
track is occupied by a train. The traditional semaphore signals must be inspected every six months and tested every two years. Detectors which show which way a switch is set must be inspected every three months. The regulations also sets standards for absolute block, interlocking, point locks and cab signals.

49 CFR 235 Modifications to Signal Systems (Signal Inspection Act 1920, 1937, 1984)

Provides for procedures to seek relief from provisions of Section 236.

\section{GRADE CROSSINGS}

\section{CFR 234 Grade-Crossing Systems (RSIA 1988)}

Activation of active warning devices must be twenty seconds before the arrival of the train. If barriers are fitted they cannot start descending until three seconds after lights are activated, and must be fully down five seconds before the train. There must be monthly inspection of physical condition of systems, standby power, gates, warning system, and highway signal preemption; and a yearly test of the length of warning time, and the alignment of lamps. Railroads have to file their inspection and maintenance procedures with the FRA. There is a requirement that reports have to be filed on crossing equipment failures.

\section{EMPLOYEES}

\section{CFR 240 Certification of Locomotive Engineers (RSIA 1988)}

The regulations set requirements for sight and hearing. A written test for knowledge of rules is required, and skills must be examined either on the road or on a simulator. Railroads must also consider an applicant's motor vehicle driving record in previous three years, any railroad rules violations in previous five years and whether the applicant is enrolled in a substance abuse program.

49 CFR 228 Hours of Service (Hours of Service Act 1907, amended 1969 and 1976)

Operating employees can only work twelve hours in twenty-four, must take at least ten hours rest after twelve hours of duty, and must rest for at least eight hours in a twenty-four-hour period. Duty time includes time on the train, rest at a location which is not a terminal, rest periods of less than four hours at a terminal, deadheading (or travel) to start duty, and non-train duties. Deadheading when returning from duty is counted as neither on-duty nor off-duty time. The law specifies records and recordkeeping requirements. There are also detailed rules on the construction of employee sleeping quarters and work cars. 
49 CFR 214 Workplace Safety (1992, and Occupational Safety and Health Act 1970)

Deals with requirements for hard hats, eye protection and foot protection. For people working on bridges, there are requirements for safety lines, safety nets and scaffolding.

49 CFR 219 Alcohol \& Drugs (1989)

Employees on duty must not be under the influence of drugs or have a Blood-Alcohol Content of more than 0.04 of one percent. Provision is made for testing employees after an accident, as part of pre-employment screening, and also with cause and on a random basis.

49 CFR 40 Workplace Drug Testing (1989)

Outlines procedures for conducting drug testing.

\section{HAZARDOUS MATERIALS TRANSPORTATION}

49 CFR 179 Specifications of Tank Cars (Transportation of Explosives Act 1960, 1964)

These requirements are administered by the AAR Committee on Tank Cars.

49 CFR 178 Hazardous Materials Packaging (Transportation of Explosives Act 1960, 1964)

Specifies performance standards for packaging of hazardous materials.

\section{CFR 180 Continued Qualifications \& Maintenance of Packaging (1989)}

49 CFR 174 Carriage of Hazardous Materials (Transportation of Explosives Act 1960, HMTA 1975)

Contains requirements that hazardous materials cars must be inspected on interchange between railroads. Shipping papers must be provided and the materials must be appropriately placarded. Regulations are given for hazardous materials that are shipped in containers and road trailers that are placed on train cars. There are detailed instructions for loading and unloading of tank cars, the segregation of hazardous materials within a car or train, and on the handling of explosives, corrosives and other categories of hazardous materials. 


\section{FEDERAL OVERSIGHT}

49 CFR 209 Railroad Safety Enforcement Procedures (FRSA 1970, HMTA 1975, Transportation Safety Act 1974, RSIA 1988)

Contains a statement of FRA policy concerning enforcement of safety laws. The FRA can impose civil penalties. The amount of the penalty is indicated in each section of the federal regulations. The Safety Appliance, Boiler Inspection, Signal Inspection, Accident Report, and Hours of Service Acts also allow for collection of civil penalties. The RSIA 1988 increased the amount of the fines. A 1983 amendment made railroads strictly liable for any penalties, irrespective of whether they were aware of the violation: "It shall be unlawful for any railroad to fail to comply with any rule, regulation, standard or order." The only criminal felonies under FRSA 1970 are for failures to keep records.

49 CFR 212 State Safety Participation Regulations (FRSA 1970)

Allows joint programs between the federal governments and states and provides that the federal government can pay up to half of the cost of state programs. The regulations set minimum qualifications for state safety inspectors.

49 CFR 216 Special Notices \& Emergency Orders (FRSA 1970, amended 1980, FRSAA 1976)

Provides the legal powers for federal inspectors to require immediate rectification of defects with freight cars, locomotives, or track. The 1980 amendment permitted very broad and sweeping powers over "conditions or practices" which need not be confined to specific "facility or piece of equipment" which had been the original 1970 wording. Another party, such as a union or an individual employee, can force the FRA to take action under an Emergency Order.

49 CFR 245 User Fees to Cover Safety Inspections (FRSA 1970)

The costs of FRA safety enforcement activities shall be collected from railroads in user fees. The fee that an individual railroad pays is determined by a formula that divides the FRA costs across the industry on the following basis: fifty-five percent allocated based on train miles operated, ten percent on the number of employee hours, and thirty-five percent on the number of miles of road. Fees were only implemented in 1992, but authority to collect the fees has currently lapsed.

\section{ACCIDENT REPORTING AND INVESTIGATION}

49 CFR 225 Accidents \& Incidents (Accident Reports Act 1910)

Requires railroads to file accident reports, and codifies the classification of accidents. 
49 CFR 233 Signal System Reporting (Signal Inspection Act 1920, 1937, 1984) Requires the filing of signal failure reports and any accidents that result from them.

\section{CFR 840 NTSB Investigation of Railroad Accidents (Transportation Safety} Act 1974)

The investigative powers of major accidents passed from the ICC to the FRA and ultimately to the independent National Transportation Safety Board (NTSB). Railroads are required to inform the NTSB of serious accidents within two hours. NTSB is allowed to examine all physical evidence, and the NTSB inquiry takes precedence over all other investigations. 


\section{APPENDIX B: HISTORICAL DATA}

Tables B1 and B2 show the number of railroad fatalities and injuries by type of person for the turn of each decade from 1890 to 1990, and for 1994, 1995 and 1996. The source of the data is the ICC/FRA Accident/Incident Bulletin. Note that the definition of injuries to employees changed in 1975 which resulted in an almost threefold increase.

Table B3 shows data on exposure to risk. The data on train miles, passenger miles and employee hours prior to 1930 are from the ICC's Statistics of Railways in the United States (employee-hours data were first collected in 1916). After 1930 the data are from the ICC/FRA's Accident/Incident Bulletin. Data on highway vehicles registered is from the FHWA's Highway Statistics. Data on population is from the Department of Commerce's Statistical Abstract of the United States.

Table B1: Annual Railroad Fatalities

\begin{tabular}{|c|c|c|c|c|c|c|}
\hline Year & Trespassers & $\begin{array}{c}\text { Highway } \\
\text { Crossings }\end{array}$ & Passengers & $\begin{array}{c}\text { Non- } \\
\text { Trespassers }\end{array}$ & Employees & Total \\
\hline 1890 & 2964 & 500 & 286 & 128 & 2451 & 6329 \\
\hline 1900 & 4175 & 901 & 249 & - & 2550 & 7875 \\
\hline 1910 & 4735 & 968 & 324 & 273 & 3382 & 9682 \\
\hline 1920 & 1978 & 1784 & 264 & 266 & 2576 & 6868 \\
\hline 1930 & 2238 & 1943 & 54 & 272 & 974 & 5481 \\
\hline 1940 & 1988 & 1798 & 87 & 159 & 580 & 4612 \\
\hline 1950 & 1124 & 1568 & 180 & 137 & 389 & 3398 \\
\hline 1960 & 586 & 1410 & 32 & 22 & 198 & 2248 \\
\hline 1970 & 517 & 1484 & 8 & 43 & 172 & 2224 \\
\hline 1980 & 457 & 832 & 4 & 16 & 108 & 1417 \\
\hline 1990 & 543 & 693 & 3 & 15 & 43 & 1297 \\
\hline 1994 & 529 & 614 & 5 & 44 & 34 & 1226 \\
\hline 1995 & 494 & 576 & 0 & 33 & 43 & 1146 \\
\hline 1996 & 471 & 487 & 12 & 27 & 42 & 1039 \\
\hline
\end{tabular}


Table B2: Annual Railroad Injuries

\begin{tabular}{|c|c|c|c|c|c|c|}
\hline Year & Trespassers & $\begin{array}{c}\text { Highway } \\
\text { Crossings }\end{array}$ & Passengers & $\begin{array}{c}\text { Non- } \\
\text { Trespassers }\end{array}$ & $\begin{array}{c}\text { Sub- } \\
\text { Total }\end{array}$ & Employees \\
\hline 1890 & 2891 & 1826 & 2425 & 489 & 7631 & 22396 \\
\hline 1900 & 4476 & 1501 & 4128 & 572 & 10677 & 39463 \\
\hline 1910 & 5195 & 2092 & 12451 & 4138 & 23876 & 95671 \\
\hline 1920 & 1909 & 5019 & 7591 & 3332 & 18716 & 149603 \\
\hline 1930 & 2848 & 5353 & 2538 & 1660 & 13558 & 35872 \\
\hline 1940 & 2006 & 4551 & 2530 & 1122 & 11240 & 18350 \\
\hline 1950 & 1055 & 4245 & 3350 & 980 & 10669 & 22585 \\
\hline 1960 & 502 & 3343 & 1463 & 559 & 5807 & 13710 \\
\hline 1970 & 509 & 3363 & 489 & 681 & 5042 & 16285 \\
\hline 1980 & 474 & 3719 & 593 & 384 & 5170 & 55379 \\
\hline 1990 & 560 & 2223 & 473 & 349 & 3605 & 20977 \\
\hline 1994 & 452 & 1750 & 497 & 475 & 3174 & 13352 \\
\hline 1995 & 466 & 1687 & 573 & 416 & 3142 & 11298 \\
\hline 1996 & 474 & 1505 & 513 & 431 & 2923 & 9635 \\
\hline
\end{tabular}

Table B3: Exposure Measures (all in millions)

\begin{tabular}{||c|c|c|c|c|c|}
\hline Year & $\begin{array}{c}\text { Train } \\
\text { Miles }\end{array}$ & $\begin{array}{c}\text { Employee } \\
\text { Hours }\end{array}$ & $\begin{array}{c}\text { Passenger } \\
\text { Miles }\end{array}$ & $\begin{array}{c}\text { Highway } \\
\text { Vehicles }\end{array}$ & Population \\
\hline 1890 & 721 & NA & 12800 & - & 63 \\
\hline 1900 & 887 & NA & 16000 & - & 76 \\
\hline 1910 & 1222 & NA & 32300 & - & 92 \\
\hline 1920 & 1843 & 5446 & 47400 & 9 & 106 \\
\hline 1930 & 1591 & 3759 & 26800 & 27 & 123 \\
\hline 1940 & 1309 & 2538 & 23800 & 32 & 132 \\
\hline 1950 & 1389 & 2722 & 31800 & 49 & 152 \\
\hline 1960 & 995 & 1670 & 21300 & 74 & 180 \\
\hline 1970 & 839 & 1195 & 10800 & 108 & 205 \\
\hline 1980 & 718 & 1011 & 11000 & 156 & 228 \\
\hline 1990 & 609 & 554 & 13200 & 189 & 250 \\
\hline 1994 & 655 & 519 & 14000 & 195 & 261 \\
\hline 1995 & 670 & 510 & 13700 & 201 & 263 \\
\hline 1996 & 671 & 505 & 13600 & 202 & 265 \\
\hline
\end{tabular}




\section{REFERENCES}

Akerlof, George A. (1970). "The market for 'lemons': quality uncertainty and the market mechanism." Quarterly Journal of Economics, vol. 84(3), pp. 488-500.

Akerlof, George A. and William T. Dickens. (1982). "The economic consequences of cognitive dissonance." American Economic Review, vol. 72(3), pp. 307-319.

Aldrich, Mark. (1992). "Safety First comes to the railroads 1910-1939." Railroad History, vol. 166, pp. 7-33.

American Automobile Manufacturers' Association. (1996). World Motor Vehicle Data. Washington, D.C.: American Automobile Manufacturers' Association.

American Law Institute. (1965). Restatement (Second) of Torts. St Paul, MN.: American Law Institute.

Association of American Railroads. (1996a). Railroad Ten Year Trends 1986-95. Washington, D.C.: Association of American Railroads.

Association of American Railroads. (1996b). Freight Loss and Damage Report. Washington, D.C.: Association of American Railroads.

Association of American Railroads. (1996c). Analysis of Class I Railroads 1995. Washington, D.C.: Association of American Railroads.

Association of American Railroads. (1997). Railroad Facts. Washington, D.C.: Association of American Railroads.

Augello, William J., and George Carl Pezold. (1995). Freight Claims in Plain English. (Third Edition). Huntington, N.Y.: Transportation Claims and Prevention Council.

Barth, Peter, and C. Telles. (1992). Workers' Compensation in California: Administrative Inventory. Cambridge, Mass.: Workers' Compensation Research Institute. 
Bein, Peter, Ted Miller, and William G. Waters II. (1994). "British Columbia road user unit costs." Proceedings of the Canadian Transportation Research Forum, 29th annual meeting, Victoria, British Columbia, pp. 714-727.

Brown, John. (1973). "Toward an economic theory of liability." Journal of Legal Studies, vol. 2, pp. 323-350.

Bulow, Jeremy, and John Shoven. (1978). "The bankruptcy decision." Bell Journal of Economics, vol. 9(2), pp. 437-456.

Bureau of Labor Statistics. (1996a). Occupational Injuries and Illnesses in the United States by Industry. Washington, D.C.: U.S. Government Printing Office.

Bureau of Labor Statistics. (1996b). Census of Fatal Occupational Injuries. Washington, D.C.: U.S. Government Printing Office.

Bureau of Labor Statistics. (1996c). Employment and Earnings. (Monthly.) Washington, D.C.: U.S. Government Printing Office.

Bureau of the Census. (1995). 1993 Commodity Flow Survey: Abridged Preliminary U.S. Summary. Washington, D.C.: U.S. Government Printing Office.

Calabresi, Guido. (1970). The Cost of Accidents: A Legal and Economic Analysis. New Haven, Conn: Yale University Press.

Clark, Christopher. (1974). "The railroad safety problem in the United States, 1900-1930." Transport History, vol. 7(2), pp. 97-123.

Combs, Barbara, and Paul Slovic. (1979). "Newspaper coverage of causes of death." Journalism Quarterly, vol. 56(4), pp. 837-843, 849.

Congressional Research Service. (1979). Hazardous Materials Transportation: A Review and Analysis of the Department of Transportation's Regulatory Program. Washington, D.C.: U.S. Government Printing Office.

Dennis, Scott M. (1996). "Estimating risk costs per unit of exposure for hazardous materials transported by rail." Logistics and Transportation Review, vol. 32(4), pp. 351-375.

Department of Commerce. (annual). Statistical Abstract of the United States. Washington, D.C.: U.S. Government Printing Office. 
Department of Transportation. (1972). Railroad-Highway Safety Part II: Recommendations for Resolving the Problem. Report to Congress from Secretary of Transportation. Washington D.C.: U.S. Department of Transportation.

Department of Transportation. (1986). Rail-Highway Crossing Resource Allocation Procedure: User's Guide. (Second Edition.) Report FHWA-IP-86-11. Washington D.C.: U.S. Government Printing Office.

Diamond, Peter. (1974a). "Accident law and resource allocation." Bell Journal of Economics, vol. 5, pp. 366-405.

Diamond, Peter. (1974b). "Single activity accidents." Journal of Legal Studies, vol. 3, pp. 107-164.

Dixit, Avinash. (1979). "Quantity and quality competition." Review of Economic Studies, vol. 46(4), pp. 587-599.

Dixit, Avinash, and Joseph E. Stiglitz. (1977). "Monopolistic competition and optimum product diversity." American Economic Review, vol. 67(3), pp. 297-308.

Ehrenberg, Ronald G. (1988). "Workers' compensation, wages, and the risk of injury." In John F. Burton, Jr. (ed) New Perspectives in Workers' Compensation. Ithaca, NY: Cornell Industrial and Labor Relations Press.

Evans, Andrew W. (1994). "Evaluating public transport and road safety measures." Accident Analysis \& Prevention, vol. 26(4), pp. 411-428.

Evans, Andrew W. (1995). "Railway safety cases and railway risk assessment in Britain." Proceedings, Fourth International Conference on Competition and Ownership in Land Passenger Transport, Rotorua, New Zealand, pp. 170-188.

Evans, Andrew W., and Antoneta X. Horbury. (1997). "The impact of Safety Cases on railway risk assessment and management." Risk and Human Behaviour Conference, York, United Kingdom.

Federal Highway Administration. (annual). Highway Statistics. Washington, D.C.: U.S. Government Printing Office.

Federal Highway Administration. (1986). Railroad-Highway Grade Crossing Handbook. Second Edition. Report FHWA-TS-86-215. Washington, D.C.: U.S. Government Printing Office. 
Federal Highway Administration. (1988). Manual on Uniform Traffic Control Devices for Streets and Highways. Washington, D.C.: U.S. Government Printing Office.

Federal Railroad Administration. (1979). Highway-Rail Crossing Accident / Incident and Inventory Bulletin No. 1 Calendar Year 1978. Washington, D.C.: U.S. Government Printing Office.

Federal Railroad Administration, Region 5. (1994). Regional Freight Car Inspection and Enforcement Program Ending Summary. Fort Worth, Texas: Federal Railroad Administration.

Federal Railroad Administration. (1995a). Accident/Incident Bulletin No. 163 Calendar Year 1994. Washington, D.C.: U.S. Government Printing Office.

Federal Railroad Administration. (1995b). Highway-Rail Crossing Accident / Incident and Inventory Bulletin No. 17 Calendar Year 1994. Washington, D.C.: U.S. Government Printing Office.

Federal Railroad Administration. (1995c). Selection and Installation of Grade Crossing Warning Systems. Notice of Proposed Rulemaking. Washington, D.C.: Federal Railroad Administration.

Federal Railroad Administration. (1996a). Accident/Incident Bulletin No. 164 Calendar Year 1995. Washington, D.C.: U.S. Government Printing Office.

Federal Railroad Administration. (1996b). Highway-Rail Crossing Accident / Incident and Inventory Bulletin No. 18 Calendar Year 1995. Washington, D.C.: U.S. Government Printing Office.

Federal Railroad Administration. (1997a). Accident/Incident Bulletin No. 165 Calendar Year 1996. Washington, D.C.: U.S. Government Printing Office.

Federal Railroad Administration. (1997b). Highway-Rail Crossing Accident / Incident and Inventory Bulletin No. 19 Calendar Year 1996. Washington, D.C.: U.S. Government Printing Office.

Fischhoff, Baruch, Paul Slovic, Sarah Lichtenstein, Stephen Reid, and Barbara Combs. (1978). "How safe is safe enough? A psychometric study of attitudes towards technological risks and benefits." Policy Sciences, vol. 9, pp. 127-152.

Fisher, Franklin M., and Gerald Kraft. (1971). "The effect of the removal of firemen on railroad accidents, 1962-67." Bell Journal of Economics and Management Science, vol. 2(2), pp. 471-494. 
General Accounting Office. (1982). The Federal Approach to Rail Safety Inspection and Enforcement: Time for Change. Report CED-82-51. Washington D.C.: U.S. Government Printing Office.

General Accounting Office. (1986). Amtrak: Comparison of Employee Injury Claims under Federal and State Laws. Report RCED-86-202. Washington D.C.: U.S. Government Printing Office.

General Accounting Office. (1989a). Railroad Safety: DOT Should Better Manage Its Hazardous Materials Inspection Program. Report GAO/RCED-90-43. Washington D.C.: U.S. Government Printing Office.

General Accounting Office. (1989b). Railroad Safety: FRA Needs to Correct Deficiencies in Reporting Injuries and Accidents. Report GAO/RCED-89-109. Washington D.C.: U.S. Government Printing Office.

General Accounting Office. (1990). Railroad Safety: More FRA Oversight Needed to Ensure Rail Safety in Region 2. Report GAO/RCED-90-140. Washington D.C.: U.S. Government Printing Office.

General Accounting Office. (1994). Railroad Safety: Continued Emphasis Needed for an Effective Track Safety Inspection Program. Report GAO/RCED-94-56. Washington D.C.: U.S. Government Printing Office.

General Accounting Office. (1996). Federal Employers' Liability Act: Issues Associated with Changing How Railroad Work-Related Injuries are Compensated. Report GAO/RCED-96-199. Washington D.C.: U.S. Government Printing Office.

General Accounting Office. (1997). Rail Transportation: Federal Railroad Administration's New Approach to Railroad Safety. Report GAO/RCED-97-142. Washington D.C.: U.S. Government Printing Office.

Golbe, Devra L. (1981). "The effects of imminent bankruptcy on stockholder risk preferences and behavior." Bell Journal of Economics, vol. 12(1), pp. 321-328.

Golbe, Devra L. (1983). "Product safety in a regulated industry: evidence from the railroads." Economic Inquiry, vol. 21(1), pp. 39-52.

Golbe, Devra L. (1988). "Risk-taking by firms near bankruptcy." Economics Letters, vol. 28(1), pp. 75-79.

Hansson, Ingemar, and Göran Skogh. (1987). "Moral hazard and safety regulation." The Geneva Papers on Risk and Insurance, vol. 12(43), pp. 132-144. 
Health \& Safety Executive. (1994). Railway Safety Cases: Guidance on Regulations. Sudbury: HSE Books.

Health \& Safety Executive. (1995). Railway Safety: HM Railway Inspectorate's Annual Report of the Railways in Great Britain during 1993/4. London: Her Majesty's Stationery Office.

Henderson, Jr., James A., Richard N. Pearson and John A. Siliciano. (1994). The Torts Process. (Fourth Edition.) Boston: Little Brown.

Hotelling, Harold. (1929). "Stability in competition." Economic Journal, vol. 39(1), pp. 41-57.

Human Resource Development Canada. (1998). Occupational Injuries and their Cost in Canada. Ottawa, Ont.: Government of Canada.

Interstate Commerce Commission. (annual). Statistics of Railways in the United States. Washington D.C.: U.S. Government Printing Office.

Interstate Commerce Commission. (1962). Prevention of Rail-Highway Grade Crossing Accidents Involving Railway Trains and Motor Vehicles. Washington D.C.: U.S. Government Printing Office.

Johnson, Eric J., and Amos Tversky. (1983). "Affect, generalization, and the perception of risk." Journal of Personality and Social Psychology, vol. 45(1), pp. 20-31.

Jones-Lee, Michael W., and Graham Loomes. (1995). "Scale and context effects in the valuation of transportation safety." Journal of Risk and Uncertainty, vol. 11(3), pp. 183-203.

Keeler, Theodore E. (1983). Railroads, Freight and Public Policy. Washington D.C.: Brookings Institution.

Kennedy III, Ralph G., Frank H. Lloyd, and Robert Lowrey. (1974). A Methodology for Evaluating the Economic Impacts of Applying Railroad Safety Standards. Two volumes. Report RP-41. Washington DC: U.S. Government Printing Office.

Kenworthy, William E. (1989). Transportation Safety Law Practice Manual. Stoneham, MA.: Butterworth Legal Publishers.

Klein, Benjamin, and Keith E. Leffler. (1981). "The role of market forces in assuring contractual performance." Journal of Political Economy, vol. 89(4), pp. 615-641. 
Koenker, Roger W., and Martin K. Perry. (1981). "Product differentiation, monopolistic competition, and public policy." Bell Journal of Economics, vol. 12(1), pp. 217-231.

Kolstad, Charles D., Thomas S. Ulen, and Gary V. Johnson. (1990). "Ex post liability for harm vs. ex ante safety regulation: Substitutes or complements?" American Economic Review, vol. 80(4), pp. 888-901.

Lewis, Edward A. (1995). American Shortline Railway Guide 1995. Aberdeen, NC.: American Shortline Railway Guide.

Lichtenstein, Sarah, Paul Slovic, Baruch Fischhoff, Mark Layman and Barbara Combs. (1978). "Judged frequency of lethal events." Journal of Experimental Psychology: Human Learning and Memory, vol. 4(6), pp. 551-578.

McFarland, Robert E. (1997). "The preemption of tort and other common causes of action against air, motor, and rail carriers." Transportation Law Journal, vol. 24(2), pp. 155-189.

Meyer, Bruce D., W. Kip Viscusi and David L. Durbin. (1995). "Workers' compensation and injury duration: evidence from a natural experiment." American Economic Review, vol. 85(3), pp. 322-340.

Miller, Luther S. (1993). "Safety (and Safety Inspections) on the Small Railroads." Railway Age, vol. 194(10), pp. 65-96.

Miller, Luther S. (1996). "How Short Lines Grade Safety Inspectors." Railway Age, vol. 197(2), pp. 44-49.

Miller, Ted R. et al. (1991). The Cost of Highway Crashes. Report DOT-FHWA-RD-91-055. Washington, D.C.: U.S. Government Printing Office.

Moore, Michael J., and W. Kip Viscusi. (1990). Compensation Mechanisms for Job Risks: Wages, Workers' Compensation and Product Liability. Princeton: Princeton University Press.

Morrow, Paula C., Michael R. Crum, and Frank J. Dooley. (1997). "Employee morale in the U.S. Class I railroad industry." Journal of Transportation Law, Logistics and Policy, vol. 64(4), pp. 439-461.

Moses, Leon N., and Ian Savage. (1992). "The effectiveness of motor carrier safety audits." Accident Analysis and Prevention, vol. 24(5), pp. 479-496. 
Moses, Leon N., and Ian Savage. (1994). "The effect of firm characteristics on truck accidents." Accident Analysis and Prevention, vol. 26(2), pp. 173-179.

Moses, Leon N., and Ian Savage. (1996). "Identifying dangerous trucking firms." Risk Analysis, vol. 16(3), pp. 351-358.

National Commission on Product Safety. (1970). Final Report. Washington, D.C.: U.S. Government Printing Office.

National Highway Traffic Safety Administration. (1994). Rail-Highway Crossing Safety: Fatal Crash and Demographic Descriptors. Report DOT-HS-808-196. Washington, D.C.: U.S. Government Printing Office.

National Mining Association. (1996). Coal Transportation Statistics. Washington, D.C.: National Mining Association.

National Safety Council. (1997). Accident Facts. Chicago, Ill.: National Safety Council.

National Transportation Safety Board. (1972). Special Report: Train Accidents Attributable to the "Negligence of Employees." Report NTSB-RSS-72-1. Washington, D.C.: U.S. Government Printing Office.

National Transportation Safety Board. (1974). Broken rails: A Major Cause of Train Accidents. Report NTSB-RSS-74-1. Washington, D.C.: U.S. Government Printing Office.

National Transportation Safety Board. (1978a). Safety Recommendation R-78-42. Washington D.C.: National Transportation Safety Board.

National Transportation Safety Board. (1978b). Safety Effectiveness Evaluation: Derailments and Hazardous Materials. Report NTSB-SEE-78-2. Washington D.C.: U.S. Government Printing Office.

National Transportation Safety Board. (1981). Safety Report: Status of Department of Transportation's Hazardous Materials Regulatory Program. Report NTSB-SR-81-2. Washington D.C.: U.S. Government Printing Office.

Office of Technology Assessment. (1978). An Evaluation of Railroad Safety. Report OTA-T-61. Washington D.C.: U.S. Government Printing Office.

Office of Technology Assessment. (1979). Railroad Safety: US - Canadian Comparison. Report OTA-T-95. Washington D.C.: U.S. Government Printing Office. 
Oi, Walter Y. (1973). "The economics of product safety." Bell Journal of Economics and Management Science, vol. 4(1), pp. 320-329.

Pelletier, Andrew. (1997). "Deaths among railroad trespassers: the role of alcohol in fatal injuries." Journal of the American Medical Association, vol. 277(13), pp. 1064-1066.

Railtrack. (1994). Railway Group Safety Plan 1994/95. London: Railtrack.

Reed, Robert C. (1968). Train Wrecks: A Pictorial History of Accidents on the Main Line. Seattle: Superior Publishing Company.

Salop, Steven. (1979). "Monopolistic competition with outside goods." Bell Journal of Economics, vol. 10(1), pp. 141-156.

Shaked, Avner, and John Sutton. (1982). "Relaxing price competition through product differentiation." Review of Economic Studies, vol. 49(1), pp. 3-13.

Shapiro, Carl. (1982). "Consumer information, product quality, and seller reputation." Bell Journal of Economics, vol. 13(1), pp. 20-35.

Shavell, Steven. (1979). "On moral hazard and insurance." Quarterly Journal of Economics, vol. 93(4), pp. 541-562.

Shavell, Steven. (1984a). "Liability for harm versus regulation of safety." Journal of Legal Studies, vol. 13(2), pp. 357-374.

Shavell, Steven. (1984b). "A model of the optimal use of liability and safety regulation." Rand Journal of Economics, vol. 15(2), pp. 271-280.

Shavell, Steven. (1987). Economic Analysis of Accident Law. Cambridge, Mass.: Harvard University Press.

Shaw, Robert B. (1978). A History of Railroad Accidents, Safety Precautions and Operating Practices. No city given: Vail-Ballou Press.

Slovic, Paul, Baruch Fischhoff and Sarah Lichtenstein. (1978). "Accident probabilities and seat-belt usage: a psychological perspective." Accident Analysis and Prevention, vol. 10(4), pp. 281-285.

Slovic, Paul, Baruch Fischhoff and Sarah Lichtenstein. (1980). "Facts and fears: understanding perceived risk." In Richard Schwing and Walter A. Albers (eds.), Societal Risk Assessment: How Safe is Safe Enough? New York: Plenum. 
Slovic, Paul, Baruch Fischhoff and Sarah Lichtenstein. (1985). "Characterizing perceived risk." In Robert W. Kates, Christoph Hohenemser and Jeanne X. Kasperson (eds.), Perilous Progress: Managing the Hazardous of Technology. Boulder, CO: Westview.

Sorkin, Saul. (1996). Goods in Transit. New York: Matthew Bender.

Spence, A. Michael. (1975). "Monopoly, quality and regulation." Bell Journal of Economics, vol. 6(2), pp. 417-429.

Spence, A. Michael. (1976). "Product selection, fixed costs, and monopolistic competition." Review of Economic Studies, vol. 43(2), pp. 217-235.

Spence, A. Michael. (1977). "Consumer misperceptions, product failure and producer liability." Review of Economic Studies, vol. 44(3), pp. 561-572.

Starr, Chauncey. (1969). "Social benefit versus technological risk." Science, vol. 165, pp. 1232-1238.

Statistics Canada. (1995). Rail in Canada 1994. Ottawa, Ont.: Government of Canada.

Transportation Research Board. (1994). Compensating Injured Railroad Workers Under the Federal Employers' Liability Act. Special Report 241. Washington DC: National Academy Press.

Transportation Safety Board of Canada. (1995). TSB Statistical Summary of Railway Occurrences 1994. Ottawa, Ont.: Government of Canada.

United States Congress, House of Representatives. (1995). Hearing of Subcommittee on Railways of House Committee on Transportation and Infrastructure, 104th Congress, September 14, 1995. Washington D.C.: U.S. Government Printing Office.

Vignau, J. et al. (1993). "Biological rhythms and sleep disorders in man: the delay sleep phase syndrome. In Lennart Witterberg (ed), Light and Biological Rhythms in Man. Oxford: Pergamon Press.

Viscusi, W. Kip. (1979). Employment Hazards: An Investigation of Market Performance. Cambridge, Mass: Harvard University Press.

Viscusi, W. Kip. (1983). Risk by Choice: Regulating Health and Safety in the Workplace. Cambridge, Mass: Harvard University Press. 
Viscusi, W. Kip. (1996). "Economics foundations of the current regulatory reform efforts." Journal of Economic Perspectives, vol. 10(3), pp. 119-134.

Viscusi, W. Kip, John M. Vernon and Joseph E. Harrington. (1995). Economics of Regulation and Anti-Trust. Cambridge, Mass: MIT Press (Second edition).

Wehr, Thomas A. (1996). "'A clock for all seasons' in the human brain." In Rudolf M. Buijs et al. (eds.), Hypothalamic Integration of Circadian Rhythms. Amsterdam: Elsevier. 


\section{SUBJECT INDEX}

Accident Reports Act of 1910 11, 22, 137, 212

Active warning devices (at grade crossings) 3, 4, 31, 38, 55, 57-62, 64-69, 76, 143, 193-195, 210

ALARP risks 39

Alaska Railroad 182, 188, 189

Alcohol 5, 6, 9, 34, 41, 55, 61-63, 71, 74, 118, 138, 139, 144, 148, 195, 211, 225

American Short Line and Regional Railroad Association ix, xiii, 118, 134, 160, 162, 163, 200, 202

Amtrak (National Railroad Passenger Corporation) 74-76, 110, 112, 116, 157, 179, 181, 182, 186, 188, 195

Anti-trust powers 129, 130

Ashpan Act of 190822

Association of American Railroads ix, xiii, 2, 22-24, 26, 74, 83, 87, 93, 97, 100, 101, 107-109, 115, 116, 122, 123, 125, 126, 131, 132, 137, 139, 142, 144, 149, 156, 163, 198, 200, 202, 211

Atchison, Topeka and Santa Fe Railway 69, 100, 182, 188

Automobiles xi, 4, 5, 14, 16, 28, 29, 30, 32, $34,37,57,61,63,64,66,71,139,144$, 210

Bangor and Aroostook Railroad 182, 188, 189

Bankruptcy 23, 101, 113-115, 133, 174

Barge transportation 26, 28, 42, 51, 95, 100 , 196

Belt Railroad of Chicago 181, 182, 186, 188

Benchmark level/model of safety 91-99, 101, 103-106, 111, 121, 122, 125, 147, 197

Bessemer and Lake Erie Railroad 181, 182, 188
Bilateral accidents 44

and grade crossings $57-70$

and occupational injuries 77-90

and trespassing 71-76

theory of 45-55

Boarding and alighting accidents 7,8

Brakes 8, 20-22, 54, 58, 73, 138, 141-143, $148,152,153,156-158,161,162,168$, 201, 208

Burlington Northern Railroad 180-182, 188

Burlington Northern Santa Fe Railway xiii, 118

Bystanders 7, 31, 34, 36, 37, 39, 40, 42-44, 93, 94, 96, 98, 113, 121-127, 130, 131, 133, 136, 139, 197-200, 207

Canada 27, 29, 30, 42, 75, 101, 107, 109, 157,161

Canadian National Railway 101

Canadian Pacific Railway 101

Carmack Amendment of 1906 22, 105, 106, 118, 131, 137, 138

Cheating by myopic railroads $113-115,119$, 132, 133, 135, 136, 169, 173, 176, 199, 200, 202-204

Chicago and North Western Railway 23, 115

Chicago, Central and Pacific Railroad 181, 182, 188, 189

Children 52, 72-75, 106, 195

Circadian rhythms 157

Class I railroads 2 2, 23, 87, 97, 101, 108, 109, $117,131,151,155,173,175,179-183$, 186, 188-190, 204, 209

Class II railroads 108, 109, 117, 173, 179-183, 186, 188-190, 204

Class III railroads 108, 109, 117, 132, 169, 172, 179, 180, 190, 204, 209 (see also short-line railroads) 
Clean up (of hazardous materials releases) 123-125, 127, 130, 132

Coal, transportation of 26, 100,101, 108, 123, 198

Cognitive dissonance 111

Collisions and derailments 1, 2, 6-8, 11, 17, 20, 24, 41-43, 91, 93, 108-110, 114, $117-119,123,124,131,150,151,153$, $155,158,159,175,177,179-181,183$, 184, 186, 187, 189, 197, 199, 202, 204

Commuter railroads 40, 110, 116, 117, 154, 179-181, 183-186, 189

Comparative negligence $48,49,63,82,105$, 196

Compensating wage differentials 79, 81

Competitive model 95, 99, 104, 106

Congress of United States 21, 24, 25, 38, 67, 74, 82, 152, 201, 205

Consolidated Rail Corporation (Conrail) xiii, 75, 101, 109, 124, 161, 181

Contributory negligence 48, 49, 63-64, 72, $81,82,84,88,105$

Cost-benefit analysis $\quad 38,39,64,66,74,147$, $148,161,162,201$

Couplers 20, 21, 24, 138, 139, 141, 142, 152, 156, 207, 208

CSX Transportation 68, 69, 75, 101, 109, 125, 182, 188

Dakota, Minnesota and Eastern Railroad 182, 188-189

Damages 19, 47-55, 63, 68, 70, 71, 82, 106, $121,124,131,194$

compensatory 53, 131

loss and damage to freight $22,107-109,131$, 134, 137, 198

medical expenses $53,82,84,86$

non-pecuniary 106,131

pain and suffering $53,82,84-86,88,106$, 131

pecuniary 106,131

punitive 51, 68, 82, 131

Department of Transportation ix, xiii, 11, 25, 26, 38, 39, 58, 67, 75, 143

Deregulation (economic) 26, 151, 155

Drugs 55, 62, 64, 118, 139, 143, 148, 157, 211

Due care 45-49, 51-53, 57, 60-64, 71, 72, 74, $83,122,193$

Duluth Missabe and Iron Range Railroad 182

Easterwood decision $\quad 69,70$
Elgin, Joliet and Eastern Railroad 182

Emergency services 124, 125

Employees xi, 4, 6, 8, 11, 12, 19-23, 25, 36, 37, 39-45, 55, 60, 92, 93, 107, 109, 114, $117,122,123,130,133,134,136,139$, 140, 143, 145, 148, 152, 153, 156-158, $160,162,164-167,169,174,175$, 179-184, 189-191, 196, 200, 203, 204, 207, 207-216

compensation for injuries 81-90

injury rates $1-3,14,16,27-29,31$

labor market for $77-81$

Environmental Protection Agency ix, 24, 38, 39

Explosives 22-24, 137, 200, 211

Externalities 93, 94, 96, 121, 122, 124-127, 130, 138, 137, 139, 198, 199

Faust attitude 111

Federal Aviation Administration 131

Federal Employers' Liability Act of 1908 22, 23, 82-90, 93, 130, 134, 137, 138, 196, 197

Federal Highway Administration ix, 30, 67-69, 143, 164-166, 171, 172, 174, 190, 194, 202, 203, 215

Federal Railroad Administration ix, 1, 2, 6, $11,24,25,30,38,40,58-60,65,68-70$, 75, 80, 83, 84, 92, 93, 108-110, 114, 117, 123, 131-133, 135, 141, 143-146, 149, 150, 152-164, 166, 169-177, 179, 180, 183, 191, 200-205, 209-213 (see also safety regulation)

inspection of railroads by 22, 23, 137, $141-145,147,150,152-162,165$, 169-173, 190, 201, 203-205, 208-210, 212

Safety Assurance and Compliance Program 145, 160, 170, 173, 174

Federal Railroad Safety Act of 1970 xi, 24, 38, 68, 114, 141, 146, 160, 201, 205, 207, 208, 209, 212

Federal Railroad Safety Authorization Act of 1976 25, 207, 209, 212

Fencing 6, 29, 36, 55, 72-76, 195

Florida East Coast Railroad 108, 181, 182, 186, 188

Freight cars 6-9, 17, 20, 21, 23, 29, 39, 87, $93,116,118,124,125,138,140-142$, 148, 149, 152-157, 161, 162, 201, 202, 207, 211 
Grain, transportation of 100,198

Grand Trunk Western Railroad 181, 182, 188, 189

Great Britain 5, 27, 29, 30, 39, 40, 42, 74-76, 164, 166-169, 173, 195, 202

Hazardous materials, transportation of 8, 22-25, 33, 34, 36-38, 41, 43, 53, 93, 121, 123-127, 137-139, 143, 146, 148, 160, 161, 165, 176, 198, 199, 207, 209, 211

pricing of 125, 126

Hazardous Materials Transportation Act of 1975 25, 146, 207, 211, 212

Hazardous Materials Transportation Uniform Safety Act of 199025

Health and Safety Executive (Great Britain) 30, 39, 40, 166-168

Highway-rail grade crossings xi, 1, 3-7, 14-16, 25, 28-31, 33, 35-42, 44, 45, 52-55, 57-71, 73, 75-77, 117, 138, 139, $143,148,175,179,180,183,185,186$, 193-195, 204, 207, 210

collision rates at $4,5,14,16,30$

number of 3,4

private crossings $3,4,76,195$

public crossings $3,4,60,65,66,76$

Highway Safety Acts of 1973 and 197625

Hours of service of employees 22, 138, 144, $145,148,149,156,157,162,165,166$, 210, 212

Hours of Service Act of 1907 22, 210, 212

ICC Termination Act of 199526

Illinois Central Railroad 101, 109, 182, 188

Imperfect information 103-110, 112, 114, 129,130

Indiana Harbor Belt Railroad 122, 181, 182, 186, 188, 189

Inexperienced railroads 114-119, 132-135, 160, 163, 168, 169, 190, 191, 200, 202

Information provision by government on safety $129,131-133$

Insurance 27, 44, 53, 63, 82, 84, 106, 129, 133-136, 163, 164, 196, 200, 202

Interchange rules $21,24,118,141,152,153$, 162, 163, 201, 207, 211

Intermodal competition 95, 100

Interstate Commerce Act of 1887 20, 22, 105
Interstate Commerce Commission ix, 11, 22, 24, 26, 66, 67, 130, 137, 213, 215

Intolerable risk 39, 40

Kansas City Southern Railroad 101, 181, 182, 186, 188, 189

Kyle Railways 115

Legal costs 86

Liability 23, 44, 45, 47-50, 52, 54, 67, 70, $74,77,82,96,105,106,110,113,121$, $122,124,125,126,129-131,133,134$, 136-138, 194, 196, 199, 200

Loading (of freight cars) 93, 125, 211

Locomotive engineers 1-3, 28, 31, 36, 41, 42, 73, 118, 142, 144, 146, 148, 156-158, 161, 201, 208, 210

Locomotive Inspection Act of 1911 22, 208

Locomotives 3, 5, 8, 9, 20-22, 24, 25, 36, 53, 54, 57, 132, 138-140, 142, 144, 146, 148, 149, 152-155, 161, 162, 174, 201, 207, 208, 210, 212

Long Island Railroad 82, 181, 183, 189

Market failure 44, 47-50, 54, 79-81, 91, 95-98, 103, 104, 106, 110, 111, 113, $119,121,122,126,127,129,130,132$, 134-137, 147, 154, 195-200, 202

Market power 44, 96-99, 101, 102, 129, 130, 198

Mergers of railroads 17, 26, 101, 116, 130

Monopolistic competition 99

Monopoly 91, 95, 97-99, 103, 125, 198

Montana Rail Link 115, 182, 188

Moral hazard 135

Myopic railroads 44, 96, 111, 113, 115, 119, 129, 132, 133, 135, 163, 168, 169, 174, 178, 179, 190, 191, 197, 199, 200, 202-204

National Highway Traffic Safety Administration ix, 4, 24, 61

National Safety Council 6, 23, 28, 29

National Transportation Safety Board ix, 5, 6, 8, 23, 74, 75, 109, 137-139, 200, 213

Natural monopoly 198

Negligence xi, 5, 8, 36, 41, 42, 48-53, 55, 57, 63-64, 67, 72, 73, 81-84, 87-89, 105, 121, 122, 124, 126, 131, 145, 196, 198

Non-Trespassers $1,6,7,40,75,117$ 
Norfolk Southern Railroad xiii, 101, 108, 109, 182, 188

Northeast Illinois Railroad Corporation 181, 183, 186, 189

Northern Indiana Commuter Transportation District 181, 183, 189

Occupational injuries xi, 23-25, 41, 42, 44, 45, 53, 77-90, 137, 195-197, 211

Occupational Safety and Health Administration ix, 24, 25, 38, 39, 166, 171, 172, 174, 201, 203, 205, 211

Cooperative Compliance Program 173

Maine 200 Program 173

Office of Motor Carriers (Federal Highway Administration) 164, 171, 190

Motor Carrier Management Information System 172

Motor Carrier Relief Demonstration Program 172

Safety audit program 164-166, 171, 172, 176, 202

Safety Status Measuring System (SafeStat) 172

Selective Compliance and Enforcement Program 172

Oligopoly 99

OmniTRAX 115

Operating practices $8,9,19,110,137,138$, 144, 148-150, 156-159, 163, 164, 169, 170, 190, 197, 209

Operating rules $21,122,138,144,148,157$, 162, 201, 209

Operation Lifesaver 25, 55, 64, 193

Operational safety 44, 91-191, 197-204

Packaging (of hazardous materials) 25, 125, 138, 139, 211

Paducah and Louisville Railroad 182, 188, 189

Passengers xi, 1, 6-8, 13, 15-17, 21, 23, 26-30, 33, 34, 36, 37, 39, 40, 43, 44, 59, 63, 91-93, 105, 106, 109-112, 116, 123, $130,131,135,140,143,166,169,179$, 181, 183, 186, 187, 189, 198, 207-209, 215, 216

commutation passengers 110,198

Passive warning devices (at grade crossings) 3, 4, 31, 41, 57-59, 61-69, 193

crossbucks signs $3,57,58,63-65,69,193$ stop signs $3,57,64,65,193$
Penalties

civil 145, 146, 212

criminal 146, 212

fines 144, 169, 170, 191, 201-203, 212

Perceptions of safety by railroad customers 103-107, 110

Pipeline transportation 26, 100

Poisson distribution 68, 108, 177, 179, 187

Port Authority Trans Hudson Corporation 182, 183, 188, 189

Port Terminal Railroad Association of Houston 182, 186, 188

Preemption by federal law of state laws 25, 69, 70, 194, 210

Premiums (insurance) 43, 82, 126, 133-135, 163, 164, 200

Preventive effort (by railroads to avoid accidents) 44, 92-96, 98, 103-106, 109, 110, 113-115, 121, 122, 130-132, 134, 135, 147, 177, 200, 204

Price of railroad transportation 26, 91, 92, 94-101, 103-106, 111, 113, 121, 125, 126, 130, 133, 139, 197-200, 203

Quantitative risk assessment 39, 43

Rail Management and Consulting Corporation 115

Rail Safety Improvement Act of 1988 25, 145, 207, 210, 215

Rail-Highway Crossing Program (Section 130 Program) 25, 57, 66, 67, 69, 70

Railroad Retirement Act 89, 197

Railroad Revitalization and Regulatory Reform Act of 197626

Railroad Safety Advisory Committee 161

RailTex 115

Railway Safety Cases (Great Britain) 166-169, 173, 202

Rationality of railroad customers 111,112 , 129, 135, 163

Regional railroads 115

Reputation 113, 114

Risk acceptance

by bystanders 37,38

by employees 36

by highway-crossing users 36

by passengers 36,37

by trespassers 36

of dread risks $34-38$

of unknown risks 35 
Risk aversion 89, 106, 107, 130

Risk perceptions

primary bias 32-34, 110

secondary bias $33,34,110$

Safety Appliance Act of 1893 20, 21, 88, 142, 156, 162, 208

Safety First 21, 23, 161

Safety inputs 92, 93, 132, 133, 174, 175, 200, 204

Safety outputs 131, 132, 175

Safety production function 92, 93

Safety regulation xi, xii, 20, 23-25, 38, 44, $68,129,130,133,135-137,145-147$, 163, 191, 198-200, 205, 207

and civil liberties 137-139

Emergency Orders 138, 146, 170, 203, 212

evaluation of $147-162$

monitoring and enforcement of 144-146

of equipment design $\quad 139-143$

of externalities 137-139

of operating practices 144

proposed delinquency system 163, 169-191, 201-204

proposed educational system 163-169, 191, 201-204

Special Notices 138, 146, 170, 203, 212

summary of 207-213

Sanitary Food Transportation Act of 1990 25

Shipper-owned railroads 116

Shippers of freight $6,8,22,25,26,37,91$, 93, 95, 101, 105-111, 114-116, 118, $119,123,125,126,130,131,135,139$, 155, 191, 198-200, 207

Short-line railroads 115-119, 134, 160, 162-164, 199, 204 (see also Class III railroads)

Sidings 6, 8, 17, 43, 197

Signal Inspection Act of 1920 22, 137, 209, 210, 213

Soo Line Railroad 109, 182, 188, 189

Southeastern Pennsylvania Transportation Authority 181, 183, 189

Southern Pacific Railroad 108, 109, 115, 182, 188

Sovereign immunity $\quad 69,70,194$

Staggers Act of 1980 26, 101, 105, 115, 161, 199

Strict liability $\quad 82,106,122,126,131$
Suicides 5, 41, 75

Surface Transportation Acts of 1978 and 1982 25

Surface Transportation Board 26, 101, 130

Switching 8, 9, 17, 21, 108, 115, 116, 118, 151, 152, 155, 159, 186, 189, 197, 202

Tank cars xi, 1, 23, 37, 124, 133, 137, 138, 160, 208, 211

Tastes of customers for safety 95, 99, 106, 107, 147

Telegraph 20, 21, 152

Texas Mexican Railroad 181, 183

Third parties see bystanders

Torts xiii, 22, 23, 48, 50-52, 54, 67, 68, 70, 72, 92, 123, 136, 194

Track 2, 3, 5-9, 21-24, 42, 43, 53, 54, 62, 65, $68,71,73,77,97,114,118,119,130$, 132, 136, 138-140, 143-145, 148-152, $155,157,159-162,166,168-170,173$, 174, 186, 189, 190, 197-199, 201-204, 207-210, 212

maintenance of $23,114,118,119,132$, 149, 174, 199, 204

regulation of $24,68,138,148-150,152$, 161, 162, 201, 207, 208

Train crew 1-3, 28, 31, 41, 42, 73, 142, 144 , 158, 208, 209

Transients 5, 72

Transportation of Explosives Act of 1909 22, 211

Transportation Safety Act of 1974 212, 213

Trespassers xi, 1, 5-8, 13-16, 28-31, 33-37, 40-42, 44, 45, 53-55, 71-77, 117, 123, $175,180,183,185,186,195,204,215$, 216

Truck transportation xiii, 26-28, 42, 82, 88, 93, 95, 100, 110, 164, 165, 167, 168, 171, 172, 174, 176, 196, 201-203

Uniform (Standard) Code of Railroad Operating Rules (1887) 21, 144, 157, 162

Union Pacific Railroad 109, 115, 119, 125, 162, 182, 188

Union Railroad of Pittsburgh 181, 183, 189

Unions (labor) 23-25, 81, 82, 89, 90, 145, 150, 157, 161, 162, 170, 196, 205

Unscrupulous railroads 80, 113, 114, 132, 133, 135, 163, 191, 199, 200, 202 
Vertically differentiated markets 95, 104

Vicarious liability 92

Wages $36,43,77-81,84-86,88,89,92,124$, 196, 197

Wheels 24, 141, 142, 152, 154, 156, 207

Willful conduct 51, 73, 82, 131, 145, 146

Wisconsin Central Railroad 115, 166, 181, 183, 189

Workers' Compensation 23, 82-84, 86-89, 131, 173, 196, 197

Workshops 1, 42, 77

Yards 6, 8, 17, 43, 151-153, 159, 187, 197, 209 